\title{
Particle Release Experiment (PRex) Final Report
}

$\begin{array}{ll}\text { ME Keillor } & \text { BD Milbrath } \\ \text { LM Arrigo } & \text { JP Rishel } \\ \text { RS Detwiler } & \text { A Seifert } \\ \text { WJ Kernan } & \text { CE Seifert } \\ \text { RR Kirkham } & \text { JE Smart } \\ \text { M MacDougall } & \text { D Emer }{ }^{1} \\ \text { V Chipman }^{1} & \end{array}$

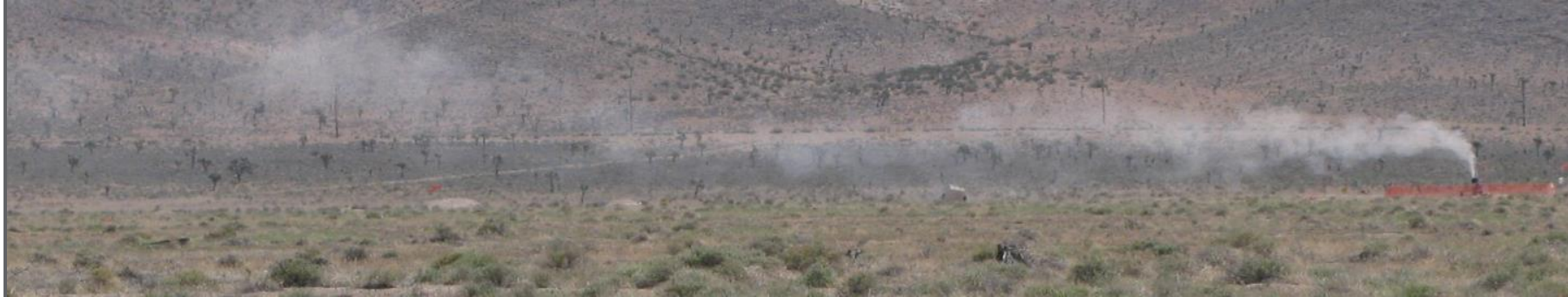

September 2014

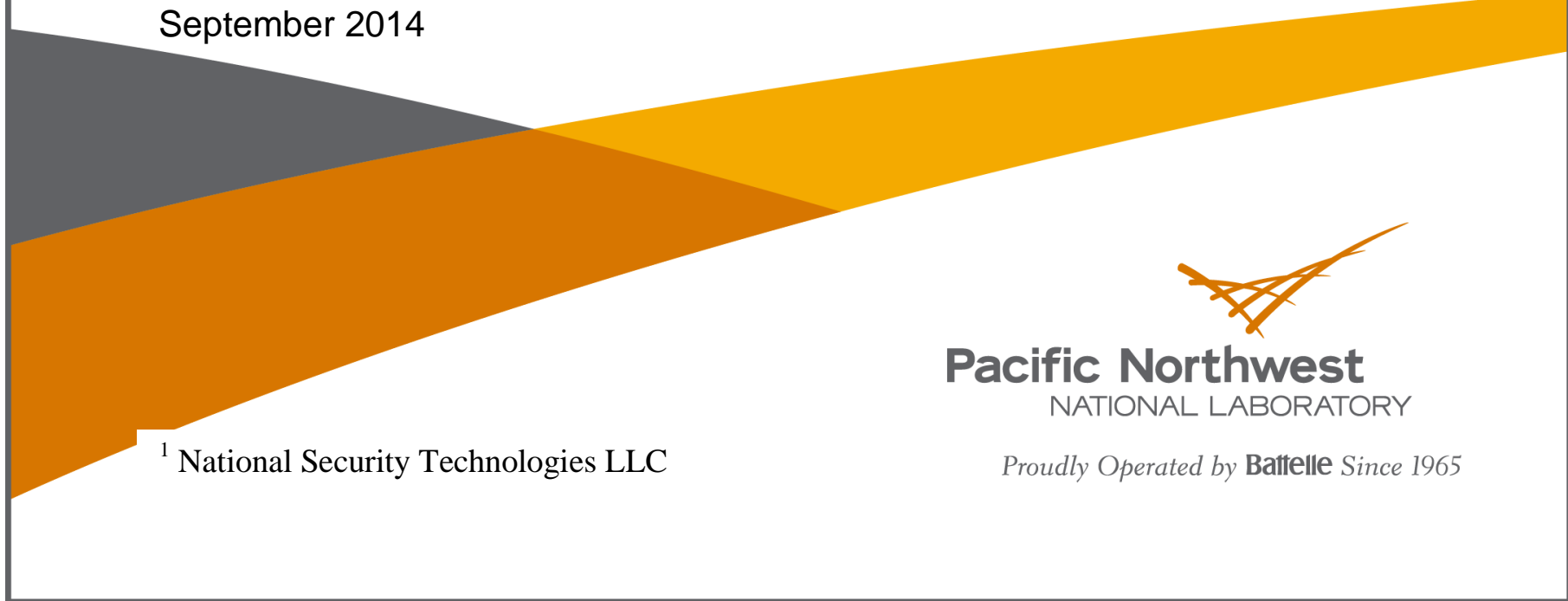




\title{
DISCLAIMER
}

This report was prepared as an account of work sponsored by an agency of the United States Government. Neither the United States Government nor any agency thereof, nor Battelle Memorial Institute, nor any of their employees, makes any warranty, express or implied, or assumes any legal liability or responsibility for the accuracy, completeness, or usefulness of any information, apparatus, product, or process disclosed, or represents that its use would not infringe privately owned rights. Reference herein to any specific commercial product, process, or service by trade name, trademark, manufacturer, or otherwise does not necessarily constitute or imply its endorsement, recommendation, or favoring by the United States Government or any agency thereof, or Battelle Memorial Institute. The views and opinions of authors expressed herein do not necessarily state or reflect those of the United States Government or any agency thereof.

\author{
PACIFIC NORTHWEST NATIONAL LABORATORY \\ operated by \\ BATTELLE \\ for the \\ UNITED STATES DEPARTMENT OF ENERGY \\ under Contract DE-AC05-76RL01830
}

Printed in the United States of America

Available to DOE and DOE contractors from the

Office of Scientific and Technical Information,

P.O. Box 62, Oak Ridge, TN 37831-0062;

ph: (865) 576-8401

fax: $(865) 576-5728$

email: reports@adonis.osti.gov

Available to the public from the National Technical Information Service

5301 Shawnee Rd., Alexandria, VA 22312 ph: (800) 553-NTIS (6847)

email: orders@ntis.gov <http://www.ntis.gov/about/form.aspx>

Online ordering: http://www.ntis.gov

This document was printed on recycled paper. 


\section{Particle Release Experiment (PRex) Final Report}

$\begin{array}{ll}\text { ME Keillor } & \text { BD Milbrath } \\ \text { LM Arrigo } & \text { JP Rishel } \\ \text { RS Detwiler } & \text { A Seifert } \\ \text { WJ Kernan } & \text { CE Seifert } \\ \text { RR Kirkham } & \text { JE Smart } \\ \text { M MacDougall } & \text { D Emer } \\ \text { V Chipman }^{1} & \end{array}$

September 2014

Prepared for

the U.S. Department of Energy

under Contract DE-AC05-76RL01830

Pacific Northwest National Laboratory

Richland, Washington 99352

\footnotetext{
${ }^{1}$ National Security Technologies LLC
} 
PNNL-23997

\section{Abstract}

An experiment to release radioactive particles representative of small-scale venting from an underground nuclear test was conducted to gather data in support of treaty verification and monitoring activities. For this experiment, a $\mathrm{CO}_{2}$-driven "air cannon" was used to release ${ }^{140} \mathrm{La}$ at ambient temperatures.

Lanthanum-140 was chosen to represent the fission fragments because of its short half-life and prominent gamma-ray emissions; the choice was also influenced by the successful production and use of ${ }^{140}$ La with low levels of radioactive contaminants in a Defence Research and Development Canada Field Trial. The source was created through activation of high-purity natural lanthanum oxide at the reactor of Washington State University, Pullman, Washington. Multiple varieties of witness plates and air samplers were laid in an irregular grid covering the area over which the plume was modeled to deposit. Aerial survey, a $\mathrm{NaI}(\mathrm{Tl})$ mobile spectrometer, and handheld and backpack instruments ranging from polyvinyl toluene to high-purity germanium were used to survey the plume. Additionally, three varieties of soil sampling were investigated. The relative sensitivity and utility of sampling and survey methods are discussed in the context of On-Site Inspection. The measurements and samples show a high degree of correlation and form a valuable set of test data. 



\section{Executive Summary}

The Comprehensive Nuclear-Test-Ban Treaty is a nuclear non-proliferation treaty adopted by the United Nations and open for signature and ratification or accession by States Parties, but not yet entered into force. The CTBT makes provision for a verification regime that includes the conduct of an On-Site Inspection. The sole purpose of an OSI is to determine whether a nuclear explosion has occurred in violation of the Treaty and, if so, gather facts that might assist in identifying the violator. The Treaty allows for an OSI to include many techniques, including the radionuclide techniques of gamma radiation survey and spectrometry and environmental sampling and analysis (of solids, liquids, and gases). A good understanding of the possible contamination distribution, along with the most valuable equipment and search techniques for locating accessible radioactive contamination, would dramatically improve the likelihood of conducting a successful OSI. In support of future OSIs, Pacific Northwest National Laboratory conducted work to understand the realistic distribution of nuclides that might occur under actual venting conditions from an underground nuclear test.

In May 2013, Pacific Northwest National Laboratory, in collaboration with National Security Technologies LLC, performed an atmospheric release of $\sim 40 \mu \mathrm{m}$ particulate $\mathrm{La}_{2} \mathrm{O}_{3}$ after neutron activation in the Washington State University research reactor produced short-lived ${ }^{140}$ La within the powder. The short-lived radioactive particulate material was successfully injected into the lowest levels of the atmosphere to simulate the release from a weakly vented underground nuclear test. Following the release, project personnel used a variety of radiation sampling and survey techniques to characterize the downwind deposition of the material. The Remote Sensing Laboratory supported this effort by performing a fixed wing aerial survey shortly after the release. The techniques applied to this test are typical of those being planned for use in the event of an international On-Site Inspection under the Comprehensive Nuclear-Test-Ban Treaty.

The contamination plume deposited on the ground for this experiment was narrow; in fact, it was more narrow than the corresponding plume generated using the meteorological conditions and plume modeling. This discrepancy is likely due to the short duration of the release (1-2 minutes), as compared to the 10 minute averaging of the plume model generated in Hotspot (Homann 1994) .

The material released for this test was successfully detected through all applied techniques. The project team found that vehicle-based ground survey provided a data set that was the most informative and readily interpreted for location and definition of the extent of the plume deposited on the ground. Germanium-based gamma spectroscopy in the field laboratory and in-situ gamma spectroscopy with handheld HPGe detectors provided roughly comparable sensitivity, however for this exercise the field team felt that, with the same manpower effort, a larger number of samples could be processed through the field laboratory than could be measured with in-situ systems. Both the sampling and in-situ gamma spectroscopy methods were limited in coverage of the plume due to the need to take discreet measurements for each physical location. Despite this limitation, the techniques are valuable for isotope identification and good sensitivity, in particular for samples that have been identified as high-interest through other inspection techniques.

The use of inert microspheres detected through optical microscopy methods did not provide sufficient results to define the deposition plume, though they did appear to track with the radiation plume. Microspheres were successfully collected and identified on optical witness plates downwind from the 
release. In order to use this method with more viable results, it would be necessary to release a larger quantity of microspheres. The use of colored or fluorescent microspheres would also aid in discriminating the released microspheres from naturally occurring spherical particles. 


\section{Acknowledgments}

This work would not have been possible without the support of many people from several organizations. The authors express their gratitude to the National Nuclear Security Administration, Defense Nuclear Nonproliferation Research and Development, and the Comprehensive Inspection Technologies working group, a multi-institutional and interdisciplinary group of scientists and engineers. This work was performed by Pacific Northwest National Laboratory under award number DEAC52-06NA25946. 

PNNL-23997

\section{Acronyms and Abbreviations}

AGL

ALARA

ASL

AMS

ATM

ATV

CA

CFM

CSS

CTBT(O)

FL

GIS

GM

GPS

GZ

HCA

HDPE

HPGe

ISOCS

MCNP

MDA

MEDA

NCNS

NNSS

NOAA

NSTec

NTS

NWS

OSI

PAPR

PDT

PNNL

PPE

PRex

PVC

PVT
Above ground level

As Low As Reasonably Achievable

Above mean sea level

Aerial Measuring System

Atmospheric transport model(ing)

All-terrain vehicle

Contaminated area

Cubic Feet per Minute

Comprehensive Sampling/Survey (Site)

Comprehensive Nuclear Test-Ban-Treaty (Organization)

Field Laboratory

Geographic Information System

Geiger-Mueller

Global Positioning System

Ground zero

High Contamination Area

High Density Polyethylene

High purity germanium

In Situ Object Counting Systems - Canberra Industries

Monte Carlo N-Particle Transport Code

Minimum detectable activity

Meteorological data acquisition

National Center for Nuclear Security

Nevada National Security Site

National Oceanic and Atmospheric Administration

National Security Technologies LLC

Nevada Test Site

National Weather Service

On-Site Inspection

Powered air-purifying respirators

Pacific Daylight Time

Pacific Northwest National Laboratory

Personal protective equipment

Particle Release Experiment

Polyvinyl chloride

Polyvinyl toluene 
RCT

ROI

RSI

RSL

RWP

UTC

UTM

WSU
Radiological Control Technician

Region of interest

Radiation Solutions Inc.

Remote Sensing Laboratory

Radiological work permit

Coordinated universal time

Universal mean time

Washington State University 


\section{Contents}

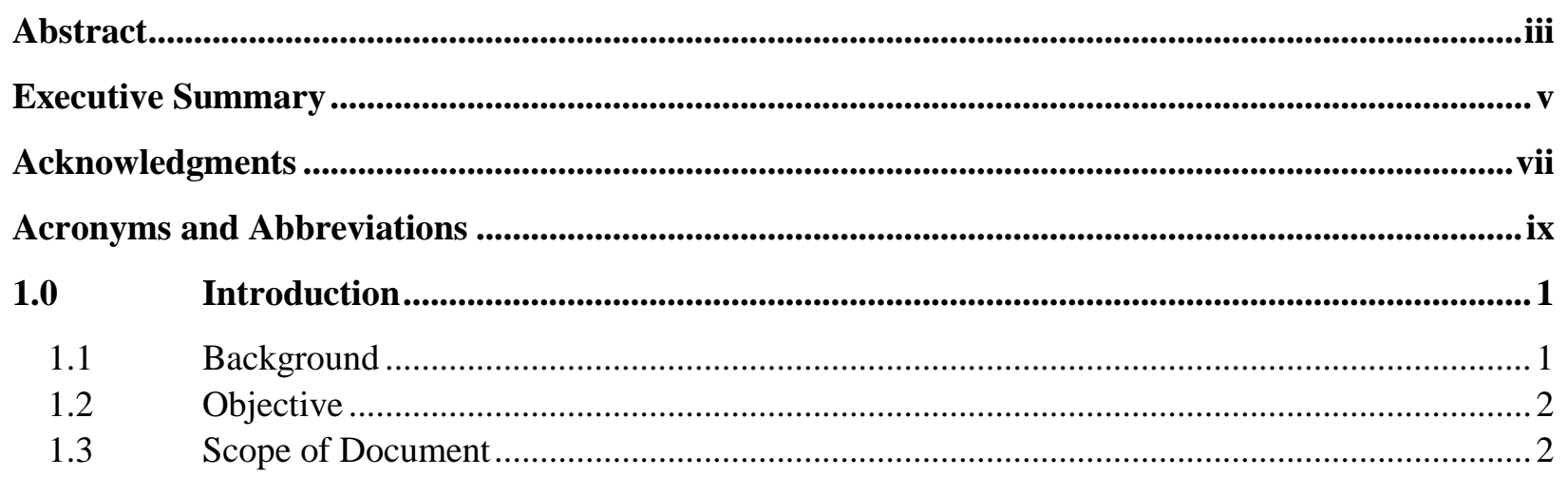

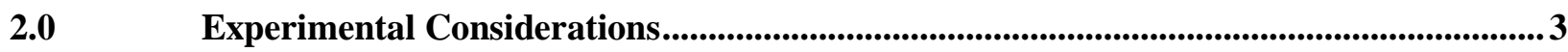

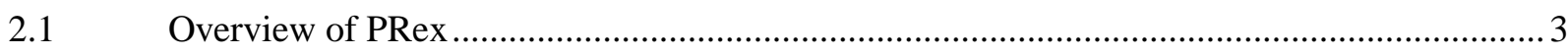

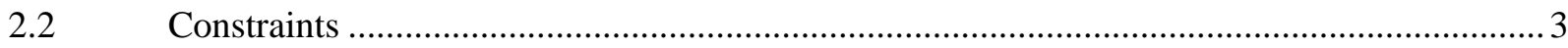

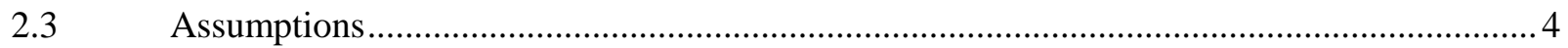

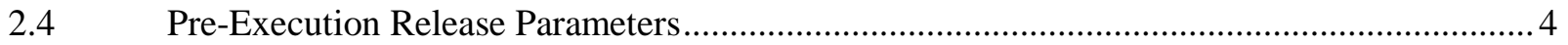

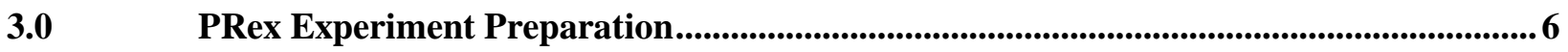

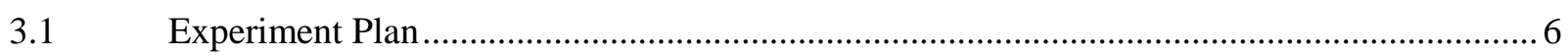

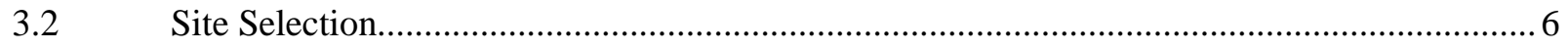

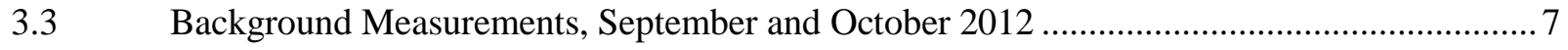

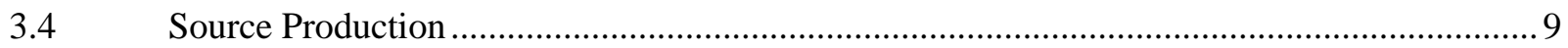

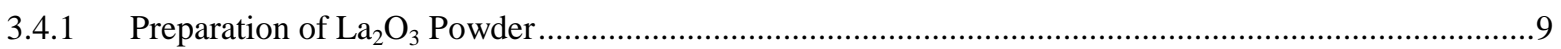

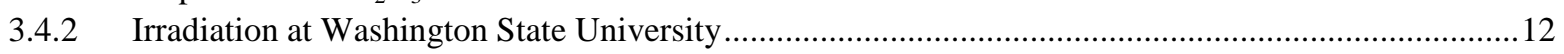

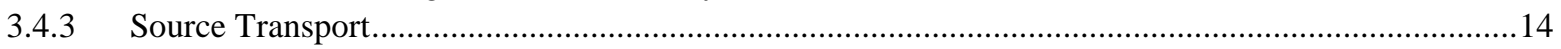

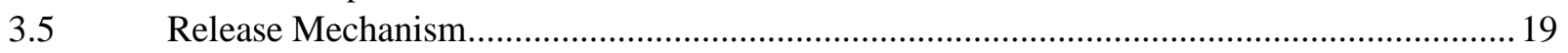

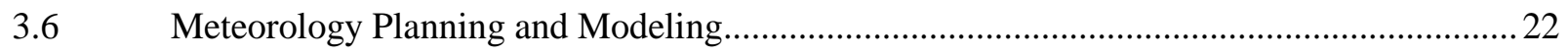

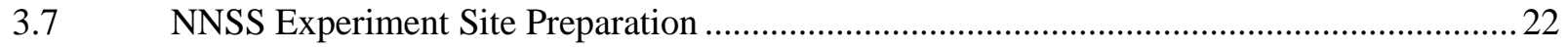

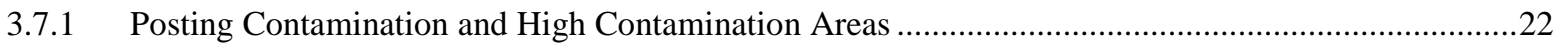

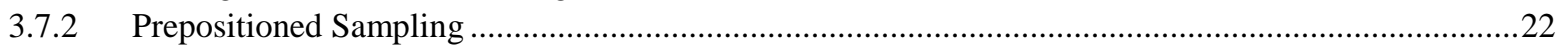

4.0 PRex Experiment Execution …........................................................................................28

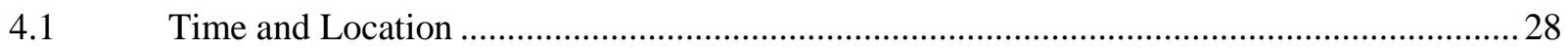

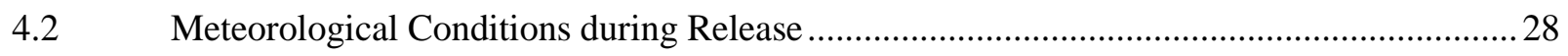

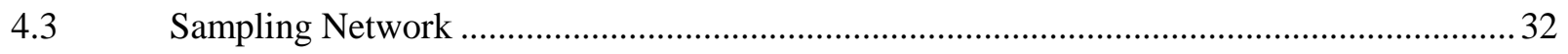

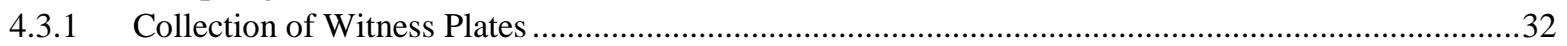

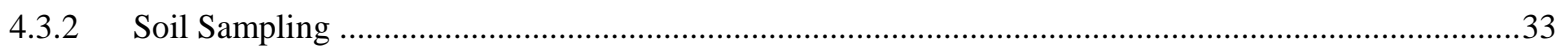

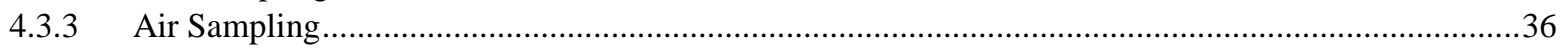

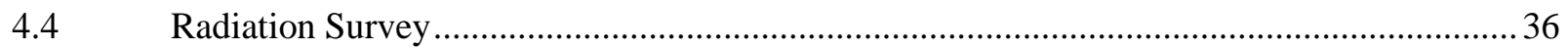

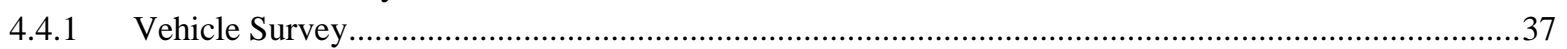

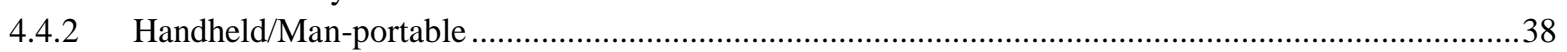

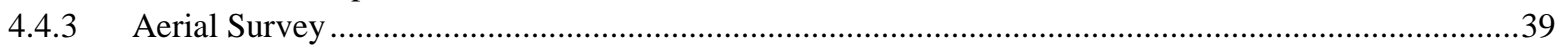

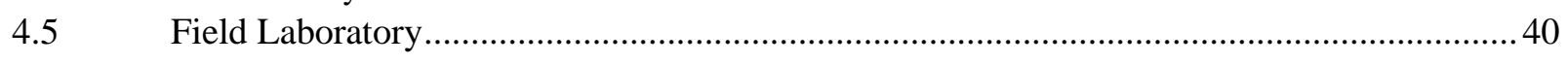




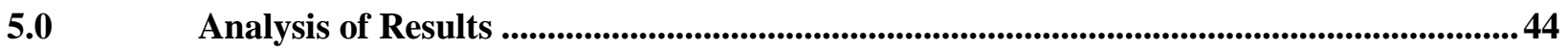

$5.2 \quad$ Witness Plate Laboratory Measurement Results...........................................................52

5.3 Comparison of Vehicle Survey and Witness Plate Results ................................................54

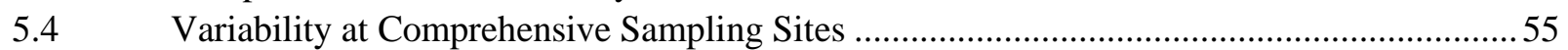

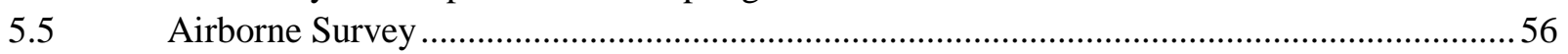

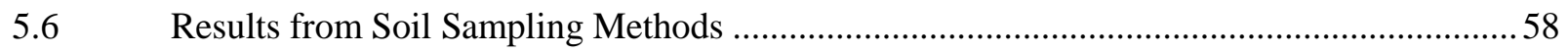

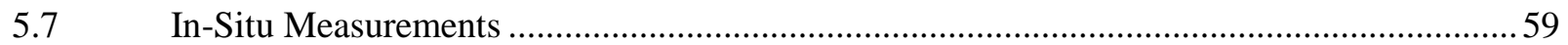

5.8 Comparison of Plume Modeling to Radiometric Results...................................................62

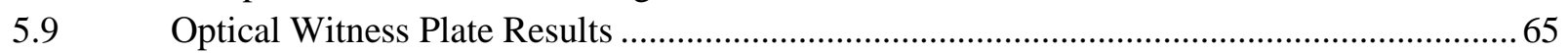

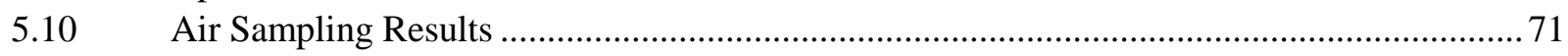

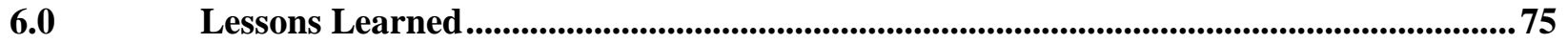

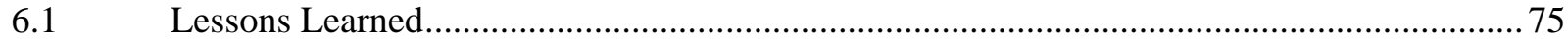

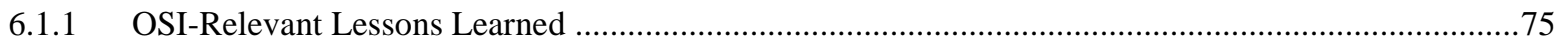

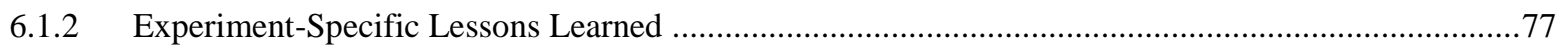

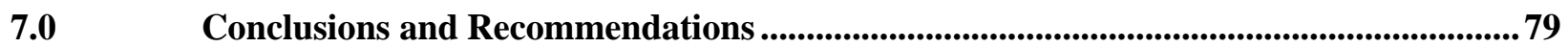

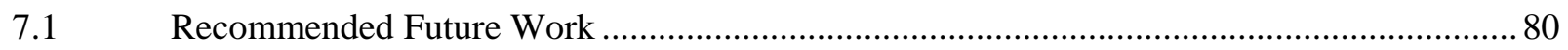

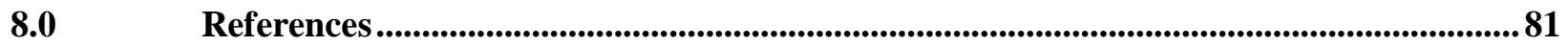

Appendix A Ground Vehicle Survey Data Corrections.............................................................................1

Appendix B Field Laboratory Gamma Assay Results................................................................................ B.1

Appendix C Sequence of Events / Events Log ................................................................................ C.1 


\section{Figures}

Figure 2.1: PRex test location on the Nevada National Security Site

Figure 3.1: NNSS release site. While not visible in the photo, several craters and un-collapsed test locations exist in close proximity to the north of the planned release point. Craters are more concentrated to the northwest; south-southwesterly winds would result in the fewest obstacles for ground survey.

Figure 3.2: Screen capture made with the RSI Software RadAssist and a GIS module showing raw data from the September 2011 background survey.

Figure 3.3: ATV used for vehicle survey at the PRex location on Yucca Flats (left); contour map of radiation survey results (right).

Figure 3.4: Gross count exposure map measured over the PRex release area in October 2012 .......9

Figure 3.5: Shaker / sieve setup including shaker, sieves, balance, and sample jars in a nitrogen filled glove bag

Figure 3.6: Shaker and sieves are shown on the left. The sieve cover with $\mathrm{La}_{2} \mathrm{O}_{3}$ powder is shown on the right.

Figure 3.7: The roll-sealed aluminum can provided by the WSU Reactor Center team. This can has been certified by the reactor center for use with non-dispersible materials. PNNL leveraged the "certified" status of this geometry as well as the geometry specific insertion and retrieval equipment already in place at the reactor center.

Figure 3.8: The 6061-T6 aluminum liner assembly. Light blue section includes a thin septum end with appropriate reinforcement areas to reduce stress. Green section is the welded end cap with a 1/2" 20-threaded plug. The light purple area is a high density polyethylene plug gasket.

Figure 3.9: A 20-foot drop test conducted with a water-filled aluminum "can liner" resulted in the expected amount of deformation, with no rupture or leakage.

Figure 3.10: The "roll-sealed aluminum can" with the custom designed aluminum liner inside. The aluminum liner has a thin annulus around its top wall to allow puncture by the material extraction needles.

Figure 3.11: This shielding assembly (cylinder and plug cap) weigh 560 pounds after being filled with lead. The main weldment is 12 " tall and has an OD of 12.75". This was mounted in the center of a Type A 55-gallon drum.

Figure 3.12: Custom lead pig at the WSU Reactor Center designed to retrieve the roll-sealed aluminum can geometry after irradiation 
Figure 3.13: A sturdy transfer tube was fit into the transport container to facilitate a safe transfer between the crane-positioned WSU sample retrieval pig and the shielded transport drum......16

Figure 3.14: The aluminum can containing $\mathrm{La}_{2} \mathrm{O}_{3}$ powder is shown in this model render after being transferred into the shielded transport drum. The image shows the shielded cap plug inserted and bolted down. Grey layers are 900-psi ethafoam. The light tan layers are plywood. Additional layers of plywood and foam were placed on top of this assembly prior to shipment

Figure 3.15: Lead-filled cap plug in place and bolted into the 4" thick drum shield assembly......17

Figure 3.16: The source extraction mechanism. (Left) cross section diagram;(Right) actual implementation. Two stainless steel needles puncture the source can; one to inject a highvelocity gas jet and the serving as an escape vent for the gas-particulate mix.

Figure 3.17: (Left) Source extraction device (two each). The weight of the 20-pound steel cylinder helps the users apply the downward force needed to puncture the aluminum source can. Two hollow needles with strategically placed side ports serve to flow gas through the particulate-filled can and evacuate the solids. (Right) An image of a prototype needle (without ports) puncturing an aluminum can lid.

Figure 3.18: A test can after being punctured by the source extraction system. (The can lid was not roll-sealed for this test)

Figure 3.19: Cross-Sectional view of the source shipping/transfer system. This image shows the system with the source extraction plug installed.

Figure 3.20: With near zero wind velocity, the dual cone air cannon injects orange smoke more than 130 feet into the air. This photo is from a practice run the week prior to the test

Figure 3.21: The air cannon is shown on the left. Initial testing at PNNL is shown on the right..21

Figure 3.22: $\mathrm{CO}_{2}$ Manifolds for use with the air cannon

Figure 3.23: Map of the planned locations for sampling sites. The dispersal point, marked "GZ," is located near the bottom center of the figure. The figure consists of a $50 \mathrm{~m} \times 50 \mathrm{~m}$ grid; the yellow highlighted boxes are $1 \mathrm{~km}$ apart in the North-South direction, and $2 \mathrm{~km}$ apart in the East-West direction. Points marked with a "1" had one of each type of witness plate installed. Points marked with a " 5 " had five of each type of witness plate installed......23

Figure 3.24: Tacky mat witness plate staked for collection of lanthanum powder...

Figure 3.25: Glass slide witness plate for the collection of microspheres .25

Figure 3.26. Comprehensive sampling site. GZ is in the direction to the right. .26

Figure 3.27: Modified gasoline-powered leaf blower modified to operate as a $1000 \mathrm{cfm}$ air sampler, located $2 \mathrm{~km}$ downwind from the release. 
Figure 4.1: Surface weather map on May 14, 2013 at 1200Z..............................................28

Figure 4.2: Wind observations across the NTS site on May 14, 2013 10:45 a.m........................29

Figure 4.3: Balloon profiles of wind, temperature, and humidity pre-PRex release (i.e., May 14, 2013 10:45 a.m.)

Figure 4.4: Collection of tacky mat witness plate hampered by the bowed shape and the wind....33

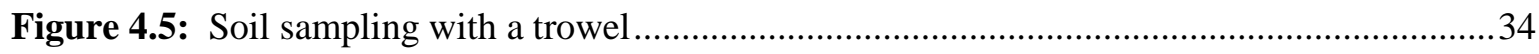

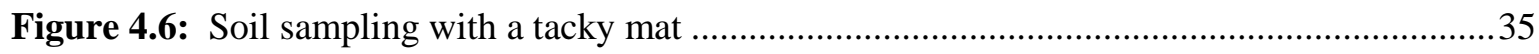

Figure 4.7: Soil sampling with battery-powered vacuum cleaner ............................................36

Figure 4.8: Survey equipment following the release of ${ }^{140} \mathrm{La}$. The two $\mathrm{NaI}(\mathrm{Tl})$ detectors were packaged in large Igloo coolers, and are next to each other, oriented front-to-back in the bed of the Kawasaki Mule.

Figure 4.9: Raven light bar (http://ravenprecision.com/products/guidance-steering/rgl-lightbarseries)and the differential GPS unit (http://www.geneq.com/catalog/en/sxblue2.html) used to guide the driver during vehicle ground survey.

Figure 4.10: Hand-held radiation detectors used for in-situ measurements, atop a high-tech detector stand

Figure 4.11: Thermo Packeye, a backpack PVT-based man-portable survey instrument

Figure 4.12: B-200 performing aerial survey of ${ }^{140}$ La release (left) and image of aircraft from an AMS presentation (right) (Lyons 2012)

Figure 4.13: Exterior of Quonset hut that housed the field laboratory for PRex. Note the liquid nitrogen dewars provided for cooling of the HPGe detectors, on right.

Figure 4.14: Two $\sim 50 \%$ relative efficiency HPGe detectors inside of $10.16 \mathrm{~cm}$ (4") thick lead shields. These detectors are set up in the field laboratory.

Figure 4.15: Single shield housing two $7.62 \mathrm{~cm} \times 12.7 \mathrm{~cm}(3 " \times 5$ ") $\mathrm{NaI}(\mathrm{Tl})$ detectors. The detectors are surrounded by $10.16 \mathrm{~cm}$ (4") of lead, and the sample chambers are also separated by $10.16 \mathrm{~cm}$ (4") of lead.

Figure 4.16: Canberra HPGe with commercial portable shield system, supplied by NSTec. The Canberra ISOCs efficiency calibration on this system was used to cross-calibrate the other HPGe detectors

Figure 5.1: RSI vehicle survey route using an ROI on the ${ }^{140} \mathrm{La} 1596 \mathrm{keV}$ gamma. Count rates are for two detectors, unintentionally multiplied by a factor of two because the system was set up with a "virtual" detector that created a sum of the two individual $\mathrm{NaI}(\mathrm{Tl})$ detectors. 
The plot shows the count rate for the sum of the two individual detectors, and the virtual detector. This figure does not show the full extent of the survey to the North.

Figure 5.2: Gross counts detected by ground survey with the RSI system. The data is the sum of two $\mathrm{NaI}(\mathrm{Tl})$ detectors. The color key is $<5000$ cps black, $5000-<5500$ cps blue, 5500$<6000$ cps green, $6000-<6500$ yellow, $\geq 6500$ red.

Figure 5.3: Gross Count contours of the RSI with two $2 " \times 4 " \times 16 " \mathrm{NaI}$ log detectors.

Figure 5.4: Contours of the surveyed deposition based on ${ }^{140} \mathrm{La}$ using the count rate in the 1596-keV line

Figure 5.5: Gross counts versus dose for one $\mathrm{NaI}(\mathrm{Tl})$ detector .48

Figure 5.6: Comparison of vehicle and backpack transects of plume. The top (near sample area 14) and bottom panel (near sample area 5-4) compare gross count (RSI) (RSI count rates are doubled due to "virtual detector") with dose rate (Packeye). The paths followed for the Packeye and RSI surveys were close, but not precisely the same.

Figure 5.7: Tacky mat (filled circles) overlaid on mobile survey contours of extracted ${ }^{140} \mathrm{La}$.......55

Figure 5.8: Aerial mapping product showing gross count exposure .57

Figure 5.9: Aerial mapping product showing plume results using an ROI over the ${ }^{140} \mathrm{La}$ 1596-keV line .58

Figure 5.10: Locations of handheld instrument comparisons. 60

Figure 5.11. Hotshot plume post-analysis assuming a $1 \mathrm{Ci}$ release. The contours based on Hotshot indicate that the measurable plume would have extended further downwind if the full $1 \mathrm{Ci}$ had been released.

Figure 5.12: Hotshot plume post-analysis assuming a $0.07 \mathrm{Ci}$ release. The yellow push-pin markers correspond to the in-situ measurement results provided in Table 5-3. The in-situ measurements are generally in good agreement with the Hotshot contours.

Figure 5.13: Lanthanum oxide powder's generally amorphous shape is visually indistinguishable from ubiquitous desert airborne particulate.

Figure 5.14: A color-enhanced micrograph of aluminosilicate glass microspheres on a test slide similar to the witness plates deployed during the NCNS test. Concentric rings around each sphere are the result of dark field lighting; and create a unique visual signature for the microspheres compared to other debris also shown.

Figure 5.15: Micrograph of aluminosilicate glass microspheres in dark field illumination without color enhancement 
Figure 5.16: Micrograph with bright field illumination of microspheres shown with red outlines indicating identification by image recognition software. The software has identified all of the microspheres in this field of view with the exception of the large sphere second from the left. This sphere has agglomerated with another particle which has prevented identification. Software filters can be set to be more tolerant of such interferences, but those settings can also lead to false identifications.

Figure 5.17: Micrograph showing a roughly spherical pollen particle roughly the same size as tested microspheres. This type of "background" particle, in certain microscope lighting conditions, may be mistakenly identified by the image analysis software as a microsphere. ..70

Figure 5.18: Left - Unidentified biological object. The outline of these bifurcated objects is easily confused with a spherical object. They exhibit similar light reflections and circular outline as microspheres. Right - Over the course of weeks, these objects were observed to "grow" from generally circular to distinct two "pedal" forms.

Figure 5.19: PAPR Air Sampler collections were consistent with the observed ground deposition72

Figure 5.20. Meteorological data from the weather station immediately south of the release point 73

Figure 5.21. Meteorological data captured from the weather station immediately south of the release point

Figure 5.22. Count rate (blue) and smoothed count rate (red) of a GM tube monitoring sample collection $1.5 \mathrm{~km}$ downwind from the release. This sampler was remotely activated shortly before the release, and the plume's arrival can be observed during the sampling period. 
PNNL-23997

\section{Tables}

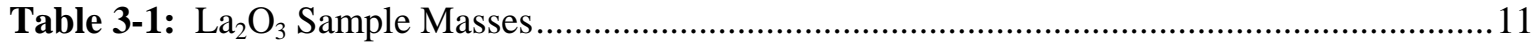

Table 4-1: Meteorological Observations at Nearby Tower Locations on May 14, 2013 10:45

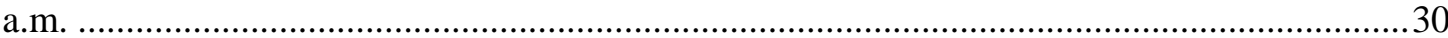

Table 5-1: Typical Values Extracted from Figure 6-3 ...........................................................49

Table 5-2: Comparison of ROI and GC Counts in Spectra with and without ${ }^{140}$ La.....................49

Table 5-4: Deposition Plume Width Estimate Based on Large Area Witness Plates ....................53

Table 5-5: Comparison of Tacky Mats and Mobile Survey …...................................................54

Table 5-3: Comparison of deposited activity measured by different instruments .......................61

Table 5-6: Table of MDAs for four detectors at $1 \mathrm{~m}$ height in terms of an infinite plane (modeled as a uniform disk source 40 meters in diameter) for 10-minute acquisition times of ${ }^{140} \mathrm{La}$ 's

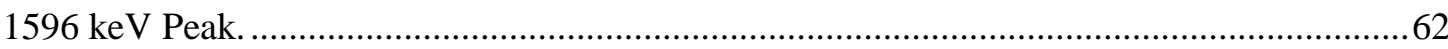

Table 5-7. Beads collected by Optical Witness Plates at Various Sampling Locations .................67 
PNNL-23997

\subsection{Introduction}

The Comprehensive Nuclear-Test-Ban Treaty (CTBT) is a nuclear non-proliferation treaty adopted by the United Nations and open for signature and ratification or accession by States Parties, but not yet entered into force. The CTBT makes provision for a verification regime that includes the conduct of an On-Site Inspection (OSI). The sole purpose of an OSI is to determine whether a nuclear explosion has occurred in violation of the treaty and, if so, gather facts that might assist in identifying the violator. The Treaty allows for an OSI to include many techniques, including the radionuclide techniques of gamma radiation survey and spectrometry and environmental sampling and analysis (of solids, liquids, and gases). A good understanding of the possible contamination distribution, along with the most valuable equipment and search techniques for locating accessible radioactive contamination, would dramatically improve the likelihood of conducting a successful OSI. In support of future OSIs, Pacific Northwest National Laboratory (PNNL) conducted work to understand the realistic distribution of nuclides that might occur under actual venting conditions from an underground nuclear test.

\subsection{Background}

OSI inspection teams will face restrictions in time and labor, as dictated by the CTBT, as well as likely logistical difficulties. The OSI challenge that this experiment investigated is to locate limited radioactive debris that has escaped an underground nuclear explosion and settled on the earth's surface near and downwind of ground zero (GZ). To support the understanding and selection of sampling and survey techniques for use in an OSI, we designed this experiment to simulate a small-scale vent from an underground nuclear explosion. This initial test used short-lived ${ }^{140} \mathrm{La}$ to provide a realistic ground deposition pattern from a single vent location. The experiment afforded an opportunity to investigate aerial and ground survey techniques, sampling OSI base-of-operations laboratory measurements, and the associated minimum detectable activities (MDAs). The work also provided a data set that may prove useful in future work to develop and benchmark local atmospheric transport models, and to develop anomaly detection and information barrier algorithms.

This experiment examined the atmospheric dispersion and subsequent ground deposition of radioactive particulates after injection into the atmosphere. During execution of the test, short-lived ${ }^{140}$ La was injected into the atmosphere from the ground to approximately a 35 -foot altitude. The most viable radionuclides originally considered for use in the test included ${ }^{24} \mathrm{Na},{ }^{111} \mathrm{In},{ }^{140} \mathrm{La}$, and ${ }^{198} \mathrm{Au}$. The test was conducted within the Yucca Flats basin on the Nevada National Security Site (NNSS). The experiment used particle sizes that 1) undergo atmospheric dispersion, and 2) have a high fraction of the particles settle out over a distance of a few kilometers. The reasons for such particle sizes include health and safety (strictly limiting the radioactive material transport to within the NNSS boundaries), cost and logistics - the initial activity required to establish a desired ground deposition is kept to a minimum if the particles do not transport long distances, and relevance to an OSI where the inspection team is attempting to locate the ground deposition in the nearby vicinity of a test.

In order to gain information on the atmospheric transport and settling at known particle sizes, $\mathrm{La}_{2} \mathrm{O}_{3}$ powder was sieved to produce a sample with a narrow size distribution of particles. Additional nonradioactive glass microspheres were also released; one secondary objective of the experiment was to determine whether we are able to plot deposition contours using optical microscopy to measure the 
deposition of microspheres collected on witness plates, and to compare the results of this method to deposition contours determined via radiation survey methods. This portion of the effort is interesting because it could enable significant further study of local transport related to vented underground nuclear explosions without the significant logistics efforts required for a radioactive release.

\subsection{Objective}

The objective of the particle release experiment (PRex) was to simulate a small-scale vent from an underground test, and to measure this release using an array of sampling/survey equipment and techniques. One of the challenges in an OSI is to locate radioactive debris that has escaped an underground nuclear explosion and settled on the surface near and downwind of GZ. Successful search and identification of such debris will enable inspectors to confirm that a nuclear test occurred. Positive results will also enable the inspection team to locate the testing site. To develop a robust OSI capability, it is necessary to understand the surface source term created by intermediate and long half-life $\left(\mathrm{t}_{1 / 2}\right.$ in the weeks to years range) particulate nuclear explosion debris. To facilitate study of the source term without the attendant long-term contamination associated with mixed fission products, this experiment used a shorter-lived radionuclide $\left({ }^{140} \mathrm{La} \mathrm{t}_{1 / 2}=1.678\right.$ days $)$. The data acquired in this experiment will be used to:

- Quantify how different sampling/survey methods affect minimum detectable activities (MDAs)

- Evaluate local variability of vented fallout

- Support development of local atmospheric models (ATMs) to enable prediction of source terms

- Support studies of anomaly detection/information barrier algorithms

Successful execution of this experiment has also further advanced the capability of NNSS to perform particulate radiological release studies.

\subsection{Scope of Document}

This report documents the execution, data collection, and analysis results for the PRex release, which occurred at 10:55 a.m. on Tuesday, May $14^{\text {th }}, 2013$. Specifically, the following aspects of the PRex experiment are discussed:

- Pre-release preparation: including site selection, source production and transport to the experiment site, dispersal mechanism, and simulations to predict the extent of dispersal

- On-site preparation: pre-event radiological survey, infrastructure, and pre-established contamination areas

- Set-up and execution of the dispersal event: including transport of the source to the site, assembly of the release mechanism, and meteorological conditions experienced during the test

- Data collection: an overview of the data collection tasks and systems used

- Data analysis and results

- Lessons Learned 
PNNL-23997

\subsection{Experimental Considerations}

\subsection{Overview of PRex}

PRex was carried out on Tuesday, May 14, 2013 with on-site experiment preparation completed during the week prior and on Monday, May 13. National Security Technologies LLC (NSTec) personnel established considerable infrastructure preparation work in advance of initial PNNL staff arrivals on Monday, May 6. The experiment was planned to involve the release of approximately $1 \mathrm{Ci}$ each of two radioisotopes: ${ }^{140} \mathrm{La}$ and ${ }^{198} \mathrm{Au}$. At the time of execution, $\sim 1 \mathrm{Ci}$ of ${ }^{140} \mathrm{La}$ was released. $\mathrm{La}_{2} \mathrm{O}_{3}$ powder was used to provide a stable precursor for production of ${ }^{140} \mathrm{La}$ through neutron capture. The powder was sieved prior to irradiation of the 32-45 micron particles in the Washington State University (WSU) TRIGA reactor. The irradiation was conducted on Friday, May 10, 2013, and the source was shipped from WSU on Sunday, May 12, arriving at the experiment site on Monday morning, May 13. Witness plates and air samplers were deployed in an array to the north of the release point in advance of the release. The radioactive particles were lofted $\sim 35 \mathrm{ft}$ in the air using an "air cannon," with the release occurring over an approximately two-minute time span. The site of the release is at latitude $36.99668^{\circ}$ and longitude $-116.00679^{\circ}$ at the northern edge of Area 6 in the Nevada National Security Site.

After the release a number of research activities occurred, including aerial survey, vehicle-based survey, in-situ measurements, handheld and backpack survey, air sampling, soil sampling, and field laboratory measurements at a "Base of Operations." Witness plate collections were used to establish a baseline debris deposition activity estimate, and to investigate the utility of non-radiation based determination of debris transport.

\subsection{Constraints}

This experiment represents a simulated release from a vented underground nuclear test in order to understand the surface source term created by particulate nuclear explosion debris. While considerable effort was made to ensure that the release was as realistic as possible, practical and safety considerations naturally imposed a number of constraints on the degree to which a "realistic" scenario was realized.

These included:

- A single radioisotope, ${ }^{140} \mathrm{La}$, was used in the PRex release. This is a fission product of interest during an OSI, however an actual vented test would be expected to release many more isotopes, with a wide range of half-lives.

- This experiment did not utilize radioactive gas, which is a frequent release form in addition to particulate, but is being studied by a different National Center for Nuclear Security (NCNS) project (with PNNL and Lawrence Livermore National Laboratory).

- The particulate size was narrowly chosen so as to favor sizes that are small enough to be non-ballistic and involve atmospheric transport, but not so small as to be transported long distances (> several $\mathrm{km}$ ) before deposition. Normal releases from an underground test will generate a broad size distribution including a large number of fine particulate aerosols that can travel great distances. However, the 
logistics of producing and transporting the radioactive source material dictated that we narrow the size distribution to ensure deposition in the near-field.

- The 40 micron particle size was also chosen to be above the size typically considered respirable.

- The location of the trial may not be representative of a broad range of test site environments. While the experiment was performed at the former Nevada Test Site (where underground nuclear explosions did take place), the specific site selected for the release was chosen in part for environmental conditions that allowed for a favorable release and relative ease of post-release survey/sampling.

\subsection{Assumptions}

The experiment plan was originally developed using the following assumptions:

- Nearly $100 \%$ of the source material will be lofted by the "air cannon" (also referred to as the $\mathrm{CO}_{2}$ gerb in this document)

- The release mechanism will loft the source material $\sim 35 \mathrm{~m}$ into the air with wind speeds at the low end of the acceptable parameters, and $\sim 15 \mathrm{~m}$ into the air with wind speeds at the high end of acceptable parameters. With favorable meteorological conditions, this material will be deposited within a "contamination area" roughly $2-4 \mathrm{~km}$ (downwind) $\times 0.5 \mathrm{~km}$ (crosswind) in size.

- All equipment used for data collection will be in good working order, including having passed calibration checks within the past year (or other period recommended by the manufacturer). It is not assumed that instruments will be calibrated specifically for isotopes used in the test.

- Favorable weather conditions within a 3-day period between 8 a.m. and 5 p.m. are likely

\subsection{Pre-Execution Release Parameters}

The following parameters were established prior to the experiment and are summarized here for easy reference. Several are addressed in more detail later in this document, and a detailed description of the release parameters is available in the experiment plan.

- Location: The experiment was held at the northern edge of Area 6 in the Nevada National Security Site (NNSS). Coordinates for the release site are (see Figure 2.1):

- Lat/Long: $36.99668^{\circ},-116.00679^{\circ}$

- Timing: The window for release was 8 a.m. -5 p.m., Tuesday, May $14^{\text {th }}$ through Thursday, May $16^{\text {th }}$, 2013. The actual release began at $\sim 10: 55$ a.m. on Tuesday, May $14^{\text {th }}, 2013$, with a duration of approximately 1 to 2 minutes.

- Source configuration:

- Release mechanism: Continuous Flow Confetti Gerb Launcher (“Air Cannon”)

- Source material: approximately $1 \mathrm{Ci}$ of ${ }^{140} \mathrm{La}$

- Meteorological conditions: Acceptable meteorological conditions for the test were documented in the PRex Experiment Plan (Seifert et al. 2013) 


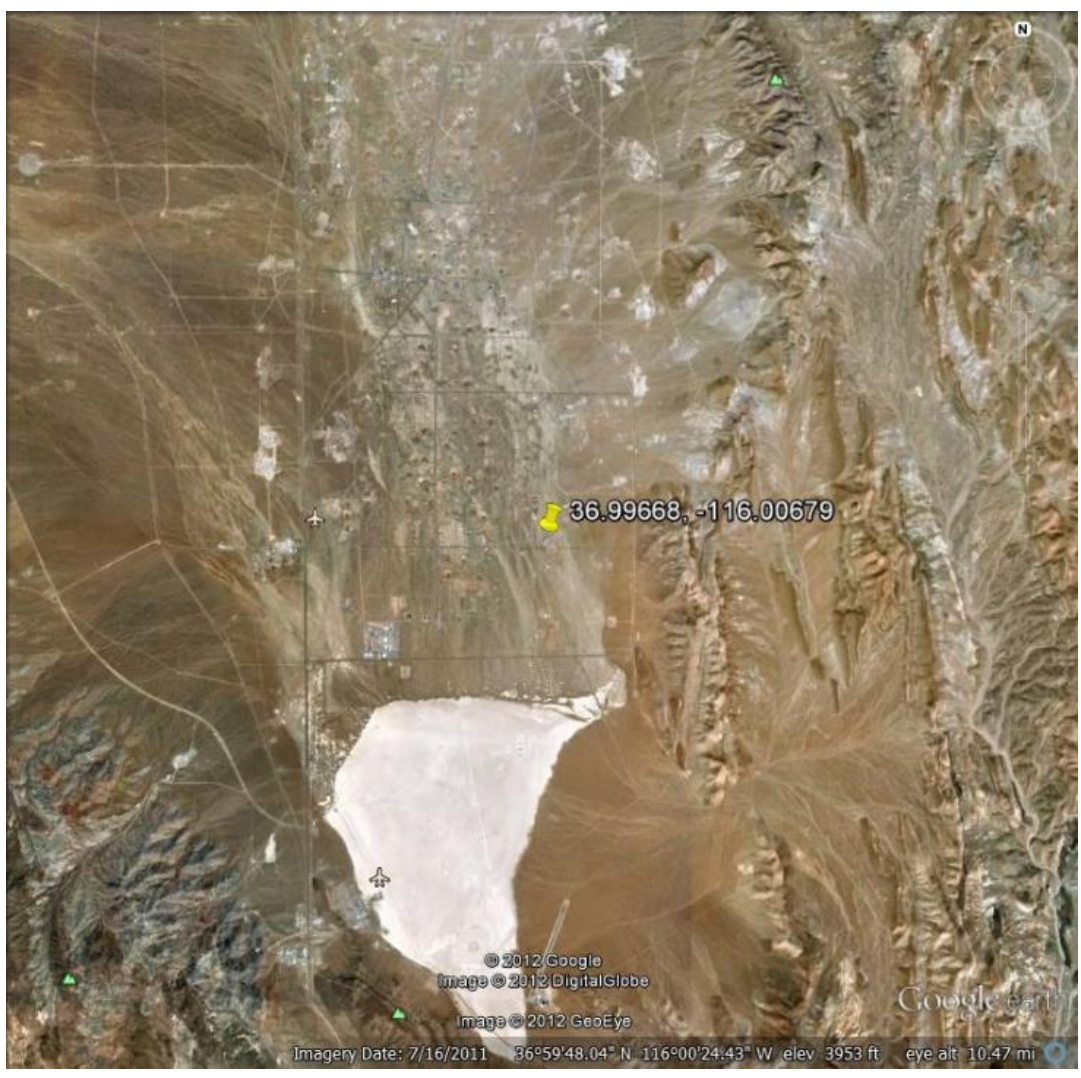

Figure 2.1: PRex test location on the Nevada National Security Site 
PNNL-23997

\subsection{PRex Experiment Preparation}

\subsection{Experiment Plan}

The PRex Experiment Plan (Seifert et al. 2013) provides many of the details used in site selection, radioisotope selection, meteorological planning, required test site infrastructure, dose estimates, and preevent concept of the sequence of events. Much of the information is not repeated in this document, and the reader is referred to the experiment plan for specifics on planning the experiment.

\subsection{Site Selection}

A number of possible sites at the NNSS were visited in January 2012 for determining the ideal site for PRex. Our initial desired criteria list was as follows:

1. A pristine (little radiological background from previous Test Site activities) location far enough from site infrastructure and borders so as not to be a health issue. Several square kilometers, including access roads, would need to be temporarily closed off.

2. Nearby and downwind, there should be an area that does have radiological background from previous tests. This is important so that data can be taken to test algorithms and procedures that can discriminate fresh tests from old tests under a CTBT OSI.

3. At least part of the downwind area should be accessible for vehicle radiation surveys so that procedures and equipment can be tested relative to OSI techniques

4. As close to Mercury as reasonable, with infrastructure like electricity, if available

5. Preferably, the area should be chemically as well as radiologically pristine because some of the research tools employed may be based on chemical analysis

We did not have sufficient information to investigate criterion 5 during our visits. There appeared to be no suitable locations with access to electricity, forcing the use of a generator during the test. In the end, criteria 3 and 4 trumped criterion 2 and a site in the northern end of Area 6 was chosen at latitude $36.99668^{\circ}$ and longitude $-116.00679^{\circ}$. The site is at the southern end of the Yucca Flats area, immediately to the south of where many underground nuclear tests occurred in the past, but on the eastern edge away from the main road (Mercury Highway). Likewise, the Area 6 Construction Support Facilities area and Control Point are a few miles away to the southwest, but not downwind of the planned release. The location is very flat with light desert grass and small shrubs, providing for straight-forward off-road and aerial survey (see Figure 3.1). Although there are radiologically-controlled areas downwind of the release site, particularly those associated with the tests Adze and Seaweed, these do not have surface radiation from old tests but are fenced to prevent the disturbance of buried contamination. 
PNNL-23997

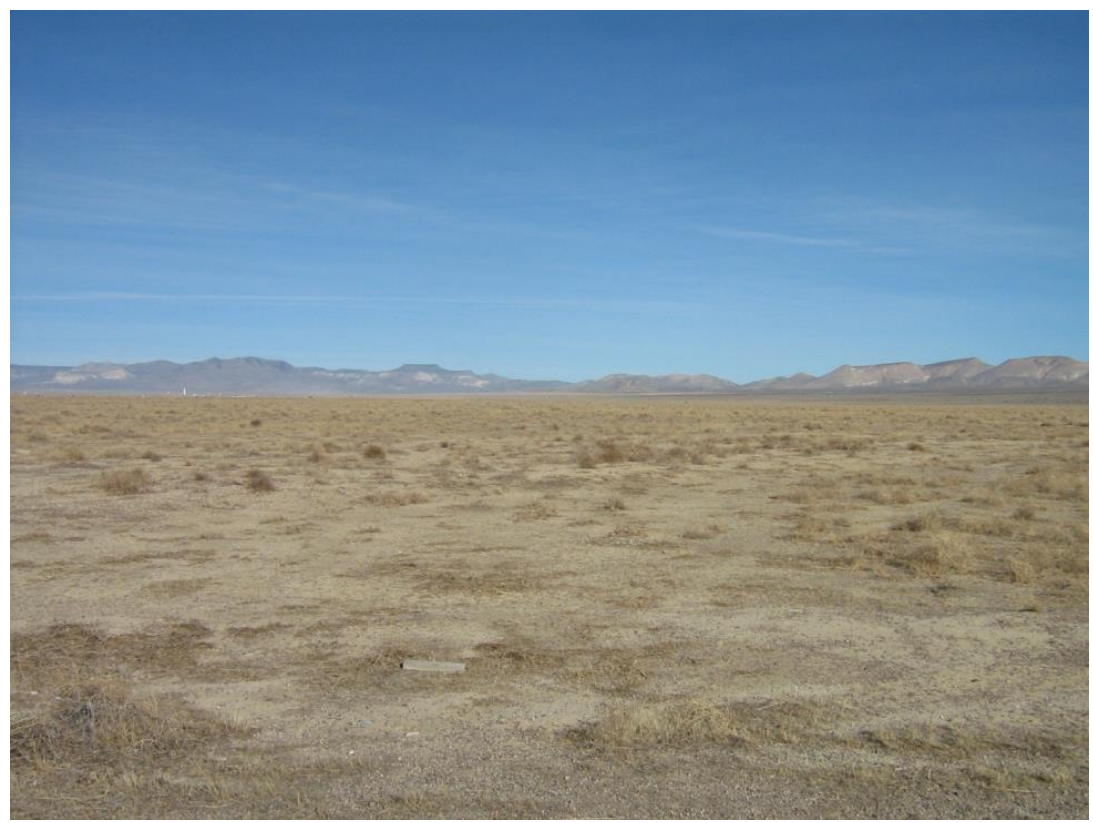

Figure 3.1: NNSS release site. While not visible in the photo, several craters and un-collapsed test locations exist in close proximity to the north of the planned release point. Craters are more concentrated to the northwest; south-southwesterly winds would result in the fewest obstacles for ground survey.

\subsection{Background Measurements, September and October 2012}

A vehicle-based background survey was performed in advance of the test using an RSI RS 700 spectrometer system with two $5.08 \mathrm{~cm} \times 10.16 \mathrm{~cm} \times 40.64 \mathrm{~cm}\left(2^{\prime \prime} \times 4^{\prime \prime} \times 16^{\prime \prime}\right) \mathrm{NaI}(\mathrm{Tl})$ detectors mounted in the bed of a Kawasaki Mule All-Terrain Vehicle (ATV). The RS 700 has an integrated global positioning system (GPS) that recorded coordinates along the path where the ATV was driven. An additional guidance system was tested in conjunction with the built-in GPS. A Raven RGL 600 system, originally designed to guide the precision driving of agricultural equipment, and an ancillary GPS unit were combined to enable driving parallel lines of arbitrary separation starting from two points determined by the user.

On September $25^{\text {th }}$ and $26^{\text {th }}, 2012$, staff members from PNNL performed a vehicle-based survey of the proposed PRex release site using the equipment described above. The survey was intended to provide a baseline for comparison with post-release measurements. This vehicle survey also served to identify whether the several-square-kilometer site would present complications not previously spotted from the road. Parallel lines of increasing length (as the vehicle moved further from the release point) were driven with the help of the Raven RGL 600 system and ancillary GPS. The ATV was driven at a nominal $3 \mathrm{mph}$, with line spacings of $50 \mathrm{~m}$ (closest to the release point) and $100 \mathrm{~m} \mathrm{(} \mathrm{1} \mathrm{km} \mathrm{and} \mathrm{further).} \mathrm{The} \mathrm{data}$ was retrieved both from the cabin system (laptop computer) and directly from the RS 700 unit. A sample of the data is shown in Figure 3.2. The final configuration of the vehicle and a contour map of the vehicle survey results are shown in Figure 3.3. 


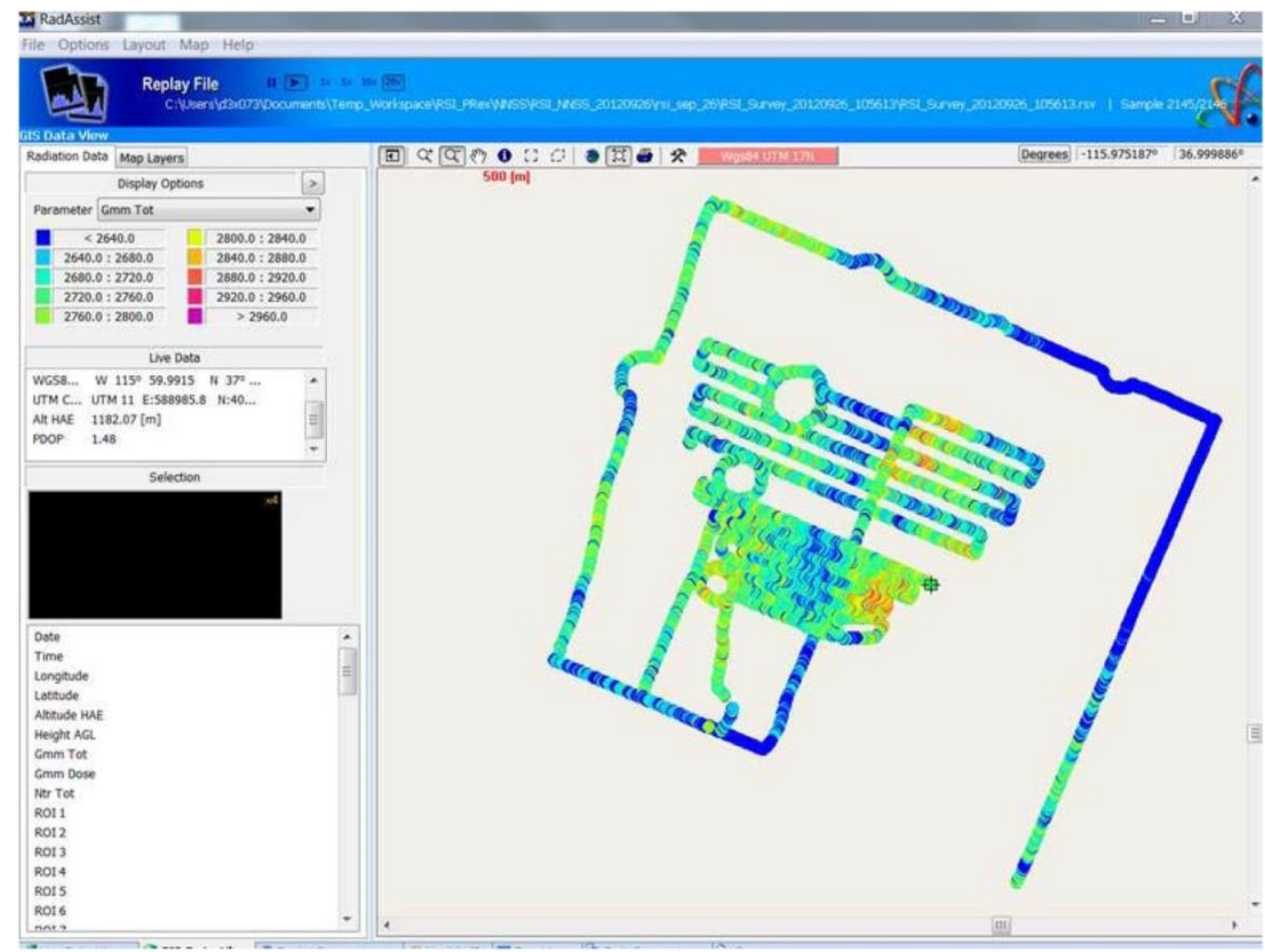

Figure 3.2: Screen capture made with the RSI Software RadAssist and a GIS module showing raw data from the September 2012 background survey
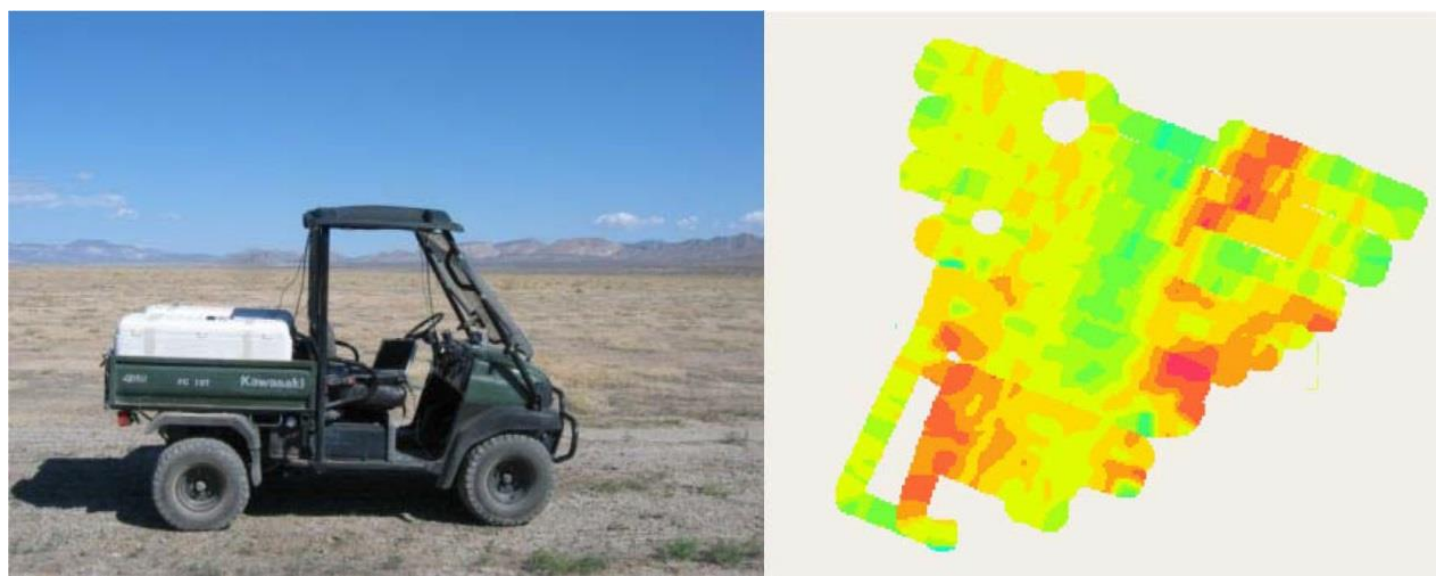

Figure 3.3: ATV used for vehicle survey at the PRex location on Yucca Flats (left); contour map of radiation survey results (right)

On October 15, 2012, NNSA’s Aerial Measuring System (AMS) flew a Radiation Solutions, Inc. (RSI) array of $12 \mathrm{NaI}(\mathrm{Tl})$ detectors over the planned site of the NCNS PRex. These flights were conducted to assess the initial radiological conditions of the experiment site, including areas where short-lived radioactivity was expected to deposit on the ground during the experiment. The AMS System was flown 
at 70 knots, 50 feet in elevation, and 75-foot line spacing. The exposure map produced is shown in Figure 3.4.

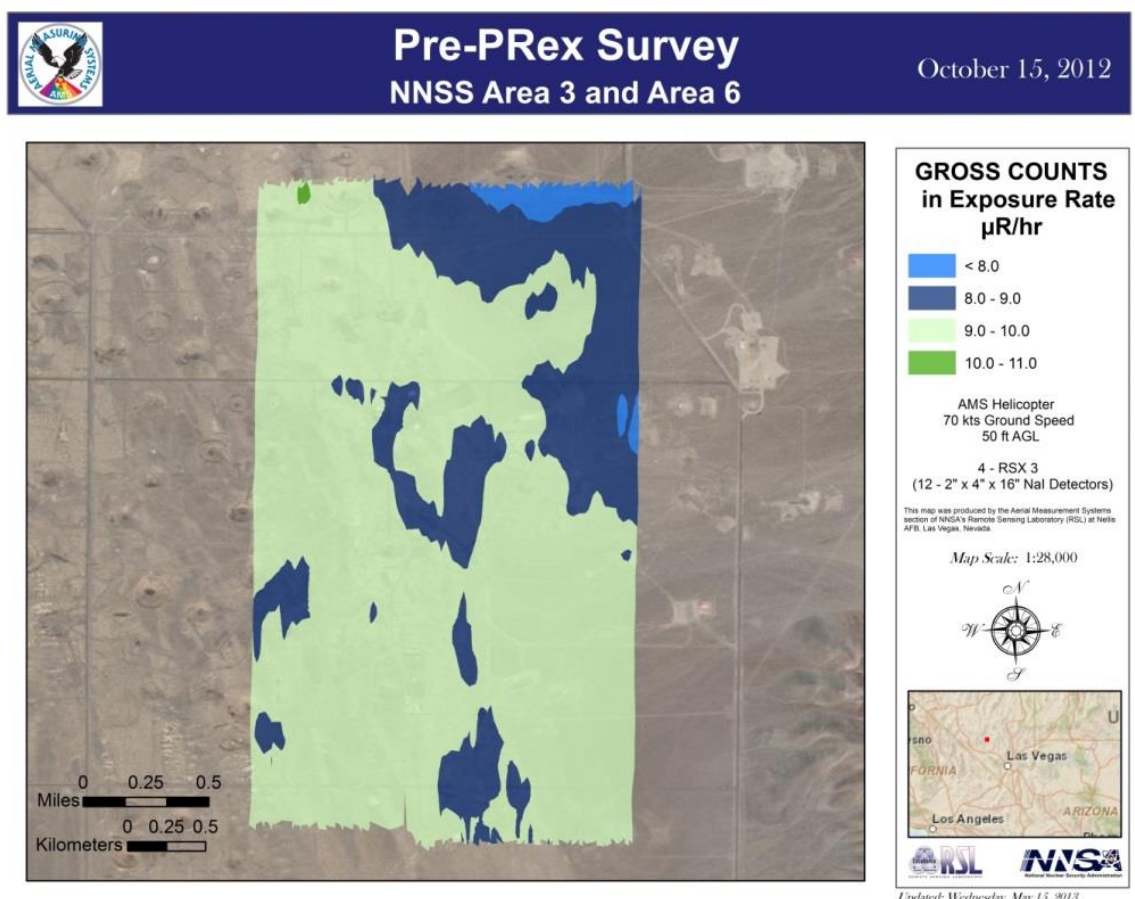

Figure 3.4: Gross count exposure map measured over the PRex release area in October 2012

\subsection{Source Production}

\subsubsection{Preparation of $\mathrm{La}_{2} \mathrm{O}_{3}$ Powder}

Lanthanum oxide, $\mathrm{La}_{2} \mathrm{O}_{3}$, was purchased from Materion at $99.99 \%$ purity and -200 mesh. The material was separated by particle size using a Retsch AS200 sieve shaker (Figure 3.5 and Figure 3.6). The sieves purchased included No $230(63 \mu \mathrm{m})$, No $270(53 \mu \mathrm{m})$, No $325(45 \mu \mathrm{m})$, No $450(32 \mu \mathrm{m})$, and No 500 $(25 \mu \mathrm{m})$. The resulting particle size ranges were $>63,53-63,45-53,32-45,25-32$, and $<25 \mu \mathrm{m}$. Chains were used to aid the sieving process. After sieving, the material selected for irradiation and release was in the $32-45 \mu \mathrm{m}$ range. In preparation for sieving, the sieves, chains, and lid were washed with alcohol by spraying the part, allowing the alcohol to run down the part, repeating the alcohol rinse, then drying the part in a flow hood. The shaker table, base of the glove bag, and balance were covered in 1.5-mil aluminum foil. $\mathrm{La}_{2} \mathrm{O}_{3}$ is hydroscopic; the sieving process was done in a nitrogen-filled disposable glove bag, see Figure 3.5 and Figure 3.6 to prevent the adsorption of water.. The glove bag was inflated at $20 \mathrm{psi}$ and then purged at $100 \mathrm{cc} / \mathrm{min}$ for 3 days. 
Following sieving, material in each sieve was carefully poured into an aluminum foil pocket from which it could then be poured into sample containers. The $\mathrm{La}_{2} \mathrm{O}_{3}$ in each sieve was split between two preweighed glass jars and the final weight recorded while in the glove bag. The jars were then sealed with vinyl tape and removed from the glove bag. Scoopulas were used to aid in material transfer and to take sub-samples for analysis. To minimize the spread of different particle size material in the glove bag, a different aluminum pocket and a new individually wrapped scoopula was used for each sample. In addition to the material stored in the glass jars, a small sample was taken for irradiation at the WSU TRIGA reactor to verify purity. Sub-samples were stored in 20-mL poly liquid scintillation counter vials. See Table 3-1 for samples generated with associated masses.

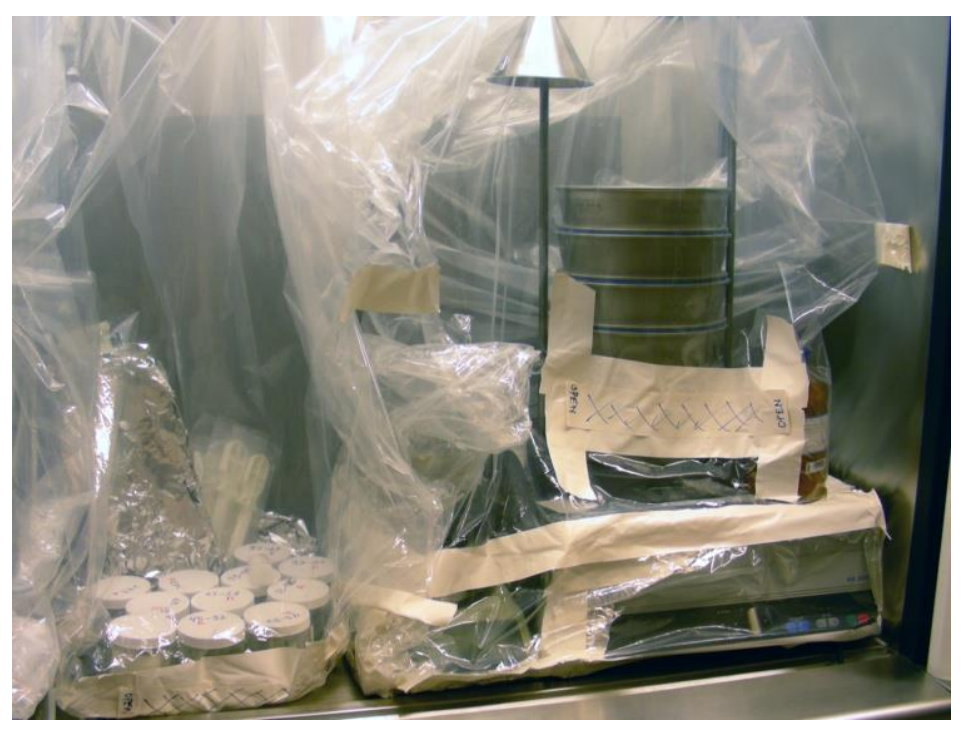

Figure 3.5: Shaker / sieve setup including shaker, sieves, balance, and sample jars in a nitrogen filled glove bag

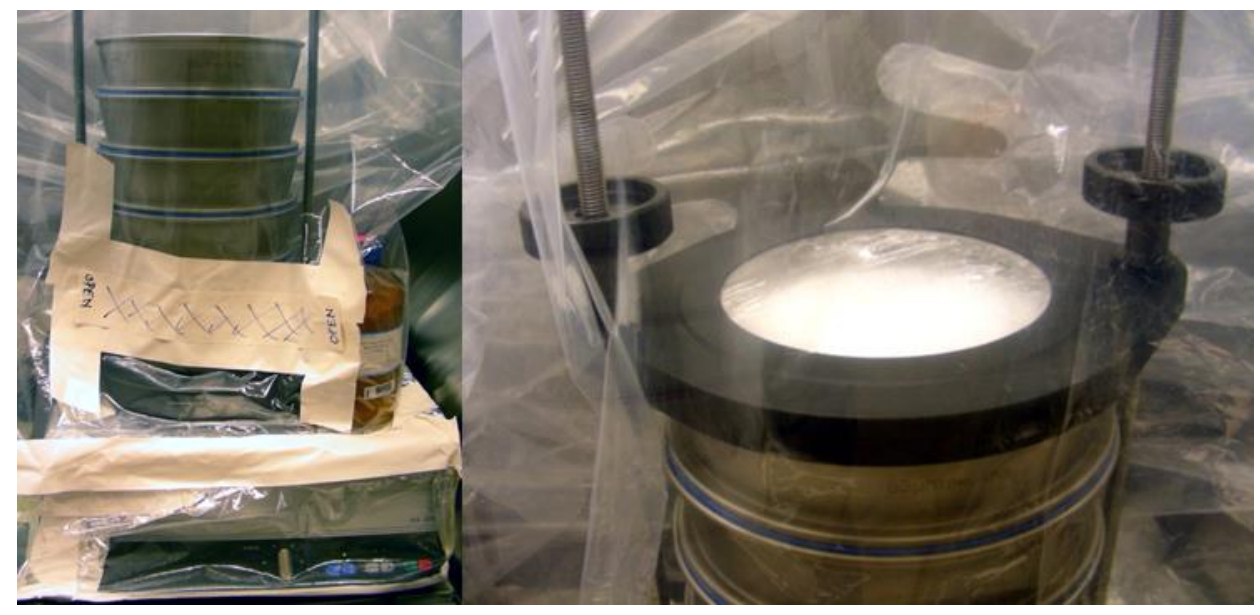

Figure 3.6: Shaker and sieves are shown on the left. The sieve cover with $\mathrm{La}_{2} \mathrm{O}_{3}$ powder is shown on the right. 
Table 3-1: $\mathrm{La}_{2} \mathrm{O}_{3}$ Sample Masses

\begin{tabular}{|c|c|c|c|c|c|c|c|}
\hline \multicolumn{3}{|c|}{ Particle Sizes } & \multirow[t]{2}{*}{$\begin{array}{c}\text { Jar } \\
\text { Designation }\end{array}$} & \multicolumn{2}{|c|}{$\begin{array}{l}\text { Tare } \\
\text { (grams) }\end{array}$} & \multirow{2}{*}{$\begin{array}{c}\text { with } \mathrm{La}_{2} \mathrm{O}_{3} \\
\text { (grams) } \\
\text { jar w/ lid }\end{array}$} & $\begin{array}{l}\text { Final weight } \\
\text { (grams) }\end{array}$ \\
\hline & & & & jar with lid & jar w/o lid & & \\
\hline 25 & - & 32 & A & 215.9 & 203.66 & 287.875 & 71.975 \\
\hline 25 & - & 32 & B & 214.3 & 201.91 & 294.818 & 80.518 \\
\hline 45 & - & 32 & A & 215.87 & 203.71 & 327.3 & material \\
\hline 45 & - & 32 & B & 215.81 & 203.57 & 332.481 & 116.671 \\
\hline WSU A & & & vial & 7.01 & 5.14 & 14.455 & 7.445 \\
\hline 25 & - & 32 & vial & 7 & & 7.597 & 0.597 \\
\hline WSU B & & & vial & 6.99 & 5.11 & 6.999 & 0.009 \\
\hline WSU C & & & vial & 7 & & 9.393 & $\begin{array}{c}2.393 \text { shipped to } \\
\text { WSU }\end{array}$ \\
\hline 53 & - & 45 & vial & 7 & & 9.204 & 2.204 \\
\hline 53 & - & 45 & A & 215.57 & 203.44 & 269.145 & 53.575 \\
\hline 53 & - & 45 & B & 214.73 & 202.42 & 284.202 & 69.472 \\
\hline 63 & - & 53 & vial & 7 & & 9.075 & 2.075 \\
\hline 63 & - & 53 & A & 216 & 203.67 & 280.692 & 64.692 \\
\hline 63 & - & 53 & B & 214.29 & 301.95 & 284.963 & 70.673 \\
\hline \multicolumn{3}{|c|}{ bottom catch pan } & & 213.94 & 201.89 & & $\begin{array}{l}\text { approximately } \\
20 \mathrm{~g}\end{array}$ \\
\hline \multicolumn{8}{|c|}{ approximate masses - vial not tared } \\
\hline
\end{tabular}




\subsubsection{Irradiation at Washington State University}

The lanthanum oxide powder was irradiated in double containment in position D8 of the WSU TRIGA research reactor. The 36 minute irradiation was performed on Friday, May 10 with a target ${ }^{140} \mathrm{La}$ production of $2.2 \mathrm{Ci}$ at noon Pacific daylight time (PDT) on Sunday, May 12. The irradiation was performed at $1 \mathrm{MW}$, with a neutron flux previously characterized as $5.3 \times 10^{12} \mathrm{n} / \mathrm{cm}^{2} / \mathrm{sec}^{2}$. Gamma assay performed after the irradiation confirmed production of the desired ${ }^{140} \mathrm{La}$ activity.

Prior to irradiation, the WSU Reactor Center Safety Committee, with input from PNNL, determined that the lanthanum oxide powder is a dispersible material. WSU had previously approved a roll-sealed aluminum can geometry (Figure 3.7) for irradiation of non-dispersible material; they subsequently requested additional measures to ensure containment of the dispersible $\mathrm{La}_{2} \mathrm{O}_{3}$ powder. To satisfy these requirements, PNNL designed an aluminum liner (Figure 3.8) to fit inside the roll-sealed drawn aluminum cans. One challenge was to design the liner to be tough enough to withstand drop forces, yet still present a section thin enough to allow puncture by the powder extraction needles. The liner was fabricated, tested and showed the expected deformation resulting from a 20-foot drop test onto a concrete floor (Figure 3.9). PNNL submitted a report on the change of design and associated experiments (Smart 2013) to the reactor safety committee, which granted permission to proceed with the irradiation using the nested can liner and aluminum roll sealed can (Figure 3.10).

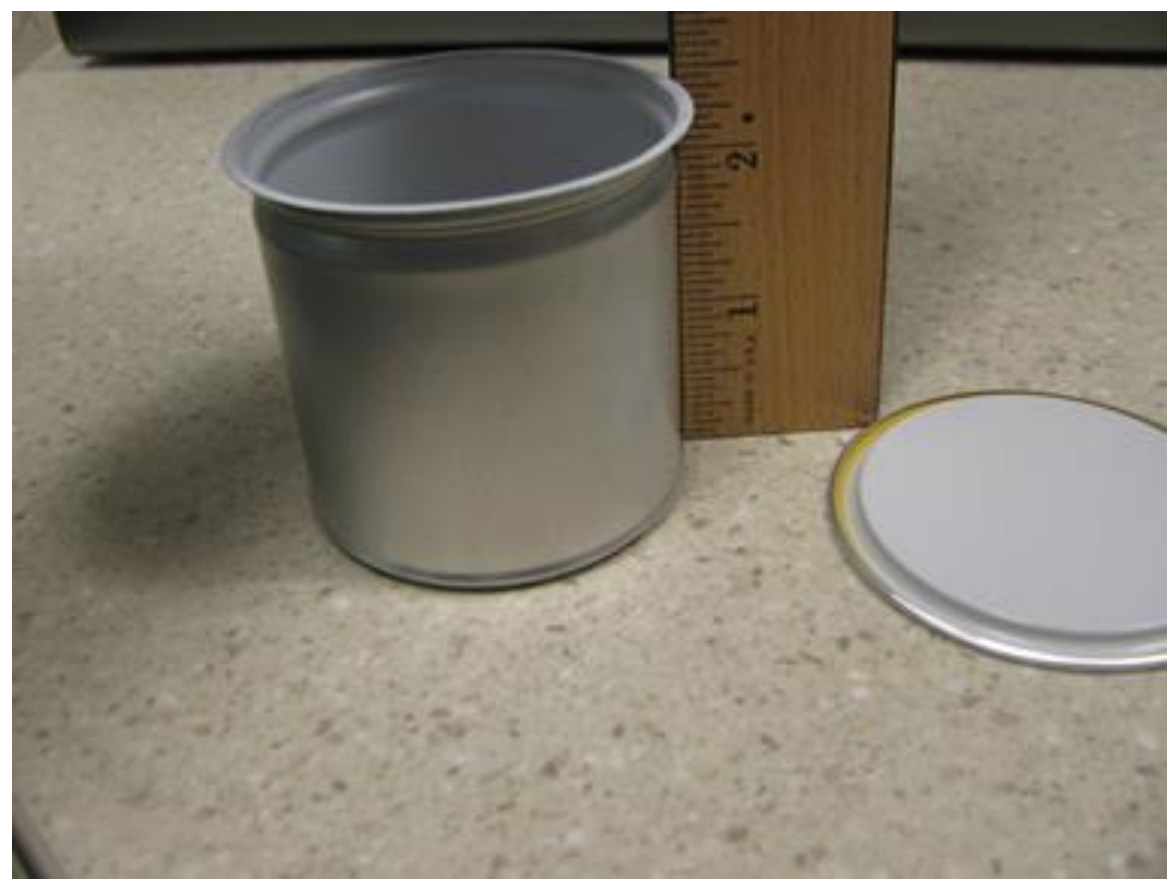

Figure 3.7: The roll-sealed aluminum can provided by the WSU Reactor Center team. This can has been certified by the reactor center for use with non-dispersible materials. PNNL leveraged the "certified" status of this geometry as well as the geometry specific insertion and retrieval equipment already in place at the reactor center. 

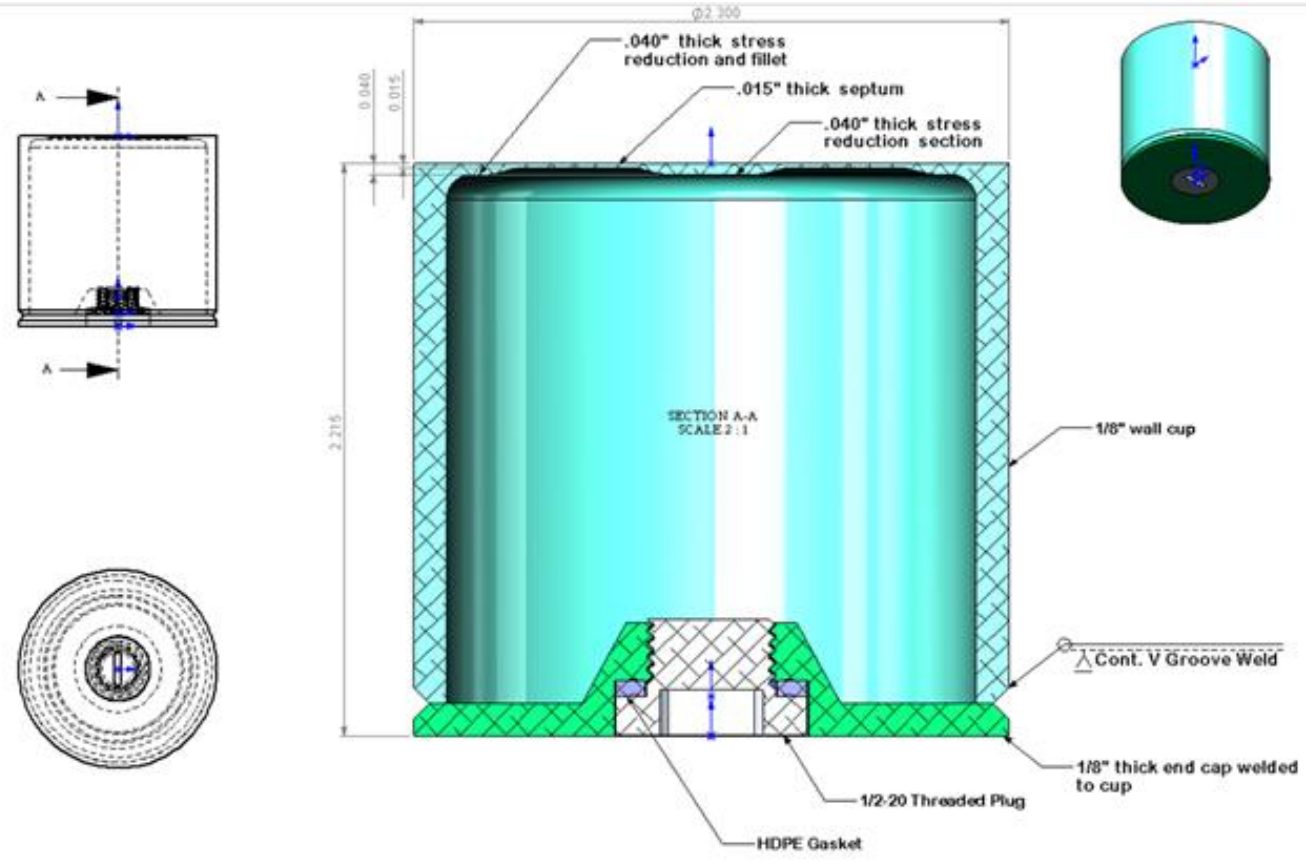

Figure 3.8: The 6061-T6 aluminum liner assembly. Light blue section includes a thin septum end with appropriate reinforcement areas to reduce stress. Green section is the welded end cap with a 1/2" 20 threaded plug. The light purple area is a high density polyethylene plug gasket.

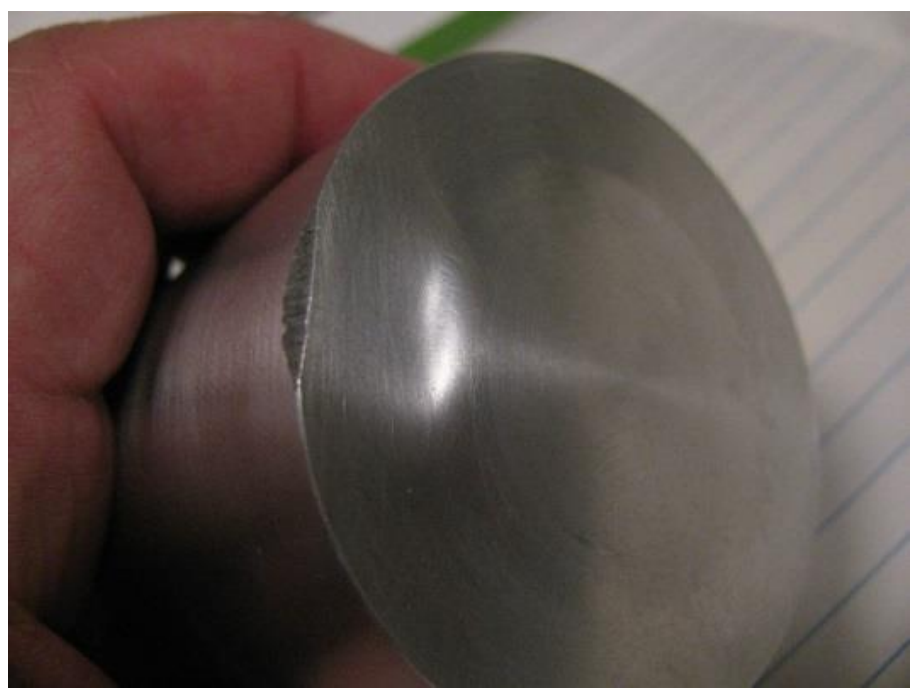

Figure 3.9: A 20-foot drop test conducted with a water-filled aluminum "can liner" resulted in the expected amount of deformation, with no rupture or leakage 
PNNL-23997

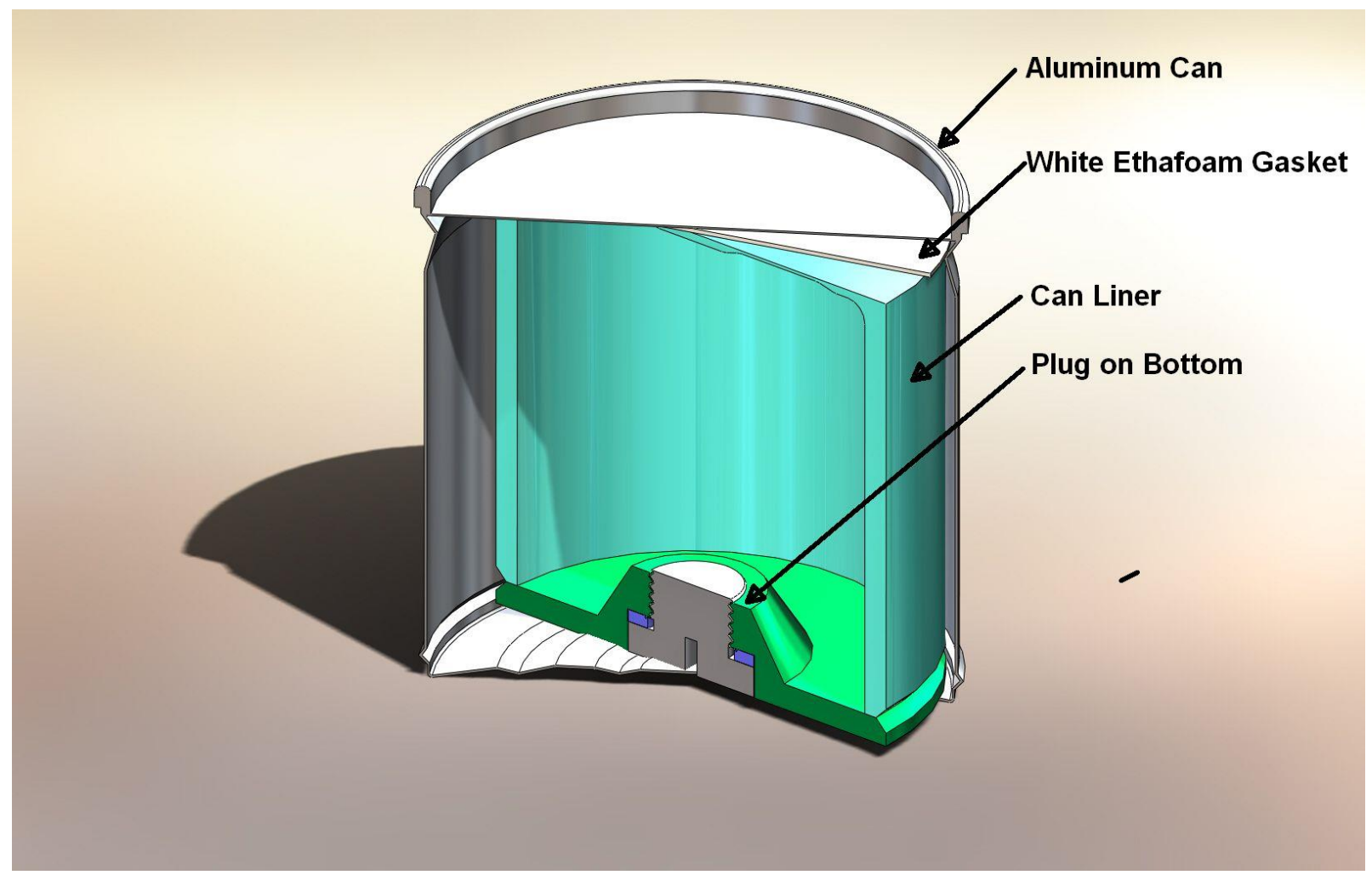

Figure 3.10: The "roll-sealed aluminum can" with the custom designed aluminum liner inside. The aluminum liner has a thin annulus around its top wall to allow puncture by the material extraction needles.

\subsubsection{Source Transport}

The design and fabrication of the shipping container took place in advance of the final experiment design. The transport shielding was designed based on $2.5 \mathrm{Ci}$ of ${ }^{140} \mathrm{La}$ activity at the time of pick-up by the shipping company. Monte Carlo N-Particle (MCNP) Version 5 (Forster et al. 2004) transport calculations showed that if centered in a type "A" 55-gallon drum, that 4 in. of lead shielding around the source would reduce drum surface dose to less than $200 \mathrm{mrem} / \mathrm{hr}$; which is below a "Yellow III" transport maximum surface dose level. A lesser source strength of $1 \mathrm{Ci}$ centered in a type A drum with 4 in. of lead shielding would result in a surface maximum surface dose of less than $50 \mathrm{mrem} / \mathrm{hr}$, which meets the requirement for a "Yellow II" shipment.

A custom designed lead shield (see Figure 3.11) mounted in the center of a type A 55-gallon transport drum reduced dose at the surface of the drum during transport, and held the source can in position during the source extraction process. The $30.5 \mathrm{~cm}$ (12") diameter by $32.4 \mathrm{~cm}(12.75 ")$ tall steel encased lead shield weighs about 560 pounds with the shielded top plug installed. The shield is supported in the center of the drum with a system of 5/8" plywood rings and disks, layered with 2-in. thick, 900-psi ethafoam sheets. The shield has three lift points used for installation into the drum.

After completing the irradiation, staff at the WSU reactor center loaded the irradiated source can into the shielded transport drum. After removing the drum lid and the top layers of foam and plywood, the exposed lead-filled cap plug was unbolted and removed. WSU staff used their existing lead pig (see 
Figure 3.12), which is suspended from an overhead crane cable, to retrieve the aluminum roll-sealed can from the reactor pool. A hole in the bottom of the pig accepts the can and prevents radiation shine in all directions except downward.

The suspended lead pig and source arrangement was then positioned over a source transfer tube that guided the source can into the shielded drum (see Figure 3.13). Once the can was in the shielded drum, the crane was used to insert the lead-filled cap plug into the shielded transport container. The cap plug was secured with a six-position bolt pattern and the foam and plywood layers were replaced to fill the drum completely (see Figure 3.14 and Figure 3.15). The drum lid was installed and the drum was loaded onto a dedicated FedEx transport to the NNSS.

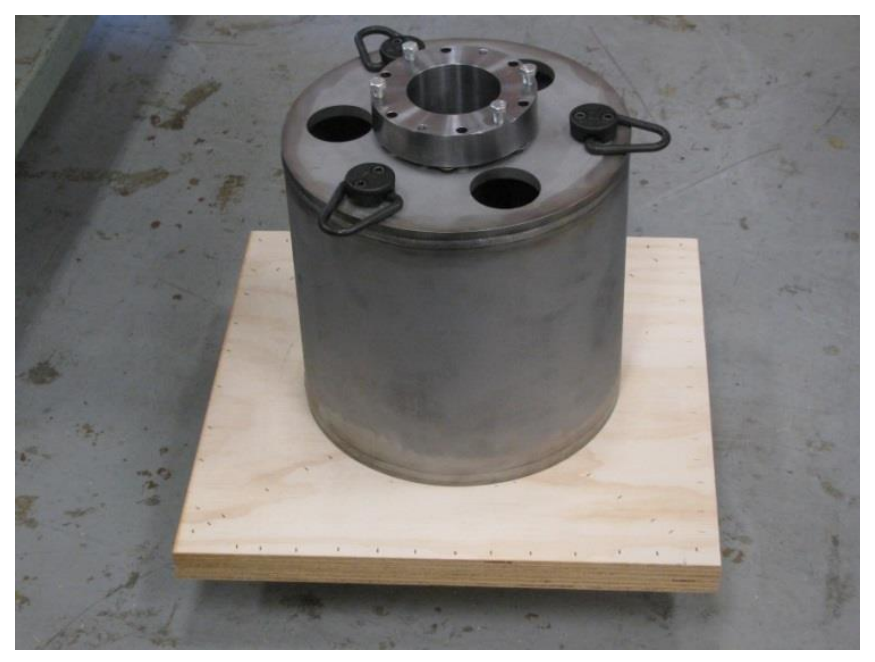

Figure 3.11: This shielding assembly (cylinder and plug cap) weigh 560 pounds after being filled with lead. The main weldment is $32.4 \mathrm{~cm}$ (12.75") tall and has an outer diameter of $30.5 \mathrm{~cm}$ (12"). This was mounted in the center of a Type A 55-gallon drum.

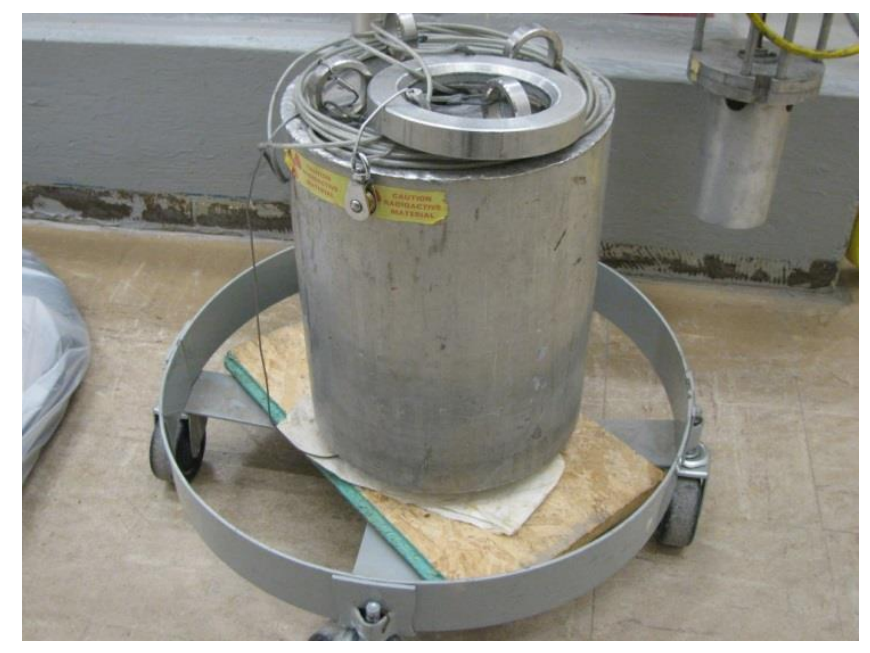

Figure 3.12: Custom lead pig at the WSU Reactor Center designed to retrieve the roll-sealed aluminum can geometry after irradiation 
PNNL-23997

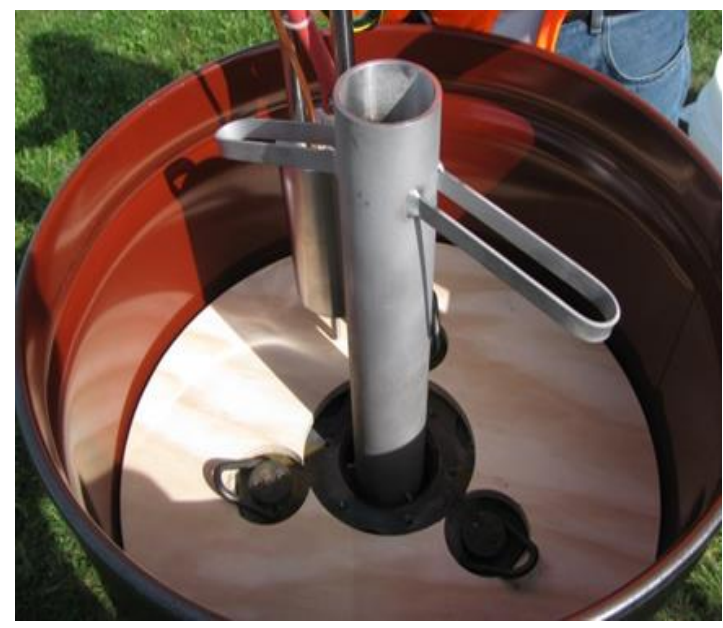

Figure 3.13: A sturdy transfer tube was fit into the transport container to facilitate a safe transfer between the crane-positioned WSU sample retrieval pig and the shielded transport drum.

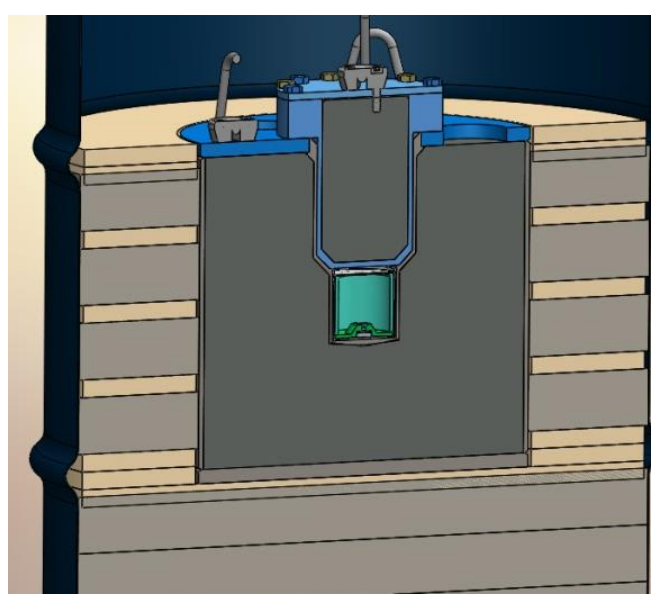

Figure 3.14: The aluminum can containing $\mathrm{La}_{2} \mathrm{O}_{3}$ powder is shown in this model render after being transferred into the shielded transport drum. The image shows the shielded cap plug inserted and bolted down. Grey layers are 900-psi ethafoam. The light tan layers are plywood. Additional layers of plywood and foam were placed on top of this assembly prior to shipment. 
PNNL-23997

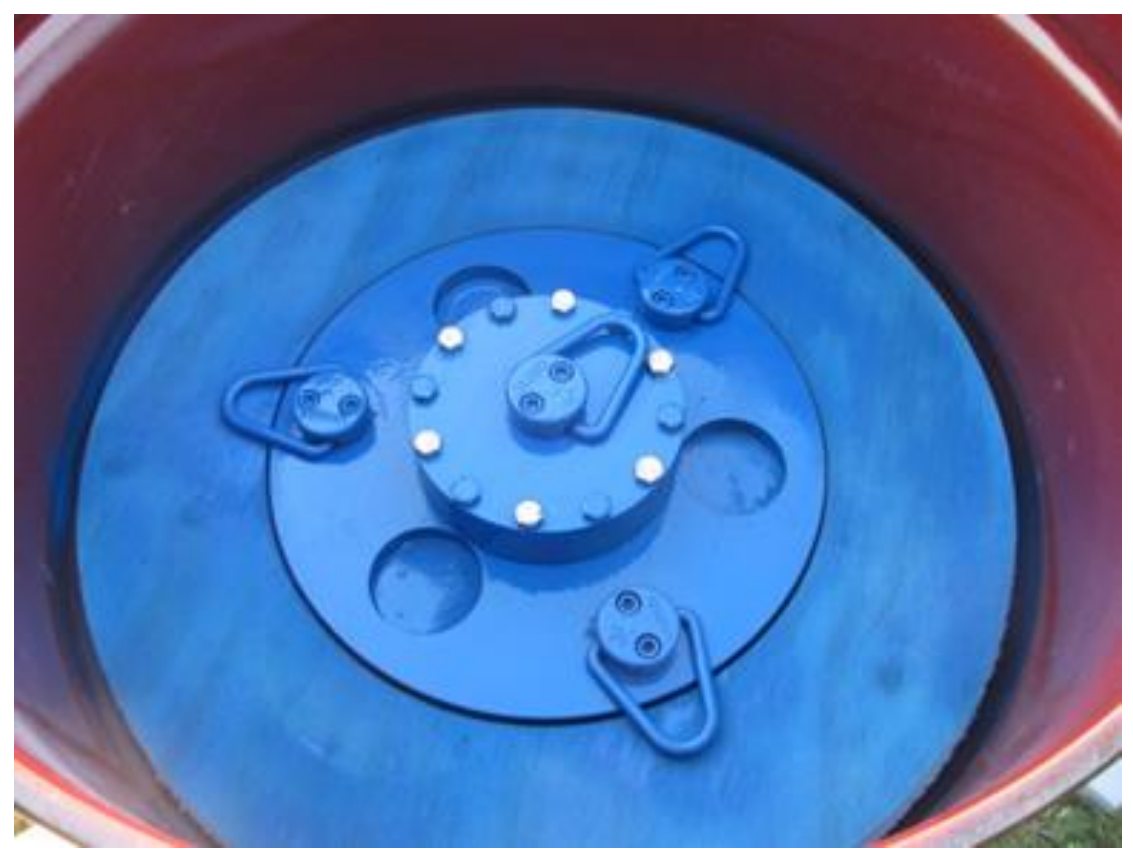

Figure 3.15: Lead-filled cap plug in place and bolted into the 4" thick drum shield assembly

A number of source-extraction and distribution methods were posited for this project, but schedule and budget greatly influenced the final design and implementation. Although a more automated process to release the source may have further reduced dose to staff, ALARA principles were given a high priority. Staff dose was kept very low in the final implemented design. Dose estimates prepared in advance of the experiment are documented in Appendix D of the experiment plan.

The procedure to extract the source began with the removal of the lead-filled cap plug. The bolts were loosened using an extended socket, then a16-foot bar with a cable and hook was used to lift the plug from the shield. Staff remained at the ends of the bar-outside of the upward-directed shine-path of the open shield.

A second 16-foot bar fitted with the "source extraction mechanism" in the middle was then lowered by staff onto the source can. The extraction mechanism consists of a 20 pound steel cylinder suspended by two stiff rods from the bar. The bottom of the steel cylinder was machined to accept two $\sim 0.75 \mathrm{~cm}$ diameter hollow needles. When the source extraction assembly was set onto the source can and pulled downward by the two staff members, these needles punctured the top of the can, providing access to the $\mathrm{La}_{2} \mathrm{O}_{3}$ powder (see Figure 3.16 through Figure 3.19). One needle was supplied with compressed nitrogen, while the other served as an exit port for the powder from the can. Using a remote valve control switch, the operator was able to flow nitrogen through the source container, evacuating a majority of the radioactive $\mathrm{La}_{2} \mathrm{O}_{3}$ particles. The exit-port needle emptied into the inlet of the airstream of the air cannon described below. 


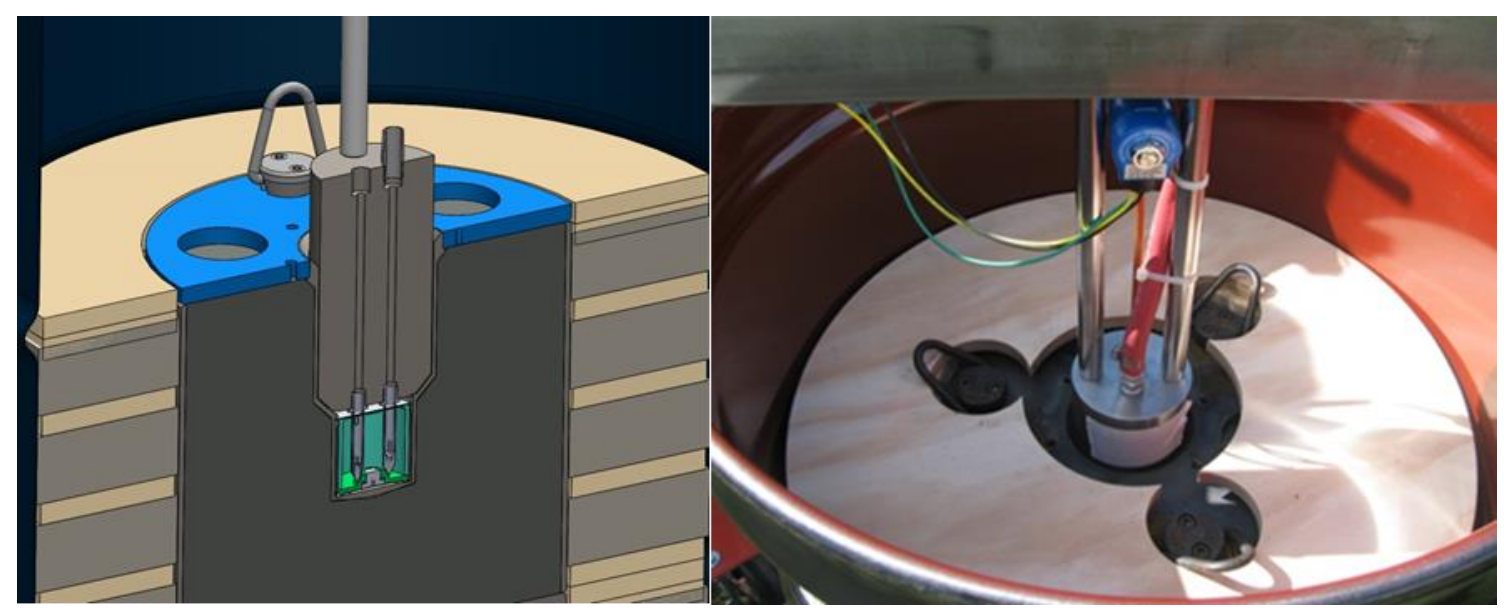

Figure 3.16: The source extraction mechanism. (Left) cross section diagram;(Right) actual implementation. Two stainless steel needles puncture the source can; one to inject a high-velocity gas jet and the serving as an escape vent for the gas-particulate mix.

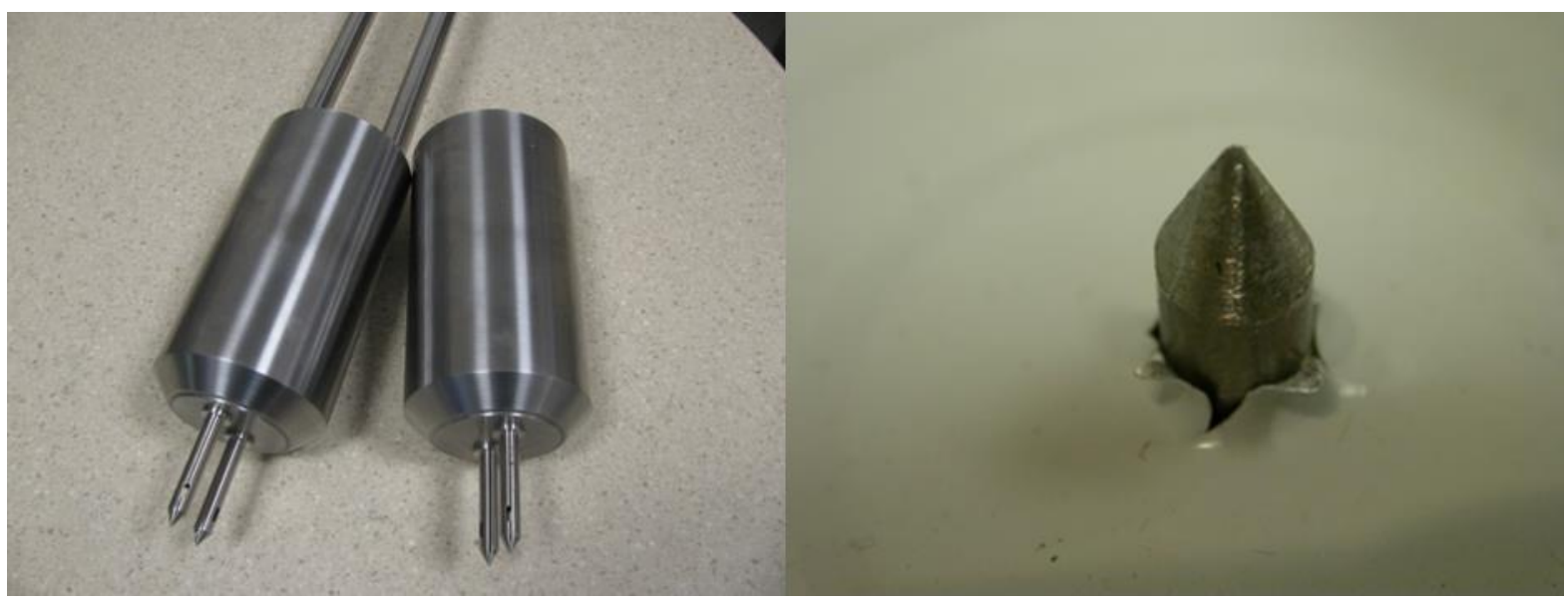

Figure 3.17: (Left) Source extraction device (two each). The weight of the 20-pound steel cylinder helps the users apply the downward force needed to puncture the aluminum source can. Two hollow needles with strategically placed side ports serve to flow gas through the particulate-filled can and evacuate the solids. (Right) An image of a prototype needle (without ports) puncturing an aluminum can lid. 
PNNL-23997

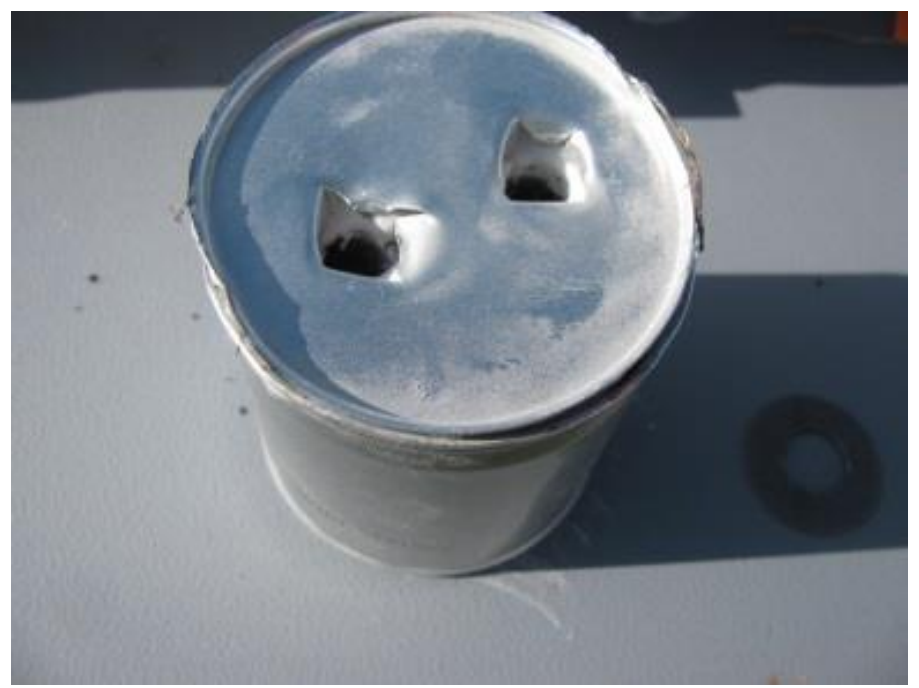

Figure 3.18: A test can after being punctured by the source extraction system. (The can lid was not rollsealed for this test)

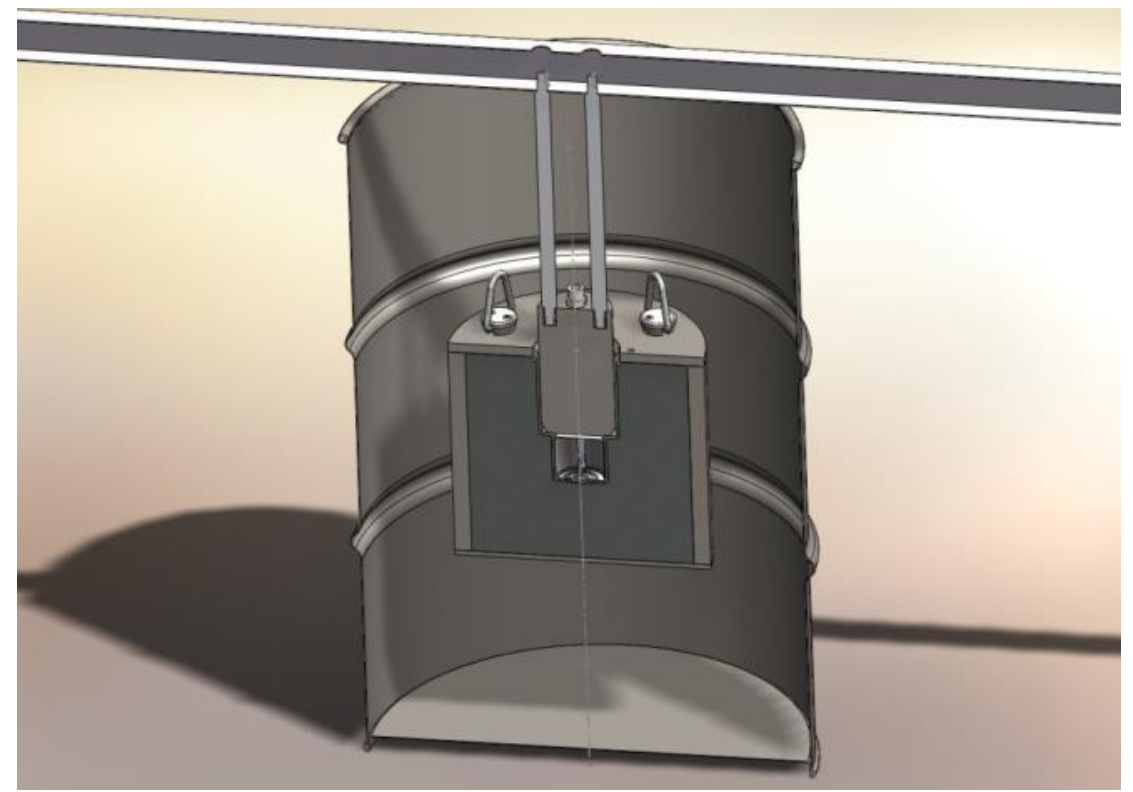

Figure 3.19: Cross-Sectional view of the source shipping/transfer system. This image shows the system with the source extraction plug installed.

\subsection{Release Mechanism}

PRex used an air cannon device (see Figure 3.21) expected to loft particulate materials over $35 \mathrm{~m}$ into the air at the lower acceptable limit of wind speed $(1.8 \mathrm{~m} / \mathrm{s}$ or $4 \mathrm{mph})$, and $\sim 15 \mathrm{~m}$ into the air at the high acceptable limit of wind speed $(6.7 \mathrm{~m} / \mathrm{s}$ or $15 \mathrm{mph})$. This type of air cannon is powered with liquid $\mathrm{CO}_{2}$, and utilizes the Coanda effect created by a nozzle structure and expansion of the $\mathrm{CO}_{2}$ into gas to produce an upward-moving air column. Initial testing at PNNL indicated that the device lofts air and materials to 
above 35 feet, although the height of the column is significantly influenced by wind speed, attaining lower injection heights at higher wind speeds. Further testing would be required to establish detailed knowledge of the lofting of particulates; for meteorological transport calculations, we assumed that particles were injected into the atmosphere at the maximum height of the plume column. Our goal was to extend the simulated "vent" to last for several minutes, which requires several bottles of $\mathrm{CO}_{2}$ linked with a manifold (see Figure 3.22).

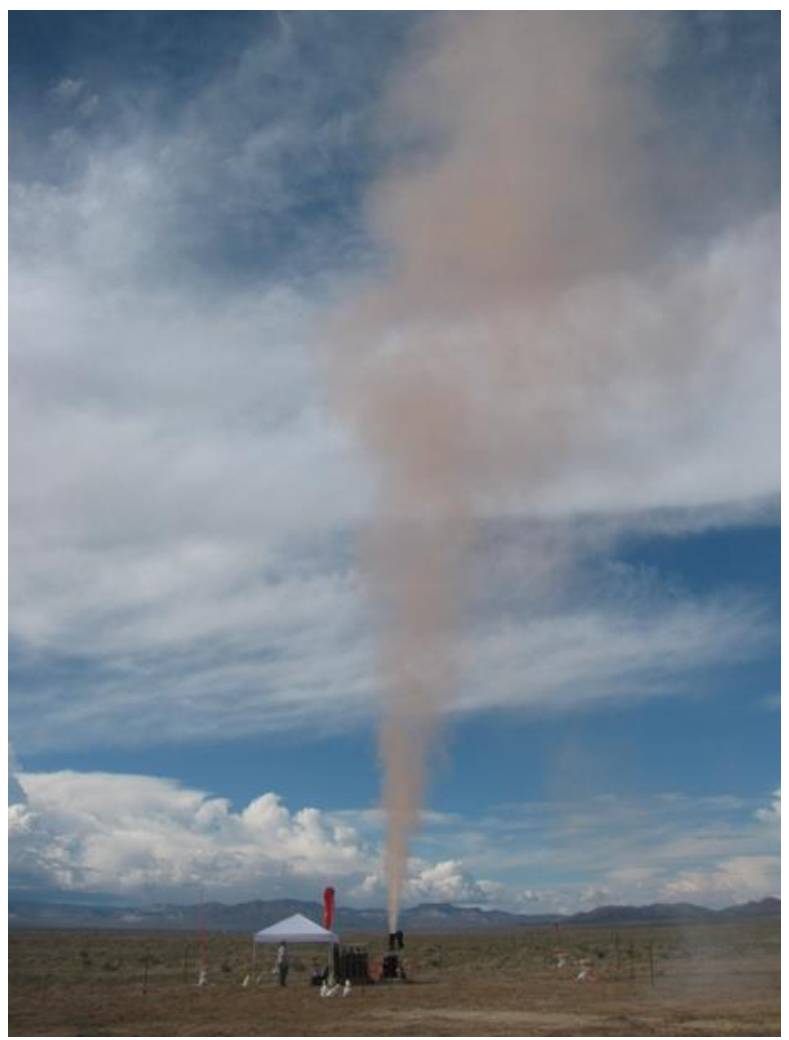

Figure 3.20: With near zero wind velocity, the dual cone air cannon injects orange smoke more than 40 meters into the air. This photo is from a practice run the week prior to the test. 

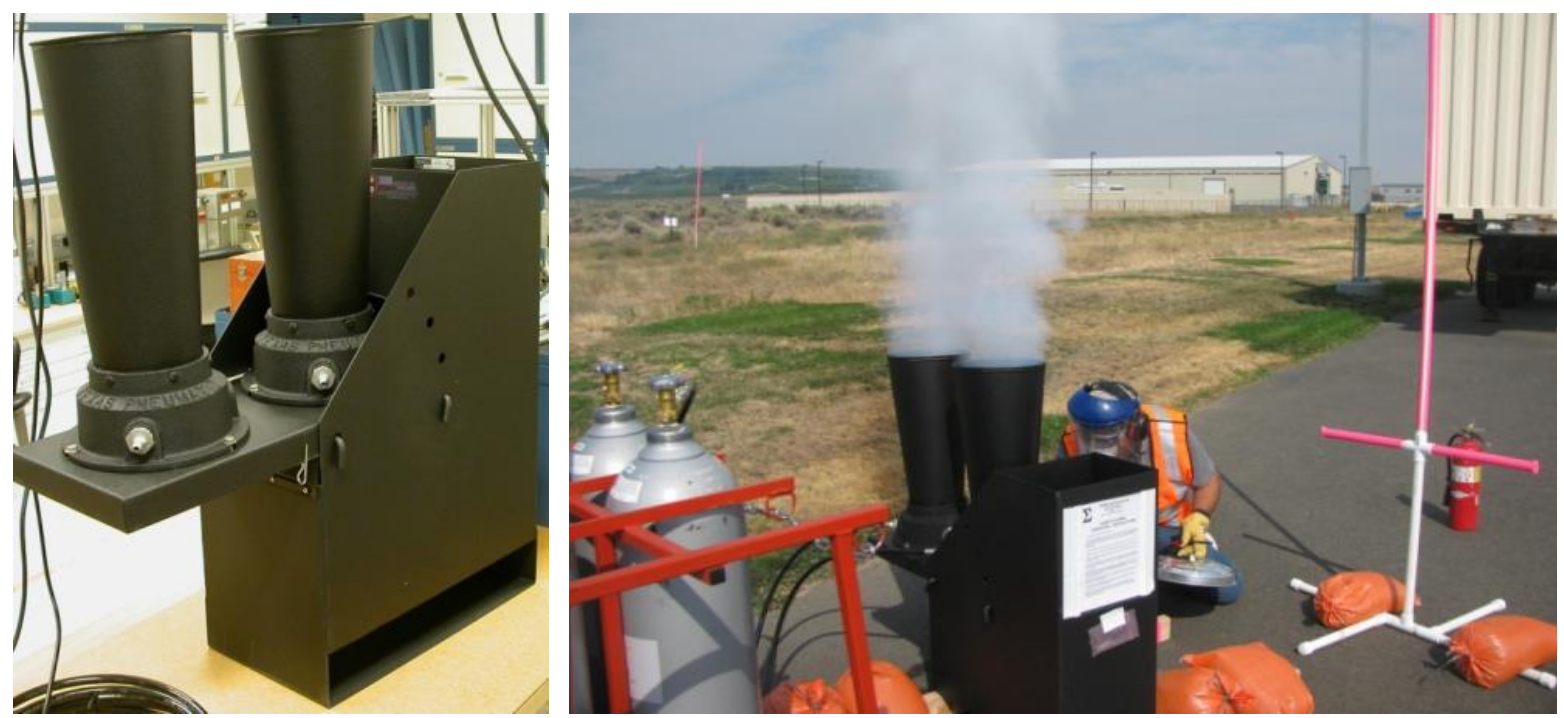

Figure 3.21: The air cannon is shown on the left. Initial testing at PNNL is shown on the right.

The shipping/transfer container was designed to limit personnel dose, consistent with ALARA principles. The shipping container was designed so that minimal shielding must be removed to prepare the source for transfer to the $\mathrm{CO}_{2}$ gerb (see Figure 3.22). A description of the process to prepare the system for source dispersal and dose estimates were documented in the experiment plan.

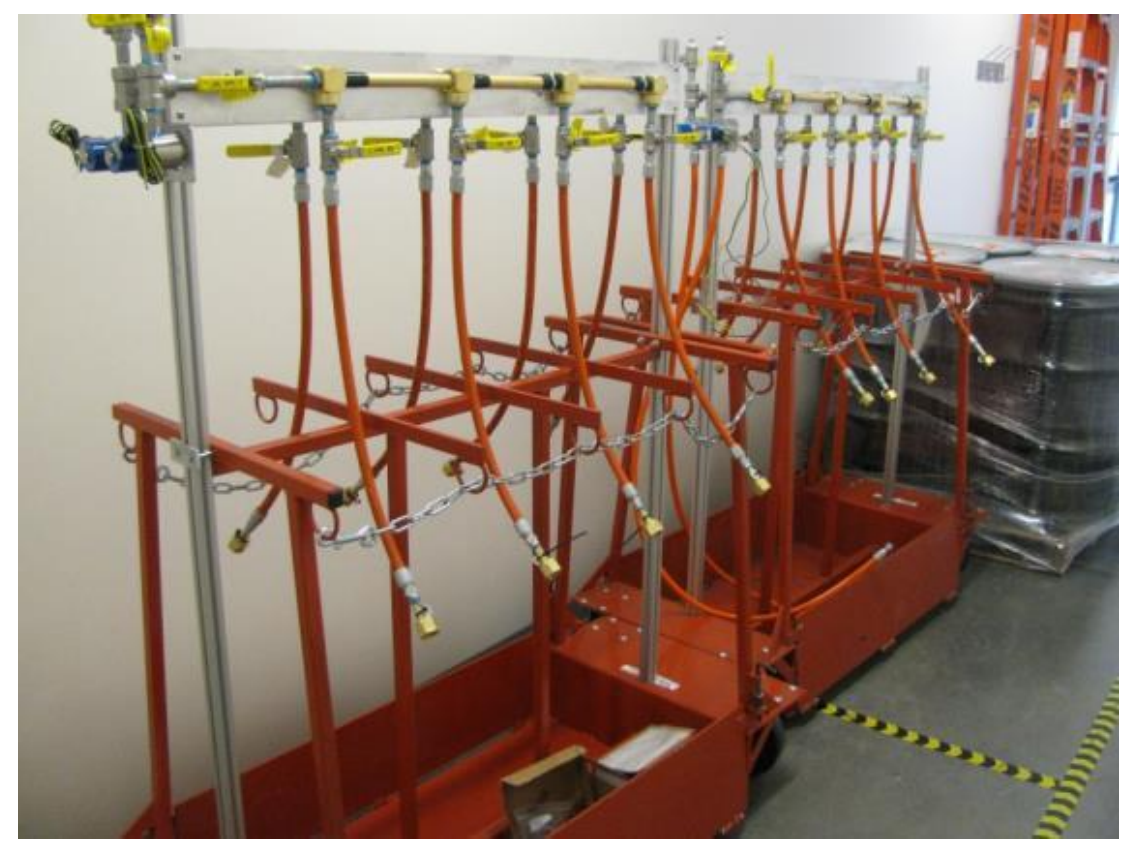

Figure 3.22: $\mathrm{CO}_{2}$ Manifolds for use with the air cannon 
PNNL-23997

\subsection{Meteorology Planning and Modeling}

Details of the meteorological planning and modeling accomplished in preparation for the test are documented in the PRex Experiment Plan.

\subsection{NNSS Experiment Site Preparation}

\subsubsection{Posting Contamination and High Contamination Areas}

NSTec personnel posted Contamination Area signs to encompass a rectangular region extending $1 \mathrm{~km}$ east, $1 \mathrm{~km}$ west, $5 \mathrm{~km}$ north, and $0.5 \mathrm{~km}$ south of the dispersal point. High Contamination Area (HCA) signs were posted around a rectangular area extending $0.1 \mathrm{~km}$ east, $0.1 \mathrm{~km}$ west, $0.5 \mathrm{~km}$ north, and $0.1 \mathrm{~km}$ south of the dispersal point. The immediate area surrounding the dispersal system $(\sim 20 \mathrm{~m} \times 20 \mathrm{~m})$ was enclosed in a temporary flexible orange fence to prevent unintended re-entry into the area. "Stomp and Tromp" surveys performed by NSTec Radiological Control Technicians (RCTs) indicated that deposition levels of ${ }^{140} \mathrm{La}$ did not reach HCA levels outside of the immediate fenced area of the dispersal system.

\subsubsection{Prepositioned Sampling}

In the days leading up to the experiment, sampling equipment was placed at predetermined locations and prepared for collection of PRex plume debris. The plume sampling network consisted of both air samplers and witness plates for the collection of debris. Two types of witness plates were used; one for the collection of the radioactive lanthanum oxide powder and the other for collection of glass microspheres. The radioactive measurements were performed quickly on site before decay of the ${ }^{140} \mathrm{La}$ would make it undetectable; the glass microspheres were examined at a later time at PNNL.

\subsubsection{Witness Plate Array}

The witness plates were placed downwind at nearly 110 locations in a pattern similar to that shown in Figure 3.23. The figure shows the planned, advance placement pattern; some of the locations were modified due to the presence of craters or fenced off areas. The actual sampling locations are captured in the data files. Since the exact path the radioactive plume would take was unknown, it was necessary to cover the range of allowed plume directions. This was done with the expectation that many of the sampling locations would not collect positive samples. It was recognized in advance that some samples would be excluded from radiation measurement based on knowledge of the actual plume axis. The slight skewing of the sample locations to the east of GZ reflects the same skewing in the range of acceptable release wind directions, as documented in the experiment plan. This range of acceptable wind directions was influenced by the presence of Mercury Highway to the west of the release. The sample locations in many West-East rows are offset relative to other rows to reduce the risk of a narrow plume missing most sampling points. One of each type of witness plate was placed at the locations designated with a "1." Those marked with a "5" had five of each type placed in the manner described below. Air samplers were 
also placed at some of these locations, as described later in this document. After the release, several of the " 5 " locations were also used as soil sampling locations. In situ measurements using various radiation survey instruments were also taken at selected sampling locations after the release.

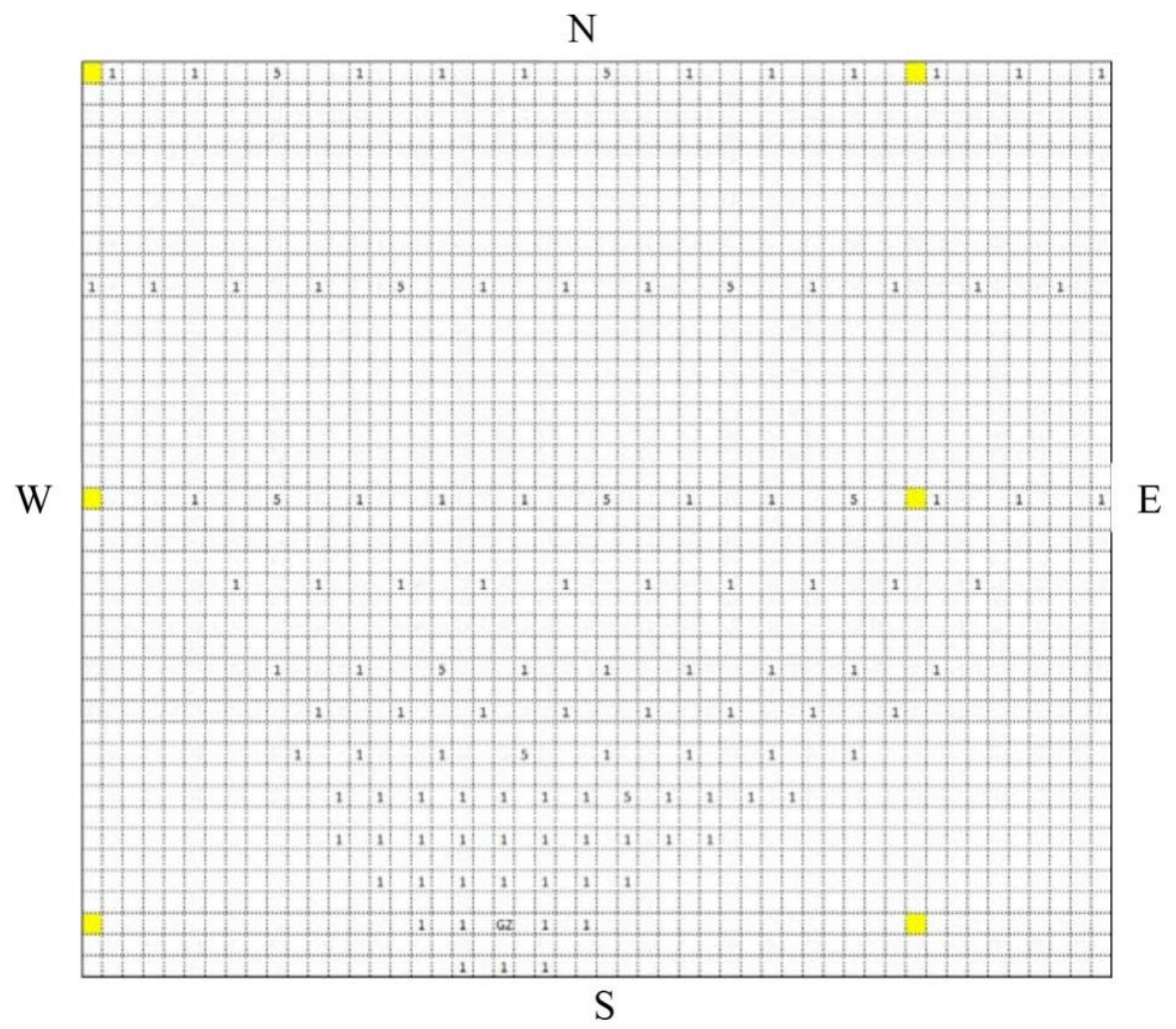

Figure 3.23: Map of the planned locations for sampling sites. The dispersal point, marked "GZ," is located near the bottom center of the figure. The figure consists of a $50 \mathrm{~m} \times 50 \mathrm{~m}$ grid; the yellow highlighted boxes are $1 \mathrm{~km}$ apart in the North-South direction, and $2 \mathrm{~km}$ apart in the East-West direction. Points marked with a " 1 " had one of each type of witness plate installed. Points marked with a "5" had five of each type of witness plate installed.

\subsection{Witness Plates for the Collection of Radioactive Powder}

To collect radioactive lanthanum oxide powder for rapid measurement, large-area witness plates comprised of "tacky mats" adhered to foam-core board were staked to the ground with aluminum tent stakes (see Figure 3.24). The tacky mats used were $45.7 \mathrm{~cm} \times 76.2 \mathrm{~cm}$ Criti Clean CRN-1836-30. Each large-area witness plate included several layers of tacky mat material, with the top-most layer being nonsticky material so they could be stacked for handling prior to placement. Placement of the witness plates (these and the ones for microsphere collection described next) took several days. The large area witness plates were placed lengthwise in the North-South direction and staking them to the ground usually resulted in a slight bowing in the shorter East-West direction. The day before the release, the top nonsticky layer was removed from the tacky mats so that they would be ready for collection. (The southernmost rows - those closest to the release point-were not uncovered until the morning of the release; there was insufficient time to uncover all 100+ sites on the morning of the test). The tacky mats 
were not so sticky as to collect the very numerous grasshoppers, though some small black flies were collected. To ease sample collection, the sampling sites were marked with bright orange ribbon on wooden stakes.

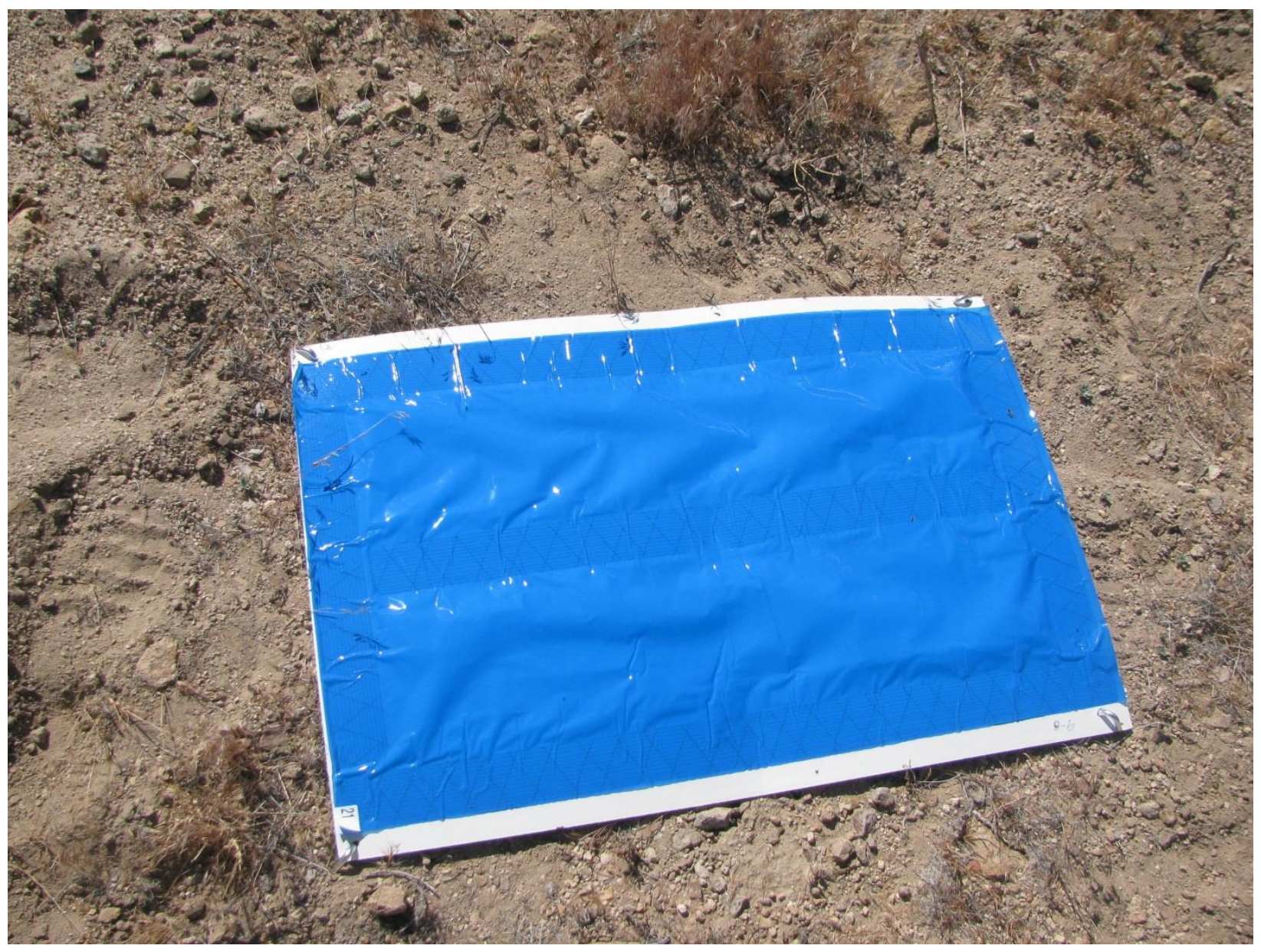

Figure 3.24: Tacky mat witness plate staked for collection of lanthanum powder

\subsection{Witness Plates for the Collection of Glass Microspheres}

To collect the nonradioactive glass microspheres, $5.08 \mathrm{~cm} \times 7.62 \mathrm{~cm}$ glass microscope slides were given an adhesive top layer using double-sided tape (see Figure 3.25). The tape backing remained on the top of the tape (and slide) when the witness plates were placed in the field, but was scored for easy removal later. The bottom of the witness plates were taped to garden stakes in the field sampling locations after the stakes had been placed at the appropriate locations. Grey duct tape was selected to secure the glass slides to the garden stakes; this tape choice held tenaciously to the glass and unfortunately could not be removed for the later analysis step. The height of the glass witness plates was approximately 30 " above the ground. In conjunction with the large tacky-mat witness plates, these microsphere witness plates had their protective top backing removed the day before or morning before the release, depending on location. 


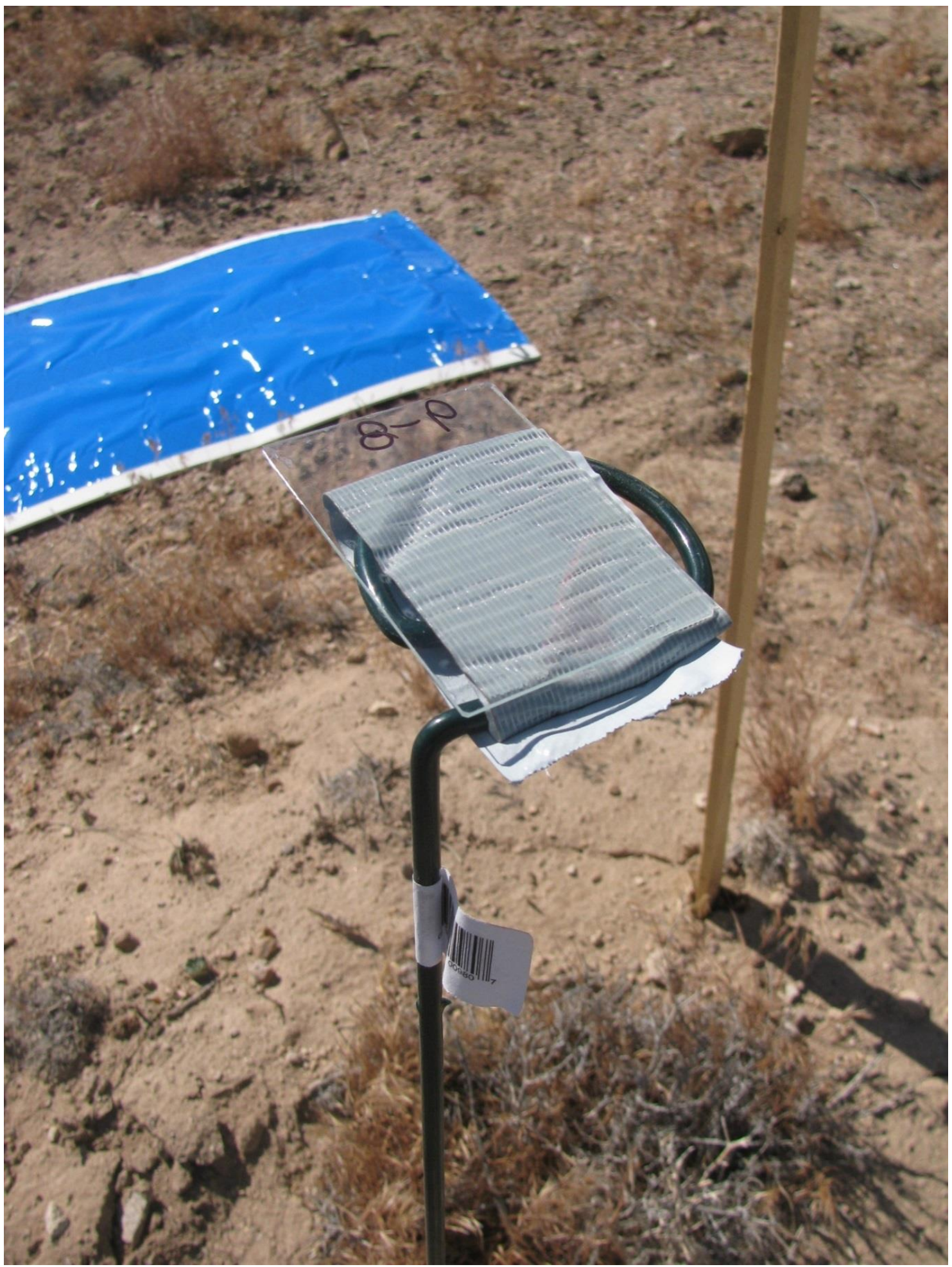

Figure 3.25: Glass slide witness plate for the collection of microspheres 


\subsection{Comprehensive Sampling Sites}

As noted earlier, some of the sampling sites had five of each type of witness plate. The purpose of this was to investigate deposition variability on the order of a few meters. The five witness plates (of each type) were placed in a "+" pattern, with the ends of the "+" pointing in the four cardinal directions and the distance from each end to the center of the "+" being $3 \mathrm{~m}$ (see Figure 3.26). The glass microsphere witness plates (in all cases and not just for the comprehensive sites) were placed just north of their corresponding tacky mat witness plate. Samples were numbered by their primary site number and appended with a position 1 through 5 (with 1 in the center, 2 to the west, 3 to the north, 4 to the east, and 5 to the south). For example, comprehensive sampling site 7-3 had large area witness plate samples labeled 7-3-1 through 7-3-5.

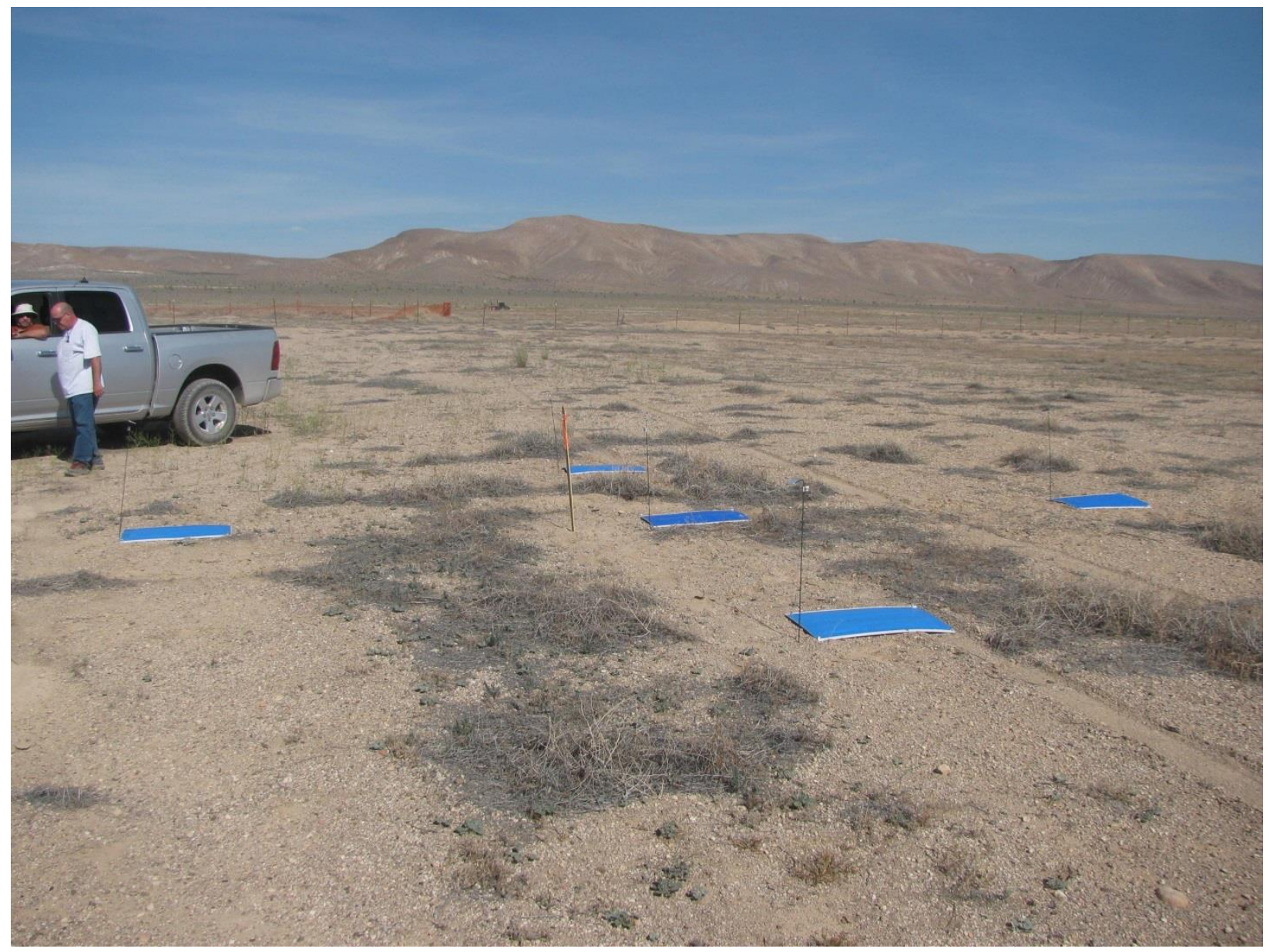

Figure 3.26. Comprehensive sampling site. $\mathrm{GZ}$ is in the direction to the right.

\subsubsection{Air Sampler Placement}

Three different types of air samplers were set up to collect the radioactive tracer. Six air samplers with 1000 cubic feet per (cfm) minute capacity were set out as follows: 
- Two battery-powered, radio-controlled units were set up near the center line at $1.5 \mathrm{~km}$ down range. These units were activated just before the release and ran for 20 minutes.

- Four large gas-powered leaf blowers with modified intakes holding filter material were located two km down range (see Figure 3.27). The high volume blowers used were used previously in Canada for a similar tracer release study.

- Seventeen powered air-purifying respirators (PAPR) with $17 \mathrm{lpm}$ airflow were located along the 400and 500-m down range transects.

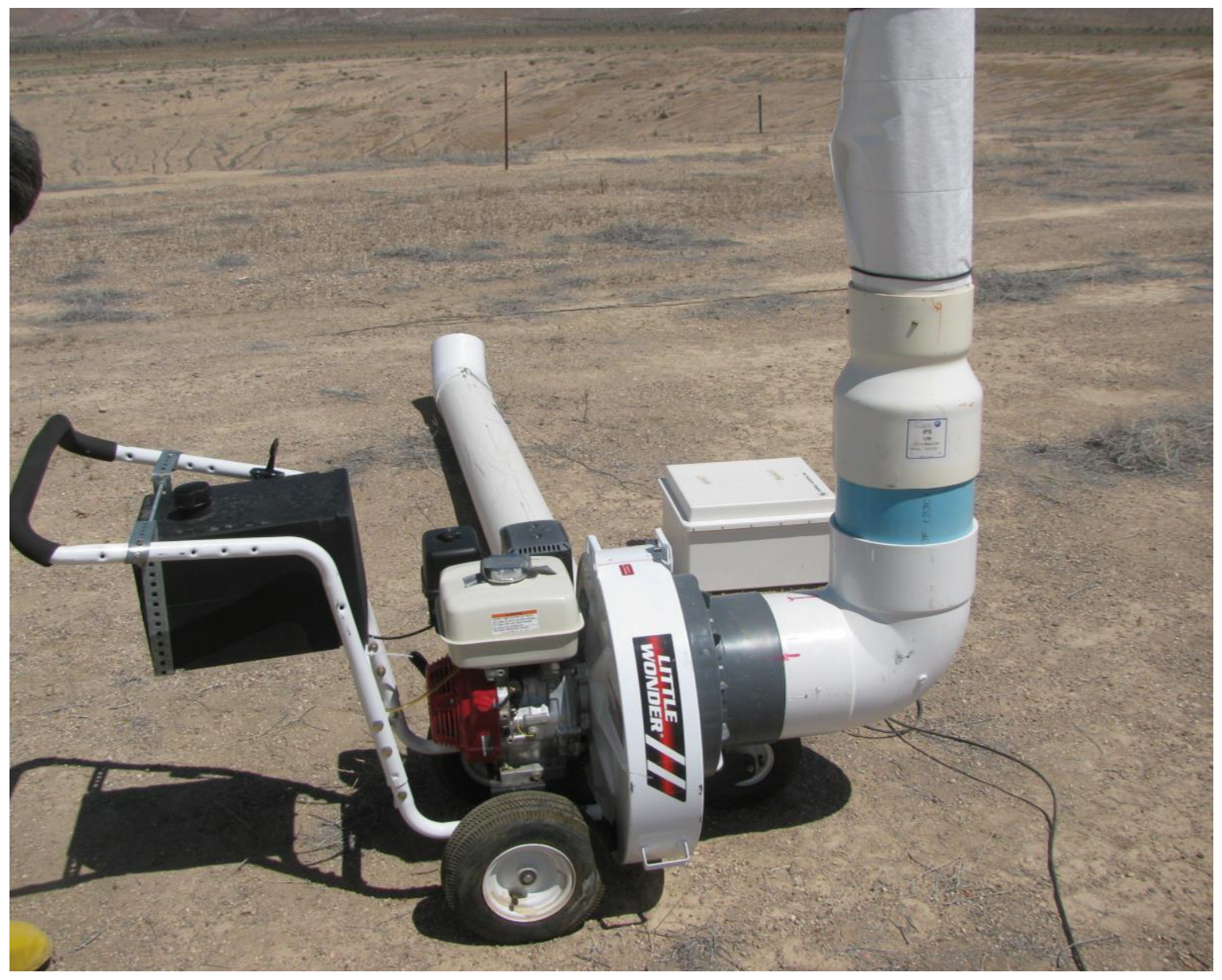

Figure 3.27: Gasoline-powered leaf blower modified to operate as a $1000 \mathrm{cfm}$ air sampler, located $2 \mathrm{~km}$ downwind from the release. 
PNNL-23997

\subsection{PRex Experiment Execution}

\subsection{Time and Location}

The PRex release began at $\sim 10: 55$ a.m. on Tuesday, May $14^{\text {th }}, 2013$, with a duration of approximately 12 minutes. The release system did not contain an on-board radiation monitor, so the exact time period over which the material was released is not known. The supply of nitrogen carrier gas was cycled on and off several times during the first minute of the release, then was left flowing (on) for several minutes.

The experiment was held at the northern edge of Area 6 in the Nevada National Security Site. Coordinates for the release site are $36.99668^{\circ} \mathrm{N}, 116.00679^{\circ} \mathrm{W}$ (see Figure 2.1). A log of events is provided in Appendix C.

\subsection{Meteorological Conditions during Release}

Figure 4.1 is a surface map showing the major synoptic weather features on the morning (May 14, 2013 1200Z) of the PRex release. High pressure dominated the east and west coasts, while a low-pressure system traversed the central United States. A weak front associated with this low extended back into northern Nevada. A weak low-pressure trough was just east of the NNSS; otherwise synoptic conditions were mostly clear and favorable at the NTS site on the morning of May 14, 2013.

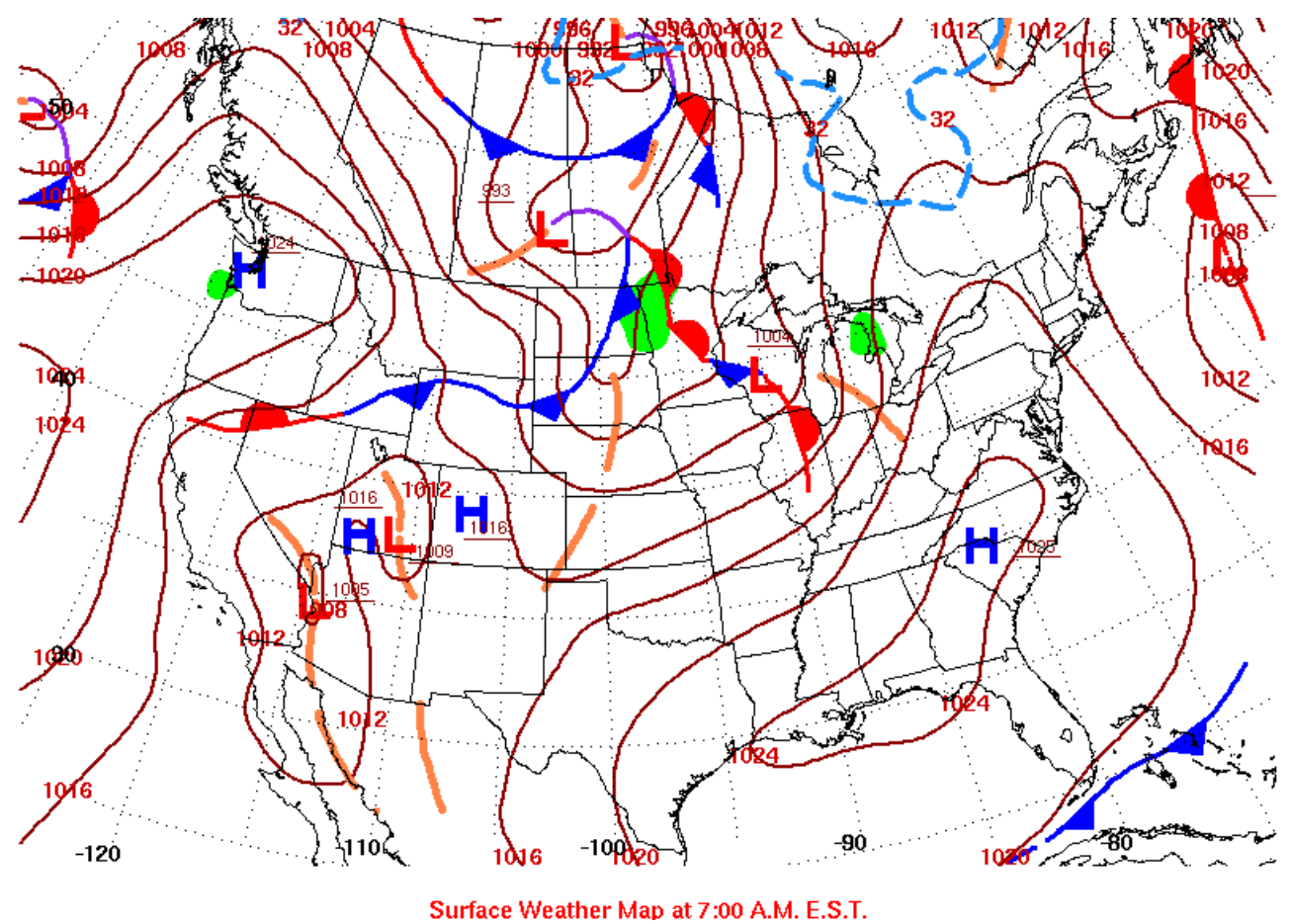

Figure 4.1: Surface weather map on May 14, 2013 at 1200Z. 
Figure 4.2 shows wind observations across the NTS site on May 14, 2013 10:45 a.m., approximately 10 minutes prior to the PRex release. Winds within the Yucca Flat basin were upslope, which is typical for this area at this time of day in the absence of any large-scale weather systems. In Area 6, winds were generally from the south at $10 \mathrm{mph}$, and became more south-southeasterly farther to the north (Areas 1, 4, and 9). Table 4-1 shows the corresponding meteorological observations at the primary PRex meteorological station (AP6) and nearby Meteorological data acquisition (MEDA) stations on May 14, 2013, 10:45 a.m.

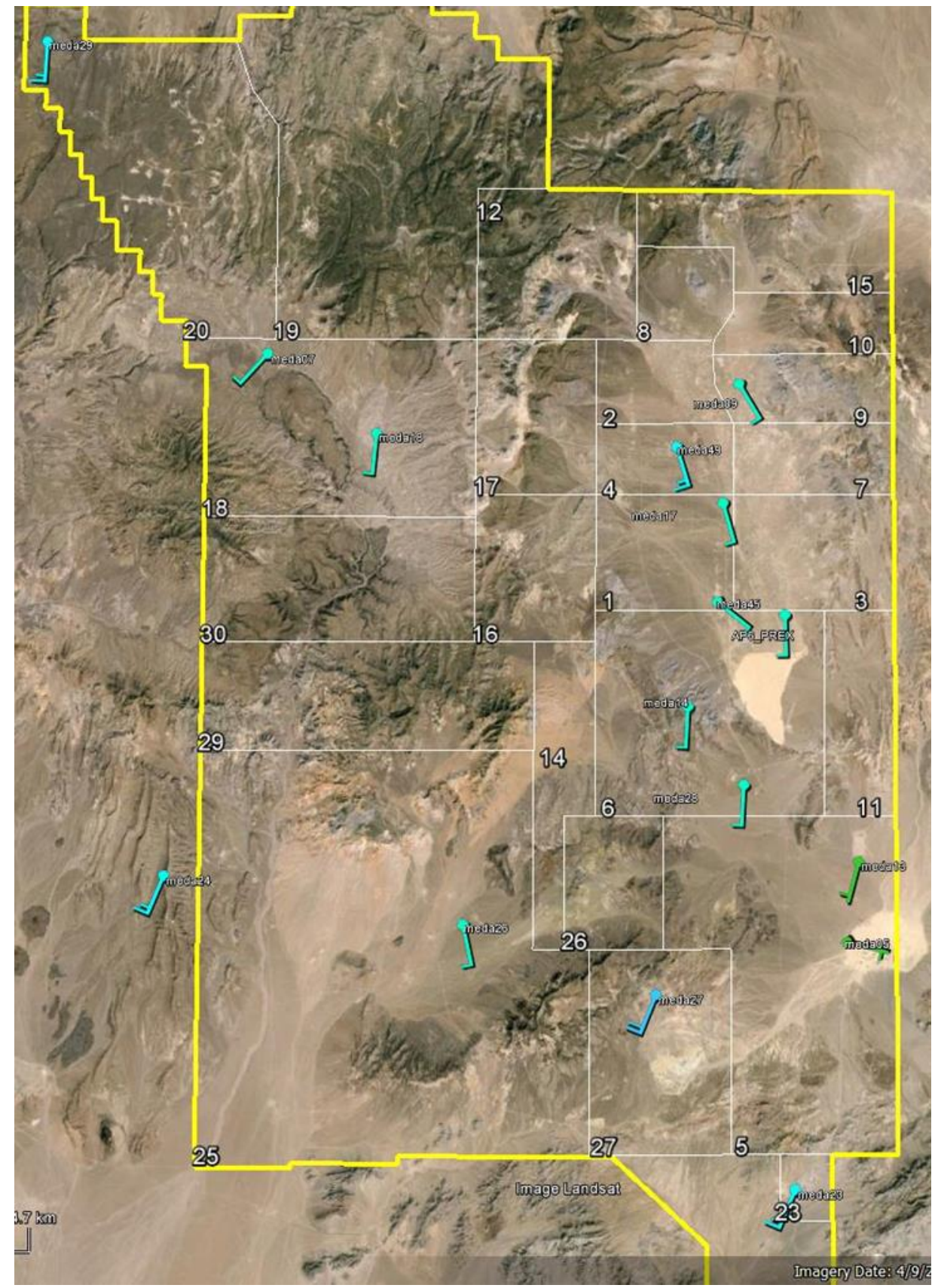

Figure 4.2: Wind observations across the NTS site on May 14, 2013 10:45 a.m. 
PNNL-23997

Table 4-1: Meteorological Observations at Nearby Tower Locations on May 14, 2013 10:45 a.m.

\begin{tabular}{ccccc}
\hline Location & $\begin{array}{c}\text { Wind Direction } \\
\text { (degrees from) }\end{array}$ & $\begin{array}{c}\text { Wind Speed } \\
(\mathrm{mph})\end{array}$ & $\begin{array}{c}\text { Temperature } \\
(\mathbf{\circ} \mathrm{C})\end{array}$ & $\begin{array}{c}\text { Humidity } \\
(\%)\end{array}$ \\
\hline AP6_PRex & 178 & 10.1 & 29.6 & 12.6 \\
\hline MEDA28 & 183 & 9.2 & 31.2 & -- \\
\hline MEDA14 & 183 & 13.8 & 28.3 & -- \\
\hline MEDA45 & 129 & 12.7 & 30.1 & - \\
\hline & & a Primary meteorological tower used for the PRex release. & \\
\hline
\end{tabular}

Upper-air wind measurements were made $\sim 1 \mathrm{~km}$ to the west of the release using a weather balloon, which is capable of providing reliable vertical profiles of wind, temperature, and humidity. Three weather balloons were launched on the day of the PRex release, including an early morning launch, and a pre- and post-PRex release launch. Figure 4.3 shows vertical profiles of wind, temperature and humidity for the pre-PRex balloon launch (i.e., May 14, 2013 10:45 a.m.). From the figure, it is evident that winds were southerly at the surface (from $180^{\circ}$ ) and became slightly south-southeasterly (i.e., $\sim 170^{\circ}$ ) up to $1400 \mathrm{~m}$ above mean sea level (ASL), where they became more south-southwesterly (i.e., between 190응 and $230^{\circ}$ ) with height. Wind speeds ranged between $10-15 \mathrm{mph}$ up to $\sim 2400 \mathrm{~m}$ ASL. Temperature decreased with height and relative humidity increased with height through this layer. Because the PRex release occurred within $30.5 \mathrm{~m}$ of the surface, the resulting plume was likely transported by the nearsurface [average] winds, which were approximately $175^{\circ}$ at $12 \mathrm{mph}$. This wind direction is consistent with the plume footprint from the vehicle survey presented in Section 6.1. 


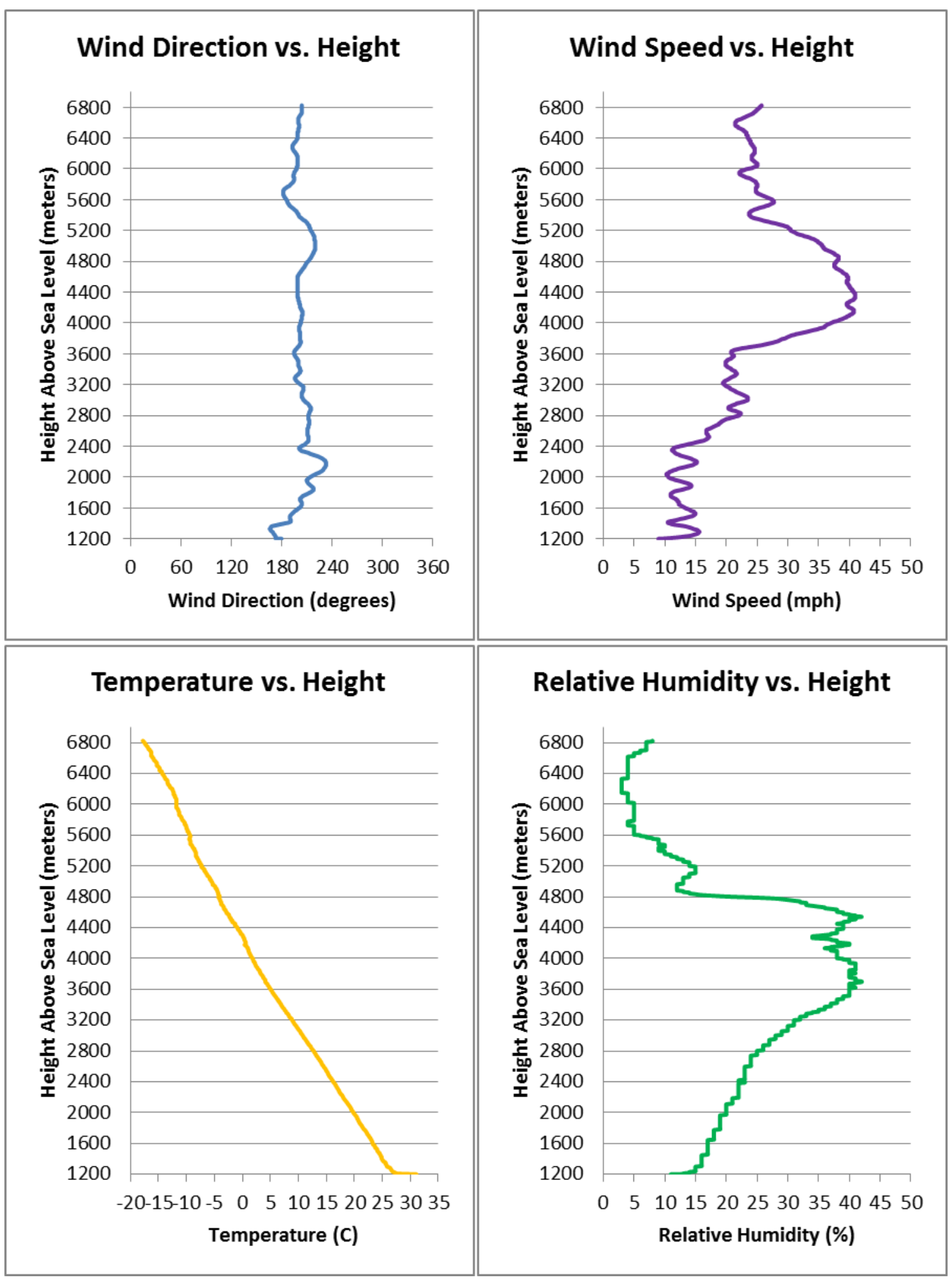

Figure 4.3: Balloon profiles of wind, temperature, and humidity pre-PRex release (i.e., May 14, 2013 10:45 a.m.) 
PNNL-23997

\subsection{Sampling Network}

\subsubsection{Collection of Witness Plates}

After an initial collection transit along the 1-km north row, when the plume location was still not fully known, the witness plates in general were collected from north to south. This sequence reflected an effort to avoid re-suspending particles in the more active regions so they would not be deposited onto uncollected witness plates further north. The most active regions of the plume area were also off-limits during the first day or so until the HCA staked out prior to the release was downgraded to a CA (except for the area immediately around the release point, which remained off-limits for several weeks). Both types of witness plates at a given location were collected at the same time and collection of all the sites was accomplished over two days, Tuesday afternoon and Wednesday. It is important to point out that the witness plates remained uncovered until they were collected, leaving open the possibility of additional radiation and microsphere collections due to resuspension. Indeed, it was quite windy after the experiment, with steady wind speeds in the vicinity of $10 \mathrm{~m} / \mathrm{s}$, and gusting to $15 \mathrm{~m} / \mathrm{s}$; dust devils were also observed to transit the plume area over the coming days (including prior to collection of the witness plates). The vehicles (pick-up truck or Kawasaki Mule) used to collect the witness plates could also potentially cause resuspension, and to the extent possible were driven downwind (north) of the immediate sampling locations.

The foam backing of each large witness plate was pre-scored so that the two halves could be folded together easily after removal of the tent stakes holding each to the ground. Unfortunately, the halves did not really adhere to each other as intended. During collection, the tacky mats were less sticky due to collection of blowing dust / debris. Also, most of the foam boards had bowed while staked to the ground (perhaps due to sun exposure), so that the two sides of the tacky mat did not come into close contact when the foam boards were folded. Consistently strong and gusty winds were present during sample collection, and it appeared that the daytime temperatures, winds, and personal protective equipment (PPE) would introduce a risk of personnel overheating while working in the field with no shade. It was decided to collect the samples quickly in the field, and to remove the tacky mats from their foam boards inside a Conex container near the exit to the CA rather than out at the sampling sites. Each large witness plate was folded and placed in its own plastic bag; these in turn were placed in a larger plastic bag in an effort to limit cross contamination (primarily from the dust resuspended by the collection vehicle. Gloves were also changed between samples. The high winds often made it difficult to place the witness plates into the plastic bags, as did the bowed corners (see Figure 4.4).

After collection, the witness plate samples were returned to the Conex container for processing into measurement geometry. The large area witness plate samples were processed on a table in the Conex; each sample was removed and placed on top of its own plastic bag to minimize cross-contamination. All of the tacky mat layers were removed from the foam and folded in a predetermined and consistent manner to fit inside a new, sealable sample bag for counting on a high-purity germanium (HPGe) detector in the Field Laboratory. The samples were folded into a square having area similar to the HPGe detector face, so the sample bag could be laid flat on the detector face for counting. Although this process resulted in 
extra unexposed tacky mat material being included in the sample, operationally it was easier to remove all of the tacky-mat layers rather than just the top-most one.

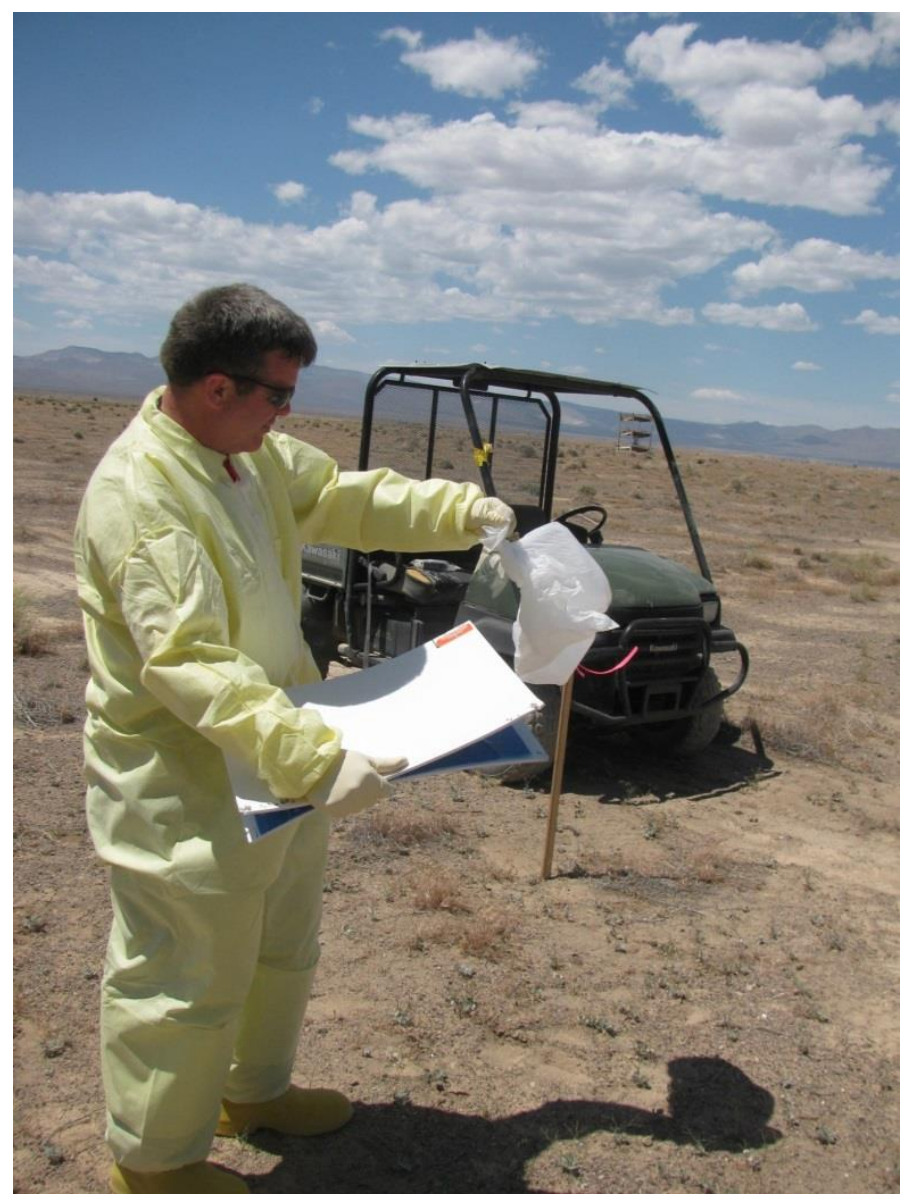

Figure 4.4: Collection of tacky mat witness plate hampered by the bowed shape and the wind

The glass witness plates were collected by first placing a second glass plate on the sticky top of the witness plate, sealing in the sampled dust and microspheres. The sandwiched sample was then removed from the garden stake and placed in a sealed sample bag (also in the Conex container). The intent had been that the tape holding the glass slide to the garden stake would be removed. However, while setting up the sampling witness plates, the decision was made to use more robust duct tape rather than shipping tape due to concerns about the wind. This duct tape, however, proved to be extremely difficult to remove from the glass slides in the field without breaking them, and so was left on the glass witness plates.

\subsubsection{Soil Sampling}

In addition to the two types of witness plates, at several sampling sites, three different soil sampling techniques were utilized during the PRex experiment. The principle motivator of this was that the three techniques were under consideration by the CTBTO for soil sampling during an OSI. While the abovementioned witness plates are ideal for pre-planned characterization of a release event, soil sampling is an 
obvious method of choice for an international post-event inspection of possible ground deposition. In a fresh release, prior to much weathering, one can expect the released radioisotope to be on the very top of the soil surface and not to have migrated into the soil matrix. To study the ramifications of this for sampling, we compared three techniques: troweling, tacky mat, and vacuum cleaner. The different techniques were used in areas near each other, as well as near large collection witness plates to allow for comparison of techniques.

Troweling involved using a simple hand trowel to scrape and scoop the topmost (as thin as the collector can manage) layer of soil. To do this, a $50.8 \mathrm{~cm} \times 50.8 \mathrm{~cm}(20$ in. $\times 20$ in.) polyvinyl chloride (PVC) pipe square template was placed on the ground. (The sampling area was taken to be $45.7 \mathrm{~cm} \times 45.7 \mathrm{~cm}$; the idea being that one could only get to within about $2.54 \mathrm{~cm}$ from the sides with the trowel). After removal of large rocks, the topmost soil was removed and placed in a 16-oz. sample jar of a diameter similar to the HPGe detector face. The top layer of soil was collected to within $\sim 1$ inch of the PVC template, providing a sample covering an $45.7 \mathrm{~cm} \times 45.7 \mathrm{~cm}(18$ in. $x 18 \mathrm{in}$.) area (see Figure 4.5$)$. Hardpan surfaces could be broken up by chopping the soil with the trowel. Inexpensive plastic trowels were used to collect a single sample to prevent cross-contamination between samples.

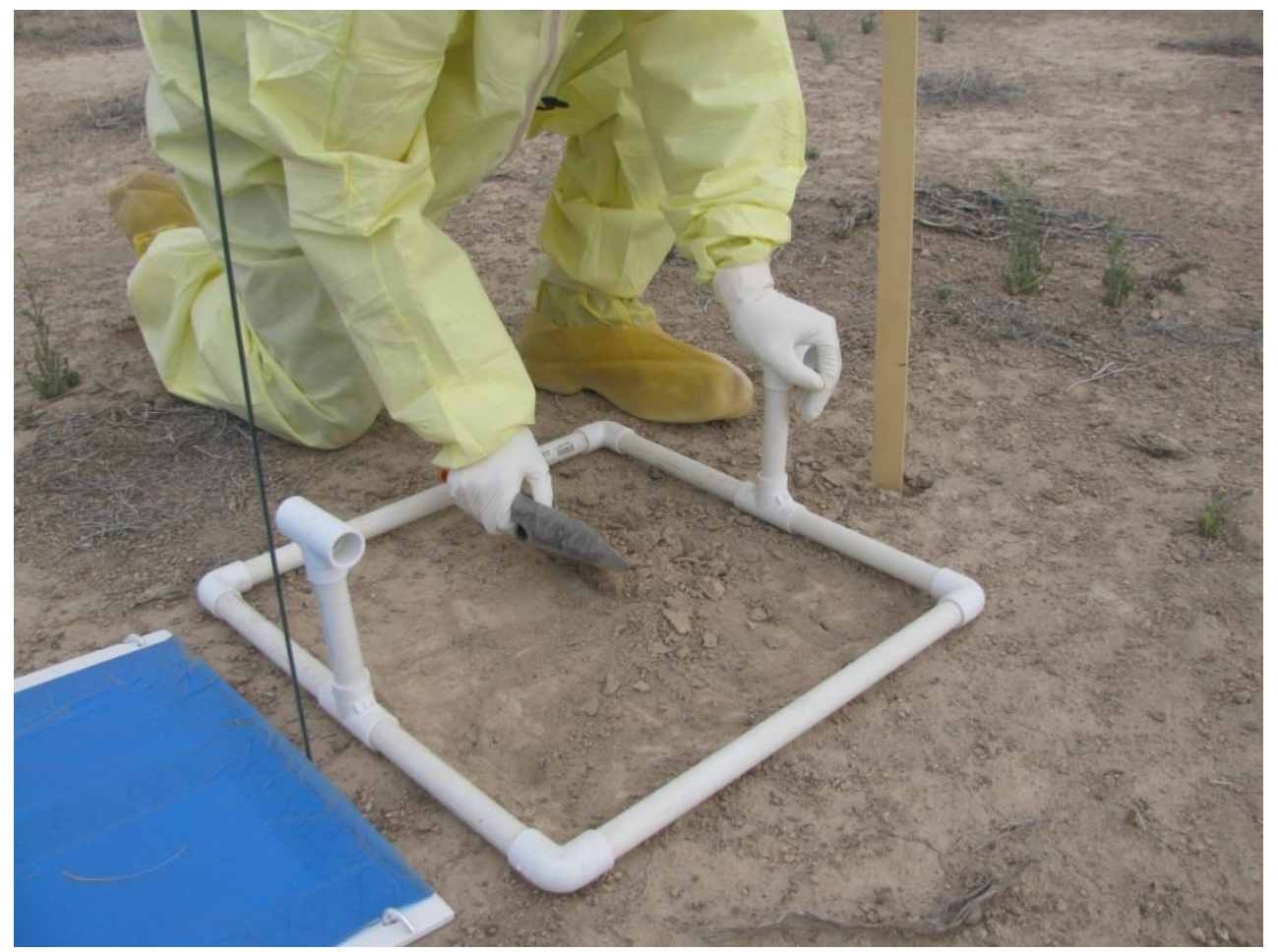

Figure 4.5: Soil sampling with a trowel

The second technique was to place a 45.72-cm $\times 76.2 \mathrm{~cm}\left(18\right.$ " $\times 30$ ", $\left.0.3484 \mathrm{~m}^{2}\right)$ "tacky mat" (the same as the ones used in the witness plates, but without foam backing) sticky side down on the surface to be sampled after removing large rocks and avoiding plants. A single layer of tacky mat was typically used, pulled off a larger pad of the material. The mat was patted and rubbed down on the soil surface (see Figure 4.6) and then folded in a fashion similar to that of the large-area witness plates (described above). 
Due to the large number of very small pebbles typically collected by this method, these folded mats would not fit into plastic bags like the witness plate samples, so they were placed in sample jars like those used for the troweled samples.

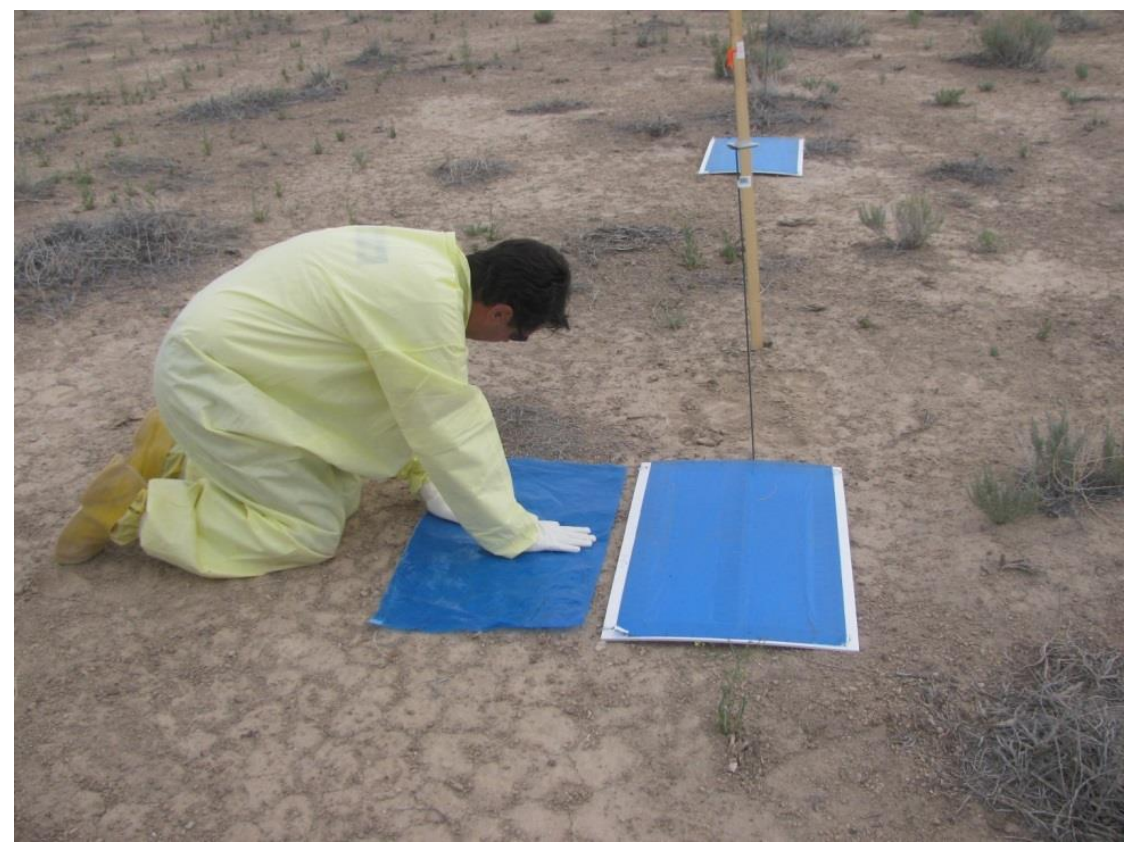

Figure 4.6: Soil sampling with a tacky mat

The third technique involved the use of a handheld vacuum cleaner (colloquially known in the U.S. as a "Dust Buster," though in this case we actually used a Dirt Devil brand Handy Duo.) These units are battery powered, though we soon observed that they do not actually last very long on battery power before needing to be recharged. For this technique, we used the same square PVC template as was used for troweling. To prevent coarse material from reaching the finer filters we improvised a filter by inserting a knee-high panty hose into the vacuum cleaner and holding it around the mouth of the vacuum cleaner while the panty hose toe was sucked inside. (No vacuum cleaner attachments were used.) The vacuum cleaner was then moved back and forth over the soil surface as close as possible (see Figure 4.7). In areas where the soil was loose enough to be sucked up en masse, it was necessary to keep the vacuum cleaner off of the surface a bit, but otherwise, it could go along the surface. As in the tacky mat case, the numerous small pebbles typically present were a challenge for this technique. The entire surface area was usually vacuumed twice. Next the vacuum cleaner was disassembled over a sample jar like those used for the previous techniques. The panty hose and the coarse material inside were placed in the sample jar, along with the material in front of the vacuum cleaner's filter. This filter was removed and shaken into the jar, along with the finer material between it and a second filter. The outer vacuum cleaner tube and initial collection area could be mostly wiped down with wet wipes between samples, but this was not true for the inner filters, which trapped moisture in their filter pores. Thus this technique is more susceptible to cross-contamination in addition to its logistical difficulties relative to the other two soil sampling techniques. 
PNNL-23997

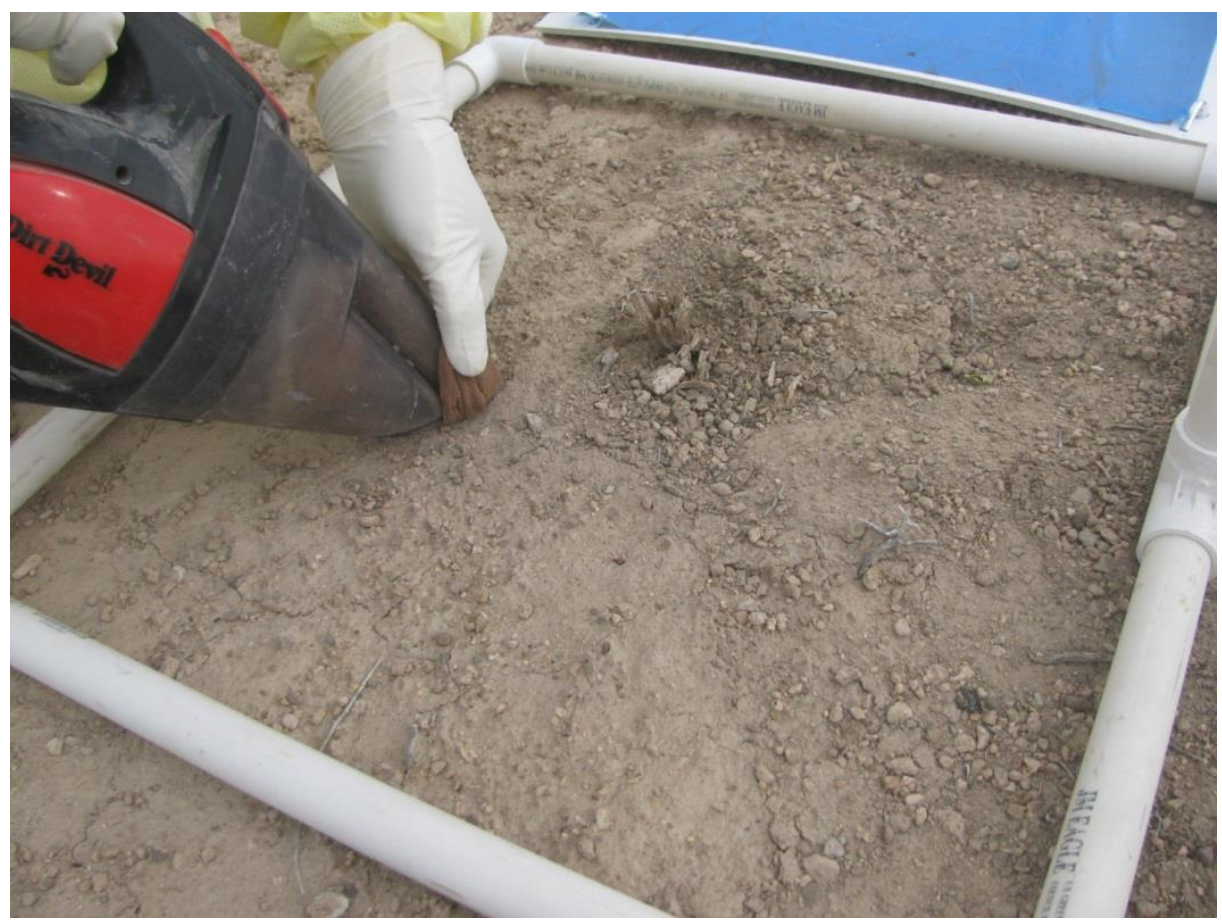

Figure 4.7: Soil sampling with battery-powered vacuum cleaner

\subsubsection{Air Sampling}

The gasoline-powered high-volume samplers placed km downwind of the dispersal were started at approximately 9:30 a.m. and allowed to run until the filter samples were collected between 3 p.m. and 4 p.m. The battery-powered high-volume samplers at $1.5 \mathrm{~km}$ downwind were remotely started a few minutes before the source release, and allowed to run for 20 minutes. Filter paper samples from both the gasoline- and battery-powered samplers were collected between 3 p.m. and 4 p.m. The PAPR samplers were started between 9 a.m. and 10 a.m., and allowed to run until their batteries were exhausted (approximately 10 hours).

The gasoline-powered high-volume air samplers were restarted at 10 a.m. on May $15^{\text {th }}$ to look for resuspension of ${ }^{140}$ La kicked up by survey activities and the afternoon winds.

\subsection{Radiation Survey}

High (HPGe), medium ( $\mathrm{LaBr}_{3}$ and NaI) and low (polyvinyl toluene (PVT) — used as gross count) energy resolution capable instrumentation was brought to NNSS by PNNL to enable comparison between these instruments' capabilities to characterize a potential release from a nuclear weapons test of interest for an OSI under CTBT.

In addition to work performed with PNNL-owned instruments, Remote Sensing Laboratory (RSL) performed a flight with their fixed-wing aircraft on the day of the release. The surveys are discussed in 
three sections: the aerial survey, the ground mapping survey, and the detector inter-comparison of a backpack and four types of handheld radioisotope identification detectors.

\subsubsection{Vehicle Survey}

The ground survey was conducted using two RSI $2.08-\mathrm{cm} \times 4.16-\mathrm{cm} \times 40.64-\mathrm{cm}\left(2^{\prime \prime} \times 4^{\prime \prime} \times 16^{\prime \prime}\right) \mathrm{NaI}(\mathrm{Tl})$ $\log$ spectrometers. The spectrometers were loaded into the back of a Kawasaki Mule, a small diesel $4 \times 4$ ATV (Figure 4.8). For these measurements, two separate GPS units were used. One GPS unit fed directly into the RSI 700 system, which combined and archived the NaI data. A second GPS was used for the steering indicator. The steering indicator guided the driver along parallel lines with a known separation. For this survey, the lines were 50 meters apart. Every line was driven near the release point and every other line (providing 100-m separation) was driven at larger down-wind distances. Although it is possible to operate the system with only a driver, it was advantageous to have an equipment operator watching the radiation survey data on a laptop while the driver focused on driving and watching the steering indicator.

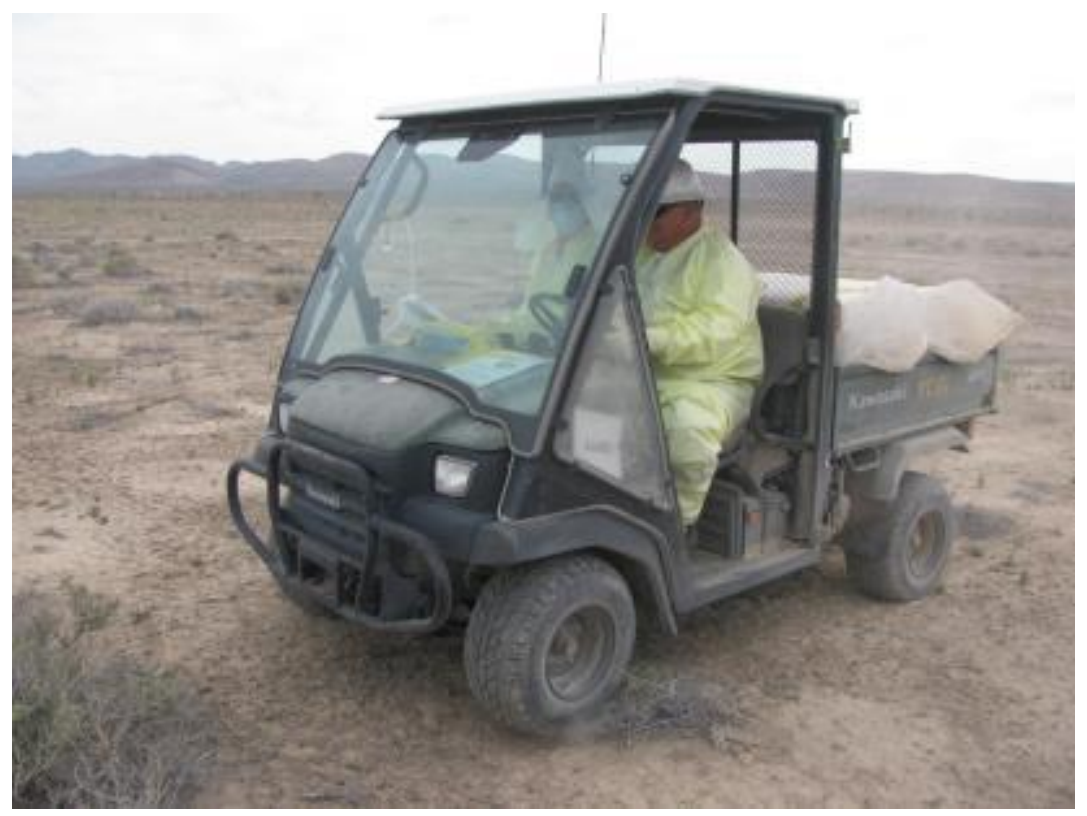

Figure 4.8: Survey equipment following the release of ${ }^{140} \mathrm{La}$. The two $\mathrm{NaI}(\mathrm{Tl})$ detectors were packaged in large Igloo coolers, and are next to each other, oriented front-to-back in the bed of the Kawasaki Mule. The coolers were used to limit thermal gradients; rapid temperature shifts can crack NaI(Tl) crystals.

Navigation heading information came from the Raven light bar. The Raven light bar produced course corrections based upon differentially corrected GPS (Figure 4.9). The system was originally designed for guiding farm vehicles, e.g., for a tractor plowing a field. The selected mode of the system was to produce swaths parallel to the road just south of the release point. The spacing was chosen to be 50 meters between swaths. During the survey every other line was surveyed except near the release point, where every line was surveyed. 

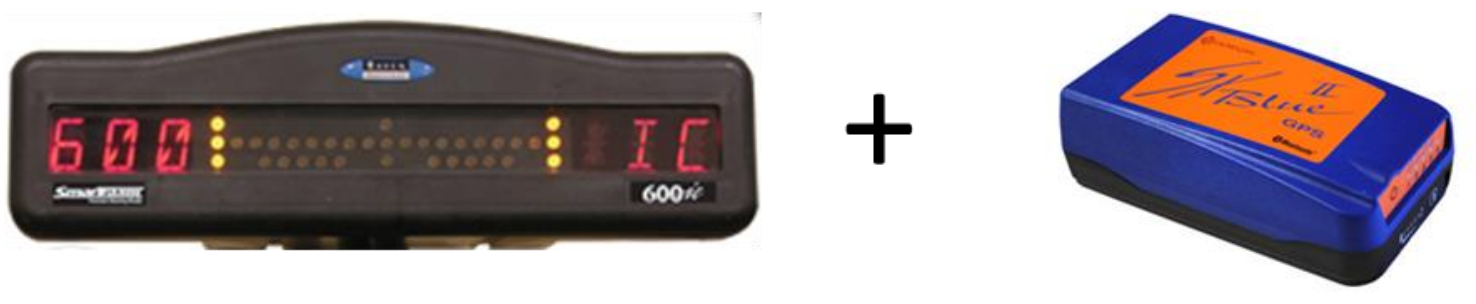

Figure 4.9: Raven light bar (http://ravenprecision.com/products/guidance-steering/rgl-lightbar-series)and the differential GPS unit (http://www.geneq.com/catalog/en/sxblue2.html) used to guide the driver during vehicle ground survey.

\subsubsection{Handheld/Man-portable}

Handheld and human-portable radiation detectors and spectrometers were evaluated. The instruments were based upon detectors that included PVT, sodium iodide (NaI), lanthanum bromide $\left(\mathrm{LaBr}_{3}\right)$ and HPGe. Figure 4.10 shows the Canberra Falcon (HPGe), the FLIR Identifinder (NaI), and the Ludlum 711 $\left(\mathrm{LaBr}_{3}\right)$, from left to right. Additionally we used the ORTEC detective (HPGe) not shown. The Falcon contains a $\emptyset 60$ x $30 \mathrm{~mm}$ HPGe crystal (18\% relative efficiency). The FLIR Identifinder contains a 1" x 2.4" NaI crystal. The Ludlum 711 contains a 1.5" x 1.5" LaBr 3 crystal. The Detective contains a $\emptyset$ 50 x $30 \mathrm{~mm}$ HPGe crystal (15\% relative efficiency). The Thermo Packeye shown in Figure 4.11 is a backpack with a $750 \mathrm{~cm}^{3}$ PVT based detector. Although PVT has some minimal energy windowing capability, the instrument was used in gross count/dose rate mode. Analysis of data is provided in Section 5.7 below.

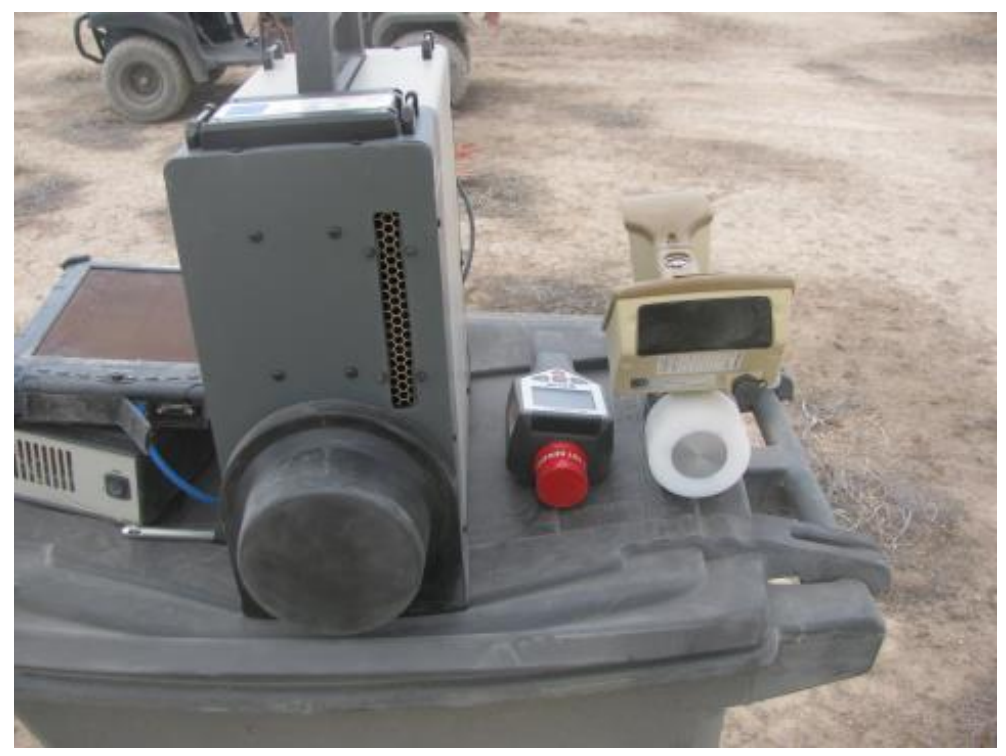

Figure 4.10: Hand-held radiation detectors used for in-situ measurements, atop a hightech detector stand 
PNNL-23997

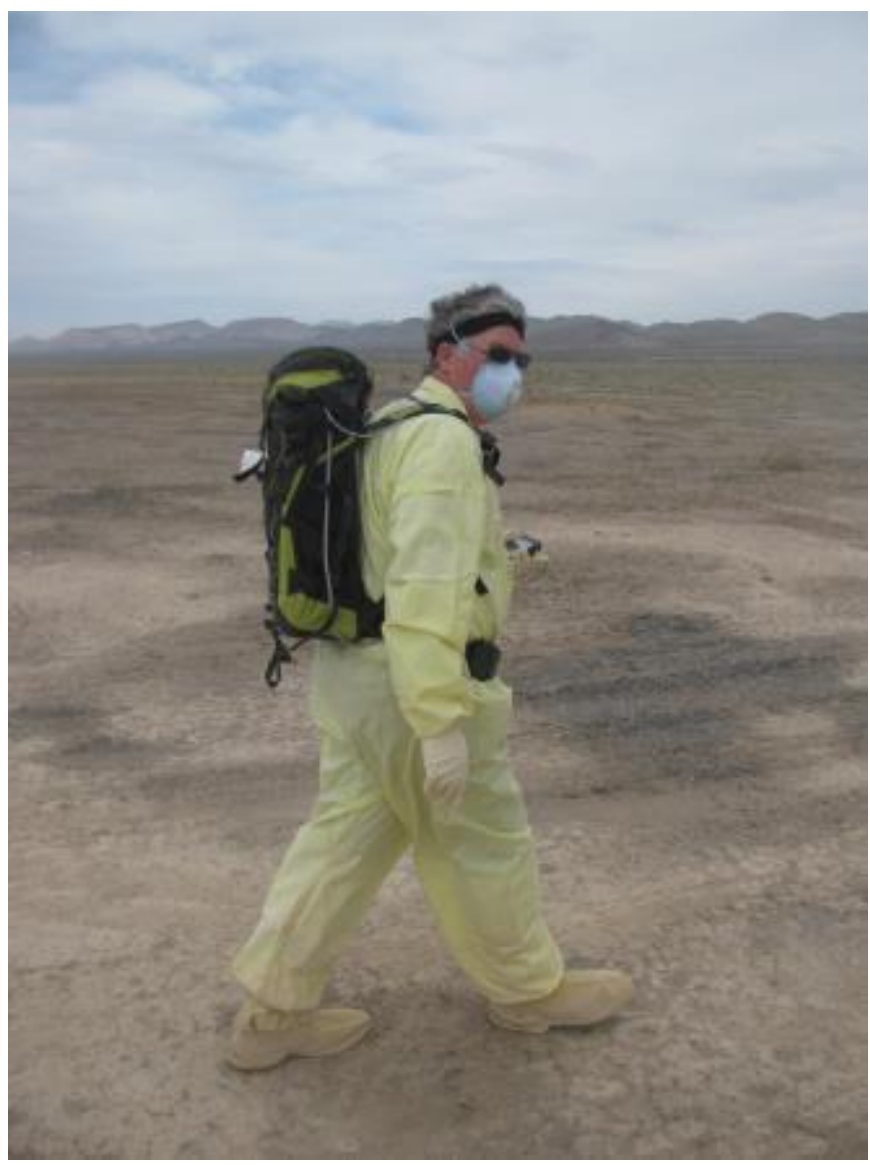

Figure 4.11: Thermo Packeye, a backpack PVT-based man-portable survey instrument

\subsubsection{Aerial Survey}

$\mathrm{RSL}^{1}$ performed a fixed-wing survey starting within $\sim 2$ hours of the ${ }^{140}$ La release. RSL's Beechcraft B-200 was equipped with an RSI survey system consisting of six 5.08-cm $\times 10.16-\mathrm{cm} \times 40.64-\mathrm{cm}(2$ " $\times$ 4 " $\times 16$ ") $\mathrm{NaI}(\mathrm{Tl})$ spectrometers.

${ }^{1}$ RSL performed the flight as a courtesy using flight proficiency funds. The Bell-412 flying at 150 feet with twelve $\mathrm{NaI} \operatorname{logs}$ would have been the preferred survey system, but the helicopter was undergoing planned maintenance at the time. Because of the short half-life of ${ }^{140} \mathrm{La}$ ( $\sim 40$ hours), no flight was conducted with the helicopter after it came out of maintenance and became available for survey work almost two weeks later. 
Flight lines were flown 500 feet above ground level (AGL) at a speed of 140 knots at a line spacing of 500 feet. Images of the B-200 taken while performing the aerial survey following the ${ }^{140} \mathrm{La}$ release and from the NNSA website are shown in Figure 4.12.
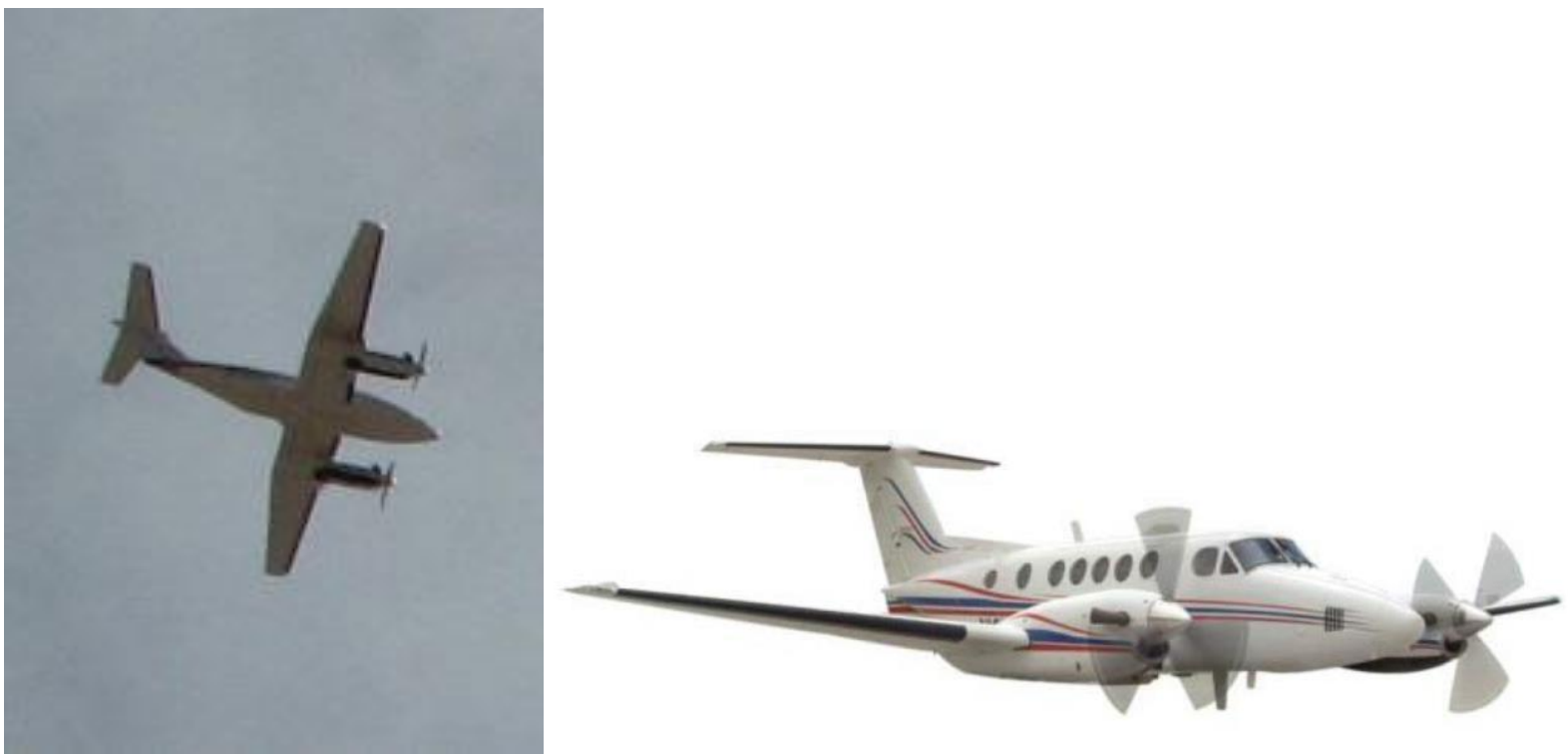

Figure 4.12: B-200 performing aerial survey of ${ }^{140}$ La release (left) and image of aircraft from an AMS presentation (right) (Lyons 2012)

\subsection{Field Laboratory}

A field laboratory was set up in a Quonset hut several miles to the southwest of the release point, in the "Command Post" area of the test site (see Figure 4.13). The laboratory included three $\sim 50 \%$ relative efficiency high resolution germanium HPGe gamma spectrometers (Canberra), as well as two low resolution $7.62 \mathrm{~cm} \times 12.7 \mathrm{~cm}(3$ " $\times 5$ ") $\mathrm{NaI}(\mathrm{Tl})$ spectrometers. The lab was manned by two to three personnel throughout the duration of sample measurements, and depended upon personnel availability. 
PNNL-23997

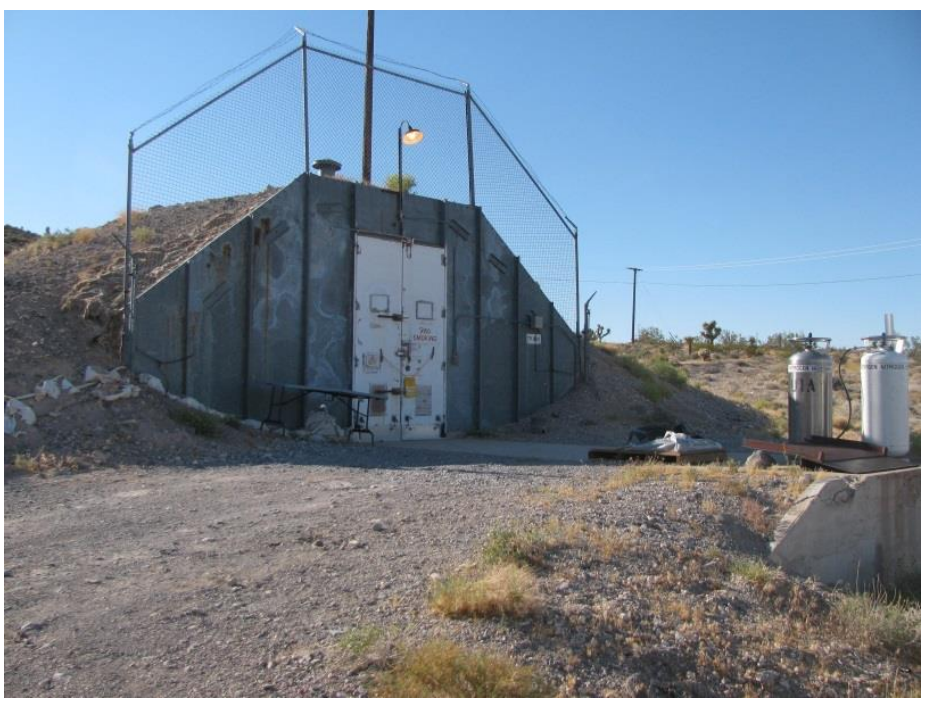

Figure 4.13: Exterior of Quonset hut that housed the field laboratory for PRex. Note the liquid nitrogen dewars provided for cooling of the HPGe detectors, on right.

Straight-forward $10.16 \mathrm{~cm}$ (4") thick lead shields were built on stands to accommodate two of the HPGe detectors (see Figure 4.14) and the two NaI(Tl) detectors (Figure 4.15). The third HPGe detector, supplied by NSTec, was housed in a Canberra portable shield (Figure 4.16). This detector was calibrated on the Canberra ISOCS system, and models were developed to establish detection efficiencies for the sample geometries during build up and preparation of the laboratory. Efficiency calibrations were also estimated for the PNNL-supplied HPGe detectors using the ISOCS methods.

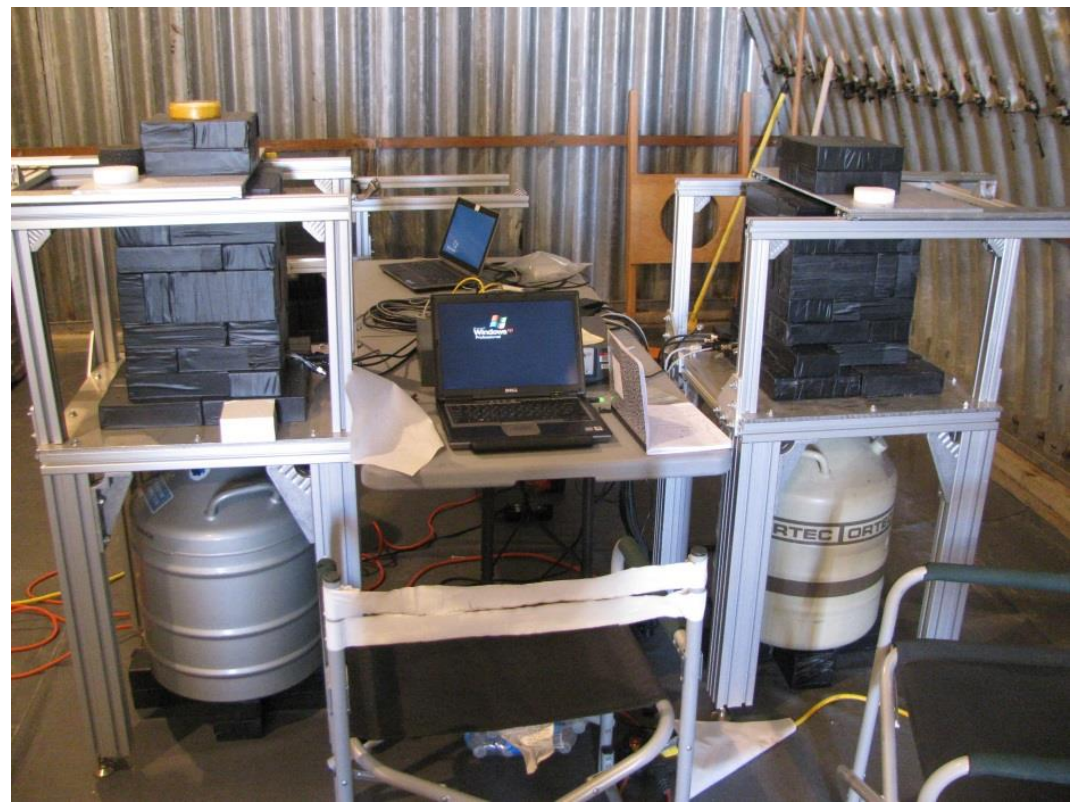

Figure 4.14: Two $~ 50 \%$ relative efficiency HPGe detectors inside of $10.16 \mathrm{~cm}$ (4”) thick lead shields. These detectors are set up in the field laboratory. 
PNNL-23997

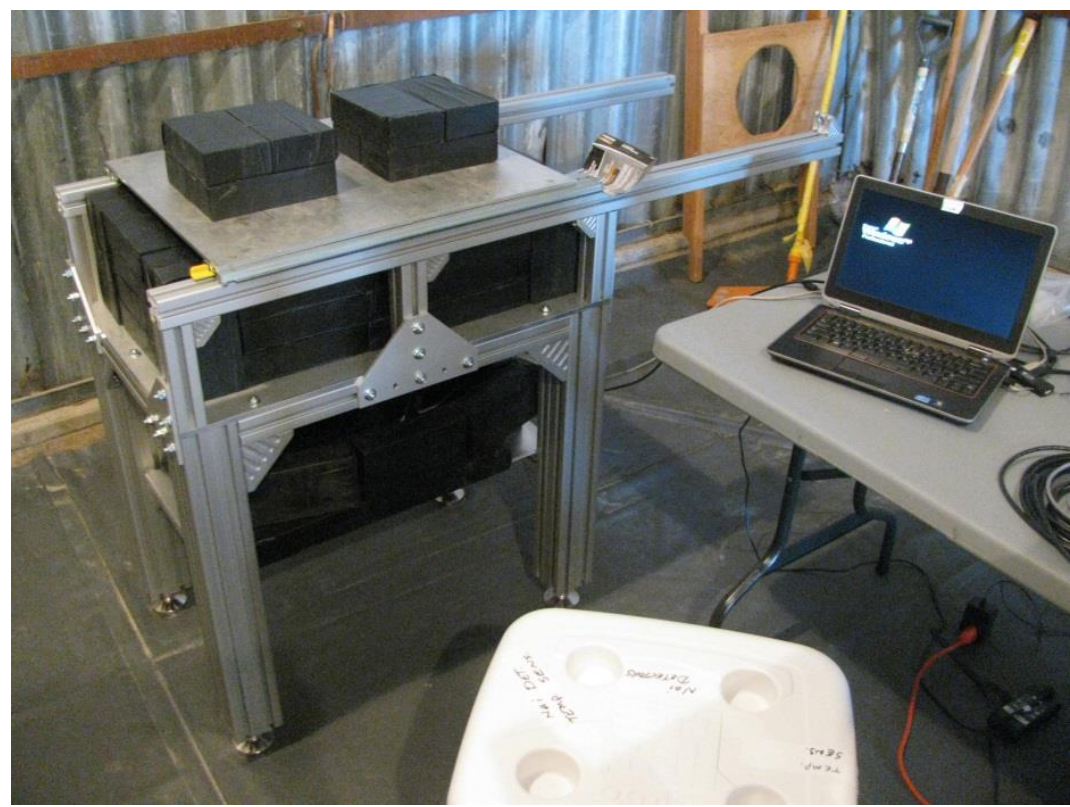

Figure 4.15: Single shield housing two $7.62 \mathrm{~cm} \times 12.7 \mathrm{~cm}(3$ " $\times 5$ ") $\mathrm{NaI}(\mathrm{Tl})$ detectors. The detectors are surrounded by $10.16 \mathrm{~cm}$ (4") of lead, and the sample chambers are also separated by $10.16 \mathrm{~cm}$ (4") of lead.

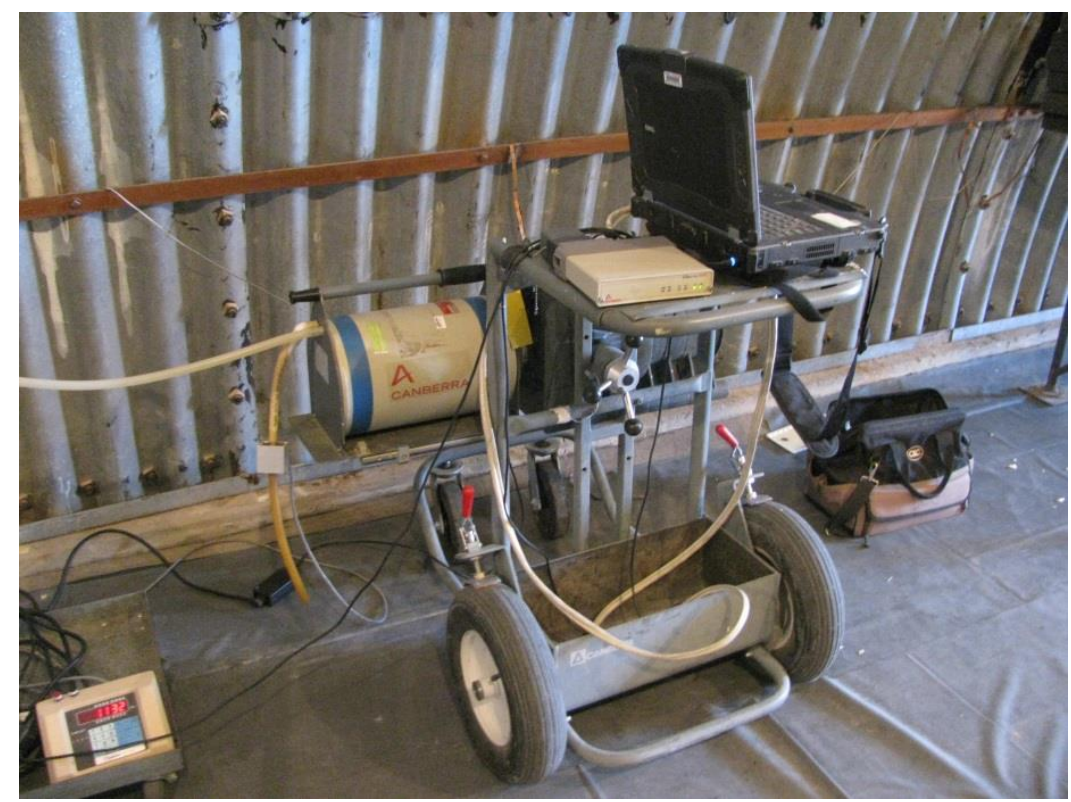

Figure 4.16: Canberra HPGe with commercial portable shield system, supplied by NSTec. The Canberra ISOCs efficiency calibration on this system was used to cross-calibrate the other HPGe detectors.

The first samples received into the field laboratory were collected by the high volume air samplers $2 \mathrm{~km}$ downwind from the release, and were brought to the laboratory late in the day on Tuesday, May $14^{\text {th }}$. A large fraction of the samples were received into the lab on Wednesday, with additional samples received Thursday morning. Counting was performed beginning late Tuesday, and was completed Friday morning, 
followed by tear-down and loading of the laboratory late Friday morning. Table A-1 provides the number of sample measurements performed. Samples were typically counted for 15 minutes; samples that had weak positive indications for ${ }^{140} \mathrm{La}$ were extended to 30 minutes of counting to improve the result.

The two $\mathrm{NaI}(\mathrm{Tl})$ detectors were included in the field laboratory because they were expected to be more reliable than the HPGe detectors; the utility and sensitivity of the NaI(Tl) detectors was unclear. Early sample measurements made it clear that the $\mathrm{NaI}(\mathrm{Tl})$ sensitivity was far inferior to that of the HPGe detectors due to the significant background rates relative to the ${ }^{140} \mathrm{La}$ activity (in the $\mathrm{NaI}(\mathrm{Tl})$ spectra, natural ${ }^{40} \mathrm{~K}$ was a significant interference for the $1596 \mathrm{keV}{ }^{140} \mathrm{La}$ line). One of the $\mathrm{NaI}(\mathrm{Tl})$ detectors also suffered from degraded energy resolution, and was essentially un-useable. After early attempts to use the $\mathrm{NaI}(\mathrm{Tl})$ detectors in a screening mode, they were no longer used as they were not providing added-value. It seems likely that scintillators, with their poorer energy resolution compared to HPGe, would likely require a high efficiency coincidence configuration to provide added value. 
PNNL-23997

\subsection{Analysis of Results}

\subsection{Vehicle Survey}

The mobile survey of the PRex release area was performed over two days, May 15 and May 16, roughly during the time windows 21-29 hours and 45-53 hours after the release. The survey was performed with a two NaI (Tl) log RSI system located in the cargo space of a Kawasaki Mule. The survey lines were driven in the East and West directions and were typically 100 meters apart. The survey started at the original northern border of the HCA $(\sim 0.5 \mathrm{~km}$ north of the release point) and moved northwards. During the morning of the $15^{\text {th }}$, the survey was performed solely by an equipment operator also acting as the driver. In the afternoon and following day, a driver from NSTec drove the vehicle freeing the PNNL operator to focus on data collection. The survey data set suffered from some data drop out periods (mainly in one detector, although in some cases data acquisition for both detectors stopped for brief periods), and from problems with the automated energy calibration function erroneously identifying the $1596 \mathrm{keV}{ }^{140} \mathrm{La}$ line as the ${ }^{40} \mathrm{~K} 1461 \mathrm{keV}$ line. Data corrections were applied, and are described in detail in Appendix A. Figure 5.1shows a survey plot typical of the products generated after data corrections were applied; in this case, detector count rates in a region of interest (ROI) around the $1596-\mathrm{keV}$ gamma energy of ${ }^{140} \mathrm{La}$ are shown.

NSTec reduced the HCA restriction down to the $\sim 20$ meter $\times 20$ meter fence surrounding the release point based upon "stomp and tromp" surveys during the afternoon of the 15. On May 16, the vehicle survey team filled in lines starting at the previous HCA northern border and measured lines south extending beyond the point of release. In this southern region of the survey, the spacing between survey lines was reduced to 50 meters to provide more detail to the close-in survey data.

On May 16, the team also surveyed the lines extending northward of where the survey had reached on the 15. The northern-most survey line was $2 \mathrm{~km}$ north of the release point. A combined path plot of the survey conducted on the 15 and 16 is shown in Figure 5.2. The path plot is based upon the gross counts of the spectral data; i.e., it is a plot of the physical position for each 1 second measurement, colorized to reflect the sum of counts (in both detectors) over the full spectrum. The energy range is $\sim 50$ to $3000 \mathrm{keV}$. In this figure the color break points were chosen to emphasize the location of plume and the level of the background with a minimal set of colors. The breakpoints are at 5000, 5500, 6000 and $6500 \mathrm{cps}$. 
PNNL-23997

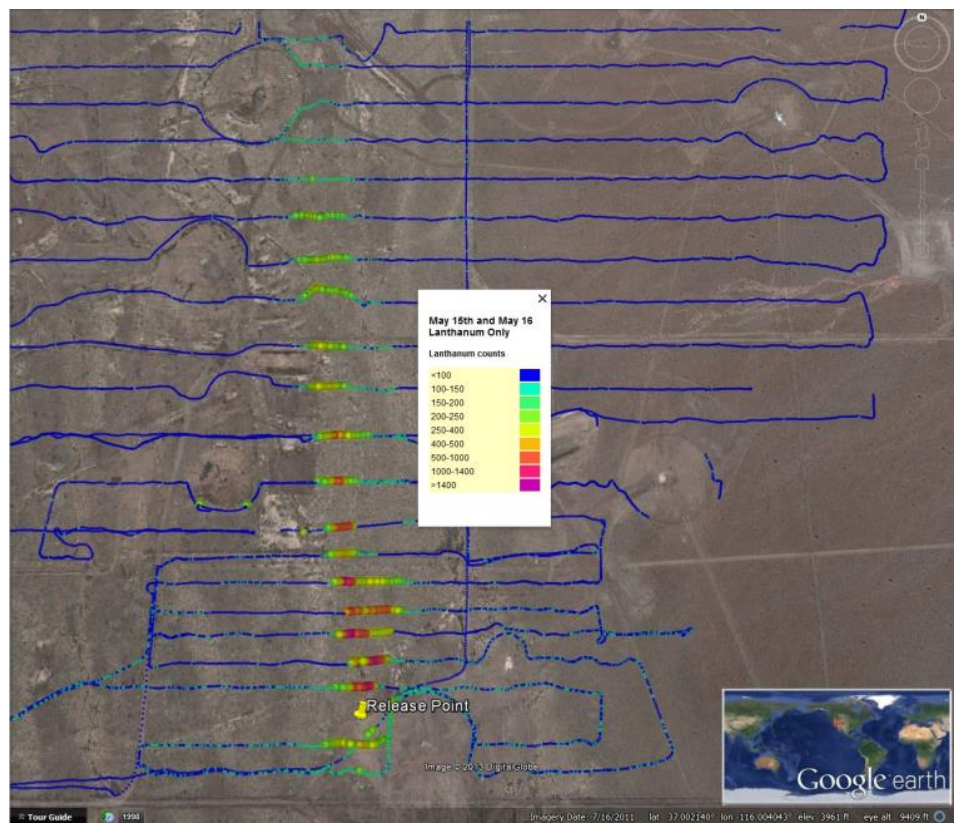

Figure 5.1: RSI vehicle survey route using an ROI on the ${ }^{140} \mathrm{La} 1596 \mathrm{keV}$ gamma. Count rates are for two detectors, unintentionally multiplied by a factor of two because the system was set up with a "virtual" detector that created a sum of the two individual $\mathrm{NaI}(\mathrm{Tl})$ detectors. The plot shows the count rate for the sum of the two individual detectors, and the virtual detector. This figure does not show the full extent of the survey to the North.

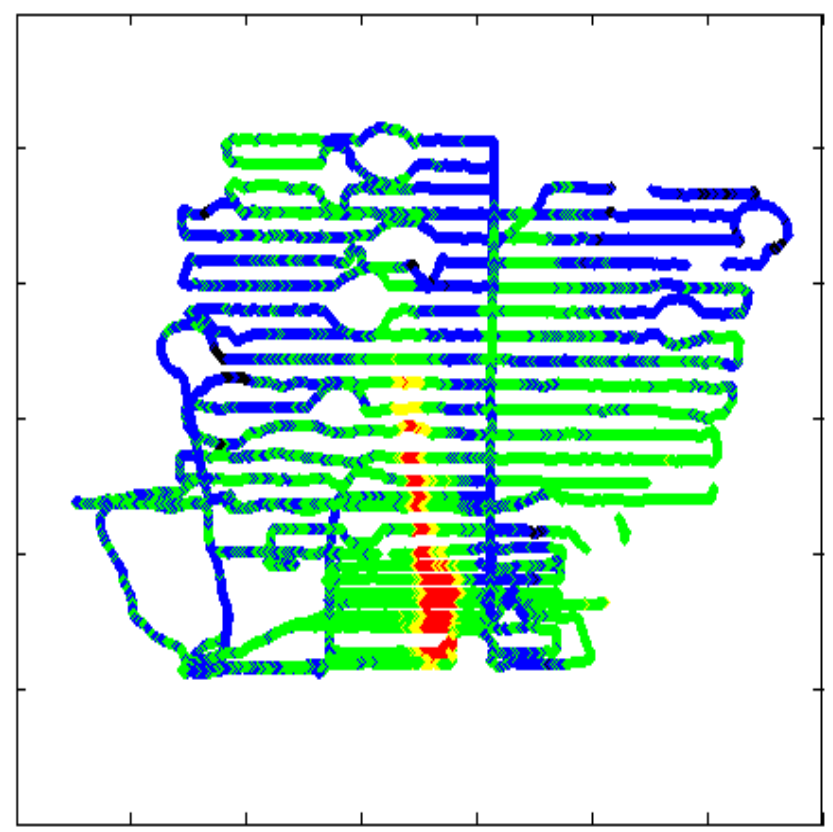

Figure 5.2: Gross counts detected by ground survey with the RSI system. The data is the sum of two $\mathrm{NaI}(\mathrm{Tl})$ detectors. The color key is $<5000$ cps black, $5000-<5500 \mathrm{cps}$ blue, $5500-<6000 \mathrm{cps}$ green, $6000-$ $<6500$ yellow, $\geq 6500$ red. 


\subsubsection{Contours}

The RSI system was set to collect data in one second intervals. This time interval leads to separation between survey measurements of 2-3 meters in the east/west direction (high spatial density of measurements) and 50 to 100 meters between measurements in the north/south direction (a much lower spatial density). This spatial asymmetry could be eliminated by summing data along the East/West direction, but detail about the cross plume profile would be lost because the plume ran approximately North/South. Hence the decision was made to use modern contouring tools such as those found in MatLab to contour the asymmetric data.

\subsubsection{Gross Counts}

Figure 5.3 provides a depiction of the deposition plume after the gross count data of Figure 5.2 were corrected (Appendix A) and contoured using MatLab [http://www.mathworks.com/products/matlab/] tools. The data was smoothed using 'smooth' over a ten point window (the equivalent of smoothing the 1 second data points with a ten second moving window). Contour plots were produced by sampling the data into a rectangular grid using the MatLab function 'meshgrid', interpolating the data using the 'TriScatteredInterp' function, and then applying the 'countourf' function to the new rectangular grid of interpolated values. The 'TriScatteredInterp' function makes use of Delaunay triangulation to establish intermediate data points. The color bar at the right of Figure 5.3 provides the color key for the magnitude of the gross counts measured in 1-second intervals, summed for the two $\mathrm{NaI}(\mathrm{Tl})$ detectors in the survey system.

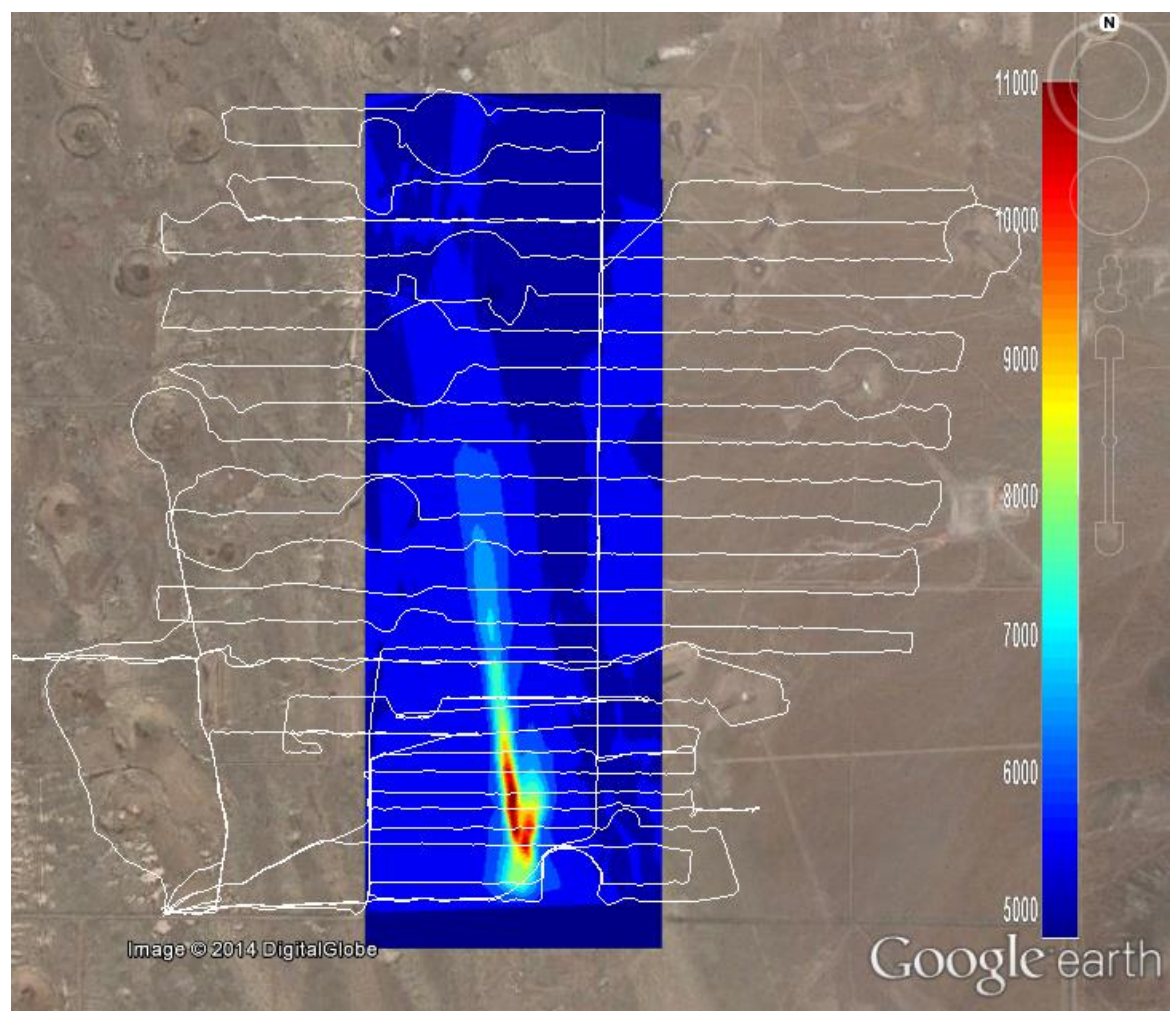

Figure 5.3: Gross Count contours of the RSI with two $2 " \times 4 " \times 16 " \mathrm{NaI} \log$ detectors. 


\subsubsection{Extracted ${ }^{140} \mathrm{La}$}

The ${ }^{140} \mathrm{La}$ component of each one second spectra was extracted using a two window background subtraction technique. In this method, the sum of counts in an ROI over the prominent $1596 \mathrm{keV}^{140} \mathrm{La}$ line is compared to counts in another ROI covering a higher energy region of the spectrum where there are few counts generated by ${ }^{140} \mathrm{La}$. The typical environmental background ratio between these two regions was established in the PRex release area using background data collected the day prior to the release. This background ratio between count rates in these two ROIs was used to scale the high energy ROI so that it could be used to perform a background subtraction ("strip") for the ROI that included the $1596 \mathrm{keV}$ peak, i.e., the result of subtracting the scaled high energy ROI from the ${ }^{140} \mathrm{La}$ ROI is the measure of the ${ }^{140} \mathrm{La}$ at that location. After this strip, the extracted ${ }^{140} \mathrm{La}$ count rate was decay corrected back to the time of the release using the UTC time that is recorded by the RSI for each one second collection. Figure 5.4 shows the contours for the extracted ${ }^{140} \mathrm{La}$ count rate in the $1596 \mathrm{keV}$ peak. The units of the color bar are the counts per second for the stripped ROI, corrected for decay. The energy range selected for the ${ }^{140} \mathrm{La}$ ROI will miss about $10 \%$ of the $1596 \mathrm{keV}$ peak as the lower energy limit of the ROI was chosen to minimize the presence of counts from ${ }^{40} \mathrm{~K}(1461 \mathrm{keV})$. The energy resolution of the $\mathrm{NaI}(\mathrm{Tl})$ detectors is insufficient to completely separate the $1596 \mathrm{keV}^{140} \mathrm{La}$ line from the $1461 \mathrm{keV}^{40} \mathrm{~K}$ line.

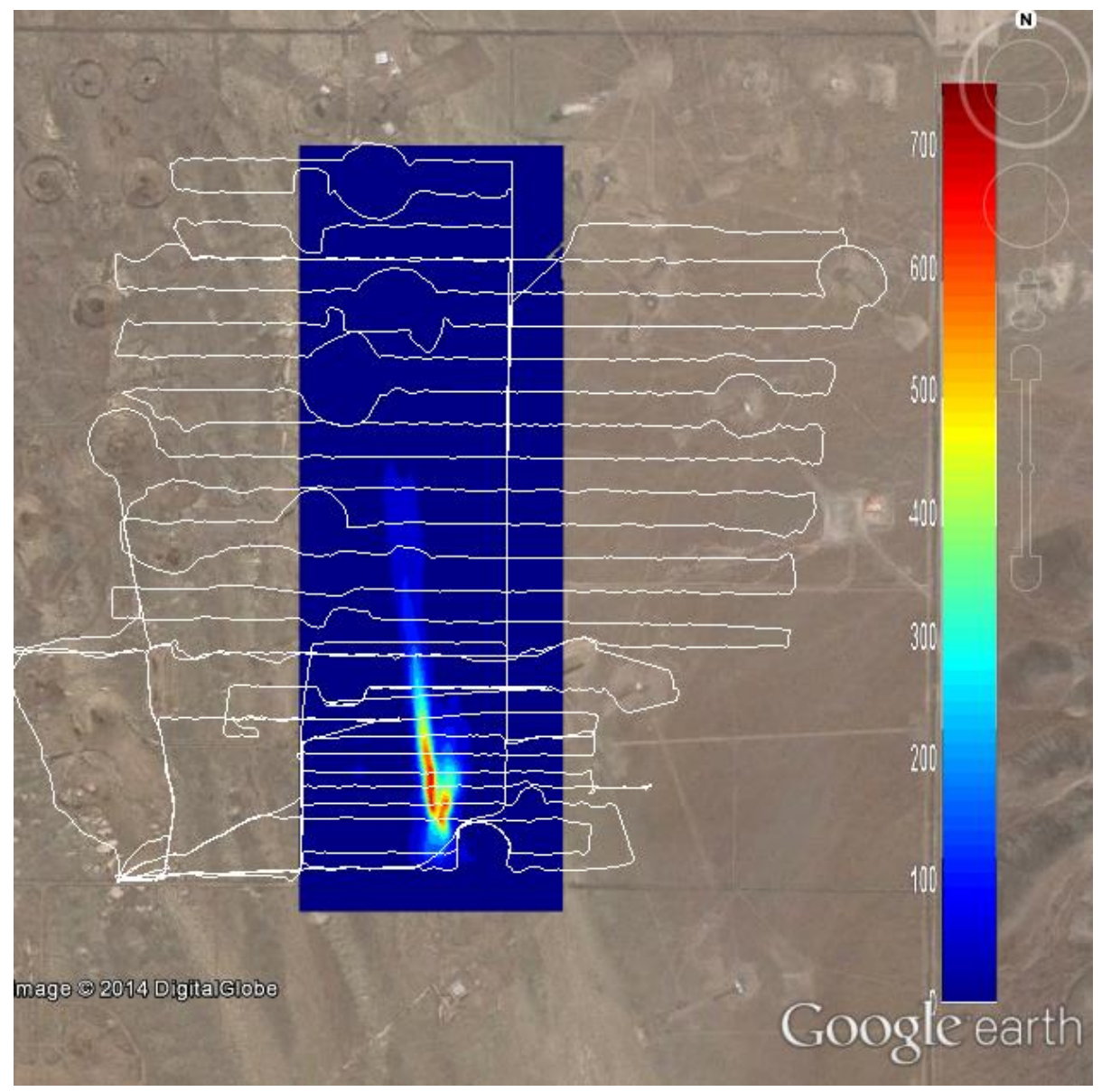

Figure 5.4: Contours of the surveyed deposition based on ${ }^{140} \mathrm{La}$ using the count rate in the $1596-\mathrm{keV}$ line 
PNNL-23997

\subsubsection{Conversion of ${ }^{140} \mathrm{La}$ Count Rate to Deposited Activity $\left(\mu \mathrm{Ci} / \mathrm{m}^{2}\right)$}

The conversion factor between the count rate (cps) in the $1596 \mathrm{keV}$ line ROI and deposited ${ }^{140}$ La activity $\left(\mu \mathrm{Ci} / \mathrm{m}^{2}\right.$ ) was established through modeling of the $\mathrm{NaI}(\mathrm{Tl})$ detector system in the Kawasaki Mule. The modeling was performed using the Monte Carlo radiation transport and detector response code MCNP. The MCNP Version 5 (Forster et al. 2004) model includes the two $5.04 \mathrm{~cm} \times 10.08 \mathrm{~cm} \times 40.32 \mathrm{~cm}(2$ " $\times$ $4 " \times 16 ") \mathrm{NaI}(\mathrm{Tl})$ detectors, a crude representation of the Kawasaki mule utility vehicle, and air above a flat plane of soil. The source is modeled as a uniform 40 meter radius disk of ${ }^{140} \mathrm{La}$ at the air-soil interface. Only the $1596 \mathrm{keV}$ line of ${ }^{140} \mathrm{La}$ was modeled to estimate the conversion factor. The code was used to model the probability of full energy absorption of the $1596 \mathrm{keV}$ photon in either of the two detectors per emitted photon $\left(3.61 \times 10^{-6}\right)$. Use of this detection efficiency implies an assumption that a $40 \mathrm{~m}$ radius source disk is sufficiently large to account for a majority of gammas detected. The conversion factor is found by multiplying the result by the source area $\left(5.03 \times 10^{3} \mathrm{~m}^{2}\right)$ times the number of photons per $\mu \mathrm{Ci} / \mathrm{m}^{2}\left(3.7 \times 10^{4}\right)$ to find $6.72 \times 10^{2} \mathrm{cps}$ in the $1596 \mathrm{keV}$ peak per $\mu \mathrm{Ci} / \mathrm{m}^{2}$. The MCNP model did not include the intensity of emission of the $1596 \mathrm{keV}$ line, therefore the conversion coefficient is further reduced to $6.41 \times 10^{2} \mathrm{cps}$ per $\mu \mathrm{Ci} / \mathrm{m}^{2}$, because the intensity for the line is $95.4 \%$. The need to model a disk 40 meters in radius which is 40 times the approximate 1 meter altitude of the system is a result of the penetration power of the $1596 \mathrm{keV}$ photon in air.

As a check on the MCNP result, we can also independently estimate the conversion factor based upon the RSI system's dose rate determination along the survey route. F is a plot of gross count versus dose rate for detector 1 for the last day of the survey. As can be seen in the figure, there appear to be regions of two different slopes. These reflect that the RSI appears to be making an energy dependent dose estimate. Specifically, the slope for counts well above background (4000-6500 cps) where the predominant radionuclide is ${ }^{140} \mathrm{La}$ is steeper than slope in the region of the background (2500-3500 cps) where the predominant radionuclides are KUT. Table 5-1 shows two points extracted from F. The first point is an estimate of the highest region applicable to background and the second is near the highest point on the plot. The slope between the points in this table provides an estimate of conversion between excess counts and dose attributable to ${ }^{140} \mathrm{La}$. The value is found to be 2460 excess cps per $\mathrm{nGy} / \mathrm{hr}$ from ${ }^{140} \mathrm{La}$ or $246 \mathrm{cps}$ $\operatorname{per} \mu \mathrm{rem} / \mathrm{hr}$.

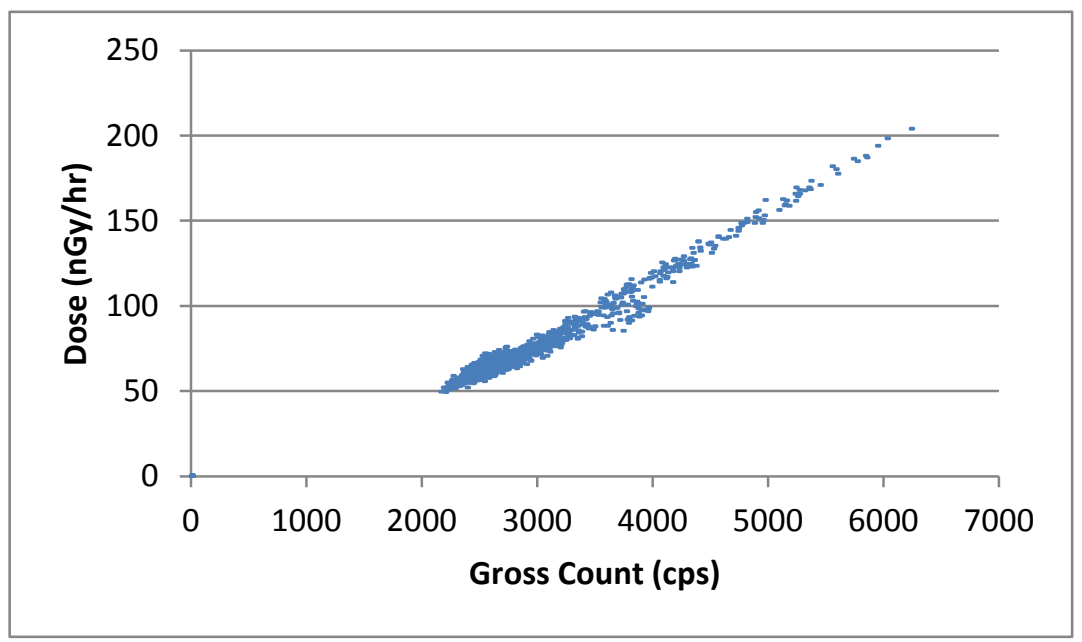

Figure 5.5: Gross counts versus dose for one $\mathrm{NaI}(\mathrm{Tl})$ detector 
PNNL-23997

Table 5-1: Typical Values Extracted from Figure 6-3

\begin{tabular}{ccc}
\hline CPS & nGy/hr & Comment \\
\hline 3728 & 101.7 & Estimated highest background \\
\hline 6232 & 203.7 & Highest value (background $\left.+{ }^{140} \mathrm{La}\right)$ \\
\hline
\end{tabular}

From Table 5-1, the conversion coefficient for ${ }^{140} \mathrm{La}$ gross counts is $(6232-3728) /((203.7-101.7) / 10)$ or $245.5 \mathrm{cps}$ per $\mu \mathrm{rem} / \mathrm{hr}$ (the conversion factor between $\mathrm{nGy} / \mathrm{hr}$ and $\mu \mathrm{rem} / \mathrm{hr}$ is approximately $1 / 10$ ). From the Nuclear Regulatory Commission's RadToolbox [NRC 2014], an infinite plane source of ${ }^{140}$ La with an activity of $1 \mu \mathrm{Ci} / \mathrm{m}^{2}$ produces a dose at $1 \mathrm{~m}$ elevation of $28.8 \mu \mathrm{rem} / \mathrm{hr}$. Hence, according to this estimate, a single $2 " \times 4 " \times 16 " \mathrm{NaI}(\mathrm{Tl})$ detector should produce $7070 \mathrm{cps}$ (gross counts) per $\mu \mathrm{Ci} / \mathrm{m}^{2}$ of ${ }^{140} \mathrm{La}$.

However, these are gross counts rather than counts in the ROI around $1596 \mathrm{keV}$. To understand the ratio of counts from ${ }^{140} \mathrm{La}$ in the gross count to those in the ROI, it was necessary to compare spectra with and without ${ }^{140} \mathrm{La}$. Two seventeen second spectra were compared. In Table 5-2, the data without ${ }^{140} \mathrm{La}$, labeled "Background", came from a survey conducted in the PRex release area on May 13 which was the day before the release. The data labeled "With ${ }^{140} \mathrm{La"} \mathrm{was} \mathrm{measured} \mathrm{on} \mathrm{the} \mathrm{morning} \mathrm{of} \mathrm{May} 15$.

Table 5-2: Comparison of ROI and GC Counts in Spectra with and without ${ }^{140} \mathrm{La}$

\begin{tabular}{lllll}
\hline & Start time index & Stop time index & ROI counts & Gross Count \\
\hline With ${ }^{140}$ La & 2640 & 2668 & 2436 & 199102 \\
Background & 400 & 428 & 391 & 157819 \\
Net & & & 2045 & 41283 \\
\hline
\end{tabular}

The ratio of ${ }^{140} \mathrm{La}$ in the full spectrum (gross count) to ${ }^{140} \mathrm{La}$ in the ROI is $\sim 20$. Therefore, the expected excess counts in one $\mathrm{NaI}(\mathrm{Tl})$ detector is $7070 / 20$, or $\sim 353 \mathrm{cps}$ per $\mu \mathrm{Ci} / \mathrm{m}^{2}$ of ${ }^{140} \mathrm{La}$. This rough estimate compares well $(\sim 10 \%)$ with the value based upon the MCNP modeled conversion of $321 \mathrm{cps} /\left(\mu \mathrm{Ci} / \mathrm{m}^{2}\right)$ for a single RSI NaI(Tl) detector.

Returning to the MCNP-derived conversion factor of $641 \mathrm{cps} /\left(\mu \mathrm{Ci} / \mathrm{m}^{2}\right)$ for two RSI NaI(Tl) detectors, it becomes possible to convert interpolated data points to a uniform grid of deposited activity values and to integrate the result to estimate the quantity of ${ }^{140} \mathrm{La}$ deposited in the observable plume. This integration of the plume results in an estimate that the measured ${ }^{140} \mathrm{La}$ is of the order of $7 \%$ of the original $\sim 1 \mathrm{Ci}$ quantity available for release. This result may reflect that the release was not fully successful (source material left in or around the transport container), or that we did not have a full understanding of the source particle size. Analyses of the particle distribution in the released powder that were completed after the release indicated a range of particles extending into smaller particles than intended; this would result in longer distance transport and less activity deposition in the near field. 
PNNL-23997

\subsubsection{MDA}

The MDA was calculated with the Currie equation. The calculation is performed for the $1596 \mathrm{keV}$ line from ${ }^{140} \mathrm{La}$.

$$
M D A=\frac{4.65 * \sqrt{N_{B}}+2.71}{\gamma * \varepsilon * T * 3.7 e 4\left(\frac{B q}{\mu C i}\right)}
$$

Here $N_{B}$ is the background for the ROI in which the $1596 \mathrm{keV}$ line is measured. The ROI background count rate was found to be $12.07 \mathrm{cps}$ based on the survey conducted the day before the release. The constant $\gamma$ is the branching ratio for the $1596 \mathrm{keV}$ which is 0.954 . The constant $\varepsilon$ is the efficiency, i.e., the probability of detection in the in $1596 \mathrm{keV}$ line per emitted photon. The constant $T$ is the time interval which is 1 second.

The efficiency, $\varepsilon$, is based upon MCNP calculation of the response of the system to a $40 \mathrm{~m}$ radius disk with a concentration of ${ }^{140} \mathrm{La}$ equal to $1 \mu \mathrm{Ci} / \mathrm{m}^{2}$. The simulation-based efficiency is $3.61 \times 10^{-6}$ for the detector response to the $40 \mathrm{~m}$ radius uniform surface source. The MDA was calculated based on the system response to a uniform surface source; the MDA was found to be $2.94 \times 10^{-2} \mu \mathrm{Ci} / \mathrm{m}^{2}$ for a 1 second count.

\subsubsection{Multi-instrument comparison Backpack, LaBr3, Nal and HPGe}

In Figure 5.6, two transects of the plume profile are shown for both the RSI vehicle-borne and Thermo Packeye backpack survey systems. The panels show the instrument readings; gross count rate for gammarays for the RSI system (the RSI count rates are doubled in the figure due to the "virtual detector", as mentioned previously) and dose rate for the Thermo Packeye. Note the overall agreement in shape for the main plume and lower elevated area seen in the top panel. The basic features of the plume cross section are corroborated by the two instruments. 
PNNL-23997
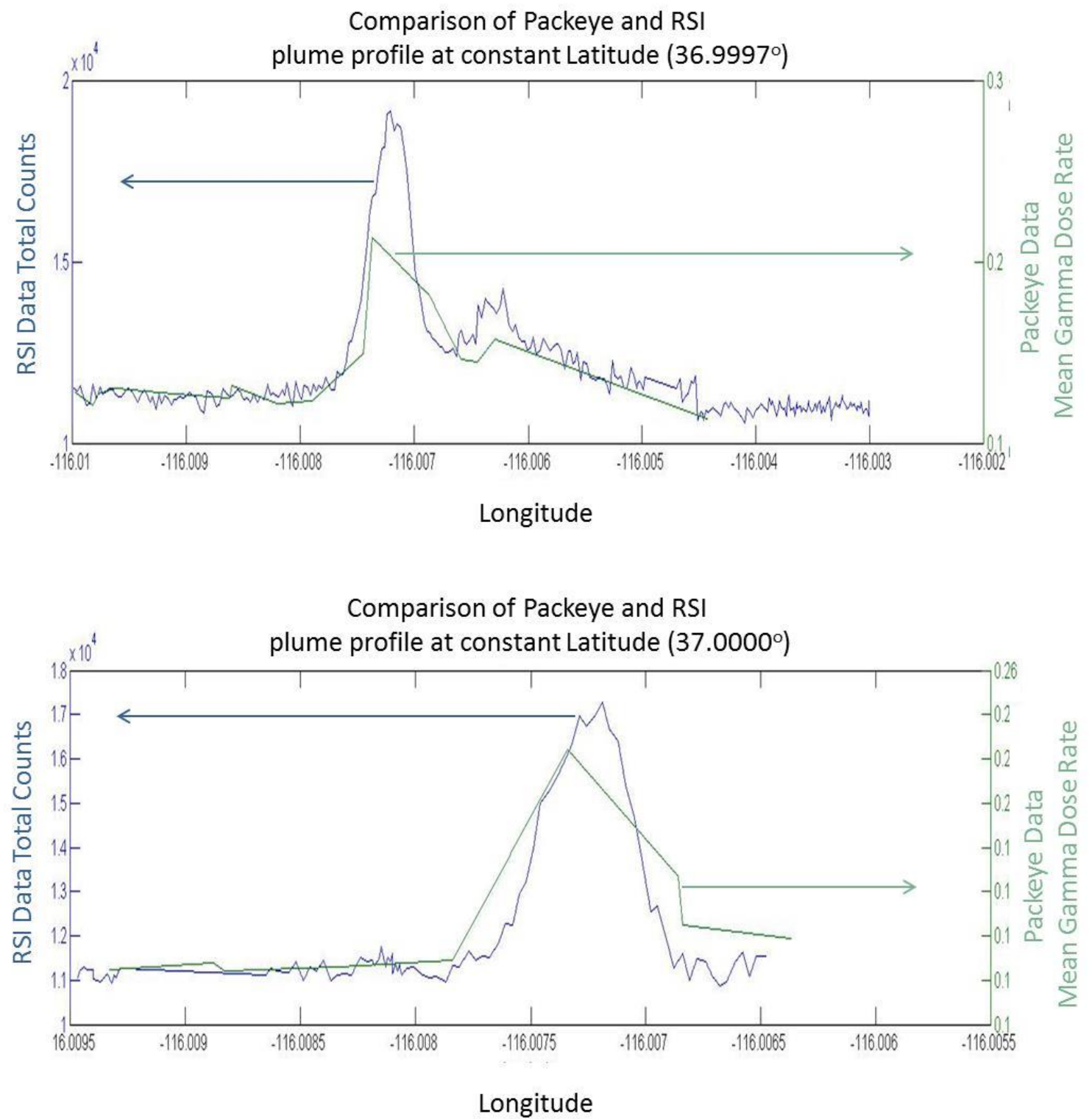

Figure 5.6: Comparison of vehicle and backpack transects of plume. The top (near sample area 1-4) and bottom panel (near sample area 5-4) compare gross count (RSI) (RSI count rates are doubled due to "virtual detector") with dose rate (Packeye). The paths followed for the Packeye and RSI surveys were close, but not precisely the same. 
PNNL-23997

\subsection{Witness Plate Laboratory Measurement Results}

Appendix B provides a table of field laboratory HPGe measurement results by sample type, including measurement of large area witness plates, selected optical witness plates, soil samples, and filter paper samples collected with the air samplers.

For PRex a large grid of witness plates were set out so that a range of wind directions could be accommodated. This was necessary to ensure a high probability that the experiment could be conducted within the available 3-day time window and before the ${ }^{140}$ La source decayed too much. The actual plume was unsurprisingly much smaller than the pre-set sample array; many of the witness plates were well outside of the contamination deposition area, and were not measured. For an OSI, the situation is a little different. With a given suspected $\mathrm{t}_{0}$ from seismic signals, an OSI inspection team might at best have an idea of probable plume direction given the general wind direction at the time, assuming any radionuclide venting occurred relatively soon after $t_{0}$ and keeping in mind that the actual vent location within an Inspection Area is not known. Without additional information, an OSI inspection team would likely try to locate a radionuclide plume via surveys and samples taken along transects roughly perpendicular to the suspected plume direction.

PRex acquired adequate tacky mat witness plates to characterize nine transects across the plume. These correspond to rows 2-5 and 7-11 in Appendix B. For example, in row 2, we see that the tacky mat witness plates had measured detects in three adjoining locations (2-3, 2-4, and 2-5) with no detects of radiation in 2-2 or 2-6. Given the $50 \mathrm{~m}$ spacing between witness plate sites, this corresponds to a transect involving measurable radiation of at least $100 \mathrm{~m}$. Since the witness plate samples were placed at fixed intervals, it is not possible to determine exactly how much more than $100 \mathrm{~m}$ the measurable transect was. At most it would be $\sim 200 \mathrm{~m}$, assuming the measureable radiation stopped just before the next sampling sites on both sides. Likely, it is far closer to $100 \mathrm{~m}$ than $200 \mathrm{~m}$ given the quick drop in activity seen between 2-4 and the locations on either side. Table 5-3 provides estimates of the plume width based on field laboratory measurements of the large area witness plate samples. Note that in row 4, site 4-5 did not have a tacky mat measured as it had blown over before the experiment, but given that its glass slide had radiation it is safe to assume that a measurement there would have had a positive result. 
PNNL-23997

Table 5-3: Deposition Plume Width Estimate Based on Large Area Witness Plates

\begin{tabular}{|c|c|}
\hline Row & $\begin{array}{c}\text { Approximate plume width (m) } \\
\text { Based on witness plate measurements }\end{array}$ \\
\hline 2 & $100-200$ \\
\hline 3 & $150-250$ \\
\hline 4 & $200-300$ \\
\hline 5 & $200-400$ \\
\hline 7 & $100-300$ \\
\hline 8 & $300-500$ \\
\hline 9 & $200-400$ \\
\hline 10 & $200-400$ \\
\hline 11 & $600-800$ \\
\hline
\end{tabular}

Insufficient measurements of the large area witness plates in row 6 were made to characterize that transect of the plume. This indicates that these samples were either not collected, were not processed correctly (e.g. the wrong decision was made on whether to measure the sample), or the measurement data was lost. In any event, this represents lost data that was intended to be available for the analysis. This is a situation that can arise during the hectic pace of work that occurred after the dispersal, and is an issue that is likely to be faced by OSI teams.

The conclusion is that for this plume and this level of activity, a sample spacing of much more than $100 \mathrm{~m}$ would have possibly missed the plume. Given the winds at the time, this might be narrower than a typical plume, but gives some idea of the challenge for an OSI team. Another thing worth pointing out about the plume for consideration is that adjoining measured activities along a given transect (as shown in Appendix B) typically differ by at least an order of magnitude. 
PNNL-23997

\subsection{Comparison of Vehicle Survey and Witness Plate Results}

The surface area and measured activity of the tacky mats was used to determine the deposited activity in $\mu \mathrm{Ci} / \mathrm{m}^{2}$. The equivalent RSI measurements are based upon the interpolation of the survey data to the location of the tacky mats. The results have been corrected to a consistent set of units $\left(\mu \mathrm{Ci} / \mathrm{m}^{2}\right)$, however the tacky mat results represent a measurement of deposition on a $0.3484 \mathrm{~m}^{2}$ surface area, while the MCNP detection efficiency calculations indicate that the RSI survey system is sensitive to large distances; this was demonstrated by a significant change in the count rate conversion factor (see section 5.1.1.3) when the MCNP modeled source disk was expanded from a ten meter radius to a forty meter radius. The deposited plume activity concentration derived from field laboratory measurement of witness plates is compared to the vehicle survey result for various witness plate locations as shown in Table 5-4 and graphically in Figure 5.7. In the figure, the tacky mat results are shown as filled circles where the coloring break points have been chosen to approximately match the colors on the contoured mobile data. The mobile data is in cps for the ROI region. The conversion factor for the survey data is $641 \mathrm{cps}$ per $\mu \mathrm{Ci} / \mathrm{m}^{2}$, as discussed above. All are in good agreement except for 7-3, as discussed in the next section.

Table 5-4: Comparison of Tacky Mats and Mobile Survey

\begin{tabular}{ccc}
\hline Location & $\begin{array}{c}\text { Tacky Mats } \\
\left(\mu \mathrm{Ci} / \mathrm{m}^{2}\right)\end{array}$ & $\begin{array}{c}\text { RSI } \\
\left(\mu \mathrm{Ci} / \mathrm{m}^{2}\right)\end{array}$ \\
\hline $\mathbf{2 - 4}$ & 0.53 & 0.78 \\
$\mathbf{5 - 4}$ & $0.092-0.12$ & 0.10 \\
$\mathbf{7 - 3}$ & $0.00051-0.0032$ & 0.18 \\
\hline $\mathbf{1 0 - 5}$ & $0.05-0.057$ & 0.06 \\
\hline
\end{tabular}




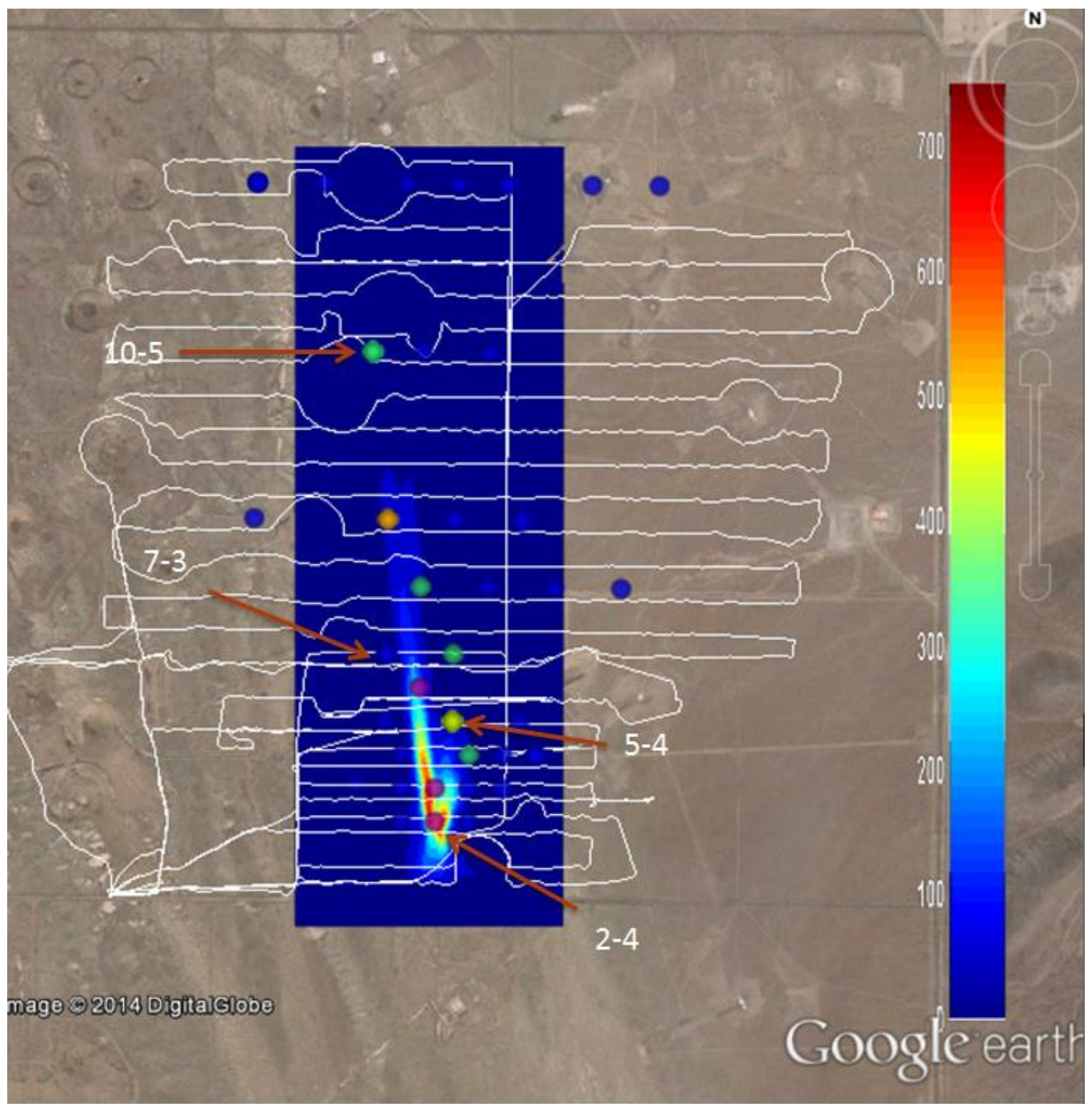

Figure 5.7: Tacky mat (filled circles) overlaid on mobile survey contours of extracted ${ }^{140} \mathrm{La}$

\subsection{Variability at Comprehensive Sampling Sites}

The data from comprehensive sampling site 7-3 are an interesting case to consider. In this instance, there were five tacky mats collected and measured in the field laboratory. The results had a wide range, from $1.79 \mathrm{E}-04 \mu \mathrm{Ci}\left(5.14 \mathrm{E}-04 \mu \mathrm{Ci} / \mathrm{m}^{2}\right)$ to $1.12 \mathrm{E}-03 \mu \mathrm{Ci}\left(3.21 \mathrm{E}-03 \mu \mathrm{Ci} / \mathrm{m}^{2}\right)$. The neighboring site to the west (72) had a null result, while the site to the east (7-4) recorded $2.23 \mathrm{E}-02 \mu \mathrm{Ci}\left(6.40 \mathrm{E}-02 \mu \mathrm{Ci} / \mathrm{m}^{2}\right)$. Closer examination of the data at site 7-3 indicates that the lowest value, $1.79 \mathrm{E}-04 \mu \mathrm{Ci}$, was observed at the western sampling point 7-3-2. Relatively consistent values of $6.45 \mathrm{E}-04$ and $4.71 \mathrm{E}-04 \mu \mathrm{Ci}$ were observed 
at the center and southern sampling points, respectively. Finally, values of $9.33 \mathrm{E}-04$ and $1.12 \mathrm{E}-03 \mu \mathrm{Ci}$ were observed at the northern and eastern points. While not conclusive, these results are consistent with a factor of 6 increase in ${ }^{140} \mathrm{La}$ deposition over the scale of a comprehensive sampling site, $\sim 6$ meters. Inspection of Figure 5.7 shows that this sampling site was likely in a location where there would be a steep upward gradient of the plume when moving from west to east. The corresponding RSI vehicle survey result was $1.8 \mathrm{E}-01 \mu \mathrm{Ci} / \mathrm{m}^{2}$, significantly higher than results from the tacky mats. This could indicate that the survey value was biased higher due to the higher activity nearby to the east.

Aside from the variation in witness plate results at sampling site 7-3, the results from the RSI vehicle survey and the witness plate samples are in good agreement, as seen in Table 5-4. Two more of these sampling locations were also comprehensive sampling sites, 5-4 and 10-5. Both of these sites displayed good agreement among the five tacky mat samples collected at each site. The activity levels at both sites were higher than at 7-3. Neither of these sites appears to lie on a steep activity gradient (see Figure 5.7), so the good agreement between samples does not rule out the possibility that the results at 7-3 are evidence of a significant deposition gradient across the 6 meters of a comprehensive sampling/survey site (CSS).

Appendix B provides the results of the HPGe sample measurements performed at the Field Laboratory by sample location and type. Tacky mat witness plate samples were measured from all ten of the Comprehensive Sampling Sites (those with five tacky mat witness plates, see Figure 3.26). Two of the CSS locations (9-9 and 10-9) had no detections of ${ }^{140} \mathrm{La}$ on any of the witness plates while a third (9-2) had only a single detect. Five of the locations (4-8, 5-4, 7-3, 9-6, and 10-5) had detections for all five witness plates. The first three are the three closest comprehensive sites to the release point, while 10-5 was well-aligned with the plume. The activities measured at 5-4 and 10-5 were approximately two orders of magnitude stronger than those measured at site 7-3, which was approximately another order of magnitude stronger than the remaining two sites (which were not particularly close to the plume). Average deviations in the individual tacky mat activities measured relative to the weighted mean for the five comprehensive sites with detects on all five tacky mats ranged from 5-149\%, with the two strong sites, 5-4 and 10-5 measuring average deviations of 10\% and 5\%, respectively. Since these deviations are considerably larger than the measurement uncertainties of the samples, it appears that the nearby tacky mats at comprehensive sites did not detect identical samples, either due to collection error or local variation in the deposition. The data from site 7-3 appear to indicate measurement of an actual gradient across the CSS, as discussed previously.

\subsection{Airborne Survey}

The airborne survey data was processed and contoured as gross counts and using an ROI over the ${ }^{140} \mathrm{La}$ line at $1596 \mathrm{keV}$. The maps from these two methods are shown in Figure 5.8 (gross count exposure) and Figure 5.9. The comparatively wide line spacing (500 feet) relative to the distance traveled between 1 second data collections ( 200 feet) makes the pixels both large and wide. In both figures, the release point is clearly seen as the bulls eye seen in the southern central part of the mapped area. The figures show an indication of the plume direction, but with little definition. In an OSI, it is not certain that the plume would have been definitively identified as an area of interest for further investigation, if not for the presence of the high activity region around the release point. However, the presence of elevated count rates along the plume axis in the ${ }^{140} \mathrm{La}$-windowed contour plot of Figure 5.9 seems likely to have drawn the attention of inspectors. 
It is apparent from consideration of the fixed-wing and ground survey plots that the sensitivity of the fixed-wing survey was significantly poorer than the ground survey. This is not particularly surprising given the altitude and airspeed of the fixed-wing survey. It does point out that a large-area fixed wing survey, while being valuable to an OSI, would not rule out later detection of debris by ground-based methods.

It was an unfortunate turn of events that resulted in the helicopter survey system being unavailable for this survey due to aircraft maintenance activities. The helicopter could have flown at 70 knots at 150' altitude with twelve detectors versus the fixed wing at 140 knots at 500' altitude with 6 detectors. During planning for this effort, the project teams' aerial survey experts believed that the helicopter-borne survey instrument (twelve 2'x4"x16" $\mathrm{NaI}(\mathrm{Tl})$ detectors) would provide comparable sensitivity when compared to the ground-based vehicle survey using two $\mathrm{NaI}(\mathrm{Tl}) \operatorname{logs}$. Direct data for this comparison is not available from this test; a data set including both the ground survey and helicopter survey would be a worthwhile data set to collect in any similar future experiment.

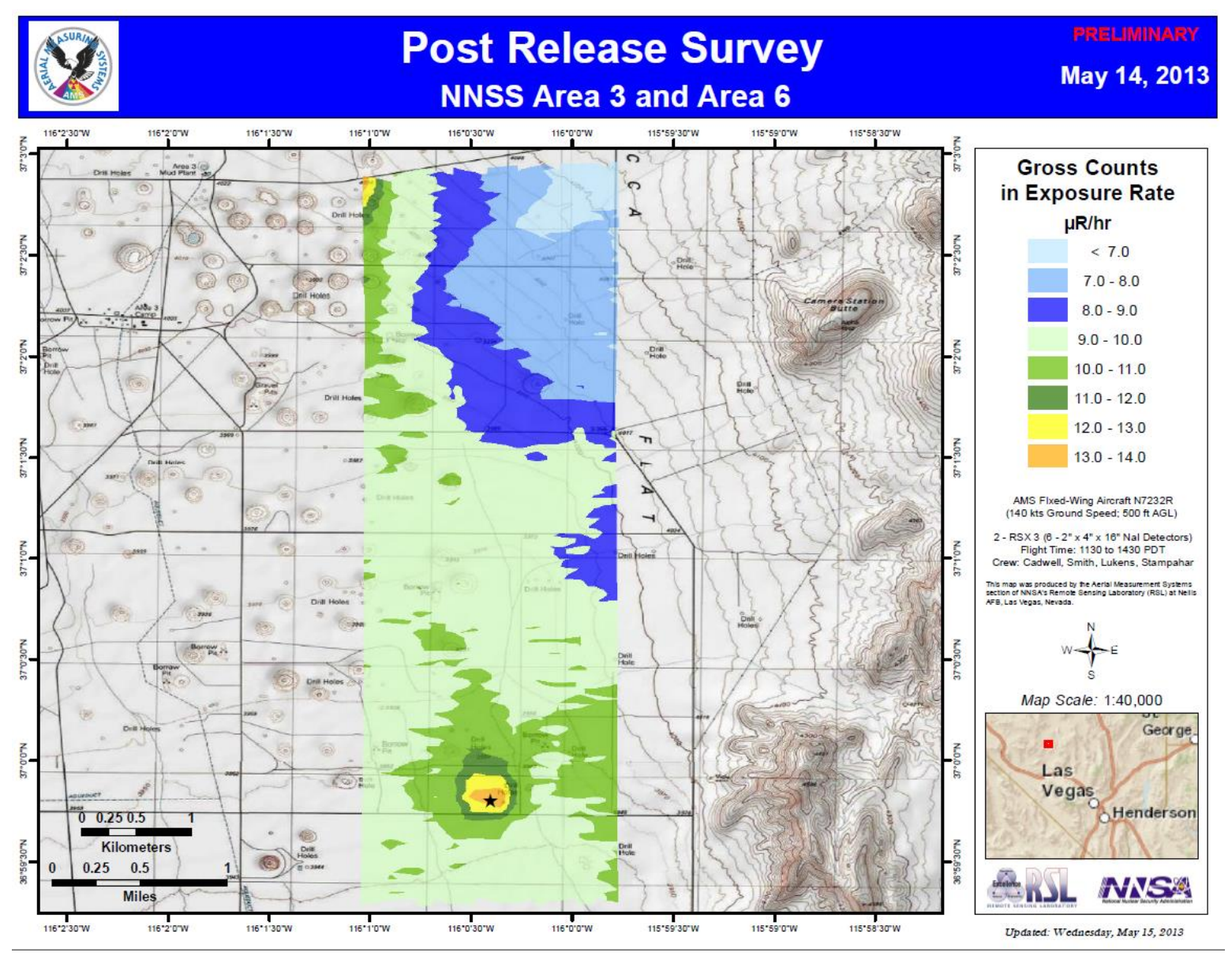

Figure 5.8: Aerial mapping product showing gross count exposure 


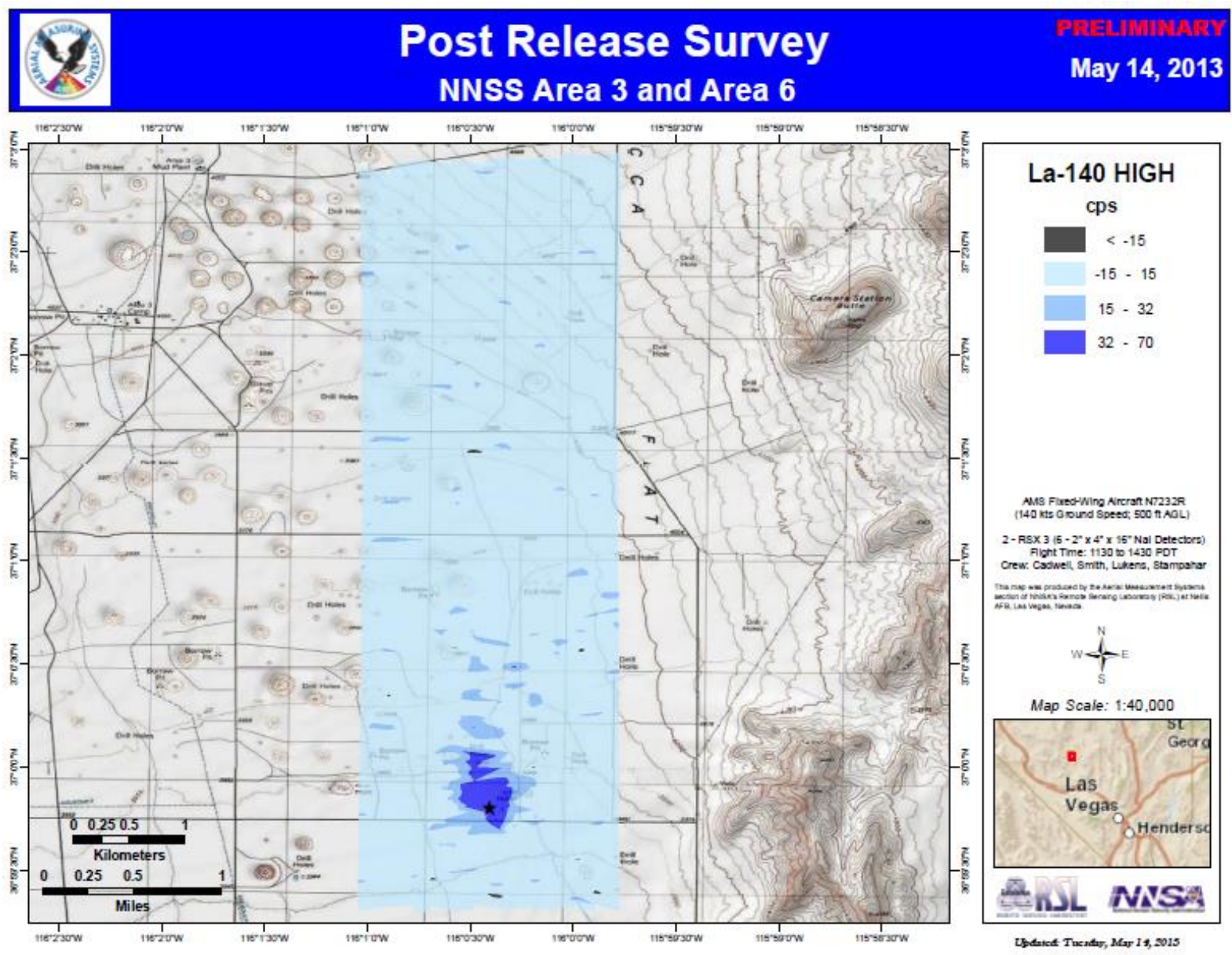

Figure 5.9: Aerial mapping product showing plume results using an ROI over the ${ }^{140} \mathrm{La} 1596-\mathrm{keV}$ line

\subsection{Results from Soil Sampling Methods}

There were three comprehensive sites where samples taken by placing tacky mats sticky-side-down on the ground (see Figure 4.6) resulted in measurable activity: 5-4, 7-3 and 10-5; with two such samples at the first two locations but only one at 10-5. As with the tacky mat witness plates, the deviations between samples were larger than the measurement uncertainties; and the deviations between samples were smaller for the strong activity site (5-4) compared to the weak activity site (7-3). The tacky mat samples measured activities of between 6-12\% of those of the initial witness plates in the same comprehensive sites, implying an order of magnitude reduction in the technique, relative to "ground truth." However, it would have been possible to apply the tacky mats to more than a single area to increase collection, which we did not do in the experiment. We estimate the technique could have been doubled in its collection before filling up the tacky mat with too much sample.

Soil samples were taken at two locations corresponding to tacky mat witness plates (where detections were noted): 5-4 and 10-5. In one of these locations (5-4) more than one soil sample was taken. In that case, the two samples agreed activity-wise to within $7 \%$. Taking into account that the tacky mats sampled an area 1.67 times that of the soil sample template, the soil samples measured activities between $15-20 \%$ 
of those of the initial witness plates, or "ground truth". However, it would have been possible to collect larger soil samples than was done with the template, which we did not do in the experiment. We estimate the technique could have been doubled in its collection before filling up the soil jars with too much sample.

Vacuum samples were taken at a number of locations corresponding to tacky mat witness plates (where detections were noted): 2-5, 5-4, and 6-3. Limited battery life prevented the taking of multiple samples at one location. Taking into account that the tacky mats sampled an area 1.67 times that of the vacuumed template, the vacuumed sample at 2-5 measured 10x the activity of the "ground truth" tacky mat witness plate while at the other two locations the vacuumed samples measured $10-15 \%$ of the activity. We do not have an explanation for the 2-5 results. We estimate the technique could have easily been increased a factor of 4-5 times in its collection area before acquiring a full sample, assuming the power and cross contamination issues are addressed.

Based on the above discussion, the soil and vacuum sampling techniques performed better in terms of collecting more recently-deposited surface activity for a given area than applying tacky mats. When one considers the amount of total recently deposited sample that can be collected, a vacuum approach is clearly favored. Drawbacks of the vacuum approach, however, include cross-contamination of equipment, and the ability to provide power to the equipment adequate to the time needed to take larger samples. Further thought and design is needed in terms of how to include sample filters in the vacuum cleaners. This technique would also be affected more so than soil samples if there were enough precipitation so as to remove the radionuclides from the surface. Soil sampling, even though it obtains much more soil depth than necessary for surface deposition, still provided reasonably robust samples in this experiment.

MDAs based on Canberra Genie 2000 reporting for the limit-value soil and inverted tacky mat samples indicated a typical range of $\sim 1 \mathrm{E}-04$ to $3 \mathrm{E}-04 \mu \mathrm{Ci}$, although some samples were found to have MDAs nearly an order of magnitude lower. Converting these to activity per unit area, based on the 18 "x 18 " sampling area, gives a range of $\sim 4.8 \mathrm{E}-04$ to $1.4 \mathrm{E}-03 \mu \mathrm{Ci} / \mathrm{m}^{2}$. Finally, assuming the $10-20 \%$ comparison for these sampling methods relative to the "ground truth" measurements of the large area witness plates gives a typical MDA range of $\sim 2.4 \mathrm{E}-03$ to $1.4 \mathrm{E}-02 \mu \mathrm{Ci} / \mathrm{m}^{2}$ detection sensitivity for samples brought to the field laboratory. Several of the field laboratory measurements of these samples indicated significantly lower MDAs.

\subsection{In-Situ Measurements}

Measurements with the $\mathrm{LaBr} 3, \mathrm{NaI}$ and HPGe handheld instuments were performed at a number of locations. These locations are shown in Figure 5.10 and Table 5-5. The conversion of the count rate in the $1596 \mathrm{keV}$ peak $\left({ }^{140} \mathrm{La}\right)$ to deposited activity is based upon MCNP simulation of the detection efficiency for each detector, calculated as described previously for the vehicle survey. The simulated source was based on a 40 meter radius disk. 


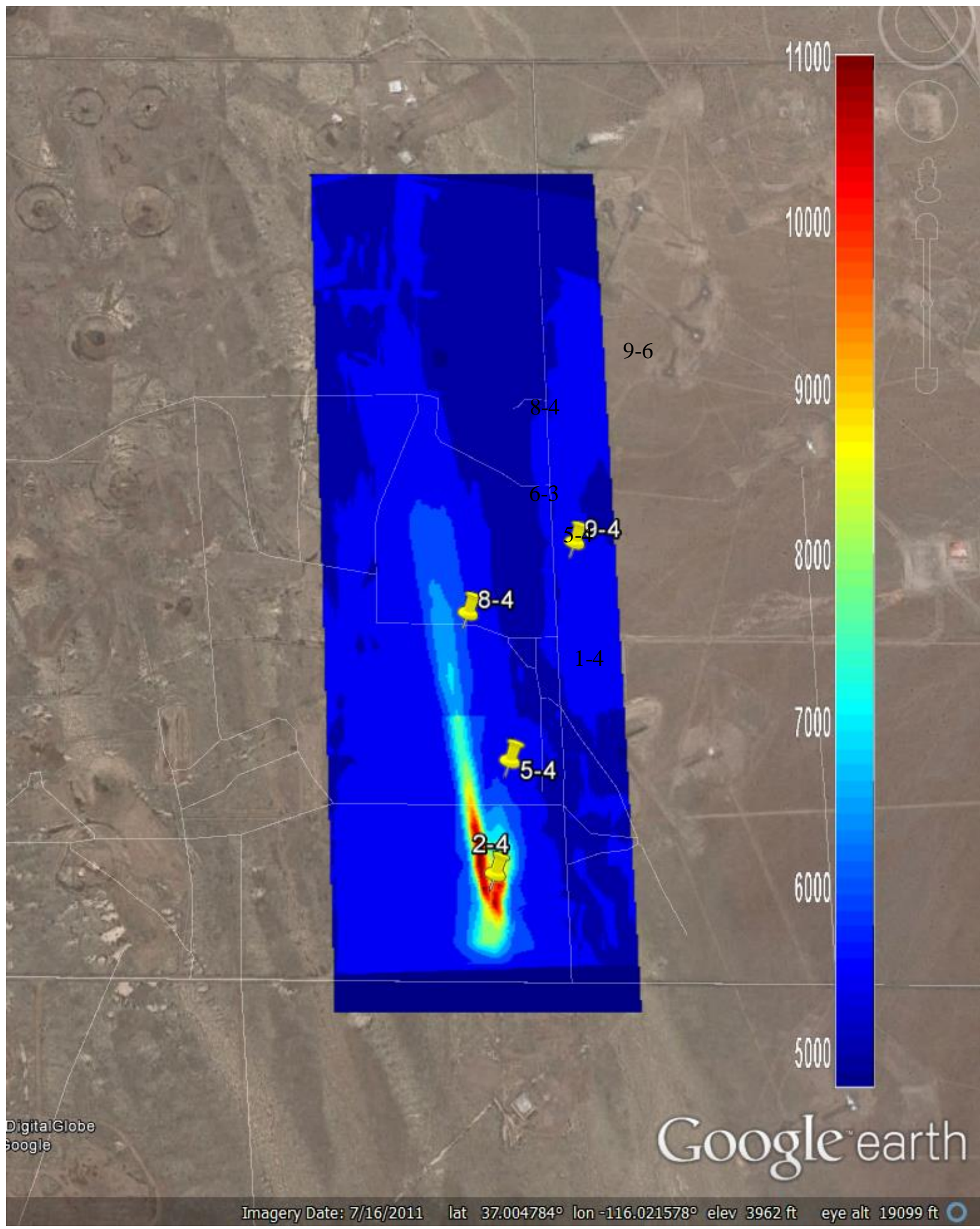

Figure 5.10: Locations of handheld instrument comparisons. 
PNNL-23997

Table 5-5: Comparison of deposited activity measured by different instruments

\begin{tabular}{|c|c|c|c|c|}
\hline $\begin{array}{l}\text { Sample } \\
\text { Location }\end{array}$ & $\begin{array}{c}\text { Nal } \\
\left(\mu \mathrm{Ci} / \mathrm{m}^{2}\right)\end{array}$ & $\begin{array}{c}\mathrm{LaBr3} \\
\left(\mu \mathrm{Ci} / \mathrm{m}^{2}\right)\end{array}$ & $\begin{array}{c}\text { HPGe } \\
\left(\mu \mathrm{Ci} / \mathrm{m}^{2}\right)\end{array}$ & $\begin{array}{c}\text { RSI } \\
\left(\mu \mathrm{Ci} / \mathrm{m}^{2}\right)\end{array}$ \\
\hline $2-4$ & $7.04 \mathrm{E}-01$ & $7.22 \mathrm{E}-01$ & $\begin{array}{c}\text { 5.01E-01 } \\
\text { Ortec }\end{array}$ & $7.50 \mathrm{E}-01$ \\
\hline $5-4$ & $1.01 \mathrm{E}-01$ & $9.35 \mathrm{E}-02$ & $\begin{array}{l}\text { 6.95E-02 } \\
\text { Canberra }\end{array}$ & $9.67 \mathrm{E}-02$ \\
\hline 8-4 & $9.74 \mathrm{E}-02$ & 1.22E-01 & $\begin{array}{c}8.83 \mathrm{E}-02 \\
\text { Ortec }\end{array}$ & 7.60E-02 \\
\hline $9-6$ & $<1.38 \mathrm{E}-02$ & $1.96 \mathrm{E}-02$ & $\begin{array}{l}\text { 1.81E-02 } \\
\text { Canberra }\end{array}$ & $<2.94 \mathrm{E}-02$ \\
\hline
\end{tabular}

Judging from the results of Table 5-5, it appears that there is a minor calibration issue between these various detectors, particularly with the HPGe detectors typically arriving at lower values when compared to the other instruments. In general, these instruments are in reasonable agreement.

Table 5-6 shows the Minimum Detectable Activities (MDAs) for the four portable detectors described in Section 5.4.2 for 10 minute measurements. The detectors were placed approximately $1 \mathrm{~m}$ above the ground in areas of active ${ }^{140}$ La contamination and spectra were acquired. Background counts in the $1596 \mathrm{keV}^{140} \mathrm{La}$ peak were determined from these spectra and those values were used in the Curie equation to determine the MDAs in milliCuries:

$$
M D A=\frac{4.65 * \sqrt{N_{B}}+2.71}{\gamma * \mathcal{E} * T * 3.7 e 4\left(\frac{B q}{\mu C i}\right)}
$$

where $\mathrm{N}_{\mathrm{B}}$ is the background count rate, $\gamma$ is the branching ratio (0.954), and $\varepsilon$ is the detection efficiency. Detection efficiency was determined by MCNP modeling over a uniform $40 \mathrm{~m}^{2}$ ground deposition. Although this does not represent a perfect model, at the distance it was clear that the model's detection count rate was approaching an asymptotic value, as one would expect due to distance and atmospheric attenuation. The efficiency values are shown in the table. Since these are roughly comparable for the four detectors, the background count rates in the detectors were the primary differentiator in the MDAs achieved by the detectors. The background count rates relate to the resolution of the detectors since smaller peak-widths result in lower background count rates. Utilizing MCNP again, these point source MDAs, in units of $\mu \mathrm{Ci}$, were converted to equivalent infinite plane source MDAs in units of $\mu \mathrm{Ci} / \mathrm{m}^{2}$. These values are also shown in Table 5-6. The Canberra HPGe handheld has an MDA nearly an order of magnitude more sensitive than the scintillator-based handheld detectors. The reader is reminded that the RSI survey MDA reported in Section 5.1.1.4 was found to be $2.94 \times 10^{-2} \mu \mathrm{Ci} / \mathrm{m}^{2}$ for a 1 second measurement, reflecting the much larger NaI detectors in that survey system. 
Table 5-6: Table of MDAs for four detectors at $1 \mathrm{~m}$ height in terms of an infinite plane (modeled as a uniform disk source 40 meters in diameter) for 10-minute acquisition times of ${ }^{140} \mathrm{La}$ 's 1596 keV Peak.

\begin{tabular}{ccc}
\hline Detector & $\varepsilon$ (Efficiency) at $1596 \mathrm{keV}$ & $\mathrm{MDA}\left(\mu \mathrm{Ci} / \mathrm{m}^{2}\right)$ \\
\hline FLIR Nal & at $1596 \mathrm{keV}$ & $\mu \mathrm{Ci} / \mathrm{m}^{2}$ \\
\hline Ludlum LaBr & $3.98 \mathrm{E}-08$ & $1.38 \mathrm{E}-02$ \\
Ortec HPGe & $5.25 \mathrm{E}-08$ & $1.24 \mathrm{E}-02$ \\
\hline Falcon HPGe & $3.51 \mathrm{E}-08$ & $3.65 \mathrm{E}-03$ \\
\hline
\end{tabular}

Comparing the sensitivities of the in-situ techniques reported in Table 5-6 to the soil sampling/field laboratory measurements discussed in the previous section indicate that the most sensitive "typical" range of soil measurements was comparable to the HPGe in-situ sensitivity, while the less sensitive "typical" range was comparable to the scintillator in-situ sensitivity. The most sensitive MDA results for field laboratory measurements were more sensitive than the in-situ systems. In general, it appears that the sensitivities are roughly comparable, so that operational considerations would drive selection of the techniques to emphasize for a given OSI scenario. For the PRex exercise, the authors believe that significantly more samples could be collected and measured in the field laboratory, when compared to the process of setting up and acquiring in-situ measurements in the field.

\subsection{Comparison of Plume Modeling to Radiometric Results}

Post-analysis of the release was performed using Hotshot 9 (Homann, 1994) using observed weather data, and using a source injection height of 30 feet. The modeled and surveyed plume directions are in agreement, although the lobe that extends in a more northerly direction is not indicated in the model. It appears likely that this lobe was created by dispersal of material from the release point at a later time, after the winds shifted more northerly.

Figure 5.11 shows deposition contours that are modeled when a source release of $1 \mathrm{Ci}$ is assumed. These contours indicate that the measurable plume would have extended significantly further downwind had the full source been released. For example, the RSI survey instrument was previously reported to have an MDA of $\sim 3 \mathrm{E}-02 \mu \mathrm{Ci} / \mathrm{m}^{2}$ for each 1 second interval. This indicates that the RSI survey would have been capable of measuring the plume beyond the extent of the green contour in Figure 5.11. The following figure (Figure 5.12), shows deposition contours based on a $0.07 \mathrm{Ci}$ release, or the $7 \%$ release calculated based on integration of the RSI ground survey data (paragraph 5.1.1.3). This Hotshot simulation of deposition of the particulate $\mathrm{La} 2 \mathrm{O} 3$ is much more consistent with the measured ground deposition, although the measured plume does appear to be narrower than the modeled plume. This is likely due to the short duration of the release: the model integrates over a 10 minute period. 


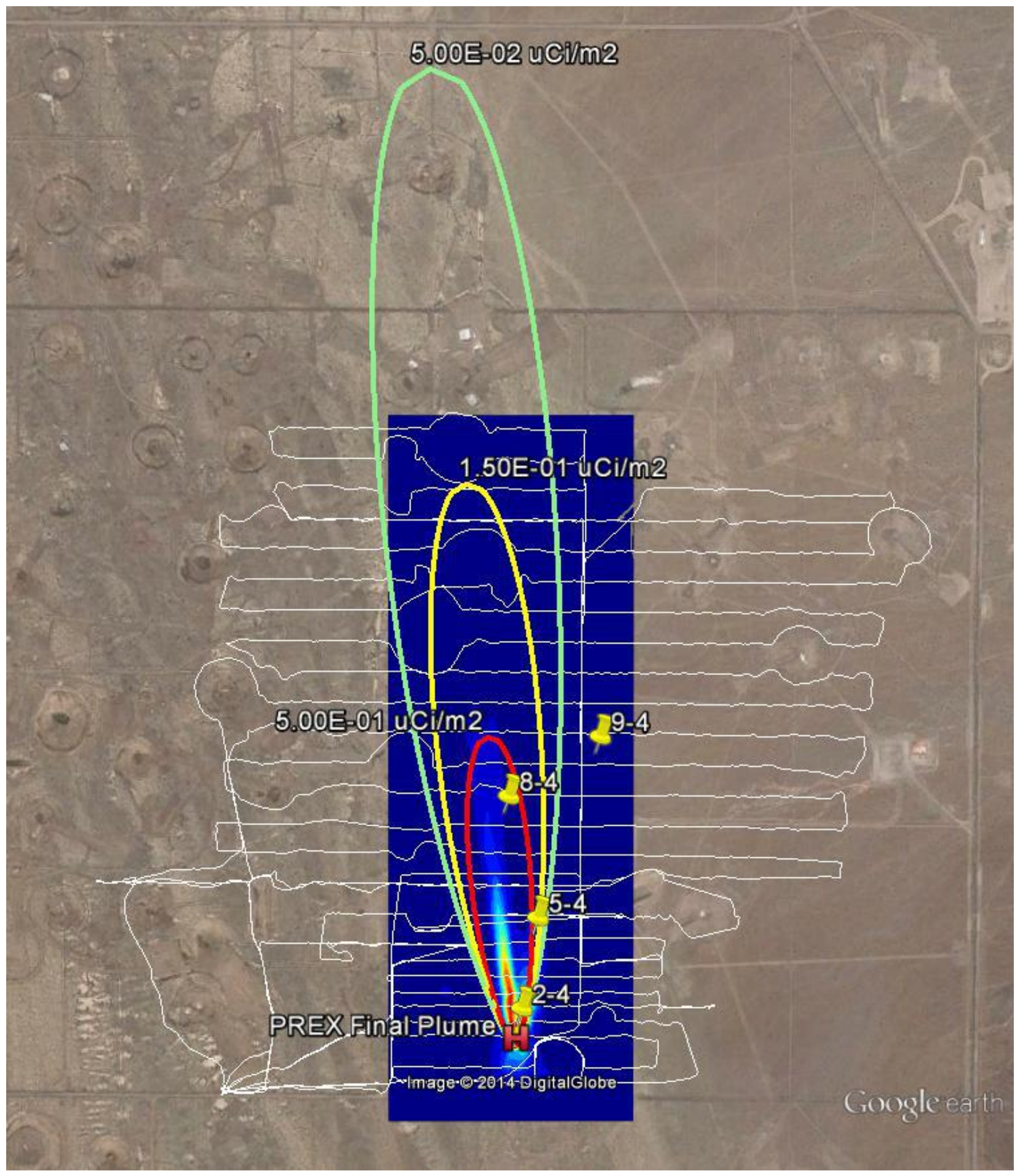

Figure 5.11. Hotshot plume post-analysis assuming a $1 \mathrm{Ci}$ release. The contours based on Hotshot indicate that the measurable plume would have extended further downwind if the full $1 \mathrm{Ci}$ had been released. 
PNNL-23997

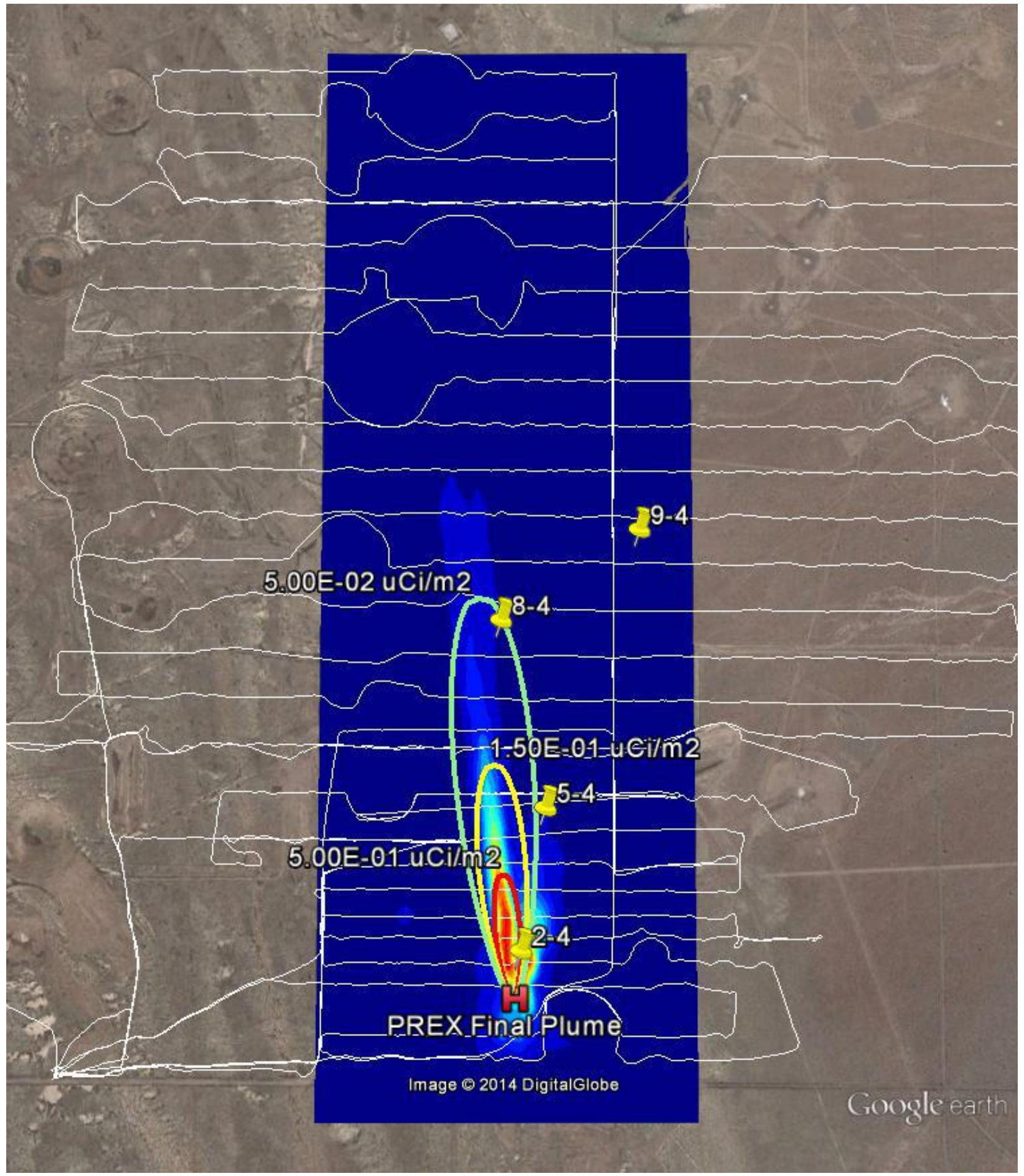

Figure 5.12: Hotshot plume post-analysis assuming a $0.07 \mathrm{Ci}$ release. The yellow push-pin markers correspond to the in-situ measurement results provided in Table 5-5. The in-situ measurements are generally in good agreement with the Hotshot contours. 


\subsection{Optical Witness Plate Results}

The objective to study short distance dispersion and fallout of lofted particulates benefits from detailed knowledge of a number of important metrics. Knowledge of the size, shape and density of the particle to be studied is perhaps the most fundamental starting point. Lofted elevation, followed by environmental metrics including wind speed, turbulence, solar radiation, humidity, ambient particulate density and character, and even ground terrain and foliage become important factors. This project strived to characterize these parameters for Lanthanum Oxide powder that had been physically sieved and graded to meet a size range around $40 \mu \mathrm{m}$. Once activated, the dispersion of this material could be detected with radiation monitoring techniques. Some of these detection techniques, like the airborne detection systems, would provide relatively low resolution indications of where the particles deposited on the ground. Ground level radiation scans provide higher spatial resolution, and witness plates counted in the laboratory provide specific spot information. Unfortunately, the spread of radioactive material to perform these type of particulate dispersion surveys has inherent risks and certain unavoidable expense.

It was thought that if one could substitute non-radioactive particles that could be distinguished from ubiquitous natural airborne particulate debris, that this substitute method could complement, or fully replace the need to spread radioactive particulate for some future transport studies. Since the vast majority of natural airborne soil is amorphous in shape, aluminosilicate glass microspheres were proposed as a substitute particulate form. Aluminosilicate glass can be formulated with a range of densities, allowing an approximate match to the average soil density of the Nevada desert. The aluminosilicate microspheres can also be effectively graded to narrow size ranges by commercial manufactures. The dispersion of multiple tightly controlled microsphere sizes would allow researchers to study, in a more ideal way, the short range transport properties of fine particulate material.

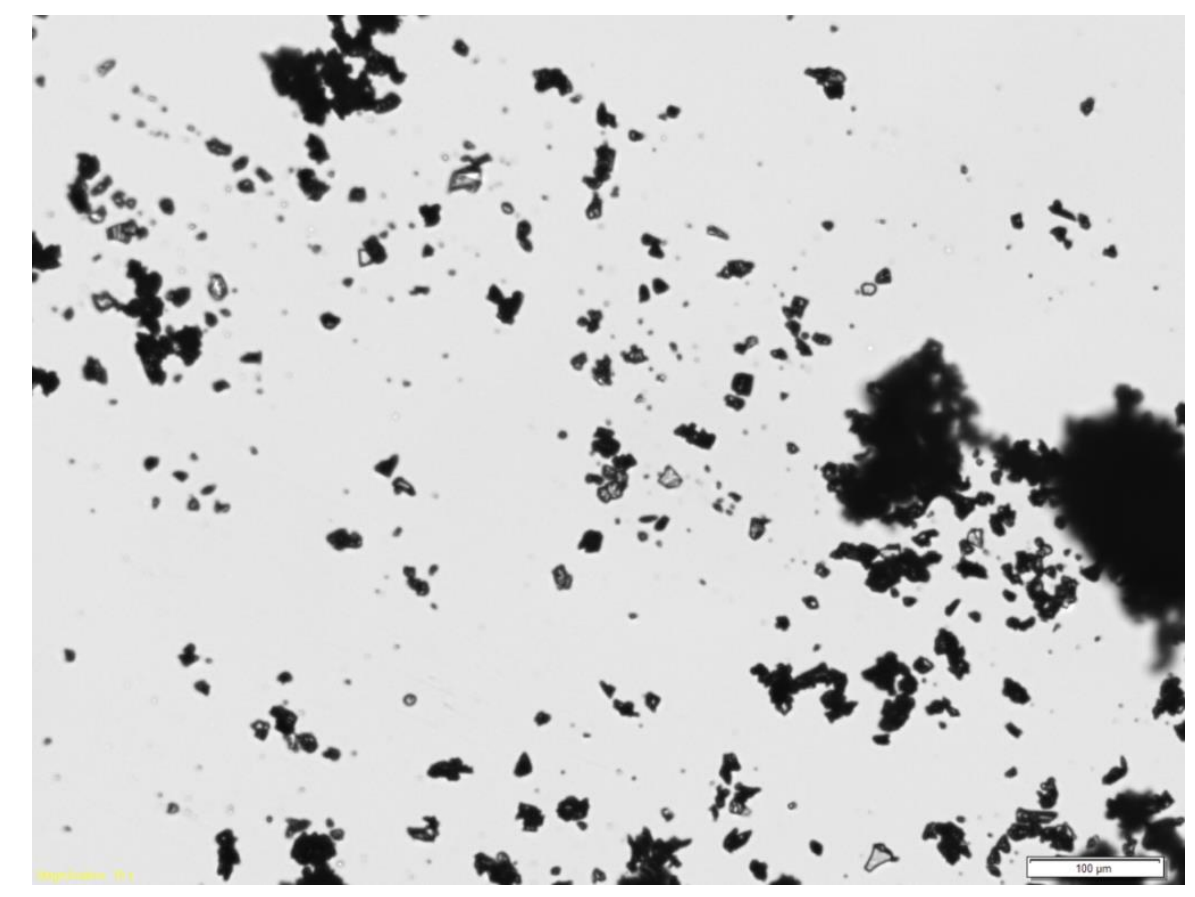

Figure 5.13: Lanthanum oxide powder's generally amorphous shape is visually indistinguishable from ubiquitous desert airborne particulate. 
The main challenge when using microspheres for particulate fallout studies is the detection of these spheres after they have deposited on the surface. The use of object recognition software combined with optical microscopy was suggested and investigated. In the laboratory, microspheres were applied to glass microscope slides and examined visually. A variety of light settings were tried and some of the better results are shown in the following figures. Olympus "Stream" image analysis software was used to color enhance the micrographs and to identify the particles. Software filters included metrics like: edge detection, edge smoothness, edge sphericity, color, grey scale, contrast gradient, major and minor axis comparison, overall area, radial continuity, and edge segment continuity. The software has the ability to automatically scan an entire $5.08 \mathrm{~cm} \times 7.62 \mathrm{~cm}(2$ " $\times 3$ ") slide and tally the number of microspheres; each logged in a table that describes the objects characteristics, including diameter - in about 20 minutes. Careful selection of filter metrics allows the software to accurately identify most of the microspheres. However, in every case tested, some microspheres were either missed, or foreign objects were included in the total count. This was confirmed by manual scans of the test slides and collected micrograph imagery. Through this investigation, we found that a slide can be manually scanned with near $100 \%$ accuracy in about the same time required for the automated software. However, the laborious manual scanning process unacceptably manpower-intensive. The best approach found for this work was to auto-scan the slides with the "loose" filter settings that locate all spheres, as well as some additional particles. The microscope software provides a function to sequentially return the stage to each object identified in the automated scan. This function was used to perform a manual "human" confirmation of each particle. This procedure saves a significant amount of eye strain on the technician, and adds 5-10 minutes to the analysis of each slide. Although this project allowed us to discover a promising technique for future slide scans, budget constraints kept us from perfecting the method and scanning the bulk of the witness plates.

In this project, we released approximately $1 \mathrm{~kg}$ of $41 \mu \mathrm{m}$ "Isospheres" purchased from XL Sci-Tech. These aluminosilicate glass microspheres were released simultaneously with the radioactive lanthanum oxide powder. The microspheres were released from a hopper, falling through a tube into the air intake region below the "air cannon." This process worked well in testing prior to the actual PRex event, however there was no on-board measurement capability to determine the exact injection profile or mass of microspheres that were successfully released into the airstream. This is a deficiency that should be corrected in any future test.

The $5.08 \mathrm{~cm} \times 7.62 \mathrm{~cm}(2 " \times 3$ ") microscope slides were used as optical witness plates, as described earlier, and pictured in Figure 3.25. Microsphere fallout density based on "Hotspot" and Gaussian model distribution calculations predicted that these witness plates would collect on the order of 20 to 300 microspheres each if centered along the downwind axis under the fallout plume. A manual microscope survey of about 20 center axis downwind witness plate slides revealed microsphere counts of between zero and five microspheres per slide as shown in Table 5-7. 
Table 5-7. Beads collected by Optical Witness Plates at Various Sampling Locations. Figure 3.23 shows the layout of the sampling locations; the first digit indicates the row, starting from row 0 at the south end of the array. The second digit indicates the sampling location starting from position 1 at the west end of each row. Appendix B also provides the coordinates for each location.

\begin{tabular}{|c|c|}
\hline Slide & Bead count \\
\hline $2-4$ & 11 \\
\hline $3-4$ & 4 \\
\hline $3-6$ & 3 \\
\hline $4-1$ & 0 \\
\hline 4-2 & 0 \\
\hline $4-5$ & 1 \\
\hline $4-6$ & 3 \\
\hline $4-8-4$ & 2 \\
\hline $4-9$ & 1 \\
\hline $5-4-1$ & 0 \\
\hline $5-4-2$ & 2 \\
\hline $5-4-3$ & 0 \\
\hline $5-4-4$ & 0 \\
\hline $5-4-5$ & 1 \\
\hline $6-3$ & 5 \\
\hline 7-3-1 & 0 \\
\hline $7-3-2$ & 1 \\
\hline $7-3-3$ & 0 \\
\hline $7-4$ & 2 \\
\hline $8-5$ & 1 \\
\hline $9-2-1$ & 1 \\
\hline $9-2-2$ & 0 \\
\hline $9-4$ & 1 \\
\hline
\end{tabular}


The low count statistics on these slides did not allow us to make a detailed correlation between the radiation measurements and the optical counting results. However, it does appear that the bead detections were consistent with the plume seen by radiation measurements. In particular, those sampling slides showing the two highest numbers of beads, 2-4 and 6-3, correspond to the tacky mats showing the highest measured radioactivity (see Appendix B) of the locations in the table above. It was found that microspheres were successfully released, transported, collected, and subsequently measured via optical microscopy. We saw no evidence that microspheres were "lost" once collected on the plates. The clear adhesive surface presented to the microspheres seemed to hold them in place - even after significant agitation while upside down and on edge. Visual inspection with the microscope along the edge frame of the collection plates showed no "collection" of microspheres that may have released from their initial deposition location. Likewise, no microspheres were found on the cover plates that were placed over the witness plates before they were moved from their field location. This indicates that the method would likely have been more successful (higher counting statistics) if a larger number of microspheres had been released during the test.

The general technique using microspheres to provide well defined parametric study of short range particle deposition showed promise, however additional instrumentation is needed to provide satisfactory results. As with the radioactive particulates, a mechanism that provides a detailed record of the release (e.g. mass per time) should be implemented. A greater number of witness plates would enhance the resolution of results and hopefully guarantee that the deposition would be detected, no matter how narrow the plume. Testing without the time restrictions associated with short half-life radioisotopes would allow staff to release during the most favorable wind and weather conditions. Further investigation into the optimization of microscope optics, lighting conditions, and image analysis software is also needed to efficiently count microspheres on witness plates. Examples of methods developed during this work are provided in Figure 5.14 through Figure 5.18. The use of florescent or colored microspheres would also significantly enhance the ability of image analysis software to identify the correct objects and count them with certainty. 
PNNL-23997

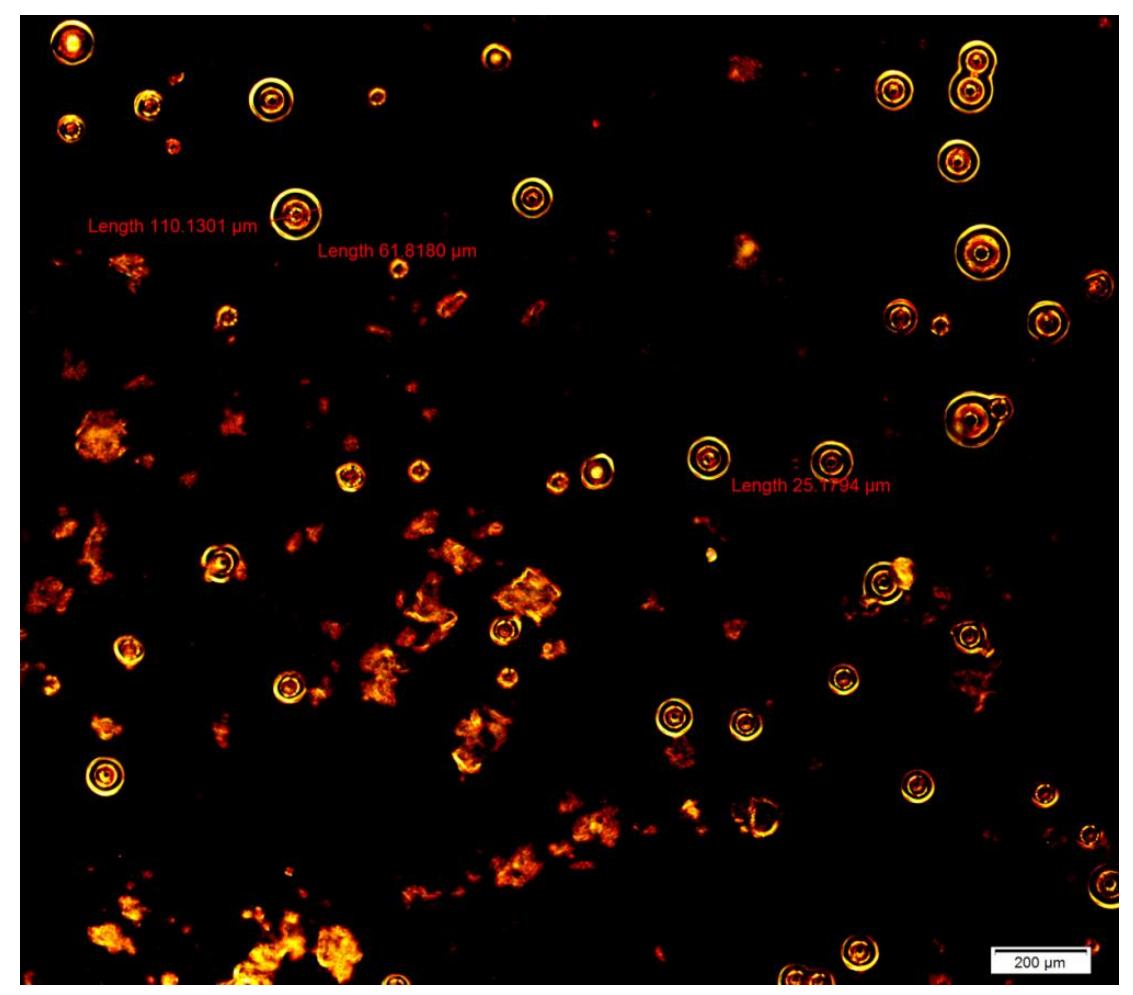

Figure 5.14: A color-enhanced micrograph of aluminosilicate glass microspheres on a test slide similar to the witness plates deployed during the NCNS test. Concentric rings around each sphere are the result of dark field lighting; and create a unique visual signature for the microspheres compared to other debris also shown.

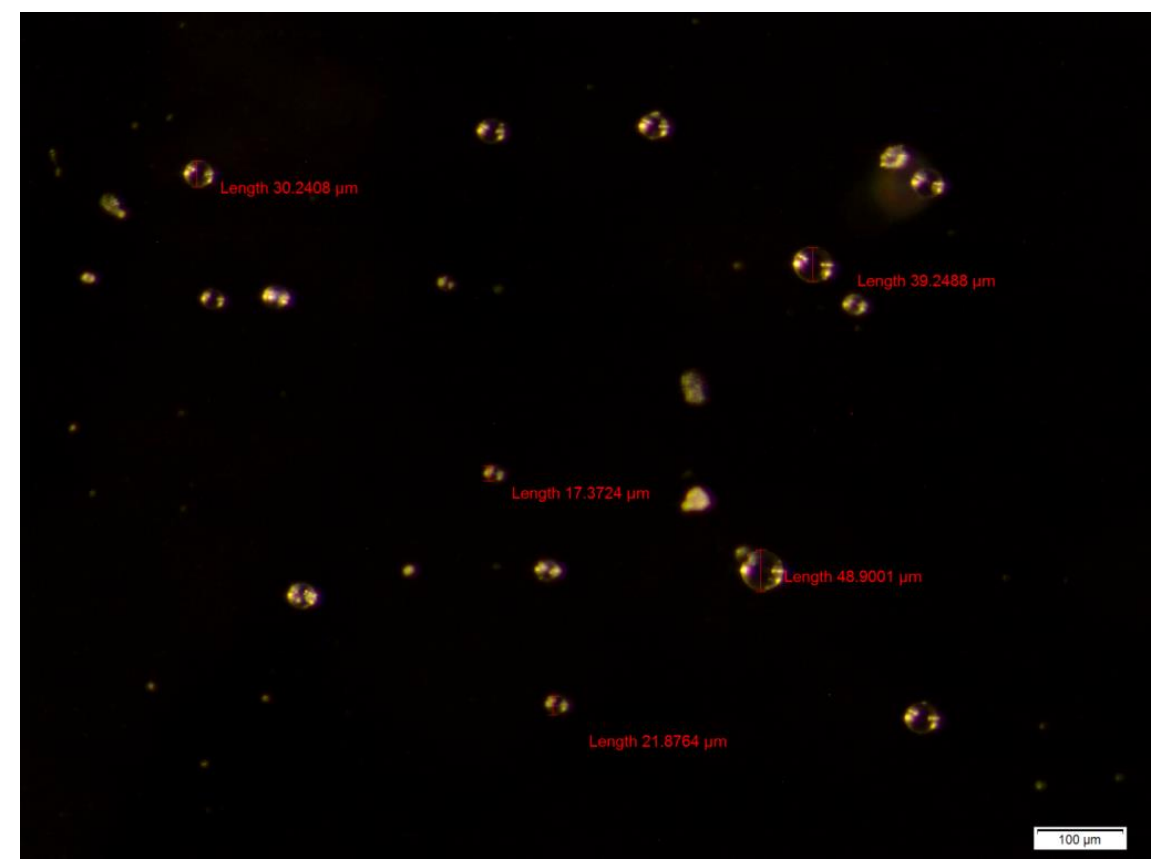

Figure 5.15: Micrograph of aluminosilicate glass microspheres in dark field illumination without color enhancement 


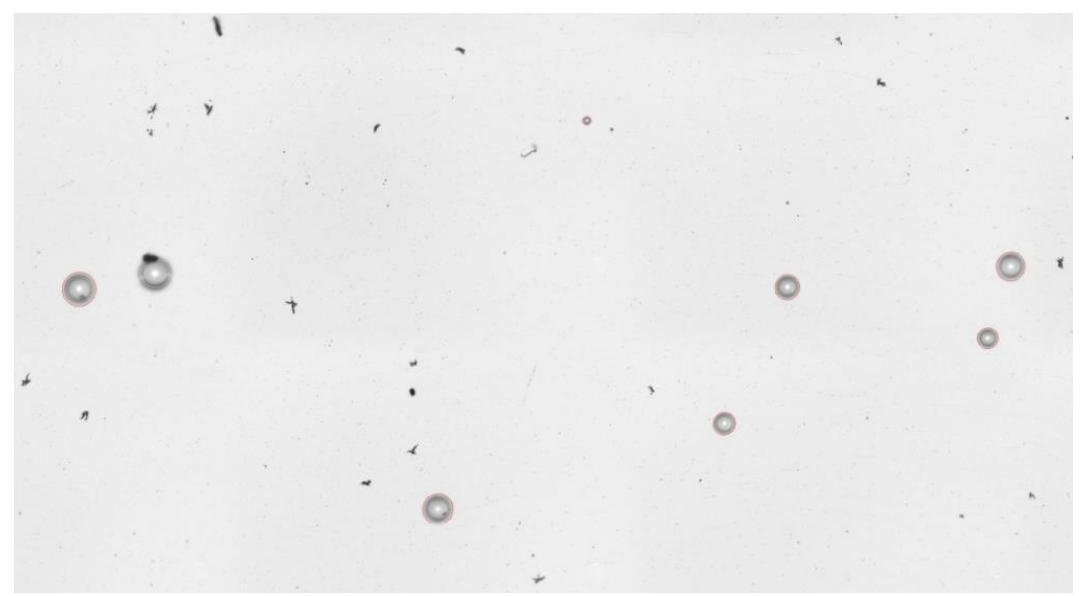

Figure 5.16: Micrograph with bright field illumination of microspheres shown with red outlines indicating identification by image recognition software. It is difficult to see the red outlines in this image, however the software has identified all of the microspheres in this field of view with the exception of the large sphere second from the left. This sphere has agglomerated with another particle which prevented identification. Software filters can be set to be more tolerant of such interferences, but those settings can also lead to false identifications.

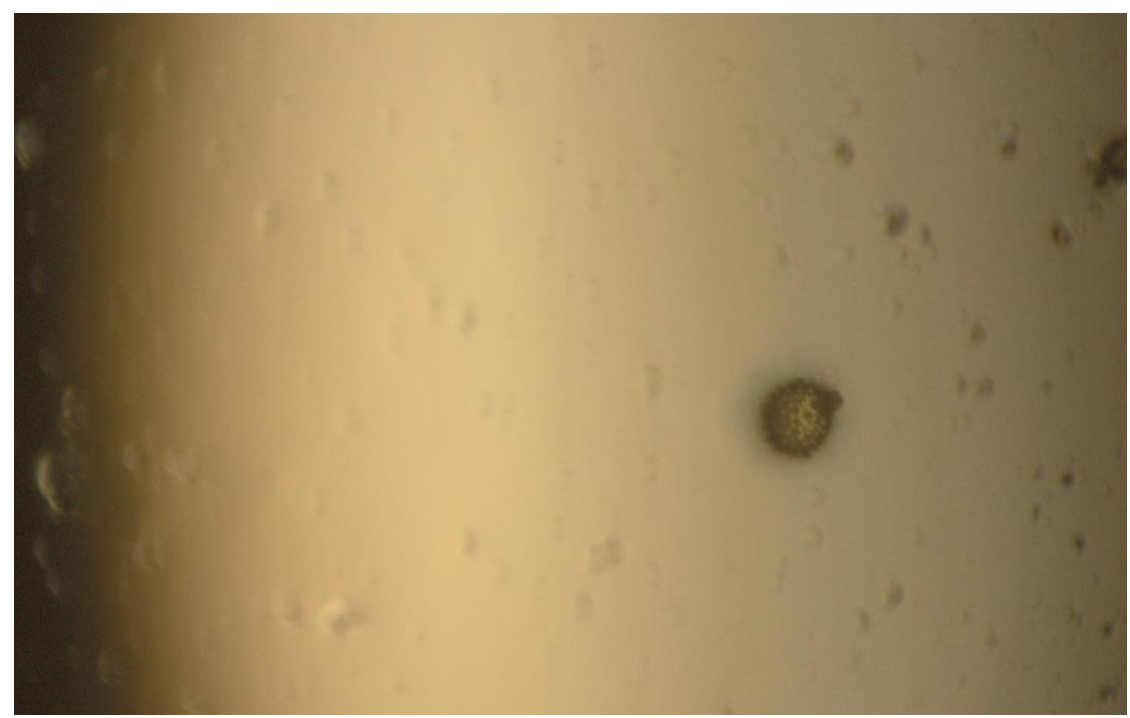

Figure 5.17: Micrograph showing a roughly spherical pollen particle roughly the same size as tested microspheres. This type of "background" particle, in certain microscope lighting conditions, may be mistakenly identified by the image analysis software as a microsphere. 


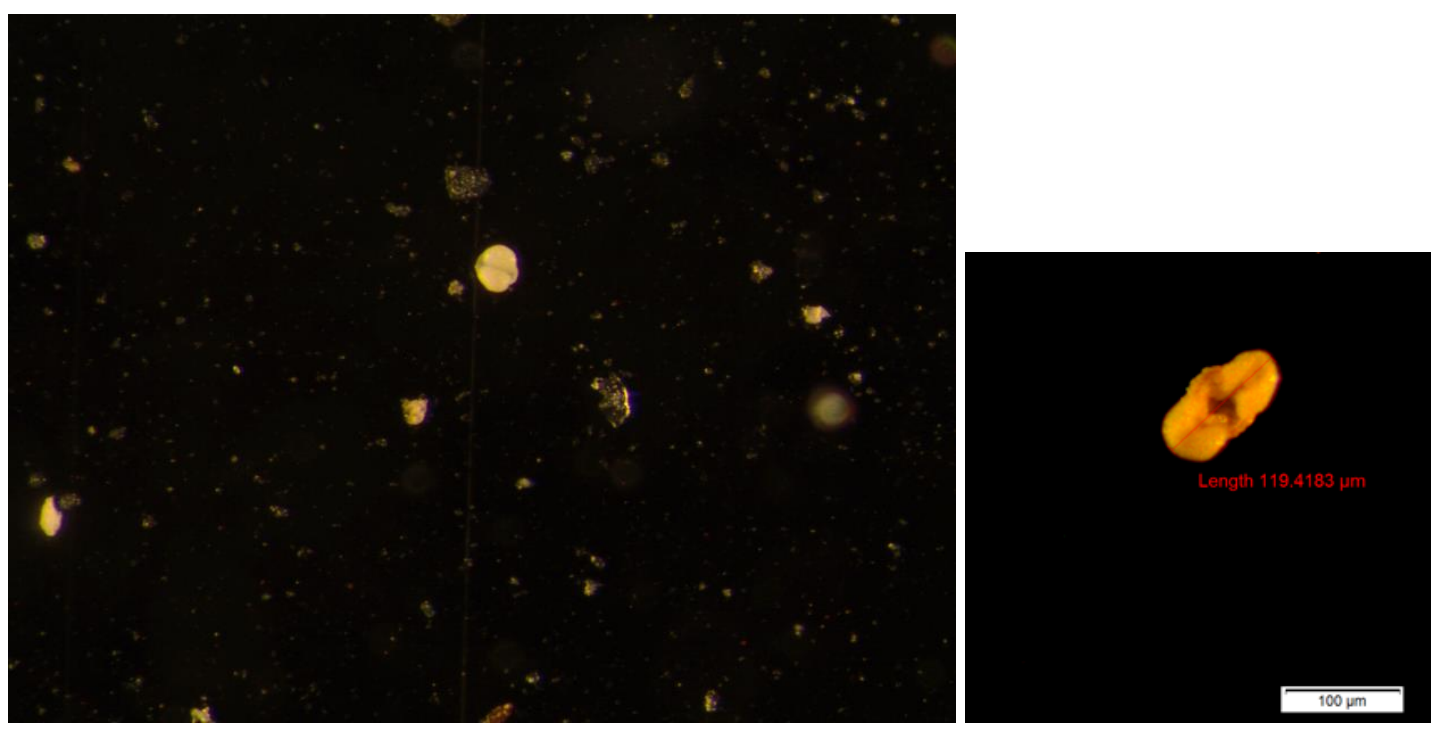

Figure 5.18: Left - Unidentified biological object. The outline of these bifurcated objects is easily confused with a spherical object. They exhibit similar light reflections and circular outline as microspheres. Right - Over the course of weeks, these objects were observed to "grow" from generally circular to distinct two "pedal" forms.

\subsection{Air Sampling Results}

The highest activity air sample of ${ }^{140}$ La was collected by a gas high volume sampler at $2 \mathrm{~km}$ which is in the path of the narrow plume trajectory measured by ground surveys. This sample (furthest east) is at least 33 times higher than the other three high-volume gas samplers located at $2 \mathrm{~km}$. The next most active air sample of ${ }^{140}$ La was collected by a battery powered high-volume sampler at $0.5 \mathrm{~km}$, also in line with the observed ground deposition. All of the high-volume air samples collected during the period of the release resulted in positive collections. 


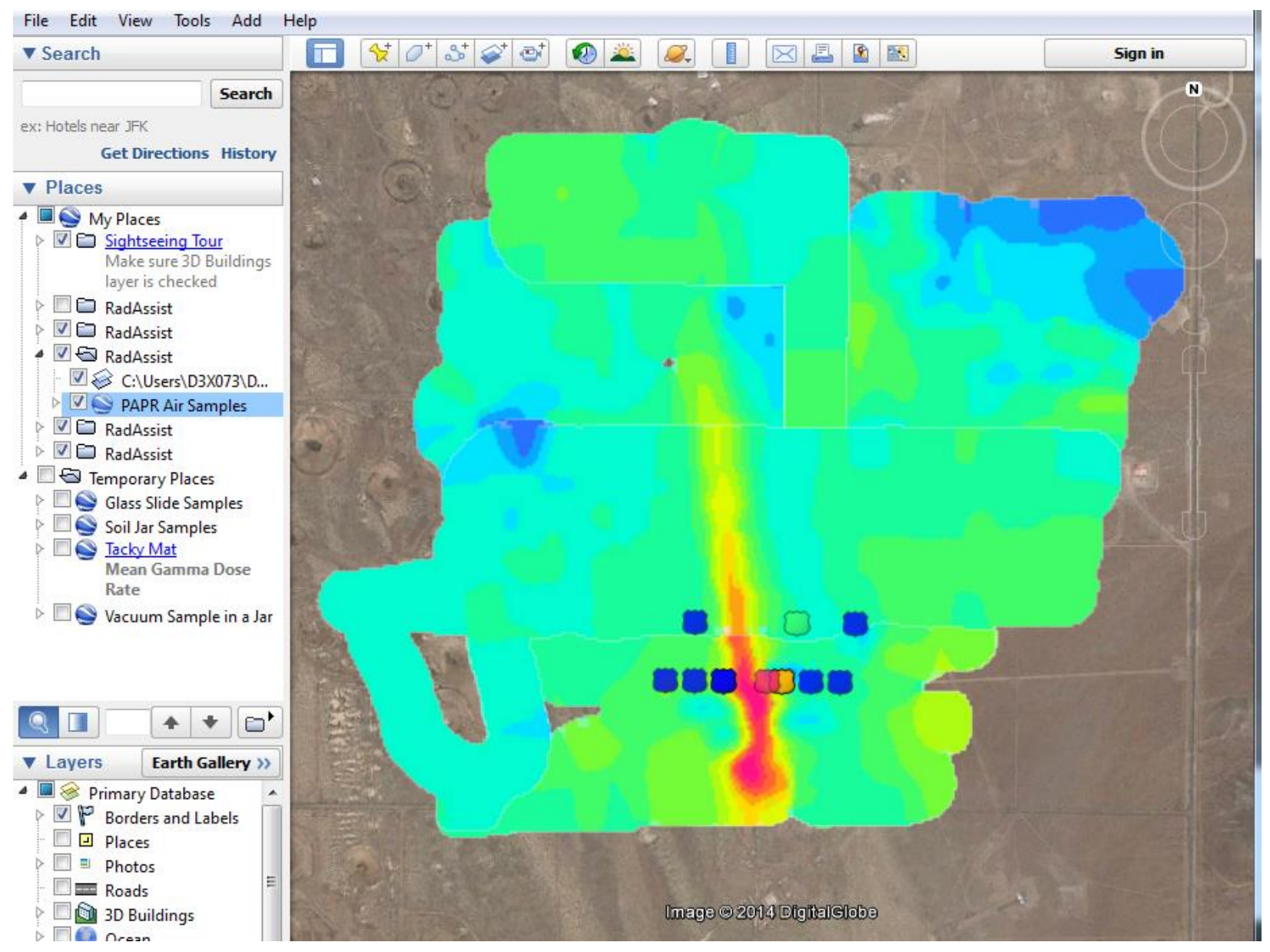

Figure 5.19: PAPR Air Sampler collections were consistent with the vehicle ground survey. Background image provided by Google Earth.

The high volume gas samplers were restarted at $10 \mathrm{a} . \mathrm{m}$. on the day following the release. None of the samples collected on May $15^{\text {th }}$ resulted in positive detection of ${ }^{140} \mathrm{La}$. The wind direction was generally the same as on the day of release but the average speed was $3 \mathrm{~m} / \mathrm{s}$ less than observed during the afternoon of the release $(10 \mathrm{~m} / \mathrm{s}$ vs. $7 \mathrm{~m} / \mathrm{s})$. The maximum wind speed observed for each 15 -minute interval is also shown in Figure 5.21. There were ten maximum wind speed events greater than $14 \mathrm{~m} / \mathrm{s}$ on May $14^{\text {th }}$, but only one event approaching $12 \mathrm{~m} / \mathrm{s}$ on the second day. The observed lower wind speeds, combined with the large particle sizes, are most likely responsible for the lack of detectable lanthanum on the filters run for resuspension on May 15. 
PNNL-23997

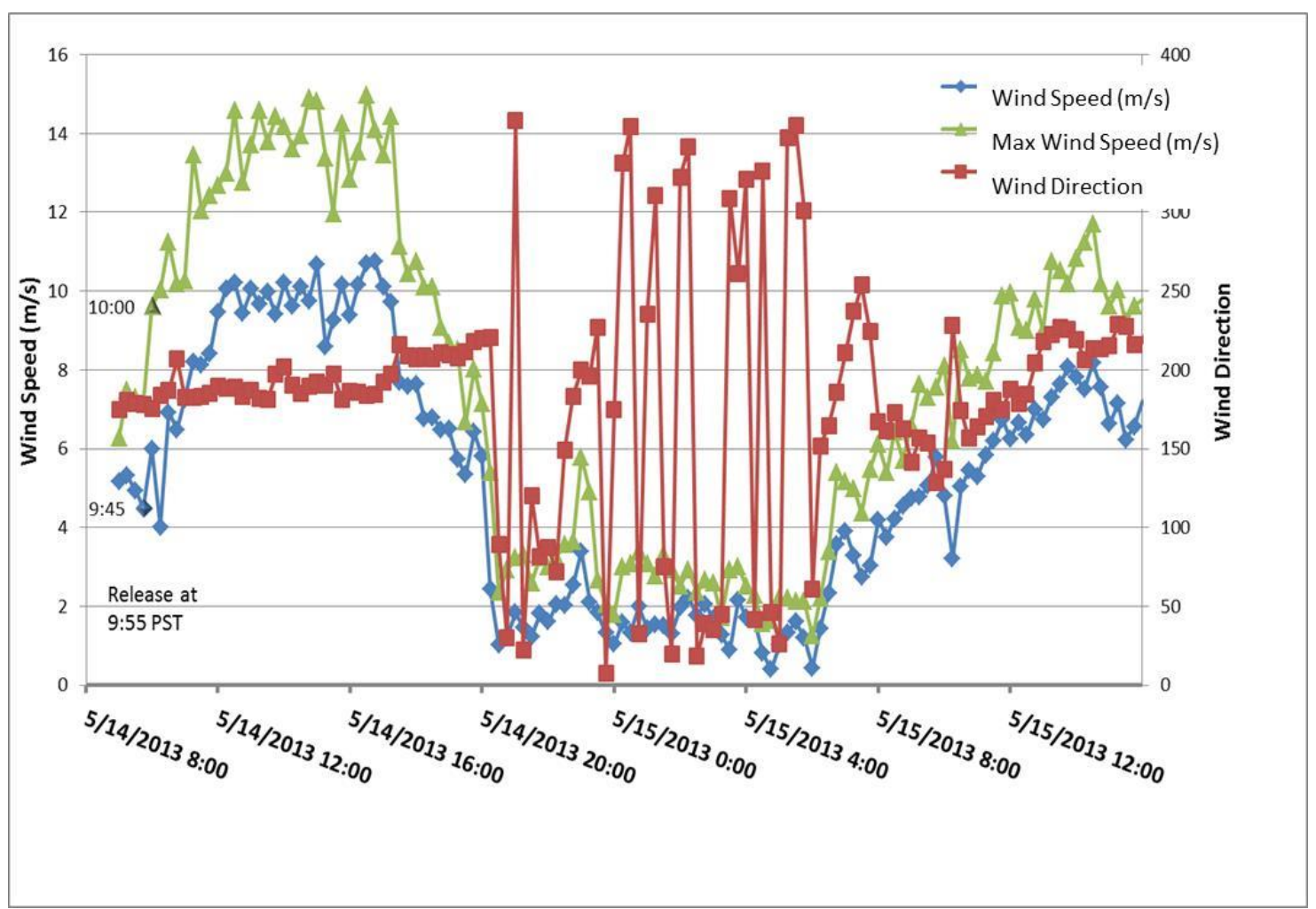

Figure 5.20. Meteorological data from the weather station immediately south of the release point

The wind direction data in Figure 5.20 are not detailed enough to show the variation in wind direction occurring immediately prior to the source release. Screen capture images of two-second interval meteorological data was captured over the radio link from approximately 10 minutes before and after the release (Figure 5.21). The gap in data is the result of reconfiguring the radio network to connect to and activate the radio-controlled, battery-powered samplers located $1.5 \mathrm{~km}$ down range. Figure 5.21 shows that the wind speed and direction varied during the time period leading up to the release, with lower wind speeds associated with south-south-westerly winds, and higher wind speeds associated with south-southeasterly winds (observed during release). The wind direction variation shown in Figure 5.21, particularly right around the time of the source release, is consistent with the two-lobe plume deposition depicted in Figure 5.3 and Figure 5.4. 


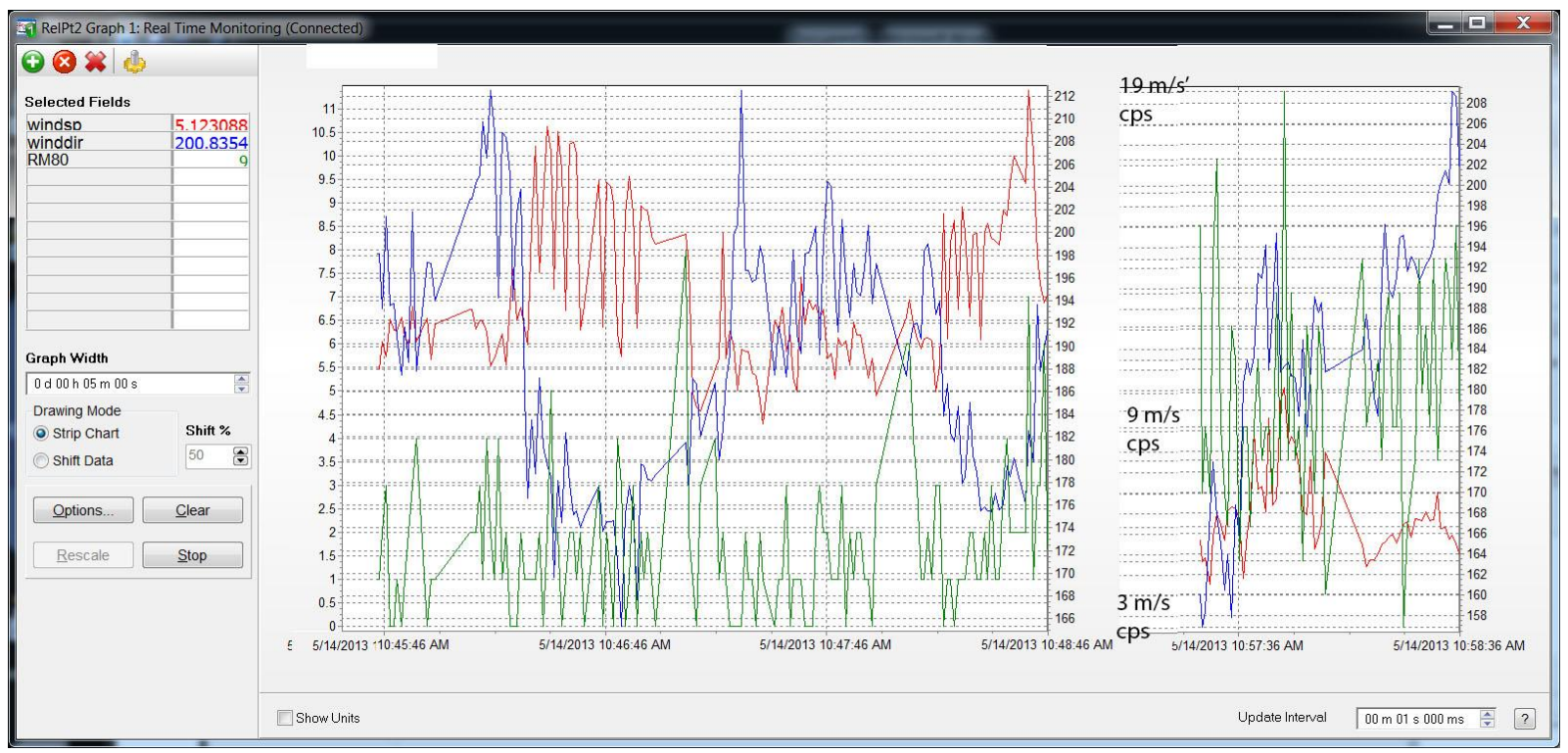

Figure 5.21. Meteorological data captured from the weather station immediately south of the release point.

A simple, low-cost Geiger-Mueller (GM) gamma detector was placed at the approach fence boundary approximately $10 \mathrm{~m}$ up wind from the release point. The background count rate before the lid was removed was approximately $1 \mathrm{cps}$. After the release, the gamma count was approximately $12 \mathrm{cps}$. A second RM-80 gamma detector was placed adjacent to the filter of the battery-powered large volume sampler at $1.5 \mathrm{~km}$ (grid 10-6). The recorded count rate at 1-minute intervals is shown in Figure 5.22. A box car filter was run to generate the smoothed red line showing an increase in the count rate approximately one minute after the sampler was activated. An outflow prop anemometer shows the voltage increasing to $12 \mathrm{mV}$, equivalent to a flow of $1000 \mathrm{CFM}\left(28.3 \mathrm{~m}^{3} / \mathrm{min}\right)$.

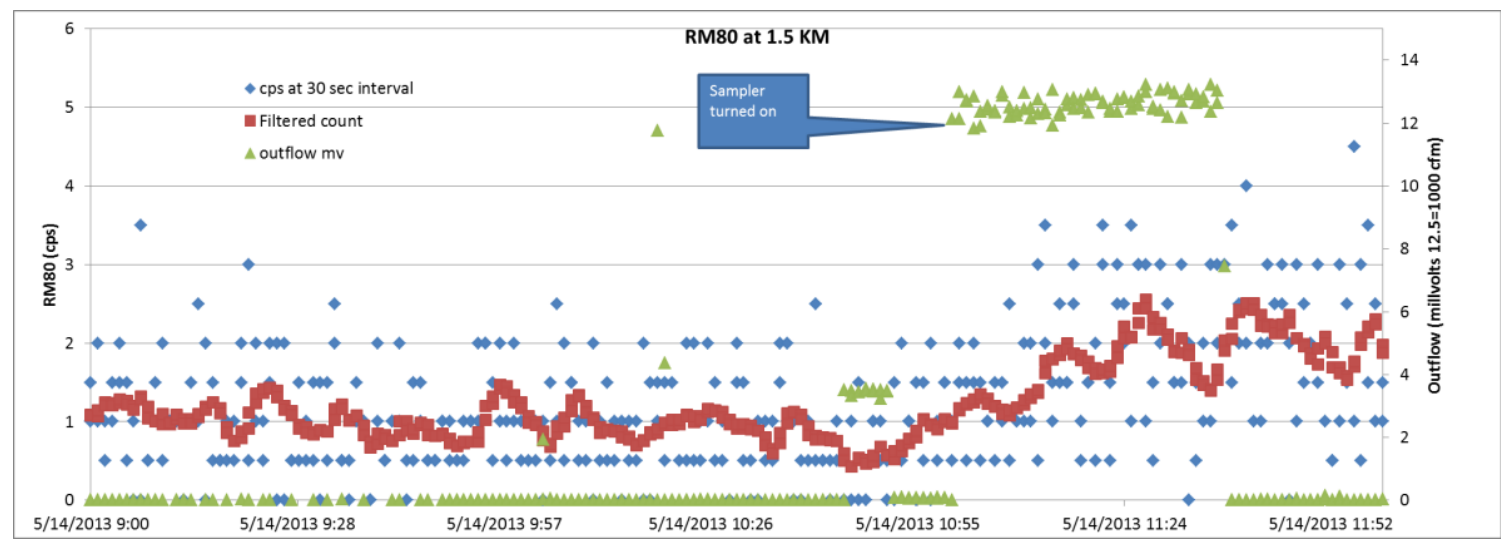

Figure 5.22. Count rate (blue) and smoothed count rate (red) of a GM tube monitoring sample collection $1.5 \mathrm{~km}$ downwind from the release. This sampler was remotely activated shortly before the release, and the plume's arrival can be observed during the sampling period. 
PNNL-23997

\subsection{Lessons Learned}

\subsection{Lessons Learned}

During the course of the experiment, the team experienced and overcame a number of issues whose impact could have been lessened with more detailed preparation. Preparing for the following items would help to ensure a smoother experiment for any similar future effort. Some of these lessons would also be valuable in planning for an On-Site Inspection. A number of these lessons are painfully obvious, however are worth including in the list because they caused delays during the experiment execution. The same types of issues are likely to plague both OSI exercises and any actual OSI in the future.

\subsubsection{OSI-Relevant Lessons Learned}

Survey navigation using GPS and the agricultural Raven light bar worked well. During our background survey in September 2012, a significant amount of time and effort was spent in setting up a grid of poles to allow relatively straight radiation survey lines to be driven with the off-road vehicle. In the PRex test, the GPS + light bar navigation allowed the survey to be driven accurately on predetermined lines with no advance set-up.

Do not overestimate the ability to cover ground on foot. The going-in assumption for this experiment was that much of the stake placement and pick-up would be on foot, but this was unrealistic. Even $2 \mathrm{~km}^{2}$ is a lot of territory and relatively short distances of 50 or $100 \mathrm{~m}$ can still be covered more quickly by vehicle. This was particularly true in areas where smaller vegetation gave way to larger bushes and Joshua trees. Had we chosen a site that could not be traversed by off-road vehicle, we would have had to reduce our sampling area drastically.

\section{Detectors should be calibrated for the expected source geometries before an experiment or} inspection. Much of the effort in preparing for the experiment was focused on preparation, transportation, and release of the source. There were valid reasons for this, because a failure in these areas would prevent execution of the experiment; however; this resulted in insufficient effort on prior calibration of the various survey and measurement instruments for the geometries that would be encountered. More advance preparation would have greatly simplified the subsequent analysis. The work of calibrating instruments ahead of the expected survey and planning sample geometries should be a main focus of OSI preparation. Wrangling through preparation of procedures, politics, etc., for an OSI could take the place of the necessary focus on source preparation and delivery, leaving the inspection team with the same calibration challenges that we faced.

All OSI operations need to be thought through with regard to situations where PPE is required. For example, it was very difficult to drive while wearing the respirator. Originally, the filter part of the respirator was on a person's lower back, making sitting to drive impossible. Even moving the filter to a person's side still made sitting and driving very difficult. Detailed procedures documentation of contamination levels requiring PPE should be in-place for an OSI. During this experiment, the RCTs determined that respirators were not required after performing breathing-zone monitoring on the first afternoon of work inside the contamination area. 
Water policies while wearing PPE should be established. NNSS often allows Contamination Area (CA) Radiological Work Permits (RWPs) to include a "one-water drink" option or internal camel-back option, but this was not raised for us initially, so it was not addressed in the RWP. Staff would have been able to stay in the field longer had these options been available. This will be a crucial issue for a warmweather OSI, when the PPE will rapidly cause inspectors to overheat, particularly if there is no provision for water.

Vehicle-based ground survey provided the most comprehensive, useful data set. This suggests that increased emphasis on highly sensitive vehicle survey instruments should be considered for OSI.

All OSI sampling operations need to be thought through in terms of windy conditions. We found it very difficult to use plastic garbage bags for sample collection in winds beyond $\sim 6 \mathrm{mph}$, though we did succeed. Such wind speeds, or much faster, are very common in desert environments.

Collecting soil samples with tacky mats is difficult in windy conditions. Putting the tacky mat on the ground and then folding it was very difficult in breezy conditions, and is definitely a two-person job. Given the gravelly nature of the soil, these turned out to be a lot more bulky than we thought, and we ended up putting them in collection jars rather than zip-lock bags.

Using a vacuum cleaner to collect samples presents a few challenges that need to be addressed. The vacuum cleaner battery quickly lost power and, since it was in a CA, we could not take it back out for recharging. It also presents a lot more cross-contamination risk than the other sampling techniquesthough some parts can be cleaned with wet wipes, the filters cannot without making them clog. Advance practice is necessary in disassembling the vacuum cleaner over a sample jar, as not all material is collected in the pre-filter panty hose.

Cross-contamination prevention procedures should be practiced in advance, in challenging (e.g. dusty) conditions. We were not satisfied with the extent of the cross-contamination controls used in this experiment. The back of the Mule was covered in kicked-up dust, and the witness tacky mats were not sealed in their individual kitchen bags as we found it very difficult to use the small zip-ties with gloves on. Results, however, seemed to indicate cross-contamination was not much of a problem. It may be that in an on-site inspection, cross-contamination is not a paramount concern because the key objective is to find relevant sampling locations rather than get a site perfectly mapped.

Dust masks and hats should be available for reducing exposure. It's important to have a good supply of dust masks to provide some protection when respirators are not required. Supplies included sufficient respirators for use through the full sampling period. When RCTs determined that respirators were not required, we found we did not have a sufficient supply of dust masks. It's also useful to wear a hat or other hair covering, even if a hood is not required, as a lot of dust can accumulate in exposed hair.

The use of each piece of OSI equipment should be thought through and practiced with regard to its operational use in a Contamination Area. It can be very difficult to use detectors in a CA if they need to be wrapped with plastic (to allow later removal from the CA for charging, other measurements, etc.). The plastic wrapping can make using instrument controls difficult and viewing the screens impossible. Radiation Control personnel may in some cases be willing to leave the screen exposed, and still clear the instrument out of the CA. 
Battery issues are an important consideration for field survey equipment. For example, the several year-old batteries for the Canberra Falcon were weak and not able to run the detector for a useful length of time. This required us to keep the Falcon plugged into the Mule's battery. The tablet batteries also died after a few hours, and then we could not use the Falcon system. We could also not bring the tablet back out of the CA at this point due to contamination.

$\mathrm{NaI}(\mathrm{Tl})$ detectors, operated in singles mode in the field laboratory, were not found to be beneficial to the experiment. Our initial thinking was that they would be useful screening tools for helping triage which samples to measure first. However, at the activities involved, they did not offer any advantage over the HPGe detectors. Operation of $\mathrm{NaI}(\mathrm{Tl})$ or other low-resolution detectors in coincidence mode may offer more beneficial results.

In-situ HPGe survey and laboratory sample analysis provided roughly comparable sensitivities. Field collection of samples followed by laboratory measurement appeared to be capable of more throughput than in-situ measurements. In addition, field collection enabled longer counts (or overnight counts) of interesting samples, and samples could be archived.

Laboratory sample analysis provided the highest sensitivity for ground deposition. It is, however, hampered by the sparse data set relative to survey. This technique will be important in cases where OSI ground survey does not find positive results, but interesting sites are identified by other techniques. It will also be very useful to verify isotopes present if ground survey locates positive results.

Some data were lost due to the age of equipment and/or the age of remote radio communications systems used during the test. It is best for the OSI team to use the most up-to-date equipment possible; however, it is likely that an OSI team in the field will face similar equipment issues.

Verify local landmarks with a compass corrected for local deviation of magnetic north. Local staff consistently referred to Tabletop Mt. for due north, however for our position on Yucca Flats this was not entirely accurate. This resulted in misalignment of some portions of the release site, which needed to be corrected after a compass was consulted.

Avoid the use of polarized sunglasses when working with electronic displays in the field. The polarization of polarized sunglasses makes viewing electronic displays which make use of polarization in the display mechanism difficult.

\subsubsection{Experiment-Specific Lessons Learned}

Tall stakes and flags are needed for visibility. The garden stakes were visible from $100 \mathrm{~m}$ away where there was little brush, but very hard to see at distances beyond $100 \mathrm{~m}$. The taller, wider wooden stakes were easier to see, and held the flags in place better than the smooth metal garden stakes. Some flags slid down to the ground on the garden stakes. Also, when attached to the tall wooden stakes, the flags were less likely to snag on the sticky glass witness slides, which were sometimes placed near enough to the garden stakes for flags to stick to them. 
Calculate coordinates in advance. It would have been helpful to have had the proper stake coordinates (in UTM form) in advance rather than having to calculate them on the spot. Occasionally, mistakes were made that had to be corrected. This issue was corrected after a couple days during the set-up phase.

Duct tape and thin glass do not mix. The witness slides were originally to be taped to the holders with packaging tape, but this was changed to duct tape due to concern about whether the tape would hold in the wind. The duct tape adhesive was too strong, however, and some slides were broken in an attempt to remove them. By the day after the release, the duct tape had adhered more strongly and entire garden stakes had to be collected and then the tape cut off at the Conex processing table. Later, project staff had to come up with a method to remove the tape so that it did not interfere with microscopy.

The experiment would have benefitted from an on-board method to quantify the total release and its temporal profile. We had discussed a few methods of measuring the release of the radioactive particles from the $\mathrm{CO}_{2}$ gerb but did not implement them due to time and funding-constraints. This created challenges in the data analysis.

It is useful to determine where the plume is as soon as possible. Had we been able to determine this earlier, it probably would have saved us time in the collection of the most relevant samples; most of the first day we only knew the general area of the plume, assuming that the release had truly been successful.

The large area witness plates need more rigid frames. The tacky mats were warped by their staking and exposure for a few days. They no longer closed like a book but stuck out at the corners and didn't really stick together at all. Putting the plates with backing into the bags was then quite difficult; they often caught on the bags, even without the strong wind causing havoc. 
PNNL-23997

\subsection{Conclusions and Recommendations}

The PRex radionuclide release test was successfully conducted during the week of May $13^{\text {th }}, 2013$. The experiment, designed to mimic a small vent of radioparticulates from an underground nuclear explosion, involved lofting approximately $1 \mathrm{Ci}$ of ${ }^{140} \mathrm{La}$ in the form of 32-45 micron-sized $\mathrm{La}_{2} \mathrm{O}_{3}$ powder via an air cannon. Integration of the deposited plume data collected with vehicle ground survey indicates that $\sim 7 \%$ of the activity in the original source was deposited within the plume area. Despite this deposition value being lower than planned, the plume provided an opportunity to collect detailed vehicle-based ground survey, and provided positive results on soil, air sample, and aerial survey. The data collected allowed for comparison of the sensitivity of survey and sampling methods. Many Lessons Learned for both planning a similar future experiment and conducting a future OSI were collected.

The vehicle ground survey was found to provide the most comprehensive data set for characterizing the location and deposition activity in the plume. This method also allowed the ground-based experiment team to cover the most area relative to the time invested. However, the ground-based vehicle survey was not as sensitive as the in-situ and sampling techniques employed. The narrowness of the plume, only a couple $100 \mathrm{~m}$, showed that survey and sampling techniques must cover a comparably tight spacing or risk missing a plume for a radioactive vent.

In-situ measurements with HPGe detectors were found to be roughly an order of magnitude more sensitive than comparable measurements with scintillator-based detectors, which were themselves more sensitive than the vehicle ground survey. The sensitivity of soil samples measured in the field laboratory was roughly comparable to the in-situ HPGe measurements, although some laboratory sample measurements achieved more sensitive results. From this work, it appears that the selection of emphasis between in-situ vs. sampling/field laboratory measurements should be based on throughput capability and other operational considerations (e.g. ability to archive samples). Both methods provide useful capability to an inspection team. However, the data provided is sparse compared to vehicle-based ground survey and should be focused on areas identified as interesting through other techniques.

The backpack survey results did not provide significant sensitivity enhancement over vehicle survey in the Kawasaki mule. Further, this survey method is very slow compared to vehicle-based survey. Backpack survey should only be used in situations where vehicle survey is not possible, or when the backpack is carried by an inspection team member who is performing other duties.

The fixed-wing aerial survey performed for this work was flown at 500 feet AGL, with 500-ft line spacing, at 140 knots. These flight parameters limited the sensitivity of the aerial survey; however, they are realistic for a large area, fixed-wing survey during an OSI. The survey provided a positive detection of the source dispersal location, and a weak indication of the presence and direction of the deposited plume. A helicopter-based survey, flown at lower elevation and closer line spacing, would have provided a much more detailed map of the plume.

Three soil sampling techniques were used during this experiment: troweling the top layer of soil, collecting the lightest dust and debris using a handheld vacuum cleaner, and collecting the top-most soil and pebbles using an inverted tacky mat. All of these methods were observed to provide surface activity level estimates that were low compared to the "ground truth" values determined through measurement of the large-area witness plate samples, roughly in the range of $6 \%$ to $20 \%$. A rough ordering of the 
techniques in terms of percent of "ground truth" activity collected, for the same surface areas, was 1) trowel soil collection, 2) vacuum cleaner, and 3) inverted tacky mat; however, the latter two techniques could easily be designed to collect from larger areas than were used in our soil collection. The vacuum cleaner method appeared to provide a good technique for collecting recent debris, but suffered from poor battery life and high potential for cross-contamination. The tacky-mat method also collected a sample from mainly the top layer of soil, but is challenging to accomplish during windy conditions. Calibration of the measurement geometry for the bulky tacky mats with soil is also challenging. Troweling a surface layer of soil was relatively straight forward, allows for good contamination control, and provides a repeatable sample geometry for laboratory measurement. This is also likely the best approach for inspections that occur later in terms of time after a detonation event, when radionuclide debris may have migrated downward into the soil.

The use of inert microspheres and optical microscopy methods did not provide sufficient results to define the deposition plume, though they did appear to track with the radiation plume. Microspheres were successfully collected and identified on optical witness plates downwind from the release. In order to use this method to produce viable results, it would be necessary to release a larger quantity of microspheres. The use of colored or fluorescent microspheres would also aid in discriminating the released microspheres from naturally occurring spherical particles.

\subsection{Recommended Future Work}

A significant portion of the effort in the PRex experiment revolved around the successful preparation, transport, and release of the radionuclide source. Based on this experience, this portion of the work would be more straightforward for a future effort, and would allow more emphasis on areas that were not fully developed in this test. For example, more detailed information on the release timing (e.g., activity injected into the atmosphere vs. time) and injection levels into the atmosphere would provide for improved atmospheric modeling of the release. This would also provide better knowledge of the release quantity. Utilizing a longer release time ( 10 minutes) could also be beneficial in comparisons to meteorological modeling.

Delays in the manufacturing of the radioactive microspheres originally expected to be used in this work forced the use of sieved $\mathrm{La}_{2} \mathrm{O}_{3}$ powder. The microspheres would have provided a much more uniform and well known particle size distribution for use in modeling the deposition. Future work utilizing radioactive microspheres would provide a more detailed dataset for comparison to meteorological modelling results. The use of microspheres in different size ranges, tagged with different radioisotopes, would also allow investigation of the atmospheric transport of multiple particle sizes in a single experiment.

Besides use of microspheres and more controlled releases, as discussed in the previous two paragraphs, another area for potential follow-on work concerns the transport of particulates within subsurface fractures, which is poorly understood. This could involve experiments from shallow tunnels or a large lysimeter. Having successfully produced a vent scenario in PRex, one could also envision involving more participants in a future exercise, in line with a recent release exercise in Canada. United Kingdom colleagues from the Atomic Weapons Establishment have expressed an interest in participating in such an exercise. 
PNNL-23997

\subsection{References}

Forster, RA, LJ Cox, RF Barrett, TE Booth, JF Briesmeister, FB Brown, JS Bull, GC Geisler, JT Goorley, RD Mosteller, SE Post, RE Prael, EC Selcow, and A Sood. 2004. "Mcnp ${ }^{\mathrm{TM}}$ Version 5." Nuclear Instruments and Methods in Physics Research Section B: Beam Interactions with Materials and Atoms 213:82-86. 10.1016/s0168-583x(03)01538-6.

Homann, SG. 1994. "Hotspot Heath Physics Codes for the Pc." Lawrence Livermore National Laboratory.

Lyons, C. 2012. Aerial Measuring System (Ams) Baseline Surveys for Emergency Planning. Presented at 22nd Annual RETS-REMP Workshop, Orlando, FL, Nuclear Energy Institute, Washington, D.C.

Seifert, AH, LM Arrigo, JEB Jr., RS Detwiler, ME Keillor, WJ Kernan, RR Kirkham, BD Milbrath, JP Rishel, CE Seifert, and JE Smart. 2013. Particle Release Experiment (Prex) Plan. Report No. PNNL-SA95357, Pacific Northwest National Laboratory, Richland, WA.

Smart, JE. 2013. Aluminum Can Liner Design Considerations. Report No. PNNL-SA-95023, Pacific Northwest National Laboratory, Richland, WA. 
PNNL-23997

\section{Appendix A}

\section{Ground Vehicle Survey Data Corrections}

This appendix provides details of the data analysis methods applied to correct errors and lost data in the original data set.

\section{A.1 Introduction}

The RSI ground survey data collected on Wednesday, May $15^{\text {th }}$ and Thursday, May $16^{\text {th }}$ suffered from two distinct data corruption problems. The first occurred because the RSI automatic energy calibration function occasionally recalibrated on the $1596 \mathrm{keV}$ peak of ${ }^{140} \mathrm{La}$ rather than on the correct $1461 \mathrm{keV}$ peak of ${ }^{40} \mathrm{~K}$. This occurred despite the fact that the auto calibration mode was inhibited during the collection; activation of the auto calibration appears to be correlated to the second problem, data drop-outs, discussed next. The survey system generally corrected the energy calibration as the count rate from ${ }^{140}$ La dropped, and the background ${ }^{40} \mathrm{~K}$ peak came to the fore. However, for the final hour of the third survey period, one of the two detectors remained incorrectly calibrated.

The second data corruption issue was a loss of data collection that tended to occur after the system transited the peak count rate encountered during transepts of the plume. These outages consistently occurred after the peak rate had been observed, during the downward trend in count rate. They did not consistently affect both of the survey detectors; there are times when data from one detector was not collected, and there are fewer times when data from both detectors were not collected. This appendix provides a description of the methods used to 1) correct the energy calibration in cases where the system incorrectly identified the $1596 \mathrm{keV}{ }^{140} \mathrm{La}$ peak as the $1461 \mathrm{keV}{ }^{40} \mathrm{~K}$ peak, and 2) fill in the missing data to allow contouring and integration of the deposited plume.

\section{A.2 Data Correction}

The following method was adopted to sum the spectra from the two $\mathrm{NaI}(\mathrm{Tl})$ detectors at each 1-second time interval. The method was applied to each of the individual surveys, i.e., May15 AM, May15 PM and May16. The steps were followed in order for all corrected survey data to ensure the desired data correction was obtained.

1. Recalibrate $\mathrm{NaI}(\mathrm{Tl})$ detector data to ${ }^{40} \mathrm{~K}$ - last hour and at several peaks

2. Where only one log is present - scale counts to other log's average and add to existing data

3. Where two logs are missing - interpolate from both directions in time. The interpolation was applied on a channel by channel basis for the spectra. 
Figure A-1 shows examples where an interpolation from both directions in time was performed to fill in a gap. These areas are evident by the straight lines crossing multiple time indexes. Figure A-2 shows summed spectra with and without recalibration.

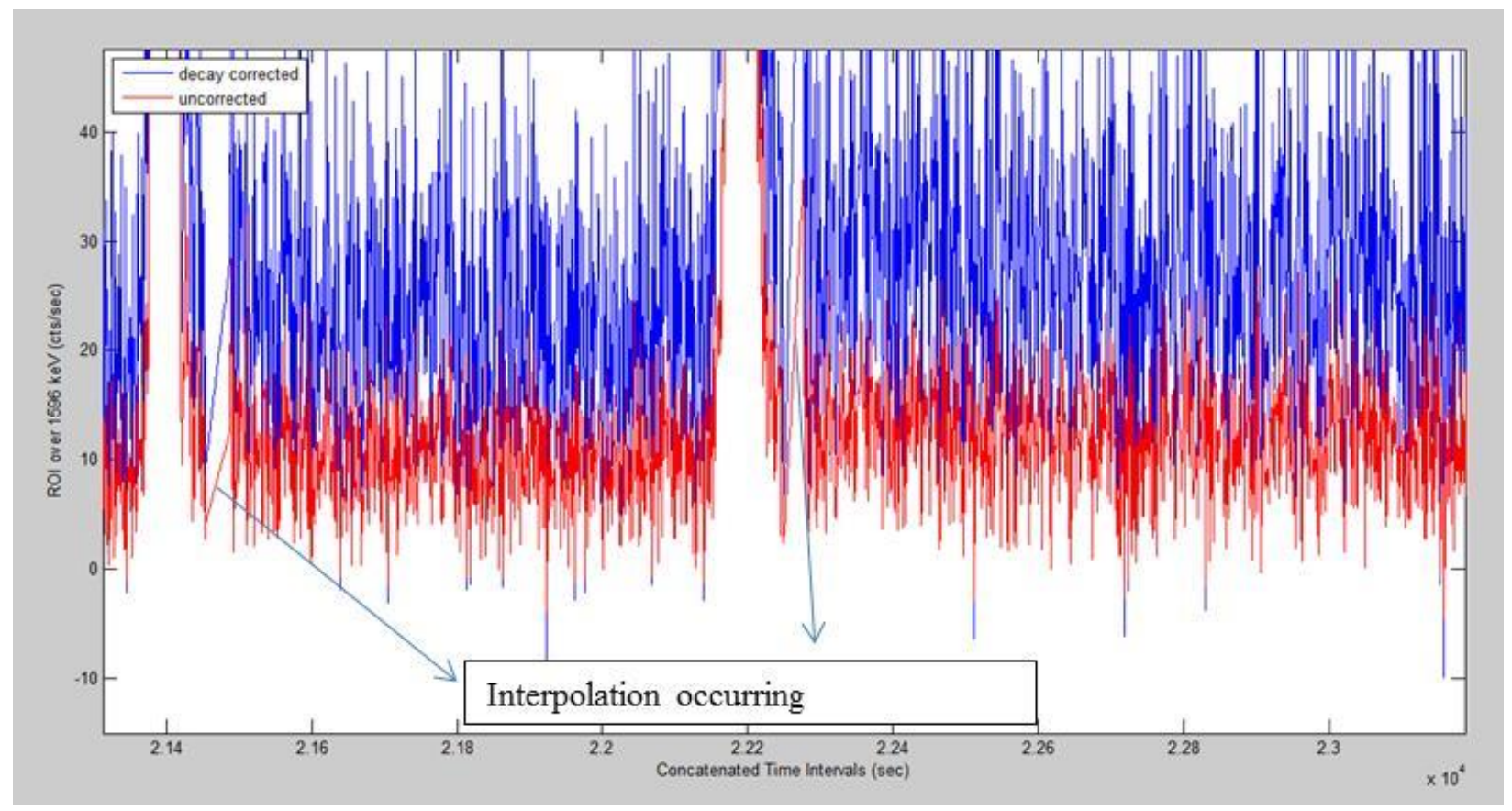

Figure A - 1: An example two time blocks in the data where both detectors ceased data collection, and the data was interpolated in time to fill in the gaps. Note that the data drop-outs occur after the survey vehicle has transited the plume, and the rate is returning to near background level. 
PNNL-23997

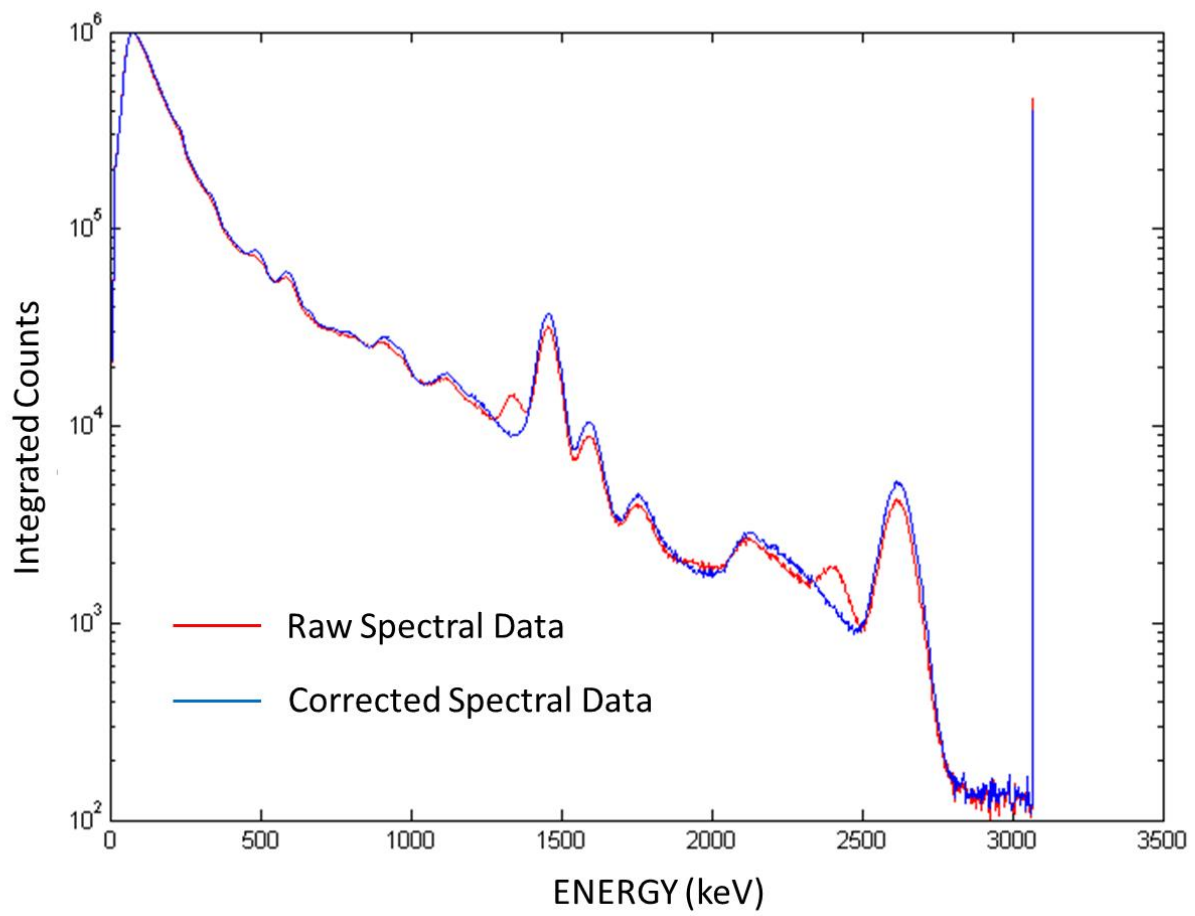

Figure A - 2: $\mathrm{NaI}(\mathrm{Tl})$ spectral data, before and after correction of the energy calibration. Note that the corrected data has the false peaks below the ${ }^{40} \mathrm{~K}$ and ${ }^{208} \mathrm{Tl}$ peaks removed.

The next two figures show the results of the data repair for the May $15^{\text {th }}$ AM survey and the May $16^{\text {th }}$ surveys. Although the figures just show gross counts, the repairs were performed on the component energy channels. The repairs to the Wednesday morning data ("May 15 AM") occurred only during one timeframe, after transit of the plume. Data from the Wednesday afternoon survey ("May 15 PM") did not require correction. This data set was collected further downwind, and did not include high ${ }^{140} \mathrm{La}$ count rate data. The survey on May $16^{\text {th }}$ required extensive correction due to both energy calibration and data drop-out issues. The last $\sim 4000$ seconds required extensive energy recalibration of data from one of the $\mathrm{NaI}(\mathrm{Tl})$ detectors. 
PNNL-23997

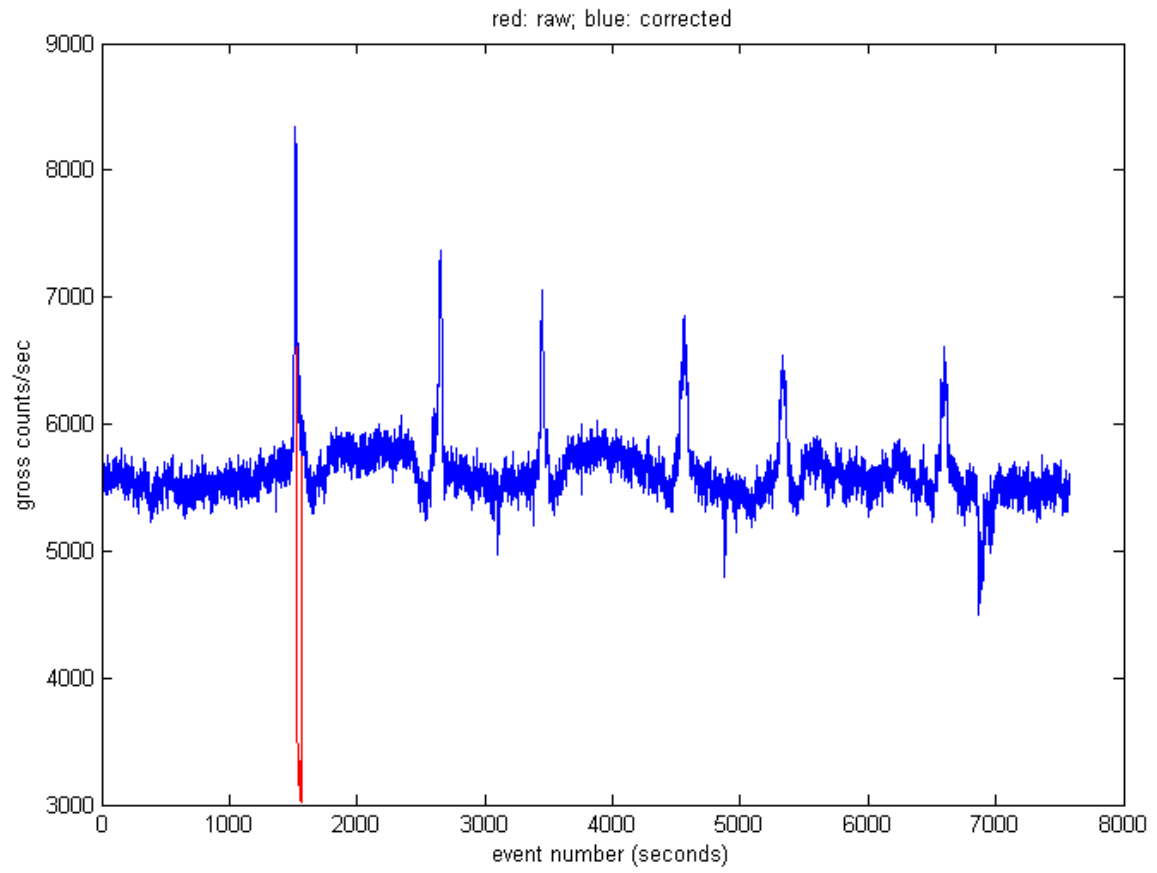

Figure A - 3: Data correction required due to data drop-out from one of the two $\mathrm{NaI}(\mathrm{Tl})$ detectors on Wednesday morning. The drop-out occurred after the survey crossed the plume on the closest-in transept of Wednesday (thus the highest count rate for the day). This correction was of the $2^{\text {nd }}$ variety (one detector drop-out). 
PNNL-23997

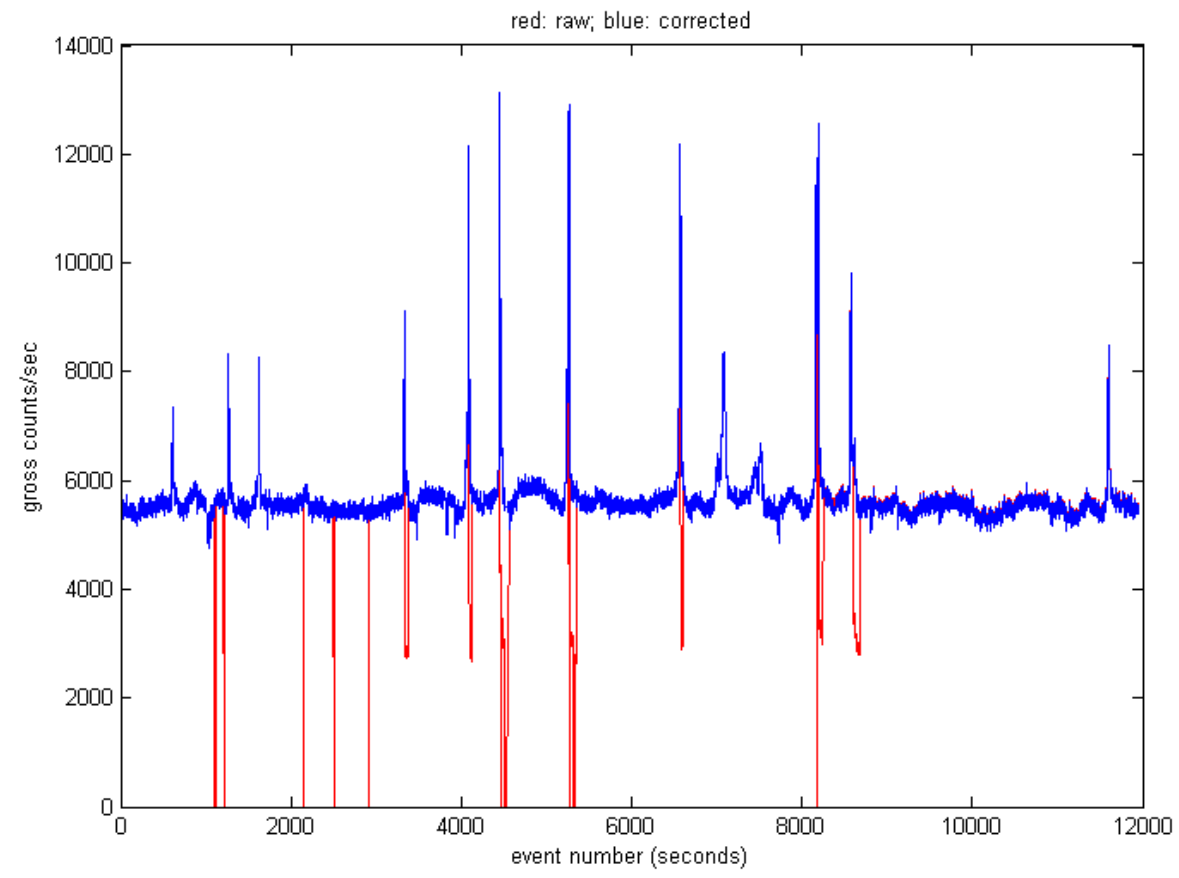

Figure A - 4: More extensive corrections were required for the Thursday morning survey data, which suffered more frequent data corruption issues. The red trace (raw data) is directly behind the blue (corrected data) where it does not show. Time periods where the red trace drops to zero indicate that both detectors stopped data collection after transiting the plume (corrected with interpolation). Drops to $\sim 3000$ cps indicate a single detector dropped out (corrected based on the operating detector rate).

After correction, the three surveys were concatenated into one file for further data processing, plume plotting, and plume activity integration. The corrected data were used to develop estimates of the total activity deposited within the plume, as discussed in the main report. 


\section{Appendix B}

\section{Field Laboratory Gamma Assay Results}

The following table contains analysis results for the HPGe-based field laboratory sample measurements of PRex samples. PNNLWD57752 and PNNL WD66091 are two 50\% relative efficiency Canberra P-type crystals (Figure 4.14). The NSTec column provides results from the portable Canberra extended-range P-type detector provided and operated by NSTec (Figure 4.16).

Table A - 1: Gamma Assay Results

\begin{tabular}{|c|c|c|c|c|c|c|c|c|}
\hline $\begin{array}{l}\text { Sample } \\
\text { Location }\end{array}$ & easting & northing & Sample Type & $\begin{array}{l}\text { PNNL WD57752 } \\
\text { (uCi) }\end{array}$ & $\begin{array}{l}\text { PNNL WD66091 } \\
\text { (uCi) }\end{array}$ & NSTec (uCi) & $\begin{array}{l}\text { MDA } \\
\text { (uCi) }\end{array}$ & Notes \\
\hline $0-1$ & 588277 & 4094865 & Tacky Mat & & No Detect & & $2.01 \mathrm{E}-5$ & No Detect \\
\hline $0-2$ & 588377 & 4094865 & Tacky Mat & No Detect & & & $1.51 \mathrm{E}-5$ & No Detect \\
\hline $0-3$ & 588477 & 4094865 & Tacky Mat & & & & & Not Counted \\
\hline $1-1$ & 588177 & 4094965 & & & & & & Not Counted \\
\hline $1-2$ & 588277 & 4094965 & Tacky Mat & No Detect & & & $3.79 \mathrm{E}-5$ & No Detect \\
\hline $2-1$ & 588077 & 4095065 & & & & & & Not Counted \\
\hline $2-2$ & 588177 & 4095065 & Tacky Mat & No Detect & & & $2.39 \mathrm{E}-5$ & No Detect \\
\hline
\end{tabular}




\begin{tabular}{|c|c|c|c|c|c|c|c|c|}
\hline $\begin{array}{l}\text { Sample } \\
\text { Location }\end{array}$ & easting & northing & Sample Type & $\begin{array}{c}\text { PNNL WD57752 } \\
\text { (uCi) }\end{array}$ & $\begin{array}{c}\text { PNNL WD66091 } \\
\text { (uCi) }\end{array}$ & NSTec (uCi) & $\begin{array}{l}\text { MDA } \\
\text { (uCi) }\end{array}$ & Notes \\
\hline $2-3$ & 588277 & 4095065 & Tacky Mat & & $3.15 E-5$ & & & \\
\hline $2-4$ & 588377 & 4095065 & Tacky Mat & & & $1.83 \mathrm{E}-1$ & & \\
\hline $2-4$ & 588377 & 4095065 & Glass Slide & & & $5.91 \mathrm{E}-4$ & & \\
\hline $2-4-1$ & 588377 & 4095065 & Vacuum Sample in a Jar & & & $4.84 \mathrm{E}-3$ & & \\
\hline $2-5$ & 588477 & 4095065 & Tacky Mat & $6.88 \mathrm{E}-4$ & & & & \\
\hline $2-5$ & 588477 & 4095065 & Vacuum Sample in a Jar & & $4.61 \mathrm{E}-3$ & & & \\
\hline $2-6$ & 588577 & 4095065 & Tacky Mat & & & No Detect & $2.56 \mathrm{E}-5$ & No Detect \\
\hline $2-7$ & 588677 & 4095065 & & & & & & Not Counted \\
\hline 3-1 & 587977 & 4095165 & & & & & & Not Counted \\
\hline $3-2$ & 588077 & 4095165 & & & & & & Not Counted \\
\hline $3-3$ & 588177 & 4095165 & Tacky Mat & No Detect & & & $2.17 \mathrm{E}-5$ & No Detect \\
\hline $3-4$ & 588277 & 4095165 & Tacky Mat & & $2.54 \mathrm{E}-4$ & & & \\
\hline $3-5$ & 588377 & 4095165 & Tacky Mat & & & $1.065 \mathrm{E}-1$ & & \\
\hline 3-5 & 588377 & 4095165 & Glass Slide & & & $5.898 E-5$ & & \\
\hline $3-6$ & 588477 & 4095165 & Tacky Mat & $2.28 \mathrm{E}-3$ & & & & \\
\hline $3-7$ & 588577 & 4095165 & Tacky Mat & & & $4.59 \mathrm{E}-5$ & & \\
\hline
\end{tabular}




\begin{tabular}{|c|c|c|c|c|c|c|c|c|}
\hline $\begin{array}{l}\text { Sample } \\
\text { Location }\end{array}$ & easting & northing & Sample Type & $\begin{array}{l}\text { PNNL WD57752 } \\
\text { (uCi) }\end{array}$ & $\begin{array}{l}\text { PNNL WD66091 } \\
\text { (uCi) }\end{array}$ & NSTec (uCi) & $\begin{array}{l}\text { MDA } \\
\text { (uCi) }\end{array}$ & Notes \\
\hline $3-8$ & 588677 & 4095165 & Tacky Mat & No Detect & & & $1.53 \mathrm{E}-5$ & No Detect \\
\hline $3-9$ & 588777 & 4095165 & Tacky Mat & & & No Detect & $1.77 \mathrm{E}-5$ & No Detect \\
\hline $3-10$ & 588877 & 4095165 & & & & & & Not Counted \\
\hline $4-1$ & 587977 & 4095265 & & & & & & Not Counted \\
\hline $4-2$ & 588077 & 4095265 & Tacky Mat & & No Detect & & $2.21 \mathrm{E}-5$ & No Detect \\
\hline $4-2$ & 588077 & 4095265 & PAPR Air Filter & & & $2.42 \mathrm{E}-4$ & & \\
\hline $4-3$ & 588177 & 4095265 & Tacky Mat & & & No Detect & $1.74 \mathrm{E}-5$ & No Detect \\
\hline $4-3$ & 588177 & 4095265 & PAPR Air Filter & & $2.40 \mathrm{E}-5$ & & & \\
\hline $4-4$ & 588277 & 4095265 & Tacky Mat & $2.81 \mathrm{E}-4$ & & & & \\
\hline $4-4$ & 588277 & 4095265 & Glass Slide & No Detect & & & $4.35 \mathrm{E}-5$ & No Detect \\
\hline $4-4-4 \mathrm{ft}$ & 588277 & 4095265 & PAPR Air Filter & & $1.21 \mathrm{E}-4$ & & & \\
\hline $4-4-22 \mathrm{ft}$ & 588277 & 4095265 & PAPR Air Filter & & No Detect & & $3.90 \mathrm{E}-5$ & No Detect \\
\hline $4-4-45 \mathrm{ft}$ & 588277 & 4095265 & PAPR Air Filter & & $1.44 \mathrm{E}-4$ & & & \\
\hline $4-5$ & 588377 & 4095265 & Glass Slide & $1.589 \mathrm{E}-4$ & & & & \\
\hline 4-5.5 & 588427 & 4095265 & PAPR Air Filter & $1.78 \mathrm{E}-2$ & & & & $\begin{array}{c}\text { half way } \\
\text { between } 4-5 \text { \& } \\
4-6\end{array}$ \\
\hline
\end{tabular}




\begin{tabular}{|c|c|c|c|c|c|c|c|c|}
\hline $\begin{array}{l}\text { Sample } \\
\text { Location }\end{array}$ & easting & northing & Sample Type & $\begin{array}{c}\text { PNNL WD57752 } \\
\text { (uCi) }\end{array}$ & $\begin{array}{c}\text { PNNL WD66091 } \\
\text { (uCi) }\end{array}$ & NSTec (uCi) & $\begin{array}{l}\text { MDA } \\
\text { (uCi) }\end{array}$ & Notes \\
\hline 4-6 & 588477 & 4095265 & Tacky Mat & $2.04 \mathrm{E}-2$ & & & & \\
\hline $4-6$ & 588477 & 4095265 & PAPR Air Filter & & 3.54 E-3 & & & \\
\hline $4-6-4 \mathrm{ft}$ & 588477 & 4095265 & PAPR Air Filter & & $6.28 \mathrm{E}-3$ & & & \\
\hline $4-6-22 \mathrm{ft}$ & 588477 & 4095265 & PAPR Air Filter & & $3.96 \mathrm{E}-4$ & & & \\
\hline $4-6-45 \mathrm{ft}$ & 588477 & 4095265 & PAPR Air Filter & & $4.72 \mathrm{E}-3$ & & & \\
\hline $4-7$ & 588577 & 4095265 & Tacky Mat & & $1.09 \mathrm{E}-4$ & & & \\
\hline $4-7$ & 588577 & 4095265 & PAPR Air Filter & & $3.61 \mathrm{E}-5$ & & & \\
\hline $4-8$ & 588677 & 4095265 & PAPR Air Filter & & & No Detect & $4.50 \mathrm{E}-5$ & No Detect \\
\hline $4-8-1$ & 588677 & 4095265 & Tacky Mat & & $2.43 \mathrm{E}-5$ & & & \\
\hline $4-8-2$ & 588677 & 4095265 & Tacky Mat & & $1.48 \mathrm{E}-4$ & & & \\
\hline $4-8-3$ & 588677 & 4095265 & Tacky Mat & $3.06 \mathrm{E}-5$ & & & & \\
\hline $4-8-4$ & 588677 & 4095265 & Tacky Mat & & $6.45 E-5$ & & & \\
\hline $4-8-5$ & 588677 & 4095265 & Tacky Mat & $4.69 \mathrm{E}-5$ & & & & \\
\hline 4-9 & 588777 & 4095265 & Tacky Mat & No Detect & & & $6.52 \mathrm{E}-6$ & No Detect \\
\hline 4-10 & 588877 & 4095265 & Tacky Mat & No Detect & & & $1.79 \mathrm{E}-5$ & No Detect \\
\hline 4-11 & 588977 & 4095265 & & & & & & Not Counted \\
\hline
\end{tabular}




\begin{tabular}{|c|c|c|c|c|c|c|c|c|}
\hline $\begin{array}{l}\text { Sample } \\
\text { Location }\end{array}$ & easting & northing & Sample Type & $\begin{array}{c}\text { PNNL WD57752 } \\
\text { (uCi) }\end{array}$ & $\begin{array}{c}\text { PNNL WD66091 } \\
\text { (uCi) }\end{array}$ & NSTec (uCi) & $\begin{array}{l}\text { MDA } \\
\text { (uCi) }\end{array}$ & Notes \\
\hline 4-12 & 589077 & 4095265 & & & & & & Not Counted \\
\hline $5-1$ & 587877 & 4095365 & & & & & & Not Counted \\
\hline $5-2$ & 588027 & 4095365 & & & & & & Not Counted \\
\hline $5-3$ & 588227 & 4095365 & Tacky Mat & $1.26 \mathrm{E}-4$ & & & & \\
\hline $5-4-1$ & 588427 & 4095365 & Tacky Mat & $3.98 \mathrm{E}-2$ & & & & \\
\hline $5-4-1$ & 588427 & 4095365 & Tacky Mat Jar & & $2.8 \mathrm{E}-3$ & $3.175 \mathrm{E}-3$ & & \\
\hline $5-4-1$ & 588427 & 4095365 & Soil Jar & $9.05 \mathrm{E}-3$ & $8.55 E-3$ & $1.00 \mathrm{E}-2$ & & \\
\hline $5-4-2$ & 588427 & 4095365 & Tacky Mat & & $3.22 \mathrm{E}-2$ & & & \\
\hline $5-4-2$ & 588427 & 4095365 & Tacky Mat Jar & & & $2.616 \mathrm{E}-3$ & & \\
\hline $5-4-2$ & 588427 & 4095365 & Glass Slide & & & 3.27 E-5 & & \\
\hline $5-4-2$ & 588427 & 4095365 & Soil Jar & & & $8.56 \mathrm{E}-3$ & & \\
\hline $5-4-3$ & 588427 & 4095365 & Tacky Mat & $3.42 \mathrm{E}-2$ & & & & \\
\hline $5-4-4$ & 588427 & 4095365 & Tacky Mat & & $4.30 \mathrm{E}-2$ & & & \\
\hline $5-4-4$ & 588427 & 4095365 & Vacuum Sample in a Jar & & & $3.39 \mathrm{E}-3$ & & \\
\hline $5-4-5$ & 588427 & 4095365 & Tacky Mat & $3.89 \mathrm{E}-2$ & & & & \\
\hline $5-5$ & 588627 & 4095365 & Tacky Mat & $7.68 \mathrm{E}-5$ & & & & \\
\hline
\end{tabular}




\begin{tabular}{|c|c|c|c|c|c|c|c|c|}
\hline $\begin{array}{l}\text { Sample } \\
\text { Location }\end{array}$ & easting & northing & Sample Type & $\begin{array}{c}\text { PNNL WD57752 } \\
\text { (uCi) }\end{array}$ & $\begin{array}{c}\text { PNNL WD66091 } \\
\text { (uCi) }\end{array}$ & NSTec (uCi) & $\begin{array}{l}\text { MDA } \\
\text { (uCi) }\end{array}$ & Notes \\
\hline $5-6$ & 588827 & 4095365 & & & & & & Not Counted \\
\hline $5-7$ & 589052 & 4095365 & & & & & & Not Counted \\
\hline $5-8$ & 589227 & 4095365 & & & & & & Not Counted \\
\hline $6-1$ & 587927 & 4095465 & & & & & & Not Counted \\
\hline $6-2$ & 588177 & 4095465 & Tacky Mat & & No Detect & & $9.55 \mathrm{E}-6$ & No Detect \\
\hline $6-2$ & 588177 & 4095465 & PAPR Air Filter & & No Detect & & $1.13 \mathrm{E}-5$ & \\
\hline $6-2$ & 588177 & 4095465 & Glass Slide & & & No Detect & $2.13 \mathrm{E}-5$ & No Detect \\
\hline $6-3$ & 588327 & 4095465 & Tacky Mat & & $5.19 \mathrm{E}-1$ & & & \\
\hline $6-3$ & 588327 & 4095465 & Vacuum Sample in a Jar & $1.16 \mathrm{E}-2$ & & & & \\
\hline $6-4$ & 588527 & 4095465 & PAPR Air Filter & & $1.48 \mathrm{E}-4$ & $1.499 \mathrm{E}-4$ & & \\
\hline $6-4$ & 588527 & 4095465 & Tacky Mat & & & & & Not Counted \\
\hline $6-5$ & 588727 & 4095451 & PAPR Air Filter & & & No Detect & $3.72 \mathrm{E}-5$ & \\
\hline $6-5$ & 588727 & 4095451 & Tacky Mat & & & & & Not Counted \\
\hline $6-6$ & 588902 & 4095465 & Tacky Mat & & & & & Not Counted \\
\hline $6-7$ & 589127 & 4095465 & Tacky Mat & & & & & Not Counted \\
\hline $6-8$ & 589327 & 4095465 & Tacky Mat & & & & & Not Counted \\
\hline
\end{tabular}




\begin{tabular}{|c|c|c|c|c|c|c|c|c|}
\hline $\begin{array}{l}\text { Sample } \\
\text { Location }\end{array}$ & easting & northing & Sample Type & $\begin{array}{c}\text { PNNL WD57752 } \\
\text { (uCi) }\end{array}$ & $\begin{array}{c}\text { PNNL WD66091 } \\
\text { (uCi) }\end{array}$ & NSTec (uCi) & $\begin{array}{l}\text { MDA } \\
\text { (uCi) }\end{array}$ & Notes \\
\hline $7-1$ & 587827 & 4095565 & & & & & & Not Counted \\
\hline $7-2$ & 588027 & 4095565 & Tacky Mat & & No Detect & & $5.04 \mathrm{E}-5$ & No Detect \\
\hline $7-3-1$ & 588227 & 4095565 & Tacky Mat & $6.45 \mathrm{E}-4$ & & & & \\
\hline $7-3-1$ & 588227 & 4095565 & Soil Jar & & & No Detect & $6.13 \mathrm{E}-5$ & \\
\hline $7-3-2$ & 588227 & 4095565 & Tacky Mat & & $1.79 \mathrm{E}-4$ & & & \\
\hline $7-3-2$ & 588227 & 4095565 & OSI Tacky Mat & $2.95 \mathrm{E}-5$ & & & & \\
\hline $7-3-3$ & 588227 & 4095565 & Tacky Mat & & $9.33 E-4$ & & & \\
\hline $7-3-4$ & 588227 & 4095565 & Tacky Mat & & $1.12 \mathrm{E}-3$ & & & \\
\hline 7-3-4 & 588227 & 4095565 & OSI Tacky Mat & $6.8 \mathrm{E}-5$ & & & & \\
\hline $7-3-5$ & 588227 & 4095565 & Tacky Mat & $4.71 \mathrm{E}-4$ & & & & \\
\hline $7-4$ & 588427 & 4095565 & Tacky Mat & $2.23 \mathrm{E}-2$ & & & & \\
\hline $7-5$ & 588627 & 4095565 & Tacky Mat & & No Detect & & $9.35 \mathrm{E}-5$ & No Detect \\
\hline $7-6$ & 588827 & 4095581 & & & & & & Not Counted \\
\hline 7-7 & 589027 & 4095565 & & & & & & Not Counted \\
\hline $7-8$ & 589227 & 4095565 & & & & & & Not Counted \\
\hline $7-9$ & 589427 & 4095565 & & & & & & Not Counted \\
\hline
\end{tabular}




\begin{tabular}{|c|c|c|c|c|c|c|c|c|}
\hline $\begin{array}{l}\text { Sample } \\
\text { Location }\end{array}$ & easting & northing & Sample Type & $\begin{array}{c}\text { PNNL WD57752 } \\
\text { (uCi) }\end{array}$ & $\begin{array}{c}\text { PNNL WD66091 } \\
\text { (uCi) }\end{array}$ & NSTec (uCi) & $\begin{array}{l}\text { MDA } \\
\text { (uCi) }\end{array}$ & Notes \\
\hline $8-1$ & 587727 & 4095765 & & & & & & Not Counted \\
\hline $8-2$ & 587927 & 4095765 & & & & & & Not Counted \\
\hline $8-3$ & 588127 & 4095765 & Tacky Mat & & & No Detect & $5.73 \mathrm{E}-5$ & No Detect \\
\hline $8-4$ & 588327 & 4095765 & Tacky Mat & $2.64 \mathrm{E}-2$ & & & & \\
\hline $8-5$ & 588527 & 4095765 & Tacky Mat & & $1.15 \mathrm{E}-3$ & & & \\
\hline $8-5$ & 588527 & 4095765 & Glass Slide & & No Detect & No Detect & $1.31 \mathrm{E}-4$ & \\
\hline $8-6$ & 588727 & 4095765 & Tacky Mat & & & $1.76 \mathrm{E}-4$ & & \\
\hline $8-7$ & 588927 & 4095765 & Tacky Mat & & 3.122 E-5 & & & \\
\hline $8-8$ & 589127 & 4095765 & Tacky Mat & & & No Detect & $1.63 \mathrm{E}-5$ & No Detect \\
\hline $8-9$ & 589327 & 4095765 & Tacky Mat & & No Detect & & 8.95 E-6 & No Detect \\
\hline $8-10$ & 589427 & 4095765 & & & & & & Not Counted \\
\hline $9-1$ & 587627 & 4095965 & & & & & & Not Counted \\
\hline $9-2-1$ & 587827 & 4095965 & Tacky Mat & & No Detect & & $1.99 \mathrm{E}-5$ & No Detect \\
\hline $9-2-2$ & 587827 & 4095965 & Tacky Mat & No Detect & & & $5.16 \mathrm{E}-5$ & No Detect \\
\hline $9-2-2$ & & & Glass Slide & No Detect & & & $6.56 \mathrm{E}-6$ & No Detect \\
\hline $9-2-3$ & 587827 & 4095965 & Tacky Mat & & & 7.82 E-4 & & \\
\hline
\end{tabular}




\begin{tabular}{|c|c|c|c|c|c|c|c|c|}
\hline $\begin{array}{l}\text { Sample } \\
\text { Location }\end{array}$ & easting & northing & Sample Type & $\begin{array}{l}\text { PNNL WD57752 } \\
\text { (uCi) }\end{array}$ & $\begin{array}{c}\text { PNNL WD66091 } \\
\text { (uCi) }\end{array}$ & NSTec (uCi) & $\begin{array}{l}\text { MDA } \\
\text { (uCi) }\end{array}$ & Notes \\
\hline $9-2-3$ & 587827 & 4095965 & Glass Slide & No Detect & & & $1.81 \mathrm{E}-4$ & No Detect \\
\hline $9-2-4$ & 587827 & 4095965 & Tacky Mat & & No Detect & & $2.00 \mathrm{E}-5$ & No Detect \\
\hline $9-2-4$ & 587827 & 4095965 & Tacky Mat Jar & No Detect & & & $1.66 \mathrm{E}-4$ & No Detect \\
\hline $9-2-4$ & 587827 & 4095965 & Soil Jar & & & No Detect & $1.12 \mathrm{E}-4$ & No Detect \\
\hline $9-2-5$ & 587827 & 4095965 & Tacky Mat & & No Detect & & $1.61 \mathrm{E}-5$ & No Detect \\
\hline $9-2-5$ & 587827 & 4095965 & Tacky Mat Jar & & No Detect & & $1.66 \mathrm{E}-4$ & No Detect \\
\hline $9-2-5$ & 587827 & 4095965 & Soil Jar & & & No Detect & $2.37 \mathrm{E}-4$ & No Detect \\
\hline $9-3$ & 588027 & 4096035 & Tacky Mat & & No Detect & & $6.1 \mathrm{E}-6$ & No Detect \\
\hline $9-3$ & 588027 & 4096035 & Glass Slide & No Detect & & & $1.71 \mathrm{E}-4$ & No Detect \\
\hline $9-4$ & 588227 & 4095965 & Tacky Mat & $5.51 \mathrm{E}-2$ & 5.99 E-2 & 7.11 E-2 & & \\
\hline $9-4$ & 588227 & 4095965 & Glass Slide & & & $3.48 \mathrm{E}-5$ & & \\
\hline $9-5$ & 588427 & 4095965 & Tacky Mat & & $1.23 \mathrm{E}-3$ & $1.48 \mathrm{E}-3$ & & \\
\hline $9-6-1$ & 588627 & 4095965 & Tacky Mat & $2.82 \mathrm{E}-4$ & & & & \\
\hline $9-6-2$ & 588627 & 4095965 & Tacky Mat & $1.66 \mathrm{E}-4$ & & & & \\
\hline $9-6-2$ & 588627 & 4095965 & Tacky Mat Jar & & & No Detect & $2.21 \mathrm{E}-4$ & No Detect \\
\hline $9-6-2$ & 588627 & 4095965 & Soil Jar & & & No Detect & 7.89 E-5 & No Detect \\
\hline
\end{tabular}




\begin{tabular}{|c|c|c|c|c|c|c|c|c|}
\hline $\begin{array}{l}\text { Sample } \\
\text { Location }\end{array}$ & easting & northing & Sample Type & $\begin{array}{l}\text { PNNL WD57752 } \\
\text { (uCi) }\end{array}$ & $\begin{array}{l}\text { PNNL WD66091 } \\
\text { (uCi) }\end{array}$ & NSTec (uCi) & $\begin{array}{l}\text { MDA } \\
\text { (uCi) }\end{array}$ & Notes \\
\hline $9-6-3$ & 588627 & 4095965 & Tacky Mat & & & $7.83 \mathrm{E}-4$ & & \\
\hline $9-6-4$ & 588627 & 4095965 & Tacky Mat & $1.91 \mathrm{E}-4$ & & & & \\
\hline $9-6-5$ & 588627 & 4095965 & Tacky Mat & & & $8.71 \mathrm{E}-5$ & & \\
\hline $9-6-5$ & 588627 & 4095965 & Tacky Mat Jar & & & No Detect & $3.14 \mathrm{E}-4$ & No Detect \\
\hline $9-6-5$ & 588627 & 4095965 & Soil Jar & & & No Detect & $1.93 \mathrm{E}-4$ & No Detect \\
\hline $9-7$ & 588827 & 4095965 & Tacky Mat & & & No Detect & $3.09 \mathrm{E}-5$ & No Detect \\
\hline $9-8$ & 589027 & 4095965 & & & & & & Not Counted \\
\hline 9-9-1 & 589227 & 4095965 & Tacky Mat & No Detect & & & $3.03 \mathrm{E}-5$ & No Detect \\
\hline 9-9-1 & 589227 & 4095965 & Soil Jar & & & No Detect & $3.33 \mathrm{E}-5$ & No Detect \\
\hline $9-9-2$ & 589227 & 4095965 & Tacky Mat & & No Detect & & $1.84 \mathrm{E}-5$ & No Detect \\
\hline $9-9-2$ & 589227 & 4095965 & Tacky Mat Jar & & & No Detect & $1.21 \mathrm{E}-4$ & No Detect \\
\hline $9-9-2$ & 589227 & 4095965 & Soil Jar & & & No Detect & $1.13 \mathrm{E}-4$ & No Detect \\
\hline $9-9-3$ & 589227 & 4095965 & Tacky Mat & No Detect & & & $1.87 \mathrm{E}-5$ & No Detect \\
\hline $9-9-4$ & 589227 & 4095965 & Tacky Mat & & No Detect & & $1.85 \mathrm{E}-5$ & No Detect \\
\hline $9-9-5$ & 589227 & 4095965 & Tacky Mat & & No Detect & & $6.87 \mathrm{E}-6$ & No Detect \\
\hline $9-10$ & 589427 & 4095965 & & & & & & Not Counted \\
\hline
\end{tabular}




\begin{tabular}{|c|c|c|c|c|c|c|c|c|}
\hline $\begin{array}{l}\text { Sample } \\
\text { Location }\end{array}$ & easting & northing & Sample Type & $\begin{array}{l}\text { PNNL WD57752 } \\
\text { (uCi) }\end{array}$ & $\begin{array}{l}\text { PNNL WD66091 } \\
\text { (uCi) }\end{array}$ & NSTec (uCi) & $\begin{array}{l}\text { MDA } \\
\text { (uCi) }\end{array}$ & Notes \\
\hline $9-11$ & 589627 & 4095965 & & & & & & Not Counted \\
\hline $9-12$ & 589827 & 4095965 & & & & & & Not Counted \\
\hline $10-1$ & 587377 & 4096465 & & & & & & Not Counted \\
\hline $10-2$ & 587527 & 4096465 & & & & & & Not Counted \\
\hline $10-2$ & 587527 & 4096465 & Tacky Mat Jar & & & $7.21 \mathrm{E}-4$ & & \\
\hline $10-2$ & 587527 & 4096465 & Soil Jar & & & $1.16 \mathrm{E}-3$ & & \\
\hline $10-3$ & 587727 & 4096465 & Tacky Mat & & No Detect & & $1.89 \mathrm{E}-5$ & No Detect \\
\hline $10-4$ & 587927 & 4096465 & Tacky Mat & No Detect & & & $1.92 \mathrm{E}-5$ & No Detect \\
\hline $10-5$ & 588177 & 4096465 & High Vol. Air Sampler & $1.7 \mathrm{E}-2$ & & & & $\begin{array}{c}\text { Electric HV Air } \\
\text { Sampler }\end{array}$ \\
\hline $10-5-1$ & 588177 & 4096465 & Tacky Mat & & $1.9 \mathrm{E}-2$ & & & \\
\hline $10-5-1$ & 588177 & 4096465 & Tacky Mat Jar & & & $1.13 \mathrm{E}-3$ & & \\
\hline $10-5-1$ & 588177 & 4096465 & Soil Jar & & & $2.23 \mathrm{E}-3$ & & \\
\hline $10-5-2$ & 588177 & 4096465 & Tacky Mat & $1.78 \mathrm{E}-2$ & & & & \\
\hline $10-5-3$ & 588177 & 4096465 & Tacky Mat & & $1.92 \mathrm{E}-2$ & & & \\
\hline $10-5-4$ & 588177 & 4096465 & Tacky Mat & $1.74 \mathrm{E}-2$ & & & & \\
\hline
\end{tabular}




\begin{tabular}{|c|c|c|c|c|c|c|c|c|}
\hline $\begin{array}{l}\text { Sample } \\
\text { Location }\end{array}$ & easting & northing & Sample Type & $\begin{array}{l}\text { PNNL WD57752 } \\
\text { (uCi) }\end{array}$ & $\begin{array}{l}\text { PNNL WD66091 } \\
\text { (uCi) }\end{array}$ & NSTec (uCi) & $\begin{array}{l}\text { MDA } \\
\text { (uCi) }\end{array}$ & Notes \\
\hline $10-5-5$ & 588177 & 4096465 & Tacky Mat & & $2.0 \mathrm{E}-2$ & & & \\
\hline $10-6$ & 588327 & 4096465 & High Vol. Air Sampler & & $3.88 \mathrm{E}-4$ & & & $\begin{array}{c}\text { Electric HV Air } \\
\text { Sampler }\end{array}$ \\
\hline $10-6$ & 588327 & 4096465 & Tacky Mat & $1.97 \mathrm{E}-3$ & & & & \\
\hline $10-7$ & 588527 & 4096465 & Tacky Mat & & $7.27 \mathrm{E}-5$ & & & \\
\hline $10-8$ & 588727 & 4096465 & Tacky Mat & No Detect & & & $6.28 \mathrm{E}-5$ & No Detect \\
\hline $10-9-1$ & 588927 & 4096465 & Tacky Mat & & No Detect & & $1.45 \mathrm{E}-5$ & No Detect \\
\hline $10-9-1$ & 588927 & 4096465 & Tacky Mat Jar & & & No Detect & $1.66 \mathrm{E}-4$ & No Detect \\
\hline $10-9-2$ & 588927 & 4096465 & Tacky Mat & & No Detect & & $1.94 \mathrm{E}-5$ & No Detect \\
\hline $10-9-3$ & 588927 & 4096465 & Tacky Mat & No Detect & & & $4.75 \mathrm{E}-5$ & No Detect \\
\hline $10-9-4$ & 588927 & 4096465 & Tacky Mat & & No Detect & & $4.54 \mathrm{E}-5$ & No Detect \\
\hline $10-9-5$ & 588927 & 4096465 & Tacky Mat & & No Detect & & $7.43 E-5$ & No Detect \\
\hline $10-10$ & 589127 & 4096465 & & & & & & Not Counted \\
\hline $10-11$ & 589327 & 4096465 & & & & & & Not Counted \\
\hline $10-12$ & 589527 & 4096465 & & & & & & Not Counted \\
\hline $10-13$ & 589727 & 4096465 & & & & & & Not Counted \\
\hline
\end{tabular}




\begin{tabular}{|c|c|c|c|c|c|c|c|c|}
\hline $\begin{array}{l}\text { Sample } \\
\text { Location }\end{array}$ & easting & northing & Sample Type & $\begin{array}{l}\text { PNNL WD57752 } \\
\text { (uCi) }\end{array}$ & $\begin{array}{l}\text { PNNL WD66091 } \\
\text { (uCi) }\end{array}$ & NSTec (uCi) & $\begin{array}{l}\text { MDA } \\
\text { (uCi) }\end{array}$ & Notes \\
\hline $11-1$ & 587373 & 4096965 & Tacky Mat & No Detect & & & $1.50 \mathrm{E}-5$ & No Detect \\
\hline $11-2$ & 587627 & 4096965 & Tacky Mat & & & No Detect & $3.76 \mathrm{E}-5$ & No Detect \\
\hline $11-3$ & 587827 & 4096965 & High Vol. Air Sampler & $5.50 \mathrm{E}-2$ & & & & $\begin{array}{c}\text { Gas-1 HV Air } \\
\text { Sampler }\end{array}$ \\
\hline $11-3-1$ & 587827 & 4096965 & Tacky Mat & & & $3.39 \mathrm{E}-4$ & & \\
\hline $11-3-2$ & 587827 & 4096965 & Tacky Mat & & & No Detect & $6.03 E-5$ & No Detect \\
\hline $11-3-3$ & 587827 & 4096965 & Tacky Mat & & & $6.07 \mathrm{E}-4$ & & \\
\hline $11-3-4$ & 587827 & 4096965 & Tacky Mat & & & $8.88 \mathrm{E}-4$ & & \\
\hline $11-3-5$ & 587827 & 4096965 & Tacky Mat & & $3.65 E-5$ & & & \\
\hline $11-4$ & 588027 & 4096965 & Tacky Mat & & & $2.66 \mathrm{E}-3$ & & \\
\hline $11-5$ & 588273 & 4096965 & High Vol. Air Sampler & & $1.40 \mathrm{E}-3$ & & & $\begin{array}{l}\text { Gas-2 HV Air } \\
\text { Sampler }\end{array}$ \\
\hline $11-5$ & 588273 & 4096965 & Tacky Mat & & & $1.57 \mathrm{E}-3$ & & \\
\hline $11-6$ & 588427 & 4096965 & Tacky Mat & $5.27 \mathrm{E}-5$ & & & & \\
\hline $11-7$ & 588573 & 4096965 & High Vol. Air Sampler & $9.14 \mathrm{E}-4$ & & & & $\begin{array}{c}\text { Gas-3 HV Air } \\
\text { Sampler }\end{array}$ \\
\hline $11-7-1$ & 588573 & 4096965 & Tacky Mat & & & No Detect & $4.32 \mathrm{E}-5$ & No Detect \\
\hline
\end{tabular}




\begin{tabular}{|c|c|c|c|c|c|c|c|c|}
\hline $\begin{array}{l}\text { Sample } \\
\text { Location }\end{array}$ & easting & northing & Sample Type & $\begin{array}{l}\text { PNNL WD57752 } \\
\text { (uCi) }\end{array}$ & $\begin{array}{l}\text { PNNL WD66091 } \\
\text { (uCi) }\end{array}$ & NSTec (uCi) & $\begin{array}{l}\text { MDA } \\
\text { (uCi) }\end{array}$ & Notes \\
\hline $11-7-2$ & 588573 & 4096965 & Tacky Mat & & $7.8 \mathrm{E}-5$ & & & \\
\hline $11-7-3$ & 588573 & 4096965 & Tacky Mat & & & $7.83 \mathrm{E}-5$ & & \\
\hline $11-7-4$ & 588573 & 4096965 & Tacky Mat & No Detect & & & $2.39 \mathrm{E}-5$ & No Detect \\
\hline $11-7-5$ & 588573 & 4096965 & Tacky Mat & & & No Detect & $3.67 \mathrm{E}-5$ & No Detect \\
\hline $11-8$ & 588827 & 4096965 & Tacky Mat & & $2.25 \mathrm{E}-5$ & & & \\
\hline $11-9$ & 589027 & 4096965 & High Vol. Air Sampler & & $1.614 \mathrm{E}-3$ & $1.507 \mathrm{E}-3$ & & $\begin{array}{l}\text { Gas-4 HV Air } \\
\text { Sampler }\end{array}$ \\
\hline $11-9$ & 589027 & 4096965 & Tacky Mat & & & $1.14 \mathrm{E}-4$ & & \\
\hline $11-10$ & 589227 & 4096965 & Tacky Mat & No Detect & & & $3.59 \mathrm{E}-5$ & No Detect \\
\hline $11-11$ & 589427 & 4096965 & & & & & & Not Counted \\
\hline $11-12$ & 589627 & 4096965 & & & & & & Not Counted \\
\hline $11-13$ & 589827 & 4096965 & & & & & & Not Counted \\
\hline
\end{tabular}


PNNL-23997

\section{Appendix C}

\section{Sequence of Events / Events Log}

\section{C.1 PRex Deployment/Execution Timeline}

\begin{tabular}{|c|c|}
\hline Date & Activity/ies \\
\hline Wednesday, 5/1/2013 & $\begin{array}{l}\text { 26-foot Penske rental truck picked up Wednesday morning. Allan Myers was } \\
\text { scheduled to review materials to be shipped, and plan truck loading. Many of } \\
\text { the materials to be shipped were not yet ready to be reviewed. }\end{array}$ \\
\hline Thursday, 5/2/2013 & $\begin{array}{l}\text { Scheduled to load most of air sampling and weather systems. This equipment } \\
\text { and materials were not ready for loading; no loading was accomplished. }\end{array}$ \\
\hline Friday, 5/3/2013 & $\begin{array}{l}\text { Scheduled to load dispersal system materials, sampling/survey materials, and } \\
\text { respirator materials. Allan worked with } 2 \text { teamsters for much of the day. } \\
\text { Teamsters left for the day at } \sim 3: 20 \text { pm. Allan Myers let me know that the } \\
\text { packing was not going well, and that it appeared that the materials would not } \\
\text { all fit in the truck. We unloaded much of the materials that had been loosely } \\
\text { placed on the truck, and repacked it, successfully loading almost all of the } \\
\text { planned cargo. }\end{array}$ \\
\hline Saturday, 5/4/2013 & $\begin{array}{l}\text { Truck departed Richland } \sim 11: 00 \text { am after final packing, about one hour after } \\
\text { planned departure. Arrived at Twin Falls, ID 7pm. Myers and Keillor. }\end{array}$ \\
\hline Sunday, 5/5/2013 & Traveled from Twin Falls to Las Vegas, NV - also about 8 hours of driving time. \\
\hline Monday, 5/6/2013 & $\begin{array}{l}\text { Truck arrived 11:00 am at Mercury (last minute purchases in Las Vegas } \\
\text { delayed arrival somewhat). Myers and Keillor completed required training and } \\
\text { received dosimetry. Truck was unloaded at the experiment site with the help } \\
\text { of several NSTec personnel. Detector tables were moved to "the bunker" at CP. } \\
\text { Brian Milbrath arrived at Mercury on Monday afternoon, and at the release } \\
\text { site } \sim 3 \text { pm, and Randy Kirkham arrived late Monday evening. }\end{array}$ \\
\hline Tuesday, 5/7/2013 & $\begin{array}{l}\text { Work gets off to a slow start waiting for forklift and ironworker (to signal } \\
\text { forklift operator). Milbrath worked with the forklift in the morning setting up } \\
\text { the release site, which included setting up the ramp up and the gas manifold. } \\
\text { Two HPGe detectors were installed and started cooling by late Tuesday } \\
\text { morning. The shield tables had been left assembled for shipment. Myers, }\end{array}$ \\
\hline
\end{tabular}




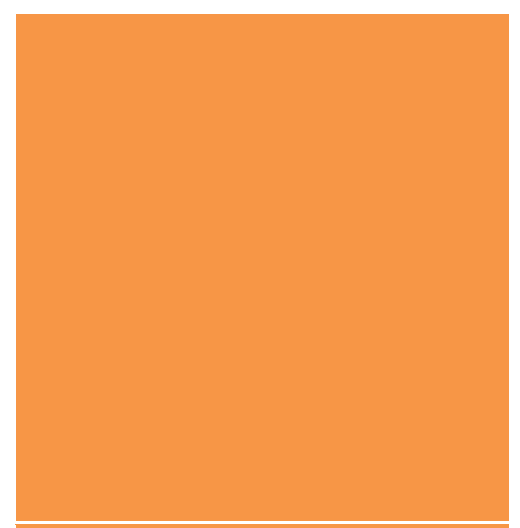

Wednesday, 5/8/2013

Thursday, 5/9/2013

Friday, 5/10/2013
Keillor, and 1 NSTec worker assembled the caves for 2 HPGe and 2 NaI(TI) detectors in $\sim 2$ hours (although it essentially took the full morning by the time we dealt with the morning ritual to get started, and travel to the field lab). Kirkham began organizing air sampler and meteorological equipment. Milbrath started marking witness plate locations in the field. Placement and assembly of the dispersal system equipment was also started on Tuesday afternoon.

After lunch, Milbrath set out slide holders (green garden party stakes) with flags on them. An NSTec laborer drove his truck while I used a laptop with GPS software on it. Because the software subscription was not paid, I had to relogin to the computer about every 20 minutes and re-start the program.

Got off to a slow start since Dudley took a while to get out for the daily prework briefing and sign-in. On subsequent days, we realized that others, including us, could do this, and get things started earlier.

The weather had been cool, breezy, with occasional showers on Monday and Tuesday. Wednesday continued to be cool, however it also rained steadily for a couple of hours at mid-day. This slowed progress on set up for the experiment. Preparations were not complete in time to perform the dry-run on schedule; Keillor departed for Richland prior to the dry-run. Assembly of the dispersal system was completed, with some troubleshooting of the control system required. The dry-run "smoke test", including a full complement of smoke generators ( 4 white, 2 red) used, and two bottles of $\mathrm{CO}_{2}$ used in the gerb (one for each nozzle), was completed on Wednesday afternoon.

Milbrath continued marking witness plate sites. The farthest lines (1.5 and 2 $\mathrm{km}$ ) were the most difficult since they were too far to see other lines or the release site well, there were more craters in the vicinity, and more of the lines were in areas with more vegetation. After the laborer left, Milbrath continued marking sites with Allan Myers in a Kawasaki Mule. Earlier, Allan successfully tested the dispersal mechanism, in still air, after Marty left for the airport. There had been an earlier attempt that had some electronics issues. The demo helped NSTec personnel feel good about the experiment's chances. Rained much of the day.

Kirkham, with NSTec support, began erecting towers for meteorological and air sampler equipment.

Milbrath continued to mark witness plate sites with NSTec laborers, finishing at $2 \mathrm{pm}$. Warnick Kernan and Brian Glasgow arrived at the experiment site late in the afternoon.

Milbrath and an NSTec laborer (driving truck) visited all the sites to stake the tacky mats down, and to put up the extra garden stakes at the comprehensive sites. This took six hours. There were some spots where driving the tent stakes in was difficult, but most were fine. Randy Kirkham put out air samplers before leaving for the airport in the early afternoon.

Allan Myers and Brian Glasgow set-up the counting labs and moved supplies 


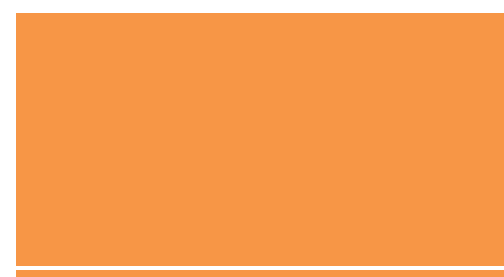

Saturday, 5/11/2013

Sunday, 5/12/2013

Monday, 5/13/2013

Tuesday, 5/14/2013 and equipment out of the Conex back onto the truck, to keep those materials out of the Contamination Area that would be in effect after the release. They also continued making the optical witness slides. Milbrath put out a witness slide and tacky mat over the weekend to see how bad the bug problem would present for them.

Glasgow and Myers continued preparing glass witness plates by attaching plastic film with double-sided adhesive (Spiral Binding, Item \#80PSMAOCPP51, Optically Clear Mount Film with Permanent/Permanent adhesive, 51" x 164' roll).

Glasgow and Myers installed glass witness plates on garden stakes in the sampling array.

Keillor and Kirkham returned to Mercury from Richland, along with Safety expert Drue Collins (present to observe the release).

The ${ }^{140}$ La source arrived at Mercury 7:30 am. The source was then delivered to the experiment site by the FEDEX truck, and stored overnight in the shipping container. The shipping container was posted as a controlled area.

Milbrath's weekend test showed small insects (black flies) stuck to the largearea witness plates, but not grasshoppers, as feared.

Keillor, Glasgow, and Myers finished assembly and testing of the dispersal system in preparation for the test. The five-amp fuse for the smoke ignition was blown, and it was determined that, if 12 volts was applied for an extended time to the ignitors, they melted and gradually became more conductive. This was corrected procedurally by ensuring that the switches were not left on for an extended period of time. The electrical system was disconnected and stored in pelican cases at the dispersal site.

Kernan performed functionality tests of the RSI vehicle-based survey system in the expected deposition area.

In the afternoon, covers were stripped off of the witness plates and optical witness plates on sample rows 5 through 11 .

Work started at 6 am at the experiment site. Myers and Keillor reconnected and tested the control system for the dispersal. Filled the hopper with $1 \mathrm{~kg}$ of 41 um diameter MoSci microspheres. Milbrath and Kernan completed removing covers from the witness and optical witness plates. The forklift moved the source moved to the dispersal location $\sim 8$ am. Kirkham installed filter papers on towers for sample collection. After source was set in place, 10 am was targeted for the dispersal. Kirkham started high volume samplers 9:30 am. Kirkham was unable to start the sequential samplers planned for use during the test due to issues with the remote communications??

The winds were initially light but too easterly. Keillor, Myers, and an RCT suited up. Randy Kirkham was last out in the field to turn on air samplers. Eventually, Kirkham was asked to stop attempting to start the sequential air 
samplers because the winds were getting stronger and stronger. To monitor the weather, Milbrath stood out with the meteorologist and his tethered balloon. As the winds got more southerly, they also got stronger. The window of allowed meteorological conditions was actually pretty narrow, in hindsight.

Keillor, Myers, and an RCT received word from Milbrath to proceed. As they approached the shipping container, they realized that is still had a security cable attached - a cable cutter was found on-site to overcome this hurdle. Final preparation of the source for dispersal was started 9:15 am PDT. The RCT measured the dose rate at the top of the barrel with the shipping plug removed, $2 \mathrm{rem} / \mathrm{hr}$ (this may well have been a value that was the meter maximum). The only snag during the preparation occurred when the copper exit tube for the source powder would not quite fit under the gerb - the transfer plug was removed two times, walked away from the shipping barrel, and the tube was adjusted.

An atmospheric sounding was released at 9:55 am.

The source was punctured, and the source was released $10: 55 \mathrm{am}$, with a Southerly wind of approximately $10 \mathrm{mph}$. The plume only appeared to reach $30 \mathrm{ft}$, and did not settle immediately. Observers could see the plume for several hundred feet downwind. The release was filmed from $100 \mathrm{~m}$ south of the release (looking north), $100 \mathrm{~m}$ west of the release (looking east), and $\sim 1.4 \mathrm{~km}$ west by $200 \mathrm{~m}$ north of the release (looking east).

RSL was notified of the release at $\sim 11: 00 \mathrm{am}$, and a fixed wing aerial survey was flown $12: 30 \mathrm{pm}$.

High winds were experienced during the afternoon of the $14^{\text {th }}$. Despite the challenging conditions, samples were collected from rows 8 and 9 (800 m and $1000 \mathrm{~m}$ downwind). Samples were collected from the high volume samplers at $1.5 \mathrm{~km}$ and $2 \mathrm{~km}$ downwind ( 3-4 pm). The site was originally posted as a CA for over a $\mathrm{km}$ in width and about $5 \mathrm{~km}$ downwind. A smaller HCA was posted a couple hundred $m$ wide and about $500 m$ downwind. At no time did PNNL staff enter a HCA, which required two sets of PPE. PNNL staff did enter the CA, which in the first afternoon required the use of respirators. After air samplers attached to the Mules, and those in the respirators, were analyzed by site RCTs, project staff were allowed to not use respirators in the CAs on the following days.

Initial counting of samples from the high volume air samplers indicated positive collections of ${ }^{140}$ La on 3 samples.

Wednesday, 5/15/2013

The project team arrived for work 6:30 - 6:45 am. RCTs arrived and were available to work $\sim 7: 15$ am. Witness plate samples that had been retrieved on Tuesday were processed out and transported to the field lab. From here on out, Dudley Emer stayed in the Counting Bunker with Allan Myers. It was important for us to get a handle on where the plume was in case we didn't need to bother collecting some samples, though we really didn't know much until the end of the day.

Respirators were not required today, though we often chose to use dust masks 


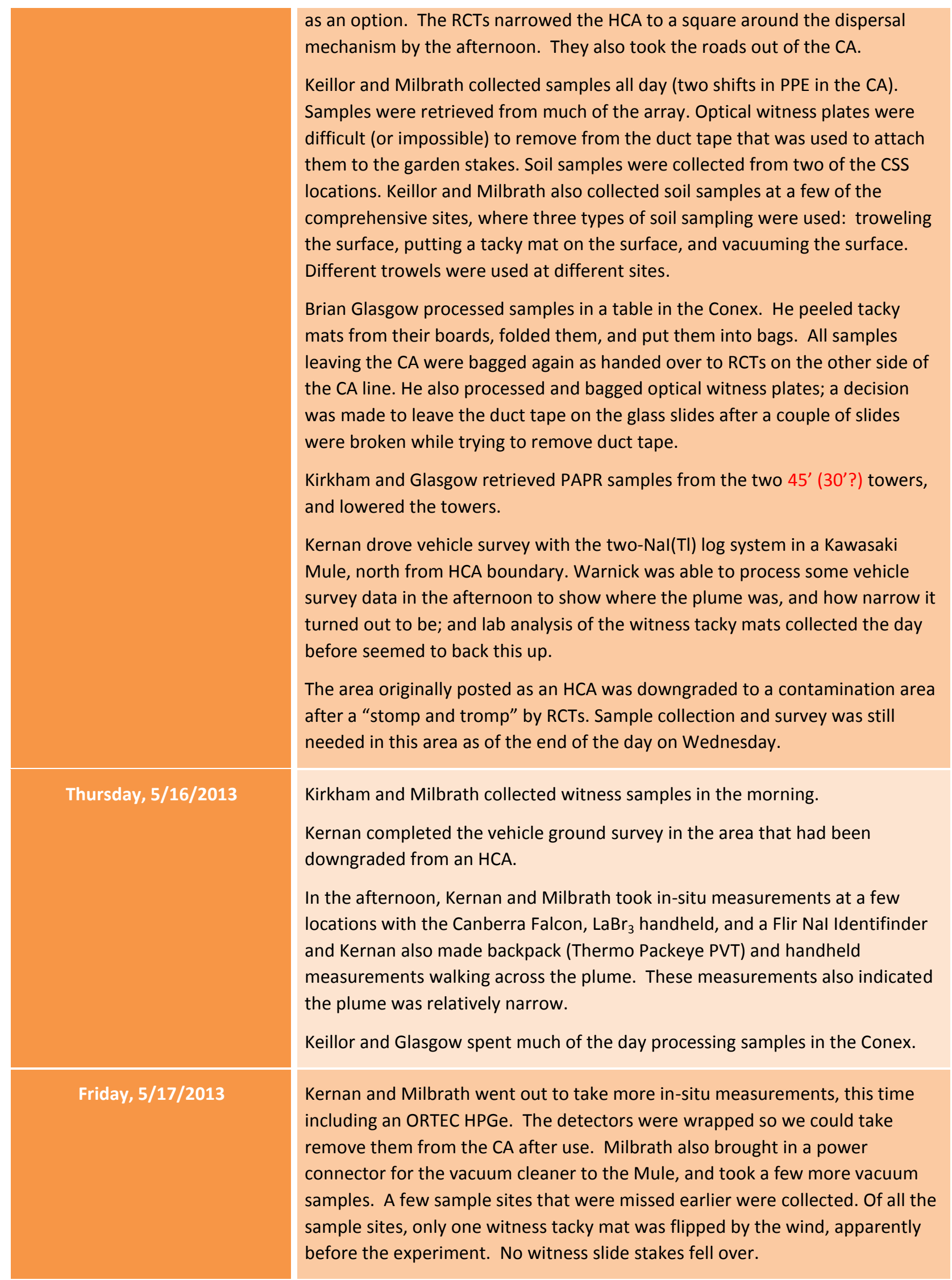




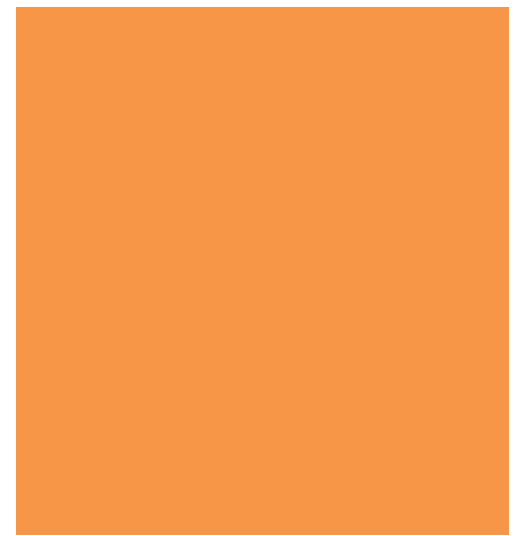

Afterwards, we sorted stuff in regards to what needed to be on the rental truck and what would stay in the Conex, within the contamination area, for a few weeks before shipping. Photographs were taken of the Conex container for a visual record of the materials left behind.

Myers and Glasgow continued to work with Dudley Emer to complete laboratory measurement of the samples.

The sample analysis finished in the afternoon and the lead caves were then taken down. Keillor, Kernan, Kirkham, and Milbrath headed for the airport. Allan and Brian G. had a rest day in Vegas on Saturday before driving the truck back Sunday and Monday. 


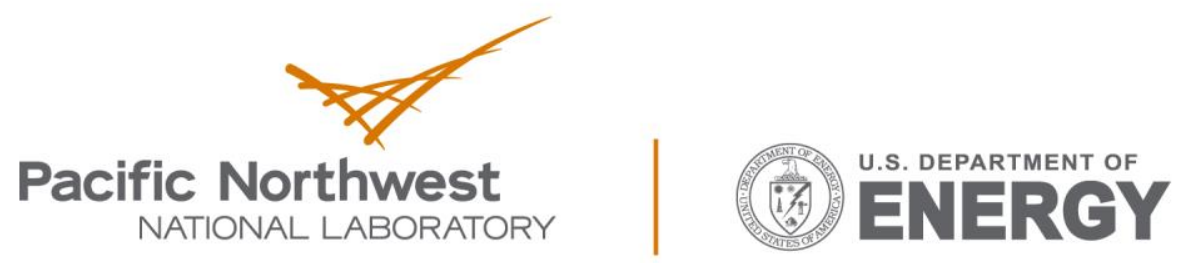

Proudly Operated by Battelle Since 1965

902 Battelle Boulevard

P.O. Box 999

Richland, WA 99352

1-888-375-PNNL (7665)

www.pnnl.gov 